\title{
₹USGS

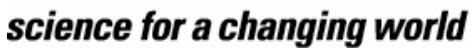

\section{Report of the Workshop on Extreme Ground Motions at Yucca Mountain, August 23-25, 2004}

By T.C. Hanks, Chair, N.A. Abrahamson, M. Board, D.M. Boore, J.N. Brune, and C.A. Cornell, Workshop Committee

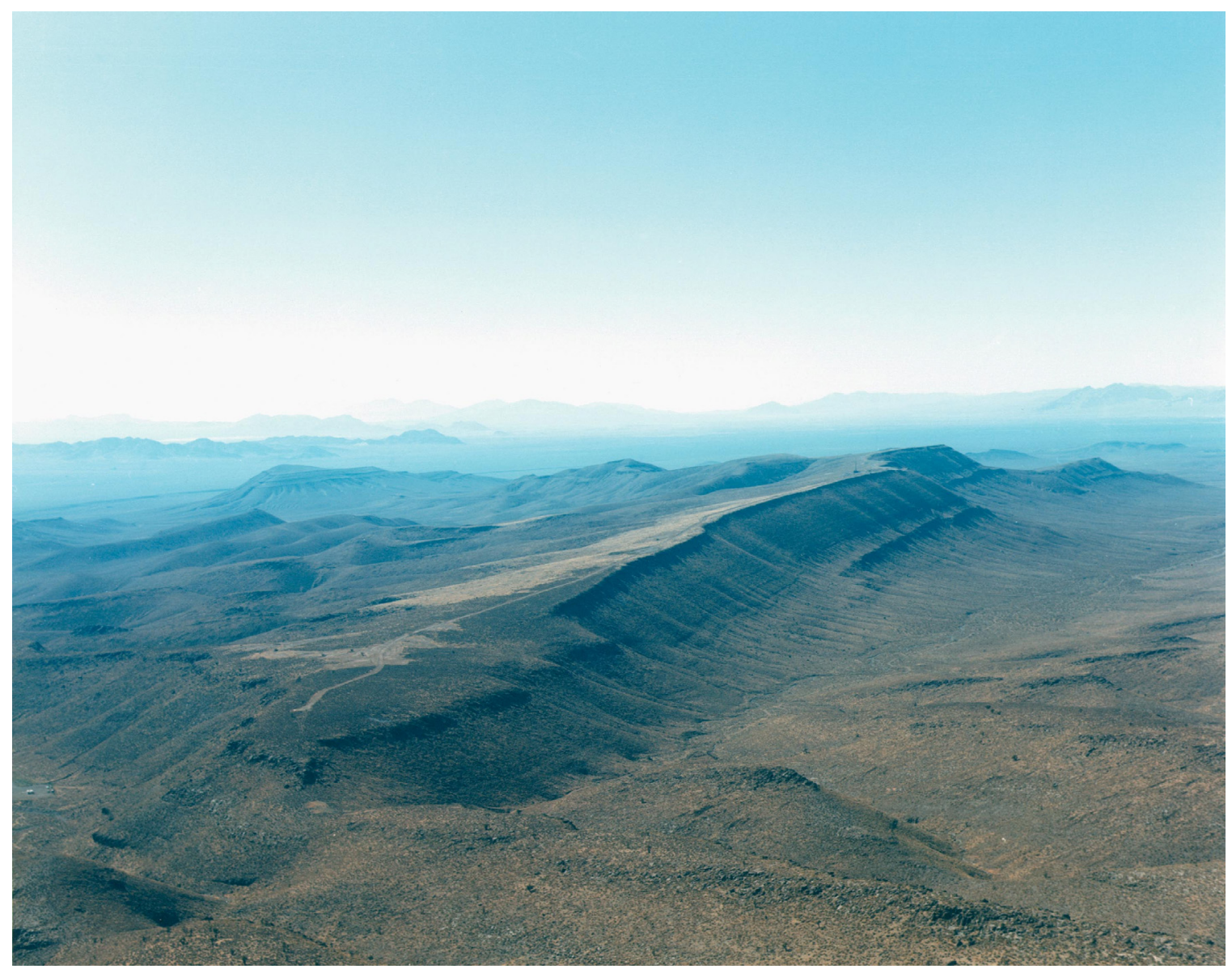

\section{Open-File Report 2006-1277}

\section{6}

Any use of trade, firm, or product names is for descriptive purposes only and does not

imply endorsement by the U.S. Government

U.S. Department of the Interior

U.S. Geological Survey 


\section{U.S. Department of the Interior}

\section{U.S. Geological Survey}

U.S. Geological Survey, Reston, Virginia 2006

For product and ordering information:

World Wide Web: http://www.usgs.gov/pubprod

Telephone: 1-888-ASK-USGS

For more information on the USGS - the Federal source for science about the Earth, its natural and living resources, natural hazards, and the environment:

World Wide Web: http://www.usgs.gov

Telephone: 1-888-ASK-USGS

Although this report is in the public domain, permission must be secured from the individual copyright owners to reproduce any copyrighted material contained within this report. 


\title{
The Workshop on Extreme Ground Motions at Yucca Mountain
}

\author{
August 23, 24 and 25, 2004 \\ U.S. Geological Survey, Menlo Park, CA 94025
}

The Workshop Committee:

T.C. Hanks, Chair, N.A. Abrahamson, M. Board, D.M. Boore, J.N. Brune, and C.A. Cornell

\section{INTRODUCTION}

This Workshop has its origins in the probabilistic seismic hazard analysis (PSHA) for Yucca Mountain, the designated site of the underground repository for the nation's high-level radioactive waste. In 1998 the Nuclear Regulatory Commission's Senior Seismic Hazard Analysis Committee (SSHAC) developed guidelines for PSHA which were published as NUREG/CR-6372, "Recommendations for probabilistic seismic hazard analysis: guidance on uncertainty and the use of experts," (SSHAC, 1997). This Level-4 study was the most complicated and complex PSHA ever undertaken at the time. The procedures, methods, and results of this PSHA are described in Stepp et al. (2001), mostly in the context of a probability of exceedance (hazard) of $10^{-4} / \mathrm{yr}$ for ground motion at Site A, a hypothetical, reference rock outcrop site at the elevation of the proposed emplacement drifts within the mountain. Analysis and inclusion of both aleatory and epistemic uncertainty were significant and time-consuming aspects of the study, which took place over three years and involved several dozen scientists, engineers, and analysts.

Because of these uncertainties, the 1998 Yucca Mountain PSHA provides for progressively higher ground motions as it is extended to progressively lower hazard levels: at mean-value hazard levels of $10^{-6} / \mathrm{yr}, 10^{-7} / \mathrm{yr}$, and $10^{-8} / \mathrm{yr}$, the resulting peak ground accelerations (PGA) and peak ground velocities (PGV) are $3 \mathrm{~g}, 6 \mathrm{~g}$, and $11 \mathrm{~g}$ and $3.5 \mathrm{~m} / \mathrm{sec}, 7 \mathrm{~m} / \mathrm{sec}$, and $13 \mathrm{~m} / \mathrm{sec}$, respectively. We refer to these as extreme ground motions, the extremely large-amplitude ground motions that will arise in any PSHA at extremely low probabilities-of-exceedance, given untruncated ground-motion distribution functions. These large-amplitude ground motions have generated considerable consternation in the scientific, engineering, and regulatory communities, for such PGV's and PGA's have never been recorded for earthquakes, present exceptional challenges to the design and construction of the underground facilities, and are regarded by at least some qualified seismologists as "physically unrealizable."

The most direct way of addressing these extreme ground motions is to re-visit and re-calculate the 1998 Yucca Mountain PSHA, but the Workshop Committee (or "Committee") concurs with the consensus view that the 1998 Yucca Mountain PSHA should not be re-opened unless and until there is a solid scientific and/or technical basis for doing so. The Workshop Committee also believes that the demonstration of physical limits to earthquake ground motion that can be meaningfully applied to the 1998 Yucca Mountain PSHA would provide such a basis.

There is more to this problem than just physical limits to ground motion, however. When Jim Brune speaks to ground accelerations associated with untoppled, precarious rocks, for example, 
he speaks to ground motions that have not been exceeded at specific sites populated by these precarious rocks for specific periods of time. These "unexceeded" ground motions are far less than likely physical limits for these sites, if only because they are considerably smaller than many instrumentally recorded ground accelerations.

It is also important to distinguish what can happen at Yucca Mountain (or any other place), which involves long, essentially open intervals of time that might involve hundreds of millions of years, and what has (or has not) happened at Yucca Mountain over the closed, much smaller interval of 12.8 Ma since the volcanic section in which the mountain exists was laid down. The Committee, for example, is convinced, for reasons discussed below, that the $10^{-6} / \mathrm{yr}$ hazard PGV $=3.5 \mathrm{~m} / \mathrm{sec}$ has not passed through the lithophysal units of the Topapah Springs tuff since these lithophysae were formed more than $10^{7}$ years ago. Whether or not such ground motions can pass through these units, which must be considered in the context of hazard levels of $10^{-7} / \mathrm{yr}$ to $10^{-8} / \mathrm{yr}$, will be decided on other grounds, however.

Unexceeded ground motions, then, are ground motions that have not happened at a specific site for a specific time interval, at the locations of precarious rocks for the past tens of thousands of years, for example, or in the lithophysal units since $12.8 \mathrm{Ma}$. Physical limits to earthquake ground motions specify amplitudes of ground motion that cannot happen, ever. PSHA calculations can employ both unexceeded ground motions and physical limits to ground motion. To a limited extent, unexceeded ground motions (for precarious rocks) were considered in the 1998 Yucca Mountain PSHA. The many participants in this exercise did not, however, consider physical limits to earthquake ground motions in their deliberations, for it was never anticipated that they might make a difference. We now know better. The primary purpose of the Workshop was to explore the state of knowledge pertaining to a wide range of geologic structures that speak to unexceeded ground-motion levels and define real or potential physical limits to earthquake ground motion, as they might apply to either the excitation or propagation of the radiated field of crustal earthquakes.

Finally, it is worth noting explicitly that physical limits to earthquake ground motion do not exist in the realm of linear elasticity, in which earthquake scientists have lived so successfully for more than a century: they arise from non-linear, dissipative deformation mechanisms that are fundamentally due to the finite strength of crustal rocks and their erosional detritus.

\section{WORKSHOP ORGANIZATION AND OVERVIEW}

Broadly speaking, the Workshop on Extreme Ground Motions at Yucca Mountain was organized around the two themes of unexceeded ground motions and physical limits to ground motion. Most of the first day, however, was devoted to presenting and exploring the results of the 1998 Yucca Mountain PSHA (Stepp et al.,2001), as well as the more recent PEGASOS PSHA conducted for nuclear power plants in Switzerland (Abrahamson et al., 2002).

The purpose of these talks was to get everyone into the same bandwidth as to how and why extreme ground motions arise in the first place and how and why unexceeded ground motions and/or physical limits might make a difference in dealing with them. Most earth scientists are not well attuned to even the basics of probabilistic hazard analysis, let alone the additional and 
subtler problems that arise at very low hazard levels. Nor do they know of the substantial body of relevant science and innovative methodology in seismic hazard analysis that the Yucca Mountain Project has contributed. At the same time, the scientists and engineers of the Yucca Mountain Project are constrained by existing PSHA methodology related to extremely rare events to accept unrealistically large ground motions. Thus the Committee, through this workshop, was looking for research that will help advance the state of the science and enable reductions in uncertainty in extreme ground motion predictions.

Physical limits to ground motion might arise from the strength of crustal materials as they exist at or near the site of interest, in the source region at 10-15 km depth, or anywhere along the path in between. Quite generally, the strength of crustal material increases with confining pressure, so we may expect that rock properties at or near the site will apply more stringent limits on ground motions than will rock properties at mid-crustal depths, where the earthquakes occur. Moreover, rocks at shallow depth are easily accessible, allowing for both in situ observation of their structure and fabric as well as sampling for laboratory testing. Such analyses, however, are inevitably site specific, at least to some degree. More general physical limits on earthquake ground motion exist, we believe, in the form of limiting conditions on the source excitation of crustal earthquakes. These more general conditions, however, are more difficult to discern with confidence, given the inaccessibility of what goes on at mid-crustal depths and the short record of instrumental recordings of earthquakes.

Physical limits to ground motion at Yucca Mountain were discussed mainly in the context of the lithophysal units. Much of this discussion, in fact, pertained to upper-bound ground motions, ground motions that have not traversed the lithophysal units since they were formed. Quasistatic failure analysis of the lithophysal units indicates that observable damage should ensue at shear strains of $\sim 0.1 \%$, which would correspond to maximum particle velocities of $\sim 2 \mathrm{~m} / \mathrm{sec}$. Preliminary numerical calculations of waveforms passing through the lithophysal units, however, suggest that velocity amplitudes in excess of $\sim 3 \mathrm{~m} / \mathrm{sec}$ could not emanate from the lithophysal units, no matter what the incoming amplitudes were beneath them, due to the dissipation of energy attending the damage to the lithophysal units.

Physical limits to the excitation of ground motion in the source region were discussed in a number of presentations, but here again we are hampered by the inability to clearly define the limits to what can happen, even if we know what has happened for tens of thousands of crustal earthquakes. Crustal earthquake stress drops are surprisingly constant (several tens of bars, although the variance is large) for the thousands of earthquakes for which they have been determined. $\mathrm{m}_{\mathrm{b}}-\mathrm{M}_{\mathrm{S}}$ data for tens of thousands of crustal earthquakes worldwide point to a similar result, although much further work needs to be performed on this huge data set. Evidence for the kilobar-type stress drops of the sort required to produce the extreme ground motions at Yucca Mountain exists, but it is rare ( p parts per thousand).

Unexceeded ground motions in the vicinity of Yucca Mountain were presented and discussed with respect to several different types of geologic structures that involve very different lifetimes. These include: (1) The undamaged lithophysal units (12.8 Ma), (2) The undamaged blades and filaments precipitated in the lithophysal cavities ( 10 Ma), (3) Absence of seismically fractured rock and absence of slip on existing cooling fractures ( 10 Ma), (4) Absence of large single- 
event slip on the Yucca Mountain faults ( 1 Ma), (5) Precipitous slopes ( 0.01-0.1 Ma) and (6) Precarious rocks ( 0.01-0.1 Ma). Like-minded presentations were made by Brune on unfractured sandstone units adjacent to the San Andreas fault ( $\sim 5 \mathrm{Ma})$ and by Stuckless on the use of fragile speleothems as paleoseismoscopes.

Unexceeded ground motions associated with one or more of these geologic structures provide important constraints on the seismic hazard at Yucca Mountain and can be used to down-weight or reject branches of the logic tree that lead to hazard curves inconsistent with these observations.

The remainder of this report consists of brief summaries of the 28 presentations delivered at the Workshop. More extensive, written summaries of these presentations have been prepared by the presenters and may be found Appendix C. The text below relies heavily on this supplementary material, which includes greater explanation and extensive reference lists, so not to be much longer than it otherwise would have been. The Workshop Program is attached as Appendix A, and workshop participant contact information is provided in Appendix B.

\section{WORKSHOP PRESENTATIONS}

The conference began Monday morning, August 23, with a short presentation by Tom Hanks of the problem of extreme ground motions at Yucca Mountain, illustrated with the PGA and PGV seismic hazard curves down to hazard levels of $10^{-8} / \mathrm{yr}$, and how this problem might be addressed in terms of either physical limits to ground motions and/or unexceeded ground motions. These introductory remarks were followed by three presentations (Ivan Wong, Norm Abrahamson, and Gabriel Toro) that discussed in detail the 1998 Yucca Mountain PSHA.

Wong presented the broad outlines of the 1998 Yucca Mountain PSHA (Stepp et al.,2001) to determine both ground-motion and fault-displacement hazard, the uncertainties that attended these hazard estimates, and the process by which all of this was achieved according to the SSHAC (1997) Level-4 procedures. The primary ingredients of any PSHA are characterization of potential earthquakes in terms of locations, magnitudes, and rates of occurrence and the estimation of the earthquake ground motion that can result from any of them. Six teams of three experts each were assembled for the "source characterization" work, and they dealt with both historical seismicity data and paleoseismic investigations of the faults local to Yucca Mountain as well as with the important regional faults. These six teams were also responsible for characterizing the rate and amount of slip per event for the Yucca Mountain faults to calculate the fault-displacement hazard. Seven ground-motion experts were chosen to estimate earthquake ground motion at Yucca Mountain.

Because uncertainties in the ground-motion estimation for the Yucca Mountain PSHA are widely agreed to be more important than uncertainties in source characterization, especially at the low hazard levels of interest to the Workshop, Abrahamson followed Wong with a detailed description of the ground-motion uncertainties.

The Yucca Mountain ground-motion experts relied primarily on empirical ground-motion prediction equations (often called attenuation relations) in the development of their ground- 
motion models (median and standard deviation for a given magnitude, distance, style-of-faulting and site condition). The ground-motion experts used these empirical ground-motion models (with adjustment factors applicable to Yucca Mountain), together with numerical simulations specific to Yucca Mountain, to develop estimates of the median ground motion and the probability distribution reflecting the aleatory (event-to-event) variability of the ground motion for a suite of earthquake magnitudes and distances. This distribution function was assumed to be log-normal, with median $\mu$ and standard deviation $\sigma$. Epistemic uncertainty was specified by distributions assigned to the median values of these two parameters, epistemic uncertainty in the median being measured by $\sigma_{\mu}$, and epistemic uncertainty in $\sigma$ by $\sigma_{\sigma}$. Although the experts were given the option of using asymmetric functions for the two epistemic distributions, they all used symmetric distributions. The intent of having the experts provide ground motions for scenario earthquakes was to focus their attention on the resulting ground motions and not just on weights assigned to models; as things turned out, the experts primarily focused on the model weights.

A key issue in the ground-motion results is the specification of epistemic uncertainty. Near the end of the 1998 PSHA project, one of the ground motion experts (Anderson) made significant increases to his epistemic uncertainty for small distances. Anderson wished to allow for the possibility that all of the ground-motion models could be wrong. Secondly, Anderson was concerned with the large discrepancy between the model predictions and the precarious rock constraints. The first concern could lead to ground motions either larger or smaller, but the second concern would lead only to lower ground motions, which should have been specified by an asymmetric distribution of the median $\mu$. The large epistemic uncertainty in Anderson's ground-motion estimates leads to a large increase in the mean hazard at low probability levels, but it is by no means the only cause of the extreme ground motions at low probability levels.

Finally, none of the experts considered truncation of the ground-motion distribution in the development of their models, principally because the 1998 Yucca Mountain PSHA was focused on the $10^{-4} / \mathrm{yr}$ hazard level. Accordingly, the experts did not know of the extreme ground motions that resulted from their models when ground-motion exceedances were computed at much smaller hazard levels.

De-aggregation of seismic hazard is the determination of the fractional contribution to the hazard associated with a given ground motion level arising from a chosen range of magnitudes, distances, and "epsilons", which measure the random deviation of a future ground-motion amplitude from its median value; basically, de-aggregation is simply differentiating the integration over magnitudes, distances, and epsilons that provides the seismic hazard estimate in the first place. As part of the Workshop organization, the Committee asked Gabriel Toro to deaggregate the 1998 Yucca Mountain PSHA with much finer resolution than had been done before.

Toro demonstrated that at hazard levels of $10^{-6} / \mathrm{yr}$ and smaller, the PGA and PGV hazard is dominated by close distances $(\mathrm{R}<5 \mathrm{~km})$, the magnitude range 6 to 7 , and epsilons of 1 to 3.5 standard deviations, revealing the Solitario Canyon fault to be the principal/only player at small hazard levels. Toro examined the sensitivity of the ground-motion hazard through expert-byexpert contributions to it; Anderson was consistently higher than the other six experts for both PGA and PGV at all hazard levels. At $10^{-6} / \mathrm{yr}$, Anderson contributed about $50 \%$ and $30 \%$ of the 
total weighted hazard for PGA and PGV, respectively. Toro did not explain why Anderson's estimates were higher, but simple equations ("tools") provided by Toro in an appendix should help to identify the cause(s).

Toro also showed that epistemic uncertainty becomes a greater contributor to the mean hazard as hazard levels becomes smaller and smaller. His results confirm that at $10^{-4} / \mathrm{yr}$ aleatory uncertainty predominates over epistemic uncertainty, but at $10^{-8} / \mathrm{yr}$ both contribute significantly. Toro also concluded that truncating the aleatory uncertainty distributions at $+3 \sigma$ will not have a significant effect on the hazard at $10^{-8} / \mathrm{yr}$. Finally, Toro provided very simple analytical representations of the hazard integral that will facilitate presentation and investigation of the impacts of various sources of uncertainty and their relative roles.

The U.S. Nuclear Waste Technical Review Board (NWTRB) held a meeting on February 24, 2003, to discuss the extreme ground motions at Yucca Mountain, and these deliberations were summarized at the Workshop by Leon Reiter of NWTRB and Art McGarr, who served as an expert consultant to NWTRB on this matter. Reiter emphasized the necessity of dealing with the extreme ground motions at Yucca Mountain in terms of physical limitations in the source, path or site and/or in terms of the treatment of uncertainty in the ground-motion estimates. NWTRB recommended to DOE that it needs to bound the extreme ground motions on the basis of sound physical principles, although NWTRB recognized the difficulty in doing so. No particular guidance was given beyond the desirability of maintaining external peer review and consideration of precarious rocks. Reiter addressed at some length objections to an early defense adopted by some with the Yucca Mountain Project that so long as the extreme ground motions could be tolerated in the Total System Performance Assessment (which is to say that they did not lead to exceeding the 10,000 year expected dose criterion) it was unnecessary to determine why the extreme ground motions arose in the first place and if they violate physical limits. Reiter dismissed this logic quickly: unrealistic/overly conservative ground motions could skew the understanding of the system behavior, lead to processes beyond our understanding, lead to unreasonable costs, undermine scientific confidence, and make subsequent reductions more difficult should that prove necessary later.

McGarr was one of four experts retained by NWTRB to attend the 2003 meeting, each of whom wrote a report to NWTRB based on what they heard at the meeting and on their own experience and expertise. McGarr recapitulated a small number of the largest recorded PGV's for earthquakes spanning ten orders of magnitude in seismic moment $\left(\mathrm{M}_{0}\right)$ to conclude that nearfault slip velocities did not exceed $\sim 2 \mathrm{~m} / \mathrm{sec}$, although the TCU068 station recorded $2.6 \mathrm{~m} / \mathrm{sec}$ for the Chi-Chi, Taiwan (Sept. 20, 1999; $\mathbf{M}=7.6$ ) earthquake, a thrust-faulting event. McGarr also assembled a large number of apparent stress observations spanning more than 16 orders of magnitude of $\mathrm{M}_{0}$ to conclude that apparent stress does not depend on $\mathrm{M}_{0}$ and has an upper-bound value of $\sim 1 \mathrm{Mpa}$ for crustal earthquake and laboratory analogues alike. Because near-fault PGV is controlled by apparent stress and because neither apparent stress nor near-fault PGV depends on $\mathbf{M}$ or $\mathrm{M}_{0}$, McGarr concluded that the "worst-case scenario at Point A" in terms of PGV is $\sim 2$ $\mathrm{m} / \mathrm{sec}$.

The Monday afternoon session began with presentations by Abrahamson and Julian Bommer on the PEGASOS project, just the second SSHAC Level-4 PSHA ever conducted, in this case for 
nuclear reactors in Switzerland (Abrahamson et al, 2002). Notably, with the Yucca Mountain experience in hand, the PEGASOS project required the ground-motion experts "to specify bounding values on the ground motions" (Bommer et al., 2004).

Abrahamson began by noting that PEGASOS was structured in a manner similar to the 1998 Yucca Mountain PSHA but with some important differences. First, site response was included as part of the problem. Thus, three groups of experts were convened for PEGASOS: one each for source characterization, hard rock ground motion, and site response.

Second, the ground motion experts developed sets of weights for models rather than distributions for the epistemic uncertainty $\left(\sigma_{\mu}\right.$ and $\left.\sigma_{\sigma}\right)$. This approach forced the experts to consider asymmetric distributions of the epistemic uncertainties. It also avoided creating epistemic distributions that included models without a technical basis (unintended models). The experts were not restricted to the available ground-motion models and were allowed to modify the existing models to develop new models as long as they had an explicit basis for the modifications.

Abrahamson and Bommer both discussed the important matter of "bounding values on ground motion" for the PEGASOS project, and it was explored in several different ways. (In the PEGASOS project, the terms "maximum" or "bounding" ground motion refer to the physical limits to ground motion, not unexceeded ground motions as defined in this report.) Maximum rock ground motions reflected perceived limits of the seismic source with the effects of geometrical spreading and attenuation considered. In contrast, the site-response experts developed physical limits to ground motions based on site-specific soil properties.

Two statistical approaches were considered for defining maximum ground motions on rock: truncation of ground motion amplitudes for a given magnitude and distance and departures from the log-normal distribution. (Distributions different from lognormal change the probability of getting very large ground motions but does not require an absolute maximum). The experts were provided with distributions of residuals from existing ground-motion prediction equations involving $\sim 1,000$ recordings and summaries of the largest empirically observed ground motions as a function of magnitude and distance.

The distributions of the residuals from a number of strong-motion data sets show that the largest observed residuals are, consistent with the total number of observations, three standard deviations (or more) removed from the median value and show no tendency to deviate from an untruncated log-normal distribution. As such, there is no statistical basis for truncating the distribution of the aleatory variability of ground motion at some maximum number of standard deviations or to depart from the log-normal distribution at all shaking levels.

Numerical simulations based on kinematic models of crustal-earthquake rupture were also provided to the ground-motion experts. As described by Paul Somerville in a Workshop presentation summarized below, these numerical simulations were calculated for a range of magnitudes, distance, and site locations around the rupture zone (at a given distance), employing a range of source-parameter combinations (e.g., fault dimensions, slip rise-time, rupture velocity, asperity size and stress drop). "Worst-case" combinations of these parameters (for, example large 
rupture velocity coupled with short rise times) and unfavorable propagation directions lead to very large ground motions, again to PGA's and PGV's that have never been recorded.

While these simulations provided a basis for the ground motion expert's choice of maximum rock ground motion, this choice apparently involved little more than replacing an arbitrary selection of the maximum ground motion in the first place with an arbitrary selection of the worst-case source parameters that would cause it. This approach appears to lead to "reasonable" estimates of very rare, rock ground motions, but it does not fundamentally address the issue of physically limited ground motions since there was not a clear technical basis for the selection of the combinations of the source parameters.

That experts must defend and document the technical basis for their assessments is an essential feature of the SSHAC Level-4 process. As the PEGASOS project developed, it became clear that while the experts felt that some very large ground motions were very unlikely, it was difficult to provide a clear technical basis for selecting a true maximum ground motion. An important consequence of all of this was the rock ground-motion experts tended to increase their estimates of the maximum ground motion as the project went on. This is an important finding, and this experience should be kept in mind for future PSHA's that may or must have to deal with maximum possible ground motions.

Jerry King summarized recent developments in the Ground Motion Saturation Evaluation project, which has as its principal focus constraints on PGV provided by the undamaged lithophysal units that underlie Yucca Mountain. Lithophysae are cavities in the volcanic tuffs, caused by gases exsolved from them following their airfall deposition at $12.8 \mathrm{Ma}$, and the lithophysae weaken these tuffs considerably. Strains at which these rocks fail can be related to PGV's which would have caused such failure had they occurred since $12.8 \mathrm{Ma}$; the absence of any observable, seismically induced damage to these units indicate that such strains and PGV's have not occurred. King provided ranges of these strains ( 0.10 to 0.35$)$ and related PGV's (1.5 to $5.0 \mathrm{~m} / \mathrm{sec}$ ) and several distribution functions for both.

Branko Damjanac presented Mark Board's review of the mechanical properties of the rocks at the repository level in Yucca Mountain. The welded tuff units at and near the repository horizon are subdivided into two basic mechanical groupings: lithophysal and nonlithophysal rocks. The primary difference in these rock units, from a mechanical perspective, is the fabric of the lithophysae. The matrix of both lithophysal and nonlithophysal rocks is mineralogically and mechanically the same. The lithophysal rocks contain up to about $30 \%$ porosity in lithophysal (gas) cavities, as well as a ubiquitous fracture fabric, both formed during the cooling process. The nonlithophysal rocks are generally devoid of these cavities, but do show three regular cooling fracture sets: one subhorizontal, long trace-length set of vapor phase partings and two shorter trace-length subvertical sets that tend to terminate against other fractures or within the rock mass.

Extensive testing of the material properties of the rock matrix, rock mass, and fractures of these units has been conducted over the past twenty years. In general, the rock matrix is a strong, elastic, and brittle material, characterized by compressive strength of about $150 \mathrm{MPa}$ for $51 \mathrm{~mm}$ diameter samples and a brittle post-peak response. Tensile strength of the rock matrix has been 
determined through indirect (Brazilian) and direct pull tensile testing. The compression to tensile strength ratio is approximately 9 to 10 .

Lithophysal rock-mass properties are size dependent due to the presence of the cavities. Testing of small cores are not representative of rock-mass properties, as they are primarily composed of the matrix and do not include lithophysae. Therefore, large $(290 \mathrm{~mm})$ cores have been tested in uniaxial compression to define the strength and deformability of the lithophysal units. These tests show that the mechanical properties are primarily a function of lithophysal porosity. Fracture properties have been determined in direct shear, showing that the vertical cooling joints are smooth, with essentially no cohesion and low friction angle. The vapor phase partings are rough and healed with secondary silicate minerals; they are cohesive and have higher friction angle. A large data base is currently available to describe the mechanical response of the lithophysal and nonlithophysal tuffs.

Ground-motion models typically are concerned only with shear strains induced in the rock mass. Shear waves from extreme ground motions can result in significant tensile strain as well. Since rock has a significantly lower strain limit in tension than in shear, physical bounds to extreme ground motions may be more sensitive to tensile limits. Unfortunately, tensile strength and strain limits of fractured rock masses are not well understood. Currently, empirical estimates of the ratio of compressive to tensile strength, based on laboratory testing of rock and concrete are used as a guide for selecting tensile strength of a jointed rock mass.

Charles Fairhurst reviewed the current theoretical basis for the strength of rock in compression (shear) and tension. He began with the basic physics of tensile rock fracture in a compressive stress field. Fairhurst used the Griffith rupture criteria and the fracture mechanics of tensile fracturing in rock to show that tensile fractures may form from the ends of pre-existing flaws in a compressive stress field, propagating in a direction perpendicular to the minimum compression. Increasing confining pressures suppress this crack growth, resulting in strengthening of the rock mass. The effect of sample size on rock strength was described as the basis for development of yield criteria for fractured rock masses. Failure criteria, such as the Hoek-Brown criteria have been developed to account for the effect of natural fracturing, primarily on failure in compression. A series of discontinuum model simulations of rock in uniaxial compression were presented to illustrate the effect of the presence of natural fracturing on rock-mass tensile strength. This modeling technique is capable of allowing tensile and shear fractures to propagate within the rock mass as the stresses dictate. An initial intact rock sample was modeled in which the ratio of compression to tensile strength was fixed at approximately 10 . Pre-existing fractures with length much less than the sample dimension were introduced into the sample, first as isolated fractures, then as sets of fractures with intervening intact "bridges". Compression and tension experiments were then simulated and the compression and tensile strength of the rock mass determined. Tensile failure of the rock mass occurs as tensile fractures propagate from the ends of existing fractures through the solid rock bridges. Fairhurst showed that compression and tensile strengths of the rock mass are controlled by the percentage of solid rock bridges, as compared to the interconnected fracture surface area. The ratio of compression to tensile strength of the rock mass falls within the range of about 9 to 14 , indicating that the ratio of the compressive to tensile strength of the rock mass is reasonably represented by the ratio of compressive strength to tensile strength for intact rock of the same material. 
Joe Andrews began the second day of the Workshop with a presentation of how one might use non-linear phenomena, both at the source and along the path, to investigate physical limits to earthquake ground motion. The use of similar non-linear methods, developed in the 1960's, to simulate the response of geologic materials to underground nuclear explosions was also discussed.

Andrews considered a two-dimensional, plane-strain, dynamic model of slip on the Solitario Canyon fault, the bounding fault on the west side of the Yucca Mountain block. Consistent with the borehole data presented later by Mark Zoback, shear stress along the fault was initialized under in situ stress conditions to be 0.6 times normal compressive stress and was near the failure condition represented by a static coefficient of friction of 0.7 used in the calculation. Stress drop and dynamic slip on the fault were induced by reducing the friction coefficient along the fault to 0.1 . This resulted in a maximum stress drop of $40 \mathrm{MPa}$ and a maximum slip of approximately 15 $\mathrm{m}$ at and near the free surface. For a $10-\mathrm{km}$ fault length, the magnitude of this event is 7.2. Results for linear elastic wave propagation and wave propagation allowing for Mohr-Coulomb (nonlinear) failure were presented, and these calculations showed a significant decrease in shearwave amplitudes, whether in the time or spectral domain, of the non-linear relative to the linear cases.

Andrew's principal conclusions were that modeling methods that take into account the nonlinear response of the geologic materials are required to investigate strength bounds and that these strength bounds will provide physical limits to ground motions, whether excited by earthquakes or nuclear explosions. Andrews also noted that non-linear modeling methods for geologic materials, while generally unknown to the community of earthquake seismologists, are nevertheless in use in closely related fields.

Peter Cundall described the use of fully nonlinear numerical methods for modeling of wave transmission through rock and compared the fully nonlinear approach to the well known and often used equivalent linear methods (ELM). Cundall described a simple example problem to compare results from SHAKE, an ELM code, and FLAC, a fully non-linear code, showing reasonable agreement of the acceleration amplification factor for ground motions to $1 \mathrm{~g}$. A sitespecific example for Yucca Mountain applying a $10^{-6} / \mathrm{yr}$ ground-motion time history to a freefield lithophysal rock mass reveals that these large motions produce both shear and tensile fracturing, even though only horizontal shear components were supplied as input ground motion.

Cundall recommended that fully nonlinear methods that account for details of rock mass constitutive behavior be used in addition to ELM in cases where ground motions are extreme and produce strains in rock beyond the typical range of application of the ELM. The nonlinear methods can be used as a means for validating ELM. Current post-closure ground motions developed from PSHA results and ELM methods at Yucca Mountain produce shear and tensile strains that are in excess of rock-mass fracture strains in repository host horizons. Consequently, extensive shear and tensile fracturing is predicted in the free field in repository tuff units at Yucca Mountain.

Chris Scholz presented fault-tip taper data, derived from faulting-displacement/ fault-length measurements, for both earthquakes (ETT) and faults (FTT) in extensional regimes. Both ETT and FTT tend to have linear displacements tapers, in agreement with the critical fault-tip taper 
(CFTT) model, an elastic-plastic model for faulting displacements. FTT are larger than ETT by one to two orders of magnitude, the unsurprising consequence of faulting displacements along any one fault being the aggregate of many earthquakes along it. ETT data are consistent with individual earthquake stress drops in the range of 10 to 100 bars, and Scholz interpreted the FTT data as pointing to crustal strengths as high as $10 \mathrm{kbar}$. Scholz also suggested that earthquake stress drops can locally be as high as a kilobar at interior fault jogs, where rupture encounters the end of the fault, and/or when the rupture tip enters the stress shadow of an earlier earthquake. Scholz then briefly summarized seismological evidence for high ( $\sim$ kilobar), sub-event stress drops for the 1968 Tokachi-oki $(\mathrm{M}=7.9), 1980$ Victoria, Mexico $(\mathrm{M}=6.1$ and 1992 Petrolia $(\mathrm{M}$ $=7$ ) earthquakes. Scholz concluded that because the faults at Yucca Mountain are intraplate faults they would be expected to have average earthquake stress drops of $\sim 100$ bars, with subevent stress drops of $\sim 1 \mathrm{kbar}$.

Considerable discussion centered around whether the strain associated with FTT's in fact supported (elastic) stresses of up to $10 \mathrm{kbar}$. High stress-drop sub-events and the ground motions they excite were addressed in later Workshop presentations by Somerville, Beroza, and Anderson. The frequency of occurrence of these events, however, remains an outstanding issue.

Paul Somerville discussed a number of topics that relate to variations in earthquake ground motion, including: 1) simulations of ground motion using distributions of parameters describing the seismic source; 2) empirical evidence suggesting a difference in ground motions for shallow and buried faulting; 3 ) comparison of dynamic rupture parameters of shallow and buried faulting earthquakes; 4) magnitude scaling of the near-fault rupture directivity pulse; 5) physical factors limiting ground motions at Yucca Mountain.

Somerville described ground motion calculations performed for the PEGASOS project which include all of the following source parameters and ranges for them: faulting mechanism (strikeslip, normal, or reverse), amounts of surface and subsurface faulting, rupture area, slip distribution, slip functions, rise time, rupture velocity, and hypocenter(s). Somerville noted that the two source parameters having the strongest influence on large-amplitude ground motions, rupture area and rise time, have an inverse correlation and that combinations of small rupture area and short rise time give rise to very large ground motions that were considered unphysical. Little was presented regarding the specific variations and correlations in the source parameters. As Abrahamson previously noted for these calculations, the specific values used in the simulations seemed to be chosen subjectively, and thus the results are of limited help in defining physical limits to ground motions. One may anticipate that such information will be crucial for any PSHA that utilizes these kinematic models of the source.

Somerville also noted that ground motions from shallow-faulting earthquakes are weaker than from buried earthquakes and that there is magnitude saturation of the rupture-directivity pulse, both of which may be important to physical limits to ground motion in specific cases.

Greg Beroza complemented and extended Somerville's presentation with his stochastic approach to estimating source effects on earthquake ground motions utilizing dynamic models. The essential feature of this approach, which Beroza developed with Martin Mai, is characterizing and scaling the spatial variability of faulting displacements that attend crustal earthquakes (heterogeneous faulting). The power spectra of slip distributions computed from seismological 
inversions of seismograms to source are considered in terms of various random field models. These stochastic slip distributions are used to develop the temporal behavior of slip using physically consistent, stochastic dynamic earthquake source models or pseudo-dynamic approximations to such models. Extreme ground motions can then be judged within the context of the known source-slip behavior of past earthquakes. Unfortunately, this library consists of just 18 earthquakes, only one of which is a normal-faulting event such as might occur at Yucca Mountain.

Beroza presented two slip-distribution models for the Solitario Canyon fault, capable of producing extreme ground motions at Yucca Mountain. Both involved large, but localized slips (as high as $10 \mathrm{~m}$ ) and stress drops (several kbar), and both these slips and stress drops exceed, by a considerable margin, corresponding values within the current library of 18 earthquakes.

John Anderson presented an observational study of PGV and PGA, concentrating mostly on the PGA data set. He looked specifically at all available recordings with PGV $>50 \mathrm{~cm} / \mathrm{s}$ and PGA $>$ $800 \mathrm{~cm} / \mathrm{s}^{2}$. For PGV his preliminary finding is that they all are for $\mathrm{M}>6$ earthquakes and are influenced by rupture propagation toward the recording site (forward directivity). Anderson expressed concern that the different processing procedures used by different institutions precluded meaningful, detailed analysis and recommended that all of these velocity records be processed in the same way.

The PGA data set comes from 36 accelerograms (see distribution below) of 22 earthquakes occurring between 1971 and 2003. PGA's are less clearly related to magnitude than PGV's. Twelve of these records came from just two earthquakes, six each for the earthquake offshore of Miyagi Prefecture, Japan (May 26, 2003; $\mathbf{M}=7.0$ ) and for the Northridge, California earthquake (Jan. 17, 1994; $\mathbf{M}=6.7$ ); remarkably for the ground motion it generated, the Japanese earthquake occurred at a depth of $75 \mathrm{~km}$. Fourteen accelerograms of 12 earthquakes yielded PGA in excess of $1 \mathrm{~g}$, and $78 \%$ of these PGA's came from a horizontal component. [The Parkfield earthquake (Sep. 28, 2004; $\mathbf{M}=6.0$ ), occurring a month after the Workshop, will alter this data set and significantly change the statistics given above and below.] 


\section{Statistics of Extreme Accelerograms}

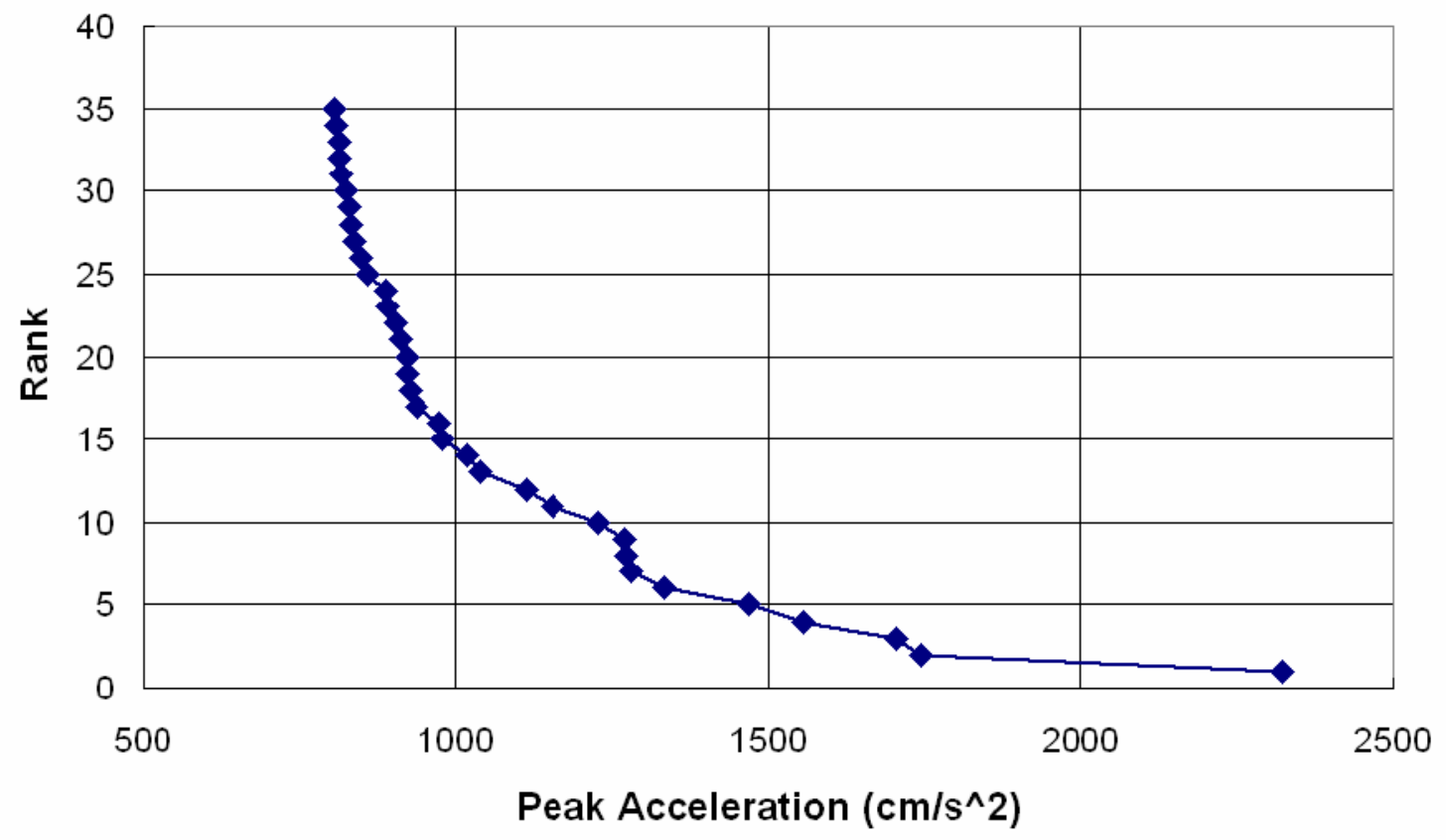

Anderson also examined the waveforms from which these PGA's came, the relation of the recording station to the fault, and a parameter characterizing the diminution of high frequencies for each recording. From this analysis, he developed the following statistics for the largest known PGA's: $69 \%$ of these values result from thrust faulting with $47 \%$ on the hanging wall of the thrust fault. Forward directivity is associated with $33 \%$ of the data. Dam abutments (topographic amplification) accounts for $20 \%$ of the data, and site condition plays an important role (soil site condition accounts for $33 \%$ and a strong resonance accounts for $6 \%$ ). Deep sources, perhaps involving very high stress drops, account for $20 \%$ of the data. Notably, every one of these records is associated with one or more of this limited set of conditions. Unfortunately, there are no normal-faulting earthquakes in this data set.

Anderson also investigated data from the Kik-Net in Japan, which features stations possessing both uphole and downhole sensors. He found that there are large amplifications of the surface ground motions relative to those at the downhole levels.

At the request of the Committee, Jim Dewey initiated a preliminary investigation of the very large $m_{b}$ (body-wave magnitude) $-\mathrm{M}_{\mathrm{S}}$ ( surface-wave magnitude) data set, available for $\mathbf{M} \geq 5$ crustal earthquake worldwide since the installation of the World Wide Standardized Seismographic Network in the 1960's. Just as underground nuclear explosions have higher $m_{b}$ for a given $\mathrm{M}_{\mathrm{S}}$ than do most crustal earthquakes, higher stress-drop earthquakes should have higher $m_{b}$ for the same $M_{S}$ than do average stress-drop earthquakes because of the enhanced excitation of high-frequency radiation.

In a presentation given by Tom Hanks, Dewey compiled $\mathrm{m}_{\mathrm{b}}-\mathbf{M}$ (moment magnitude, which for all but the very largest earthquakes, $\mathbf{M}>8.5$, is very close to $\mathrm{M}_{\mathrm{S}}$ ) data for more than 13,000 
worldwide crustal earthquakes for the interval 1977-2002. A small percentage of these earthquakes indicated stress drops $>500$ bars, but this is mostly due to the western U.S. attenuation rules applied to the entire data set. No more than 3 of these $>13,000$ events indicated a stress drop $>500$ bars when eastern U.S. attenuation equations were used. For earthquakes actually occurring in the western U.S., mostly in California, three of 103 events indicated stress drops $>500$ bars.

Dewey cautioned that reasons other than earthquake stress drops exist that can result in large $m_{b}$ for a given $\mathrm{M}_{\mathrm{S}}$. Thus, this analysis identifies events that should be examined individually for their source characteristics. Nevertheless, the $\mathrm{m}_{\mathrm{b}}-\mathrm{M}_{\mathrm{S}}$ data sets are huge and should allow us to reckon the frequency of occurrence of high stress-drop at fairly low probabilities.

Of great interest to the matter of extreme ground motions are those ground motions far removed from the median values, as they are known from model calculations or empirical analyses, the so-called "outliers", and Julian Bommer addressed this matter in his presentation "Outliers in Strong-Motion Datasets". He noted that aleatory variability in ground-motion data sets has not decreased over the past several decades, despite the addition of large amounts of data or the many recent studies including more complicated prediction equations. Moreover, he showed that for large sets of PGA data, probability distributions conform to the log-normal distribution out to two and even three standard deviations.

In a detailed study of data with logarithmic residuals at $>+2 \sigma$, Bommer pointed out several interesting observations. Even though the higher residuals are reasonably well correlated with ground-motion amplitudes, the highest residuals are mostly associated with ground motion of small enough amplitude to be of little engineering significance, as indicated in the plot below: 


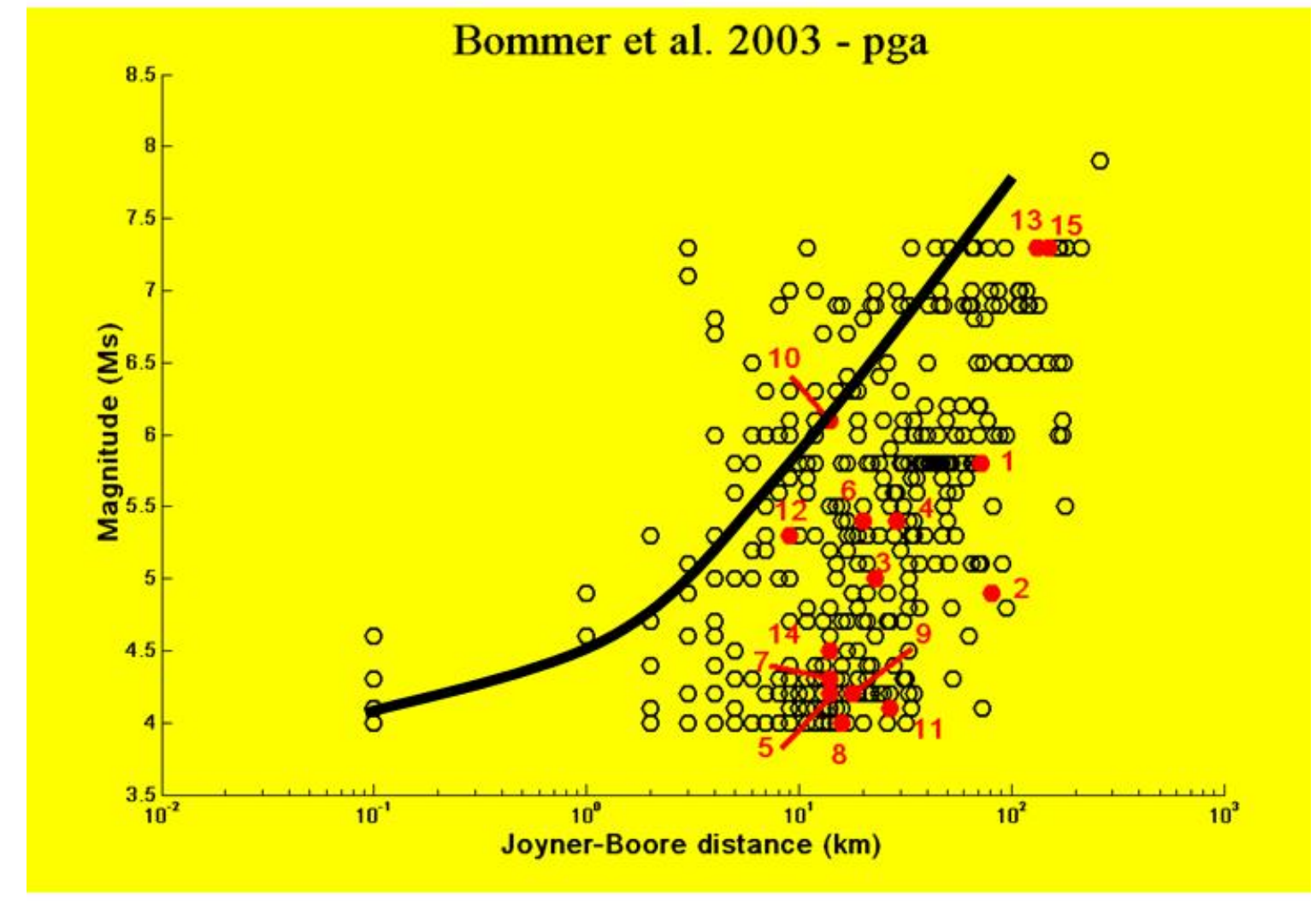

The red numbers and arrows identify the 15 largest residuals in magnitude and distance space. The heavy curve is an approximate boundary dividing regions where damage might be expected (above the curve) from magnitudes and distances with little expected damage. All of the residuals fall in the little-to-no-expected damage region (small magnitudes, or larger magnitudes at greater distances). There is no tendency for the largest outliers to be from a particular type of site or from a particular earthquake as would be expected if the outliers were caused by a strong systematic site effect or by an overall source effect (e.g. stress-drop). Factors that may be responsible for these large, positive residuals include forward directivity, seismic-ray focussing, site effects, and, possibly, processing noise.

Extensional tectonic regimes, such as the Basin and Range province in which the Yucca Mountain region is set, are typified by thinned crust and high heat flow, and the extension of the Basin and Range province has been considerable over the past 20 Ma. Extensional tectonic regimes are generally thought of as low-stress environments, and earthquake stress drops in extensional tectonic regimes are somewhat lower than for compressional regimes. Mark Zoback reviewed the in situ stress measurements to depths of $\sim 1.3 \mathrm{~km}$ depth in the Yucca Mountain block. They indicate, although the extrapolation to seismogenic depths is considerable, that the Solitario Canyon fault, and other faults in the vicinity of Yucca Mountain, exists within a high shear-stress field, only marginally stable with respect to normal faulting due to frictional shear failure. Indeed, such in situ stress measurements indicate that the upper (seismogenic) continental crust everywhere, with the notable exception of the San Andreas fault, is affected by high absolute deviatoric stresses corresponding to Byerlee's Law and hydrostatic fluid pressures. 
An outstanding issue is whether earthquake source parameters and the ground motion they control should be greater in high-stress regimes than in low-stress regimes. In successive talks, Mark Zoback spoke to these matters with respect to Yucca Mountain, and Art McGarr described the situation in deep-level gold mines in South Africa, in which the mining operations themselves induce high shear stresses.

Zoback noted that rotations of hydrofracture orientations along the borehole suggested that, at least in some circumstances, the associated stress drops could be near total, a result of near frictionless faulting. The rotations were modeled by dislocations near or crossing the borehole. Dimensions of these faulting events varied from a few meters to a few tens of meters. Some of the inferred stress drops were much larger than those observed for most crustal earthquakes, tens to hundreds of bars. Zoback suggested that near total stress drop with near frictionless faulting might be a common phenomenon. Unfortunately, no instrumental records of this faulting process are known to exist. Neither are much instrumental data available for the few earthquakes in and around Yucca Mountain, apart from the Little Skull Mountain sequence in 1992. Jim Brune noted that data collected by the University of Nevada, Reno, indicate that the stress drops near Yucca Mountain are not noticeably different than those at Anza along the San Jacinto fault, part of the San Andreas system.

McGarr noted that the deep-level gold mines in South Africa also exist in a marginally stable, regional extensional stress regime. The mining operations depress the water table in the vicinity of the mines, stabilizing the rock mass locally with respect to frictional failure, but also induce large deviatoric stress fields about the advancing stopes, in which most of the rockbursts occur. Like their California cousins, these rockbursts have quadripole radiation patterns indicative of shear failure and stress drops of several tens of bars making them indistinguishable from crustal earthquakes anywhere of comparable magnitudes. McGarr noted, however, that these events occur in shear stress fields that he estimates to be 300 to 600 bars. Using an intact rock strength of $164 \mathrm{MPa}$, McGarr estimated a maximum near-source particle velocity of $4.1 \mathrm{~m} / \mathrm{sec}$. He also noted that even higher ground motions might result from failure of intact-rock asperities. McGarr concluded by noting that ground motion results from mining-induced earthquakes could be applied to Yucca Mountain if the differences in rock strength were taken into account.

As we learned from Jerry King on the first day of the Workshop, the Yucca Mountain Project is currently pursuing the development of an upper-bound PGV for ground motions based on the absence of seismically induced damage to the lithophysal units in the 12.8 Ma welded tuffs exposed in underground excavations at the site. David Buesch began the Wednesday presentations with observations of the structural features in the lithophysal and nonlithophysal subunits of the Topopah Spring tuff, which include the lithophysae themselves (voids created by gases exsolved during cooling) and cooling-related fractures. These observations are captured in $1 \mathrm{~m} \times 3 \mathrm{~m}$ "panel maps" of the walls in the ECRB (Enhanced Characterization of the Repository Block) Cross Drift, detailed line surveys of fractures in all of the underground excavations at the site, and in sectioned slabs of rock derived from the various repository host horizons.

In the lithophysal units, Buesch found that the lithophysal cavities show no evidence of postformation damage. Moreover, the inter-lithophysal fracturing isconsistent with a cooling origin indicated by the orientation, short trace length, lack of offset of the fractures and the occurrence of vapor-phase alteration minerals within them. In the nonlithophysal rock units, Buesch found 
that $\sim 70 \%$ of the fractures can be traced directly to a cooling origin, with the remainder classified as of indeterminate origin, although they could be a result of cooling as well. There is minimal evidence of post-formation shear dislocation on these features. Buesch concluded from his enormous number of observations that strains due to earthquake ground motions since $12.8 \mathrm{Ma}$ have not been sufficient to cause obvious structural disturbance to the ubiquitous lithophysae in the lower lithophysal unit of the Topopah Spring tuff or to form new fractures or cause shear offset on existing fractures in the lithophysal and nonlithophysal units of the Topopah Spring tuff.

Joe Whelan took the Workshop into the small world of the lithophysal cavities and the even smaller world (millimeters) of the delicate calcite/silica blades and filaments within them, precipitated from meteoric water percolating slowly through the mountain over millions of years. These secondary mineral assemblages have been forming for at least $8 \mathrm{Ma}$, and suggest that the repository horizon has been an unsaturated zone at least since then. Potentially, these undamaged fragile blades and filaments also speak to unexceeded ground motions since $8 \mathrm{Ma}$.

Dave McCallen analyzed the dynamic response of these structures to earthquake ground motion in terms of a Bernoulli-Euler beam. Typically, given their dimensions and material properties, these blades and filaments would have natural frequencies of vibrations of a kilohertz or so, and would respond to typical earthquake ground motion as undeformed, rigid bodies requiring very large accelerations (25-130 g) to overcome their tensile strength.

Branko Damjanac followed this summary of observational evidence with a presentation of the shear strains at failure of the lithophysal rock as well as shear strains in nonlithophysal rock that would result in $1 \mathrm{~mm}$ (about the observable limit) of offset on preexisting cooling fractures. The analyses, conducted using discontinuum numerical models, also provide a physical interpretation of the type of fracturing one would expect to observe in underground exposures in these units. Shear strain levels of about $0.1 \%$ are required to fail these rock units, and would result in observable inter-lithophysal fracturing. The $0.1 \%$ shear strain limit corresponds to a PGV of approximately $2 \mathrm{~m} / \mathrm{sec}$. Amplitudes larger than this level would also result in significant shear displacement on induced fractures, with observable offset in lithophysae. Because no damage of either type has been observed, PGV of $2 \mathrm{~m} / \mathrm{sec}$ is a likely upper bound for particle velocities traversing the Topopah Spring tuff in the past $\sim 10$ million years.

Bill Foxall reported on a preliminary investigation of the availability and accessibility of groundmotion recordings of underground nuclear explosions on the nearby Nevada Test Site, many of them detonated in the same or very similar volcanic tuffs that underlie Yucca Mountain. At close distances, these explosions generate large-amplitude ground motions, although with a source mechanism (radial compression) much different from earthquakes (shear failure) and with a far greater energy density. These data provide insights into material response and stress propagation and attenuation in the high-strain (nonlinear) regime and thus should provide information and constraints on these properties for the Yucca Mountain tuffs. Typically, ground motions generated by these nuclear explosions attenuate rapidly due to highly nonlinear damage mechanisms and yielding within a few hundred meters of the shotpoint. 
Jim Brune presented numerous examples of precarious rocks and precipitous slopes from California and Nevada, as well as unfractured, Miocene-age sandstones adjacent to the San Andreas fault. These observations speak to unexceeded ground motions on time scales of $\sim 10 \mathrm{ka}$ to $\sim 10 \mathrm{Ma}$ or more. Brune also showed examples of precarious rocks and precipitous slopes that were toppled/activated by the 1992 Little Skull Mountain earthquake $(\mathbf{M}=5.6)$ and underground nuclear explosions on the Nevada test Site, observations that validate, at least qualitatively, laboratory and field determinations of toppling accelerations. Brune has estimated that precarious rocks on Yucca Mountain, with ages of $\sim 30 \mathrm{ka}$ to $\sim 250 \mathrm{ka}$, would have been toppled by peak accelerations of $0.15-0.35 \mathrm{~g}$, significantly less than the $10^{-4} / \mathrm{yr}$ Site A value of $0.53 \mathrm{~g}$. Brune also noted that Miocene sandstones adjacent to the San Andreas fault in southern California, with a tensile strength of $\sim 10$ bars have been unfractured by the 20,000 or so $\mathbf{M} \sim 8$ earthquakes that have occurred along the fault since $\sim 5 \mathrm{Ma}$. Both the diversity in type and in age of these indicators of unexceeded ground motions provide numerous opportunities to constrain seismic hazard.

As yet another example of fragile geologic structures serving as potential paleoseismoscopes, John Stuckless summarized the use of speleothems in caves to develop pre-historic earthquake chronologies. Considerable work has been done with this approach in Italy and Israel, much less so in the United States. Stuckless reviewed several candidate caves in the American Southwest that might be amenable to this analysis, but none of them are close to Yucca Mountain. Stuckless did not indicate whether caves suitable for this analysis exist near Yucca Mountain. Stuckless also presented a number of examples of natural and anthropogenic caves, tunnels, and excavations in seismically active areas that have never been damaged by earthquake shaking, over time spans of thousands to millions of years.

The Committee asked John Whitney and David Schwartz to speak on the largest faulting displacements observed for normal faults, the faults local to Yucca Mountain in the case of Whitney and faults elsewhere in the Basin and Range Province in the case of Schwartz. For the Yucca Mountain area, available erosion-rate data indicate that $\sim 15 \mathrm{~m}$ surface-faulting displacements (or even 5 to $10 \mathrm{~m}$ fault scarps) would last for a million years or more in this terrain of erosionally resistant, bedrock scarps. Whitney presented an overview of the paleoseismic history of the Yucca Mountain faults, by far the most complete paleoseismic history for any place on the planet. It is complete for all the Yucca Mountain faults to $100 \mathrm{ka}$ and extends back to $700 \mathrm{ka}$ for individual faults. Average co-seismic displacements range from 20 to $127 \mathrm{~cm}$; maximum co-seismic displacements are 32 to $205 \mathrm{~cm}$ for the Yucca Mountain faults and are $300 \mathrm{~cm}$ for the Bare Mountain fault. Perhaps the most interesting event in this history is the distributed surface ruptures along three of the Yucca Mountain faults that are related to a volcanic eruption of the Lathrop Wells cone at $77 \mathrm{ka}$. Thus, there is nothing in this long history that points to unusually large faulting displacements, and large faulting displacements $(>5 \mathrm{~m})$ of even greater antiquity $(\sim 1 \mathrm{Ma})$ would still be observable.

Schwartz followed Whitney with a similar discussion of normal-faulting behavior throughout the Basin and Range province. Unlike the Yucca Mountain area, large normal-faulting earthquakes do provide, at least occasionally, for faulting displacements in excess of $5 \mathrm{~m}$. Such vertical offsets were observed at a few places along the fault traces for the 1915 Pleasant Valley, Nevada $(\mathbf{M}=7.3)$ and 1959 Hebgen Lake, Montana $(\mathbf{M}=7.4)$ earthquakes, with fault lengths of 61 and $26 \mathrm{~km}$, respectively. Both of these earthquakes have magnitudes in excess of those believed 
possible for the faults local Yucca Mountain, and the Pleasant Valley earthquake has a fault length much greater than those of the Yucca Mountain faults. As a matter of fault length alone, the Hebgen Lake earthquake could fit on the Yucca Mountain faults. Had this been the case in the last $\sim 0.5 \mathrm{Ma}$, however, its large displacements, typically $3 \mathrm{~m}$ or more, would have been readily observable.

\section{FINDINGS}

The findings listed below are given primarily to inform the research recommendations which follow. They do not constitute an all-inclusive summary of the many things that come to mind as a result of the Workshop presentations.

As an overall and quite general finding-and also as a brief summary of the findings that followthe Committee finds that there are many lines of evidence and argument that can be drawn from a wide range of geological, geophysical, seismological, and material-properties studies that all point to the same general conclusion: at probabilities of exceedance of $10^{-4} / \mathrm{yr}$ and smaller the seismic hazard at Yucca Mountain as calculated from the 1998 PSHA is too high.

For the purposes of clearly explaining matters of interest in this Report, the Committee has found it necessary to define "unexceeded ground motions" as ground motions that have not occurred at a specific site during a specific period of time and "physical limits to ground motion" as amplitudes of ground motion that cannot happen, ever.

The Yucca Mountain site is composed of laterally extensive and relatively flat-lying welded and bedded tuff units. The proposed repository footprint is approximately $6 \mathrm{~km}$ by $2.5 \mathrm{~km}$ in plan dimension. The footprint is completely underlain by the laterally extensive, relatively weak and unfractured Calico Hills formation, a $\sim 50-\mathrm{m}$ thick bedded tuff unit that underlies the entire repository. The repository itself is located largely within (about 85\%) the lower lithophysal unit of the Topopah Spring formation. As described by numerous speakers during this workshop, the lower lithophysal unit has relatively high porosity and is significantly weaker than the overlying and underlying welded, nonlithophysal units. Both of these geologic formations-the Calico Hills tuff and the lower lithophysal unit-provide constraints on unexceeded ground motions at Yucca Mountain.

The Committee endorses the current efforts at the Yucca Mountain Project in which the lithophysal rock strain limits are being used as a means for determining unexceeded PGV's experienced at the site in the past $12.8 \mathrm{Ma}$; however, the Committee believes that the distribution function of bounding horizontal PGV's presented by Jerry King may be too broad, insofar as no seismically induced damage to the lithophysae has been observed. Presumably, there is considerable variation in the local strength of the lithophysal units due to variable density/void fractions of the lithophysae. Given the negative observations, then, the lower ranges of King's distribution are more likely upper ranges to PGV's that have not passed through Yucca Mountain in the past 12.8 Ma. That these units could have/should have failed at even lower strengths associated with tensile failure would reduce these values even more. The Committee believes that similar analyses should be conducted for the Calico Hills formation. 
The shear and tensile strains induced by the earthquake source are limited by the strength of the rock mass. At source depths of 10 to $15 \mathrm{~km}$, the lithostatic (overburden) pressure results in high rock strength and strain limits. As the seismic wave propagates to shallower depths, the confining pressure and strength are reduced, with subsequently lower strain limits. The amplitude of extreme ground motions are thus most stringently limited by the nonlinear constitutive behavior of rock at relatively shallow depths.

The ground motions corresponding to shear strain limits are derived from an equivalent-linear site response model which accounts, in only a general way, for rock-mass yield in shear which includes slip on existing fractures, the creation of new ones, and potential tensile failure mechanisms. Uncertainty in the nonlinear material properties of the rock units is accounted for through bounding material-properties assumptions. These assumptions yield a conservative estimate of the physical limit of the ground motions. Defining physical limits to ground motion that arise from the finite strength of rocks, specifically the Calico Hills formation and the lower lithophysal unit, requires calculation of stress propagation through these units that fully accounts for their nonlinear, dissipative response.

The data sets available to seismologists to study the excitation and propagation of strong ground motion are large and diverse, and it was not surprising that the seismological presentations, including those of McGarr, Somerville, Beroza, Anderson, Dewey, and Bommer were drawn mainly from existing data sets. The Committee believes, however, that the essential matter here is whether or not the metric of what can happen, at very low probabilities of occurrence/exceedance, is determined by what has happened, and this was a recurring theme in these presentations, whether the particulars involved earthquake stress drops, PGA and PGV data, or rise time and asperity sizes. While seismologists indeed have large data sets with which to work, they are not so large and so definitive as to rule out the occurrence of high-stress-drop events at the rate of a few events per thousand or more, for example. Unfortunately, existing rheological rules and constraints provide considerable latitude as to what can happen in the source region, as indicated by Andrews' presentation.

Unexceeded ground motions in the vicinity of Yucca Mountain were presented and discussed with respect to several different types of geologic structures that involve very different lifetimes. These include: (1) The undamaged lithophysal units (12.8 Ma), (2) The undamaged blades and filaments precipitated in the lithophysal cavities ( $\sim 10 \mathrm{Ma})$, (3) Absence of seismically fractured rock and absence of slip on existing cooling fractures ( 10 Ma), (4) Absence of large singleevent slip on the Yucca Mountain faults ( 1 Ma), (5) Precipitous slopes ( 0.01-0.1 Ma) and (6) Precarious rocks $(\sim 0.01-0.1 \mathrm{Ma})$. Additional presentations were made by Brune on unfractured sandstone units adjacent to the San Andreas fault ( $\sim 5 \mathrm{Ma})$ and by Stuckless on the use of fragile speleothems as paleoseismoscopes. Because of the higher rate of occurrence of large earthquakes on the San Andreas fault compared to Yucca Mountain, the sandstones along the San Andreas fault have the potential of constraining inferred ground motions at Yucca Mountain at $10^{-8} / \mathrm{yr}$ annual probability.

Unexceeded ground motions associated with one or more of these geologic structures provide important constraints on the seismic hazard at Yucca Mountain and can be used to down-weight or reject branches of the logic tree that lead to hazard curves inconsistent with these 
observations. Some question yet remains just how to put these constraints into play in the PSHA format, and further work is necessary, in some cases, to document and quantify the amplitudes of ground motion from the various indicators and the time intervals over which that ground motion has not occurred.

The undamaged lithophysal units, (1) above, are the subject of continuing study. The cavity blades and filaments (2) described by Whelan and analyzed for their dynamic behavior by McCallen have resonance frequencies much higher than those of interest to repository design and safety issues at Yucca Mountain. The possible use of speleothems for Yucca Mountain groundmotion constraints depends on the location and accessibility of limestone caves in the area, to which the Committee cannot speak. The Committee notes, however, that DOE, for reasons entirely separate from the ones that motivate this Workshop, could apply this approach to limestone caves in Kentucky and Tennessee to extend the history of large earthquakes in the New Madrid seismic zone back thousands and perhaps tens of thousands of years.

The absence of earthquake faulting with surface displacements greater than $2 \mathrm{~m}$ in the case of the Yucca Mountain faults (Whitney) over the past $700 \mathrm{ka}$ or surface displacements greater than $6 \mathrm{~m}$ for earthquake faulting anywhere in the Basin and Range province (Schwartz) suggests that Andrews' model earthquake, with its $15 \mathrm{~m}$ of surface displacement, is an unlikely if not impossible event in this geologic setting. Andrews, Beroza, and Somerville generally confirmed the view that large displacements/stress drops are required somewhere in the source region if the source itself is the causative agent of extreme ground motions, although other possibilities exist in the way of forward directivity, seismic-ray focusing, and site amplification.

No consistent use of unexceeded ground motions or physical limits to ground motion was employed in the 1998 Yucca Mountain PSHA. No formal feedback was provided to the experts about extending the 1998 results to hazard levels of $10^{-6} / \mathrm{yr}$ and smaller.

The Committee finds the Point A PGV $=3.5 \mathrm{~m} / \mathrm{sec}$ at a hazard level of $10^{-6} / \mathrm{yr}$ as determined from the 1998 Yucca Mountain PSHA is contradicted by the undamaged lithophysal units and the existing corpus of PGV data. First, such a PGV would have caused observable damage to the lithophysal units, which has not occurred in $10^{7} \mathrm{yrs}$. Second, assuming such a large PGV would have been the result of a large event $(6.5 \leq \mathbf{M} \leq 7)$ on the Solitario Canyon fault, with a recurrence interval of $\sim 50,000$ years, a PGV occurring in one of 20 events suffices to reach $10^{-}$ $6 / \mathrm{yr}$. In the PEER strong motion data set, there are 73 recordings from 20 earthquakes with $6.3 \leq$ $\mathbf{M} \leq 7.3$ at distance from 0 to $10 \mathrm{~km}$. The largest PGV for the average horizontal component from this subset is $1.1 \mathrm{~m} / \mathrm{s}$. (This record is from a soil site; the largest average horizontal PGV in this subset from a rock site is $0.9 \mathrm{~m} / \mathrm{sec}$.) This subset includes distances greater than the distance from Point A to the Solitario Canyon fault, but it also includes sites with near-surface shear wave velocity $\left(\mathrm{V}_{\mathrm{s}}\right)$ values of $200-2000 \mathrm{~m} / \mathrm{sec}$, which are on average lower than the $\mathrm{V}_{\mathrm{s}}$ for Point A. These data indicate that the 1 in $20 \mathrm{PGV}$ for Point $\mathrm{A}$ is much smaller than $3.5 \mathrm{~m} / \mathrm{sec}$. Furthermore, the largest PGV ever recorded of $3.0 \mathrm{~m} / \mathrm{s}$ from the 1999 Chi-Chi earthquake $(\mathbf{M}=$ 7.6) is associated with $9 \mathrm{~m}$ of fault slip near the recording site, fault displacements larger by a factor of $\sim 5$ than those on faults near Yucca Mountain. 


\section{RECOMMENDATIONS FOR RESEARCH}

The research recommendations that follow below are placed in three categories: physical limits, unexceeded values, and frequency of occurrence. Physical limits to and unexceeded values of earthquake ground motion have been discussed at length in this report, but things like frequency of occurrence of high-stress-drop earthquakes or the frequency of occurrence of PGA's $>1 \mathrm{~g}$ and PGV's $>1 \mathrm{~m} / \mathrm{sec}$ do not fit easily into either of these categories; hence the third.

\section{A. PHYSICAL LIMITS}

The Committee recommends that research be conducted into the physical limits on ground motion in two specific areas: 1) nonlinear effects due to rock-mass degradation, including slip on pre-existing fractures and creation of new fractures, along the travel path of the seismic wave as it transits from the source to the ground surface at the Yucca Mountain site, and, 2) nonlinear effects at the source resulting from slip on the fault and rock-mass damage in the source region.

\section{A.1. Nonlinear Modeling of the Seismic Travel Path}

The shear and tensile strain limits of the rock mass provide physical limits to seismic wave propagation through the rock units at the Yucca Mountain site. Using nonlinear wave propagation models, these physical limits can be used to provide an estimate of the largest possible ground motions.

The Committee recommends a nonlinear numerical analysis of the response of the site-specific rock units at Yucca Mountain to the seismic waves. Joe Andrews (USGS), Peter Cundall and Branko Damjanac (Itasca) described preliminary results from nonlinear one and two-dimensional site response calculations during the workshop. This analysis would account for wave propagation from a seismic source in the linear elastic regime at depth that subsequently travels through the rock units underlying the repository, the repository horizon and the overlying tuff units to the ground surface. Numerical models capable of accounting for the nonlinear effects and energy dissipation mechanisms of shear and tensile strain limits of welded, fractured rock tuff as well as the nonwelded, bedded rocks are required.

Energy is naturally dissipated as a rock mass undergoes shear and tensile failure in the intact rock matrix as well as along natural fractures such as joints and bedding surfaces. Dissipation of energy during yield is taken into account in nonlinear numerical models through enforcement of inelastic material stress-strain laws for the rock matrix as well as fractures. For example, yield and energy dissipation within the rock matrix may be represented by a continuum-based constitutive law (e.g., Mohr-Coulomb with a brittle post-peak softening using a finite element or finite difference numerical formulation) or by models that explicitly account for rock fracture and creation of new surface area (e.g., discontinuum or particle models). An example of the continuum-based method was presented by Joe Andrews, and examples of the use of discontinuum approaches to model rock shear and tensile fracturing were presented by Branko Damjanac and Peter Cundall. Nonlinear response and energy dissipation due to shear or tensile failure along fractures or bedding surfaces along the travel path are typically accounted for through the use of explicit fracture representations or continuum-based in the rock mass. Slip 
and/or separation, and the associated energy dissipation mechanisms, on fractures or bedding surfaces is often modeled explicitly using discontinuities within the rock mass upon which a constitutive law for slip (e.g., Mohr-Coulomb) is enforced. Alternatively, the general effect of fracture sets may be represented using equivalent rock mass shear strength in which the presence of fracturing has been accounted for in a reduction of strength and moduli. A potentially important mechanism of energy dissipation at the Yucca Mountain site is separation of subhorizontal bedding surfaces or creation of subhorizontal fractures due to verticallypropagating shear and compression waves near the ground surface (e.g., a spalling-type phenomena).

For the Yucca Mountain site, in particular, the input seismic waves would begin in the limestone units at depth and travel through the Bullfrog, Prow Pass and Tram welded and Calico Hills nonwelded units below the repository horizon. Representation of the proposed repository host horizon should include the weaker lithophysal units. Rock mass properties estimates and mechanical constitutive laws developed for the Yucca Mountain project can be used as input to these studies. The analyses would provide the input and output seismograms from each of the site geologic units as the wave transits to the ground surface. The results will be used to provide a detailed understanding of the mechanism and extent to which the site response is altered due to nonlinear effects, and to provide a more realistic, mechanistic-based assessment of physical limits to the ground motions.

The Committee notes that these calculations will require a considerable amount of materialproperties input data, together with associated uncertainties. The Committee is not informed as to what scope of effort may be needed to assemble this information.

\section{A.2. Nonlinear Modeling of the Source}

Limits on the ground motions generated by the source provide a mechanism for physical limits to the ground motions that are input into the rock units at the Yucca Mountain site.

The Committee recommends that research be conducted into nonlinear modeling of the seismic source to gain a better understanding of the effect of the physical strength limits of rock on the source mechanisms and energy generation resulting from fault slip. The ultimate purpose of this work is to examine whether the geometry, properties and constitutive behavior of the fault, the in situ state of stress, and the rheology of the surrounding rock mass result in a bound to the magnitude of energy release from slip events. Such nonlinear source modeling, which dates back to the 1960's to simulate nuclear weapons effects, should extend the Workshop presentations of Andrews and Cundall to other material rheologies, stress states, and faulting geometries, including the roughness geometry of faults

Nonlinear response and energy dissipation due to shear or tensile failure along faults, and in the near field of the faults is an area in which research may be performed using existing numerical modeling methods. For example, the slip and/or separation on the fault surface and the yield and fracturing in the fault near field may be modeled using interfaces within the rock mass upon which a constitutive law for slip is enforced. The representation of the fault surface could include roughness (e.g., asperities), and thus an inhomogeneous representation of strength. 
Other factors, such as time-dependency could be included. Energy dissipation via yield in the fault near field may be represented through continuum-based plasticity models or via explicit fracturing as described by Cundall.

This task will lead to source models and computational tools that can be used to compute the ground motions in the near-fault region, before they are propagated into the shallow rock (task A.1.).

\section{A.3. Nevada Test Site (NTS) Nuclear Explosion Data}

The Committee believes that instrumental recordings of the downhole response of rock to the extreme strain pulses from NTS nuclear explosions at close distances would be valuable in assessing extreme ground motions at nearby Yucca Mountain. Such data could, in principle, be used to validate the nonlinear models discussed above and also to assess the validity of various estimates of the levels of ground motion that fracture rock. Such data could also be valuable in assessing the nonlinear response of the alluvium beneath and adjacent to the surface wastehandling facilities. Questions remain, however, as to the availability, accessibility, and the quality of these data. The Committee recommends funding further analysis of these matters, building on Foxall's findings as reported in his Workshop presentation.

\section{A.4 Implementation of Source Models}

The Committee recommends that initial application of the source constraints from task A.2 be used to develop more computationally efficient, representative kinematic source models. These kinematic representations of the source should then be used to compute broadband seismic motions that can be used as inputs to the nonlinear wave propagation models. By using representative kinematic models, initial simulation results can be derived in a relatively short time, whereas some broadband non-linear source models may not be readily available for engineering application. This also has the advantage that the source is parameterized in a simplified manner that is familiar to ground motion experts.

\section{Working Groups}

The nonlinear modeling of the wave propagation and source involve a range of expertise. The Committee recommends that working groups of rock-mechanics modeling specialists and seismologists be assembled to conduct these research tasks. Seismologists will provide expertise in source mechanics and ground motion characterization; the rock mechanics specialists will bring a detailed understanding of the rheological behavior of rocks and state-of-the art experience in development and use of dynamic, nonlinear modeling. Recent research by Andrews and by Cundall and Scholz in dynamic modeling of rough faults provides examples of the modeling approaches that can be applied to this problem.

For the new models developed by the working groups to be accepted for use, some calibration/validation of the source models and non-linear wave propagation using empirical observations will be needed to show that the models are working properly. The compilation of 
the empirical data for the source model calibration is discussed in tasks $\mathrm{A} 3$ and $\mathrm{C} 1$. The compilation of the data for the non-linear wave propagation model is discussed in task A.3.

\section{B. UNEXCEEDED VALUES}

B.1. The Committee supports continuation of the ongoing study and analysis of the lithophysal units within the Yucca Mountain Project to determine unexceeded ground motions for the repository level since $12.8 \mathrm{Ma}$. The Committee recommends extending such studies to the underlying Calico Hills tuff.

B.2. The Committee recommends that the present status of unexceeded ground-motion amplitudes associated with precarious rocks, precipitous slopes, and unfractured rock, together with available age determinations for these structures, be synthesized for the Yucca Mountain Project. This synthesis should also serve as plan for supplemental age determinations as necessary. Likewise, the Committee recommends that similar information be developed for the unfractured sandstones adjacent to the San Andreas fault.

B.3. The Committee also recommends that syntheses of the Whitney and Schwartz presentations with respect to single-event faulting displacements for the Yucca Mountain and the entire Basin and Range, respectively, be written for the Yucca Mountain Project.

B.4. The Committee also recommends that research be conducted as to the ways in which unexceeded ground motions can be formally employed in PSHA, for example through Bayesian updating.

\section{EVENT FREQUENCIES OF OCCURRENCE}

Earthquake source parameters and ground-motion peak parameters in the existing literature and catalogues can be used to establish empirical constraints on the distributions of source/groundmotion properties. Such studies should emphasize the upper tail of the distributions. With tens of thousands of earthquakes and ground-motion records now available, the upper tail of these distributions can be reliably determined. These distributions can be used directly in simple ground-motion models (e.g. point-source stochastic models) or they can be used to test the nonlinear source models developed in task A.2.

\section{C.1. Earthquake Stress Drops}

Despite three decades of study of crustal earthquake stress drops involving hundreds of seismologists around the world, the frequency-of-occurrence of high-stress-drop earthquakes is still poorly known. The most comprehensive way to explore this, the Committee believes, is through the $m_{b}-M_{S}$ pairs that exist for tens of thousands of crustal earthquakes, as described by Dewey. This will also be the most time-consuming approach, as those earthquakes that do suggest high stress drop will need to be studied individually to verify that this the case. A less time-consuming alternative would be to conduct a literature search for all $\mathbf{M}>5$ earthquakes for which a Brune stress drop has been determined, which still involves perhaps a thousand (or 
more) earthquakes. In both cases, it would be desirable that the tectonic regime be specified, for the particular interest at Yucca Mountain is the extensional faulting regime.

\section{C.2. The Larger PGA's and PGV's}

In a like manner, the Committee recommends documentation and analysis of the 100 largest PGA's and PGV's, in a manner building on Anderson's presentation. Further, the Committee recommends a synthesis of the analysis of ground-motion outliers as parameterized by their normalized residuals, after Bommer's presentation. Of particular importance is the association of the largest known absolute values (PGA's and PGV's) and relative values (normalized residuals) with forward directivity, faulting mechanism, and earthquake magnitude. These empirical results can then be compared to the numerical calculations of the non-linear modeling of the source and wave propagation.

\section{C.3. Simplified Representation of Nonlinear Source Models}

To provide a method for calibrating the non-linear source models from Task A.2, the Committee recommends that equivalent (representative) simplified source parameters from task C.1 and C. 2 be computed for a suite of source model realizations. The shape of the distribution of these simplified parameters should be compared to that from the catalog data (task C.1) as a check of the non-linear source models. For example, the distribution of the equivalent Brune stress drop from the non-linear source models can be compared to the empirical distribution determined in Task C.1.

\section{IMPLEMENTATION OF RESEARCH RESULTS IN PSHA}

This Committee was constituted by Bob Budnitz, with the Science and Technology Program of the Office of Civilian Radioactive Waste Management, to review the guidelines and procedures for PSHA in the context of the extreme ground motions resulting from the 1998 Yucca Mountain PSHA. As a prelude to that task (Task A), the Committee undertook the present one (Task B) on the basis that the application of either physical limits to ground motion or unexceeded groundmotion amplitudes within the PSHA formalism would require new and different guidelines, procedures, and rules.

Given the very large PGA's and PGV's arising from the 1998 PSHA at hazard levels of $10^{-6} / \mathrm{yr}$ and smaller, the Committee has little doubt that the application of both physical limits and unexceeeded values for specific time intervals will reduce these ground-motion amplitudes at hazard levels of at least $10^{-6} / \mathrm{yr}$ and smaller and perhaps at larger hazard levels as well. While the Committee makes no recommendation about re-visiting the 1998 Yucca Mountain PSHA or conducting a new one, it nevertheless believes that work should be conducted in a manner that keeps implementation into PSHA in mind. 


\section{REFERENCES}

Abrahamson, N.A., P. Birkhauser, M. Koller, D. Mayer-Rosa, P. Smit, C. Sprecher, S. Tinic, and R.Graf (2002). PEGASOS: A comprehensive probabilistic seismic hazard assessment for nuclear power plants in Switzerland, Proceedings of the Twelfth European Conference on Earthquake Engineering, London: Elsevier, Paper No. 633.

Bommer, J.J., N.A. Abrahamson, F.O. Strasser, A. Pecker, P.-Y.Bard, H. Bungum, F. Cotton, D. Fah, F. Sabetta, F. Scherbaum, and J. Studer (2004). The challenge of defining upper bounds on earthquake ground motions, Seismological Research Letters 75, 82-95.

SSHAC(1997). Senior Seismic Hazard Analysis Committee (Budnitz, R.J., chair, G. Apostolakis, D.M. Boore, L.S. Cluff, K.J. Coppersmith, C.A. Cornell, and P.A. Morris), Recommendations for probabilistic seismic hazard analysis: guidance on uncertainty and the use of experts, NUREG/CR-6372, U.S. Nuclear Regulatory Commission.

Stepp, J.C., I. Wong, J.Whitney, R. Quittmeyer, N. Abrahamson, G. Toro, R. Youngs, K. Coppersmith, J. Savy, T. Sullivan and Yucca Mountain PSHA project members (2001). Probabilistic seismic hazard analyses for ground motions and fault displacements at Yucca Mountain, Earthquake Spectra 17, 113-151. 
Appendix A

\section{Workshop on Extreme Ground Motions at Yucca Mountain BACKGROUND \\ Monday, August 23, 2004}

0900 Tom Hanks: The Workshop on Extreme Ground Motion at Yucca Mountain

0920 Ivan Wong: Overview of the probabilistic seismic hazard analyses of Yucca Mountain

1000 Norm Abrahamson: Ground-Motion Methods and Results for the1998 PSHA

1040 Break

1100 Gabriel Toro: Seismic Hazard De-Aggregation and Ground-Motion Sensitivities for Yucca Mountain

1140 Art McGarr/Leon Reiter: Bounds on PGV at the Yucca Mountain Repository Based on Earthquake Source Constraints/NWTRB Perspective on Extreme Ground Motions

1220 Lunch

1330 Norm Abrahamson/Julian Bommer: The PEGASOS Project, Methods and Results/The Use of Empirical Data, Numerical Simulation and Expert Judgment to Define Upper Bounds on Ground Motions: Insights from the PEGASOS Project

1430 Jerry King: Peak Ground Velocities for Seismic Events at Yucca Mountain, Nevada 1510 Break

1530 Charles Fairhurst and Mark Board: Fundamental Considerations Relating To The Strength of Rock

1630 Discussion

\section{SOVRCE EXCITATION}

Tuesday, August 24, 2004

0830 D.J. Andrews: Deterministic Modeling of Physically-Limited Ground Motion

0910 Peter Cundall: Fully nonlinear modeling of dynamic transmission in rock

0950 Chris Scholz: Strength of Faults and Maximum Stress-Drops in Earthquakes

1030 Break

1050 Paul Somerville: Physical Constraints on Upper Bound Ground Motions

1130 Greg Beroza: A Stochastic Approach to Predicting Source Effects on Extreme Ground Motion

1210 Lunch

1300 John Anderson: Large-amplitude PGA's and PGV's, and arms stress drop variability

1340 Jim Dewey: $m b$ vs Mw in the Search for High Stress-Drop Earthquakes 
1420 Julian Bommer: Outliers in Strong-Motion Datasets

1440 Break

1500 Mark Zoback: Direct observations of stress magnitudes and stress drops at depth

1540 Art McGarr: Source properties of mining-induced seismicity

1620 Discussion

1900 Dinner at Il Fornaio

\section{PROPAGATION AND TRANSMISSION}

Wednesday, August 25, 2004

0830 Dave Buesch: Geologic Evidence for Limited Ground-Motion Damage in the Topopah Spring Tuff, Yucca Mountain, Nevada

0910 Joe Whelan/Dave McCallen : Petrographic Evidence of Past seismicity From Secondary Mineral Deposits in the Unsaturated Zone at Yucca Mountain Nevada

0950 Branko Damjanac: Rock mechanics analysis of absence of seismic damage in lithophysal units

1030 Break

1050 Bill Foxall: Extreme Ground Motion Recorded in the Near-Source Region of Underground Nuclear Explosions

1130 Jim Brune: Precarious rocks and precipitous slopes at Yucca Mountain

1210 Lunch

1300 John Stuckless: Caves, speleothems, and excavations in seismically active areas Potential geomorphology of large slip events near Yucca Mountain

1340 John Whitney: Character of faulting at Yucca Mountain, local and regional

1420 Dave Schwartz: Character of faulting in the Basin and Range Province

1500 Break

1520 Discussion: Recommendations for research 


\begin{tabular}{|c|c|c|c|}
\hline NAME & E-MALL & ADDRESS & PHONE NUMBER \\
\hline Norm Abrahamson & $\begin{array}{l}\text { naa2@pge.com } \\
\text { naa3@earthlink.net }\end{array}$ & $\begin{array}{l}\text { 152 Dracena Avenue } \\
\text { Piedmont, CA 94611-3903 }\end{array}$ & (510) 428-9823 \\
\hline Jon Ake & $\begin{array}{l}\text { jon.ake@ymp.gov } \\
\text { jake@do.usbr.gov }\end{array}$ & $\begin{array}{l}\text { U.S. Bureau of Reclamation, MS D-8330 PO } \\
\text { Box } 25007 \\
\text { Denver, CO } 80225\end{array}$ & $(303) 445-3169$ \\
\hline John Anderson & jga@seismo.unr.edu & $\begin{array}{l}\text { University of Nevada, Mackay School of } \\
\text { Mines, Seismological Lab, MS } 174 \\
\text { Reno, Nevada 89557-0141 }\end{array}$ & (775) 784-4265 \\
\hline Joe Andrews & jandrews@usgs.gov & $\begin{array}{l}\text { US Geological Survey } \\
345 \text { Middlefield Road, MS } 977 \\
\text { Menlo Park, CA } 94025\end{array}$ & (650) 329-5606 \\
\hline Greg Beroza & $\begin{array}{l}\text { beroza@ } \\
\text { pangea.standford.edu }\end{array}$ & $\begin{array}{l}\text { Stanford University, Department of } \\
\text { Geophysics, Mail Code } 2215 \\
\text { Stanford, CA 94305-2215 }\end{array}$ & (650) 723-4958 \\
\hline Mark Board & $\begin{array}{l}\text { mpboard@yahoo.com } \\
\text { mboard@itascacg.com }\end{array}$ & $\begin{array}{l}\text { Itasca Consulting Group } \\
1528 \text { E. } 53^{\text {rd }} \text { Avenue } \\
\text { Spokane, Washington } 99223 \\
\end{array}$ & $+1-509-443-1478$ \\
\hline Julian Bommer & j.bommer@imperial.ac.uk & $\begin{array}{l}\text { Imperial College, Department of Civil } \\
\text { Engineering } \\
\text { South Kensington, London SW7 2BU } \\
\text { England, UK }\end{array}$ & $44-171-594-5984$ \\
\hline David Boore & boore@usgs.gov & $\begin{array}{l}\text { US Geological Survey } \\
345 \text { Middlefield Road MS } 977 \\
\text { Menlo Park, CA } 94025\end{array}$ & (650) 329-5616 \\
\hline Jim Brune & brune@seismo.unr.edu & $\begin{array}{l}\text { University of Nevada, Seismological Lab } \\
\text { MS } 174 \\
1664 \text { North Virginia Street }\end{array}$ & (775) 784-4974 \\
\hline
\end{tabular}




\begin{tabular}{|c|c|c|c|}
\hline & & Reno, Nevada 89557-0141 & \\
\hline Robert Budnitz & budnitz1@1lnl.gov & $\begin{array}{l}\text { Lawrence Livermore National Laboratory } \\
\text { Energy \& Environment Directorate } \\
7000 \text { East Avenue PO Box } 808 \text { MS L-632 } \\
\text { Livermore, CA } 94551\end{array}$ & $+1-925-423-4648$ \\
\hline David Buesch & dbuesch@usgs.gov & $\begin{array}{l}\text { US Geological Survey HQ WRD } \\
\text { Nevada Operations Programs, Mail Stop } \\
423 \\
\text { Las Vegas, Nevada } 89144\end{array}$ & (702) 295-5623 \\
\hline Allin Cornell & cornell@standford.edu & $\begin{array}{l}110 \text { Coquito Way } \\
\text { Portola Valley, CA } 94028\end{array}$ & (650) 854-8053 \\
\hline Peter Cundall & pac@compuserve.com & $\begin{array}{l}\text { Itasca Consulting Group, Inc. } \\
111 \text { Third Avenue South, Suite } 450 \\
\text { Minneapolis, Minnesota } 55401\end{array}$ & (612) 371-4711 \\
\hline Branko Damjanac & branko@itascacg.com & $\begin{array}{l}\text { Itasca Consulting Group, Inc. } \\
111 \text { Third Avenue South, Suite } 450 \\
\text { Minneapolis, Minnesota } 55401\end{array}$ & (612) 371-4711 \\
\hline Jim Dewey & dewey@usgs.gov & $\begin{array}{l}\text { US Geological Survey } \\
\text { Denver Federal Center MS } 966 \text { Box } \\
25046 \\
\text { Denver, Colorado 80225-0046 }\end{array}$ & (303) 273-8419 \\
\hline Doug Duncan & dduncan@usgs.gov & $\begin{array}{l}\text { US Geological Survey } \\
411 \text { National Center } \\
\text { Reston, VA } 21092 \\
\end{array}$ & (703) 648-5896 \\
\hline Charles Fairhurst & fairh001@umn.edu & $\begin{array}{l}417 \text { North Fifth Avenue } \\
\text { South Saint Paul, MN 55075-2035 }\end{array}$ & (651) 451-1234 \\
\hline Bill Foxall & foxall1@1lnl.gov & $\begin{array}{l}323 \text { Coleman Drive } \\
\text { San Rafael, CA 94901-1210 }\end{array}$ & (925) 424-3767 \\
\hline Tom Hanks & thanks@usgs.gov & $\begin{array}{l}\text { US Geological Survey, Robert E. } \\
\text { Wallace Earthquake Center }\end{array}$ & (650) 329-5634 \\
\hline
\end{tabular}




\begin{tabular}{|c|c|c|c|}
\hline & & $\begin{array}{l}345 \text { Middlefield Road MS } 977 \\
\text { Menlo Park, CA } 94025\end{array}$ & \\
\hline Buck Ibrahim & aki@nrc.gov & $\begin{array}{l}\text { US Nuclear Regulatory Committee } \\
11545 \text { Rockville Pike MS T7C6 } \\
\text { Rockville, MD 20852-2738 }\end{array}$ & (301) 415-6651 \\
\hline Jerry King & jerry_king@ymp.gov & $\begin{array}{l}\text { Bechtel SAIC Company, LLC } \\
1180 \text { Town Center Drive } \\
\text { Las Vegas, Nevada } 89144\end{array}$ & (702) 295-6997 \\
\hline David McCallen & mccallen2@1lnl.gov & $\begin{array}{l}\text { Lawrence Livermore National Lab } \\
\text { MS L-447 PO Box } 808 \\
\text { Livermore, CA } 94550\end{array}$ & (924) 423-1219 \\
\hline Arthur McGarr & mcgarr@usgs.gov & $\begin{array}{l}\text { US Geological Survey, Office of Earthquake } \\
\text { Studies } \\
345 \text { Middlefield Road MS } 977 \\
\text { Menlo Park, CA } 94025\end{array}$ & (650) 329-5645 \\
\hline Leon Reiter & reiter@nwtrb.gov & $\begin{array}{l}\text { US Nuclear Waste Tech Rev Brd } \\
2300 \text { Clarendon Blvd. Ste. } 1300 \\
\text { Arlington, VA } 22201\end{array}$ & (703) 235-4473 \\
\hline Christopher Scholz & $\begin{array}{l}\text { scholz@lamont.ldeo.colum } \\
\text { bia.edu }\end{array}$ & $\begin{array}{l}\text { Lamont Doherty Earth Observatory } \\
\text { Columbia University PO Box } 1000 \\
61 \text { Route NW } \\
\text { Palisades, NY } 10964\end{array}$ & (914) 359-2900 \\
\hline David Schwartz & dschwartz@usgs.gov & $\begin{array}{l}\text { US Geological Survey } \\
345 \text { Middlefield Road MS } 977 \\
\text { Menlo Park, CA } 94025\end{array}$ & (650) 329-5651 \\
\hline Walter Silva & $\begin{array}{l}\text { pacificengineering@juno.c } \\
\text { om }\end{array}$ & $\begin{array}{l}311 \text { Pomona Avenue } \\
\text { El Cerrito, CA } 94530\end{array}$ & (510) 528-2821 \\
\hline Paul Somerville & $\begin{array}{l}\text { paul_somerville@urscorp.c } \\
\text { om }\end{array}$ & $\begin{array}{l}\text { URS Corporation } \\
566 \text { El Dorado Street } 2^{\text {nd }} \text { Floor } \\
\text { Pasadena, CA 91101-2560 }\end{array}$ & (626) 449-7650 \\
\hline
\end{tabular}




\begin{tabular}{|l|l|l|l|}
\hline Paul Spudich & spudich@usgs.gov & $\begin{array}{l}\text { US Geological Survey } \\
\text { 345 Middlefield Road MS 977 } \\
\text { Menlo Park, CA 94025 }\end{array}$ & (650) 329-5654 \\
\hline John Stuckless & stuckles@usgs.gov & $\begin{array}{l}\text { US Geological Survey } \\
\text { Box 25046 Mail Stop: 421 } \\
\text { Denver, Colorado 80225-0046 } \\
\text { Room: H2128 }\end{array}$ & (303) 236-5050 x251 \\
\hline Gabriel Toro & toro@riskeng.com & $\begin{array}{l}\text { Risk Engineering Incorporated } \\
\text { 3 Farmers Row } \\
\text { Action, MA 01720 }\end{array}$ & (978) 266-2639 \\
\hline Joe Whelan & jfwhelan@usgs.gov & $\begin{array}{l}\text { Research Geologist, USGS HQ WRD } \\
\text { Box 25046, Mail Stop 963 } \\
\text { Denver, Colorado 80225-0046 }\end{array}$ & (303) 236-7671 \\
\hline John Whitney & jwhitney@usgs.gov & $\begin{array}{l}\text { Box 25046, Mail Stop 980 } \\
\text { Denver, Colorado 80225-0046 } \\
\text { Room: 1718 }\end{array}$ & (303) 236-7803 \\
\hline Ivan Wong & ivan_wong@urscorp.com & $\begin{array}{l}\text { URS Corporation, Seismic Hazards } \\
\text { Group } \\
\text { 1333 Broadway STE 800 } \\
\text { Oakland, CA 94612 }\end{array}$ & (510) 874-3014 \\
& $\begin{array}{l}\text { Stanford University, Geophysics Dept. } \\
\text { Mitchell Building Room 359 } \\
\text { 397 Panama Mall } \\
\text { Stanford, CA 94305-2215 }\end{array}$ & (650) 725-9295 \\
\hline Mark Zoback & zoback@pangea.stanford.e \\
du & & & \\
\hline
\end{tabular}




\title{
THE WORKSHOP ON EXTREME GROUND MOTIONS AT YUCCA MOUNTAIN
}

\author{
Thomas C. Hanks \\ U.S. Geological Survey \\ 345 Middlefield Road \\ Menlo Park, CA 94025
}

This workshop has its origins in the probabilistic seismic hazard analysis (PSHA) for Yucca Mountain, the designated site of the underground repository for the nation's high-level radioactive waste. Completed in 1998, this SSHAC Level-4 (Budnitz et al., 1997) study was the most complicated and complex PSHA ever undertaken at the time. The procedures, methods, and results of this PSHA are described in Stepp et al. (2001), mostly in the context of a probability of exceedance (hazard) of $10^{-4} / \mathrm{yr}$ for ground motion at Site A, a hypothetical, reference rock outcrop site at the elevation of the proposed emplacement drifts within the mountain. Analysis and inclusion of both aleatory and epistemic uncertainty were significant and time-consuming aspects of the study, which took place over three years and involved several dozen scientists, engineers, and analysts.

Because of these uncertainties, the 1998 Yucca Mountain PSHA provides for progressively higher ground motions as it is extended to progressively lower hazard levels: at mean-value hazard levels of $10^{-6} / \mathrm{yr}, 10^{-7} / \mathrm{yr}$, and $10^{-8} / \mathrm{yr}$, the resulting peak ground accelerations (PGA) and peak ground velocities (PGV) are $3 \mathrm{~g}, 6 \mathrm{~g}$, and $11 \mathrm{~g}$ and $3.5 \mathrm{~m} / \mathrm{sec}, 7 \mathrm{~m} / \mathrm{sec}$, and 13 $\mathrm{m} / \mathrm{sec}$, respectively (Figs. 1 and 2 ). We refer to these as extreme ground motions, the extremely large-amplitude ground motions that will arise in any PSHA at extremely low probabilities-ofexceedance, given untruncated ground-motion distribution functions. These large-amplitude ground motions have generated considerable consternation in the scientific, engineering, and regulatory communities, for such PGV's and PGA's have never been recorded for earthquakes, present exceptional challenges to the design and construction of the underground facilities, and are regarded by at least some qualified seismologists as "physically unrealizable."

In the fall of 2003, the Science and Technology Program of the Office of Civilian Radioactive Waste management in the U.S. Department of Energy formed a committee of six scientists (N.A. Abrahamson, M. Board, D.M. Boore, J.N. Brune, C.A. Cornell, and T.C. Hanks, chair) to look into this matter of extreme ground motions at Yucca Mountain and how they came to be. This workshop is the first recommendation of this committee and is made possible with the support of the Science and Technology Progam. It brings together scientists from a wide range of the earth and engineering sciences that speak to extreme ground motions, in terms that are often specific to Yucca Mountain but in other cases are quite general.

\section{References}

Budnitz, R.J., G. Apostolakis, D.M. Boore, L.S. Cluff, K.J. Coppersmith, C.A. Cornell, and P.A. Morris (1997). Recommendations for probabilistic seismic hazard analysis: guidance on uncertainty and the use of experts, NUREG/CR-6372, U.S. Nuclear Regulatory Commission.

Stepp, J.C., I. Wong, J.Whitney, R. Quittmeyer, N. Abrahamson, G. Toro, R. Youngs, K. Coppersmith, J. Savy, T. Sullivan and Yucca Mountain PSHA project members (2001). 
Probabilistic seismic hazard analyses for ground motions and fault displacements at Yucca Mountain, Earthquake Spectra 17, 113-151.

Stepp, C. and I.G. Wong, Probabilistic seismic hazard analysis (PSHA) for Yucca Mountain, presented to U.S. Nuclear Waste Technical Review Board, 24 February 2003.)

Figures

\section{Ground Motion Hazard Results (cont'd.)}

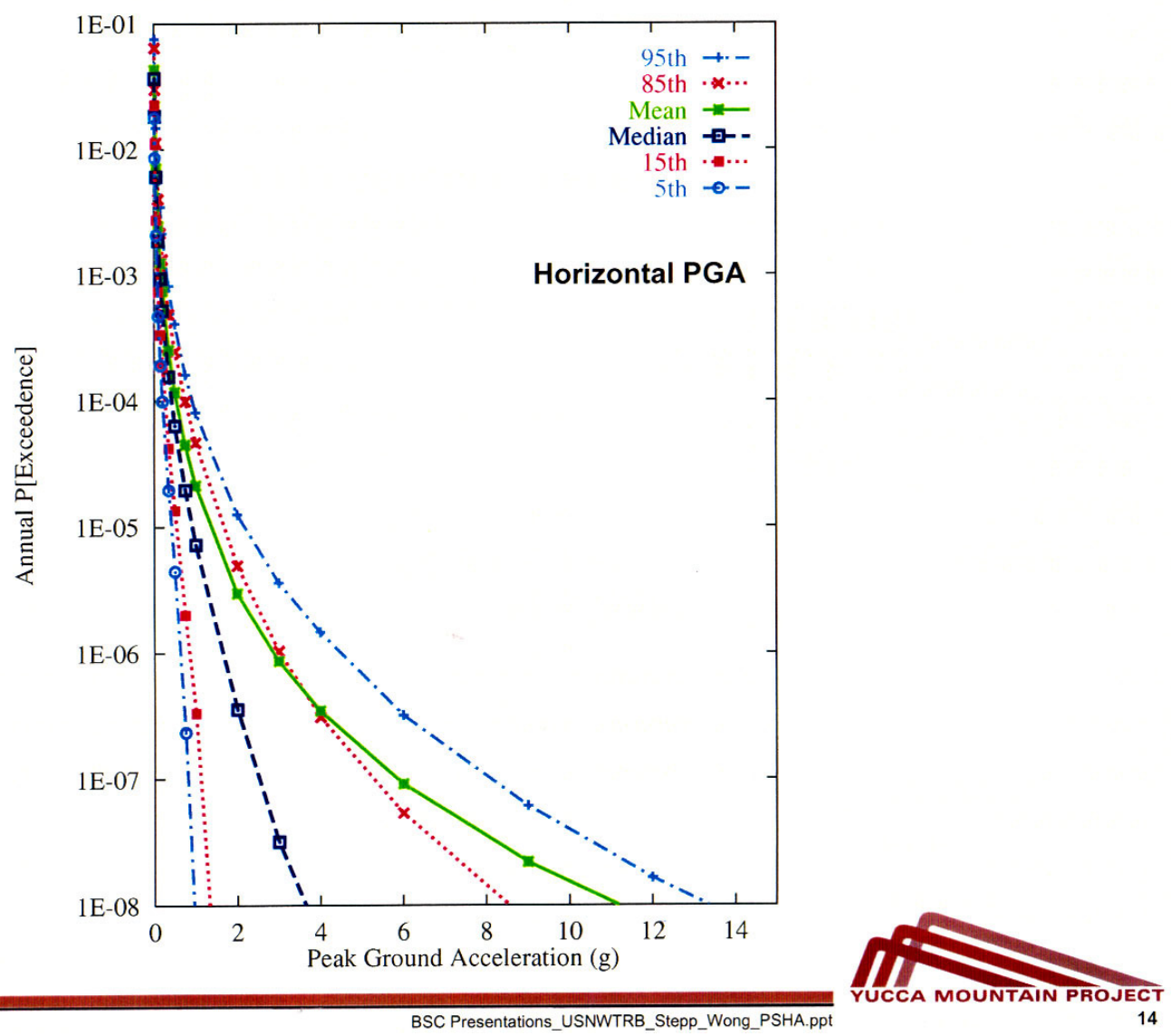

1. Seismic hazard curves for Yucca Mountain, Horizontal PGA (peak ground acceleration), from Stepp and Wong (2003). 


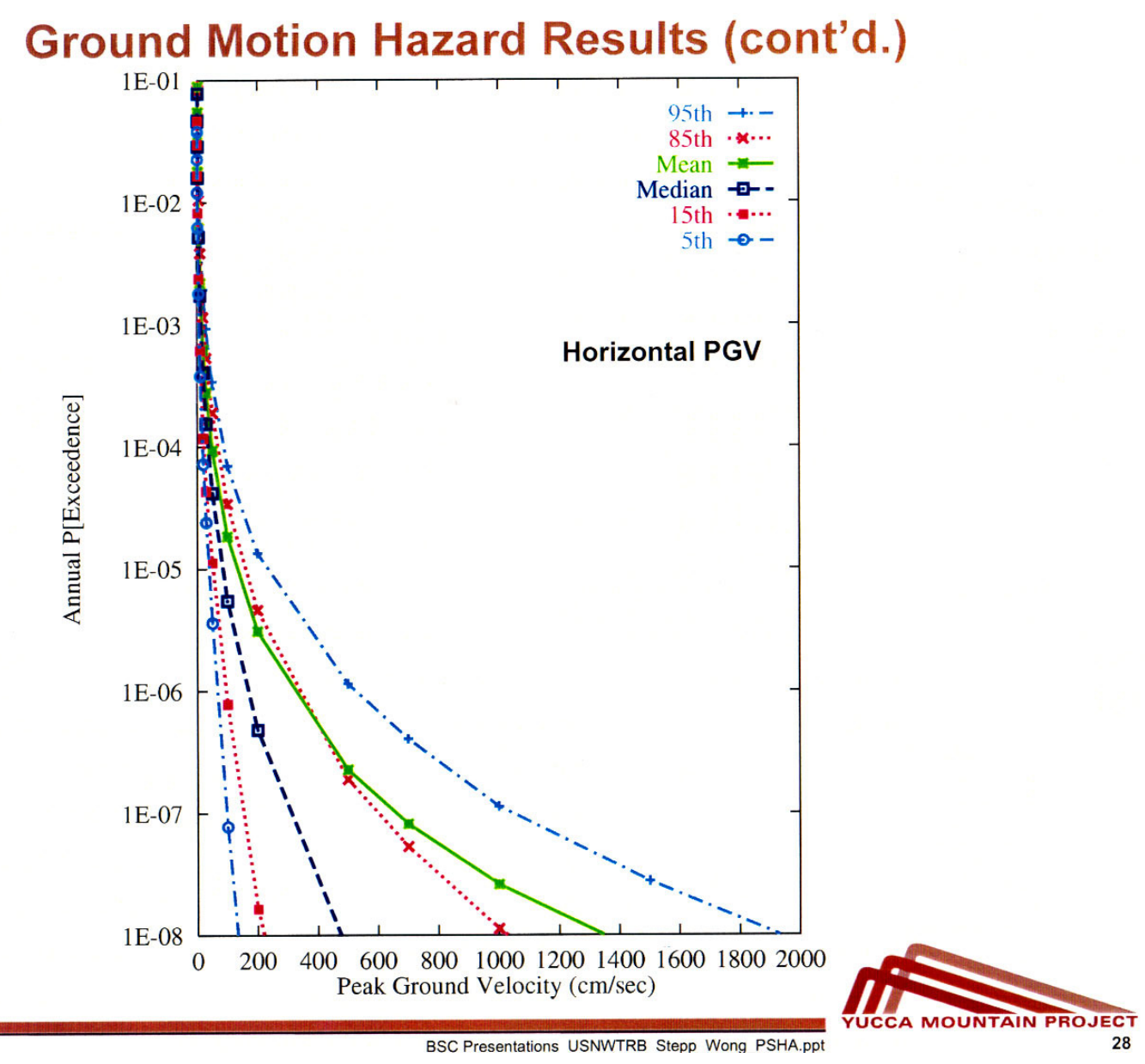

2. Seismic hazard curves for Yucca Mountain, Horizontal PGV (peak ground velocity), from Stepp and Wong (2003). 


\title{
OVERVIEW OF THE PROBABILISTIC SEISMIC HAZARD ANALYSES OF YUCCA MOUNTAIN
}

\author{
Ivan G. Wong \\ Seismic Hazards Group \\ URS Corporation \\ 1333 Broadway, Suite 800 \\ Oakland, CA 94612 \\ ivan_wong@urscorp.com
}

Probabilistic seismic hazard analysis (PSHA) is now established practice as the basis for determining seismic design ground motions for important nuclear facilities. Consistent with this practice, PSHAs for ground motion and fault displacement have been performed for the Yucca Mountain site (Stepp et al., 2001). The methodology used for the PSHAs incorporated multiple expert evaluations of seismic sources, the potential for fault displacement, and ground motion estimation. The experts provided weighted alternative evaluations to characterize uncertainties in their interpretations. Based on these alternative interpretations, hazards were calculated and expressed as the annual frequency at which levels of ground motion or fault displacement are expected to be exceeded.

The objective of the PSHAs was to provide ground motion and fault displacement hazard results for both determining preclosure (up to 300 years) seismic design requirements and for postclosure (10,000 years or more) assessment for long-term waste containment and isolation performance of the potential repository. The governing regulation requires consideration of two categories of design basis events. Category-1 events are expected to occur 1 or more times during the preclosure operational period of the facility. For ground motion, the target hazard for Category-1 events has been established at $10^{-3}$ annual frequency of exceedance. For Category-2 events, ground motion will be based on hazard at an annual exceedance frequency of $10^{-4}$. For postclosure assessment, annual exceedance frequencies as small as $10^{-7}$ may need to be considered.

\section{APPROACH}

The approach that was implemented to perform the PSHAs for Yucca Mountain is generally consistent with state-of-the-practice guidance for a Level 4 analysis as defined by the Senior Seismic Hazard Analysis Committee (SSHAC, 1997). A Level 4 PSHA involves evaluations of the inputs by multiple experts in a series of workshops and individual elicitation meetings facilitated by a technical facilitator/integrator (TFI). The Level 4 approach was implemented because of the perceived technical complexity of the required evaluations, the first-of-a-kind evaluations of fault displacement potential for probabilistic analysis, the desire to include a sufficiently broad range of diverse technical interpretations to represent the epistemic uncertainty of the scientific community, and the public and regulatory importance of the project. Implementation of the project departed from the recommended Level 4 approach in one respect: throughout the project it was strongly emphasized that primary ownership of the PSHA results rests with the expert evaluators instead of the TFI. This emphasis ensured full compliance with regulatory procedures and practice while implementing the scope of a Level 4 evaluation. The PSHAs were performed in three strongly integrated parallel activities: (1) evaluation and 
characterization of seismic sources including the potential for fault displacement; (2) evaluation and characterization of ground motion attenuation, including the effects of earthquake source, wave propagation path, and site rock properties; and (3) probabilistic calculations of both fault displacement and ground motion hazards (Stepp et al., 2001).

To capture the state of knowledge of the informed scientific community, epistemic uncertainty was evaluated by six teams of three earth science experts. Each team characterized seismic sources in the Yucca Mountain site region (generally within a distance of about $100 \mathrm{~km}$ ) and fault displacement potential at the site. Similarly, to capture epistemic uncertainty in ground motion, seven ground motion experts characterized ground motion attenuation in the site region.

Ground motion hazard was computed for a defined reference rock outcrop indicated by Point A in Figure 1. (Points B, D, and E are locations where seismic design ground motions have been calculated through a site response analysis using ground motions derived at Point $\mathrm{A}$ as control motions.) Point $\mathrm{A}$ is characterized by a shear-wave velocity of $1900 \mathrm{~m} / \mathrm{sec}$ and a kappa of $0.0186 \mathrm{sec}$.

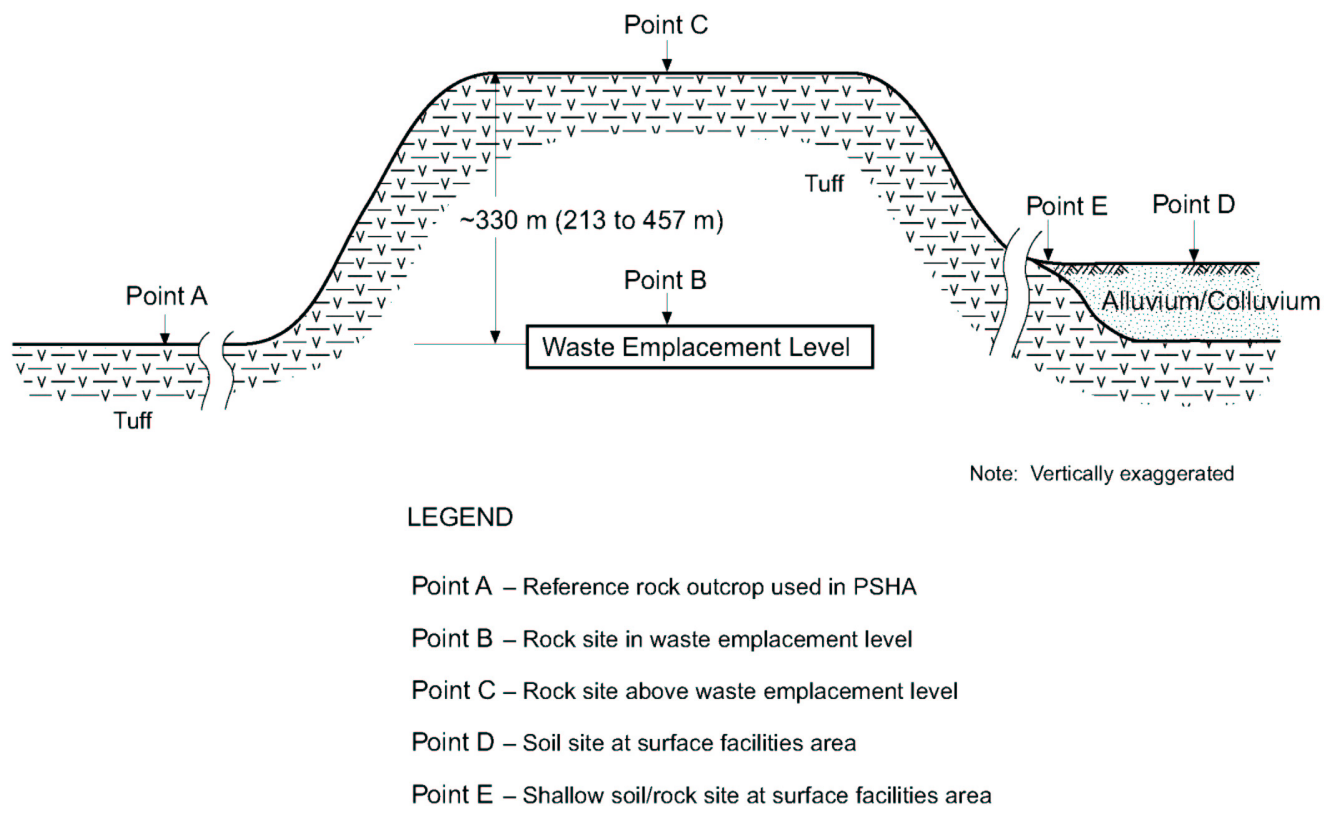

Figure 1. Locations of specified design earthquake ground motions. Point $\mathrm{A}$ is a hypothetical site and does not correspond to an actual location at Yucca Mountain.

\section{EVALUATION AND CHARACTERIZATION OF SEISMIC SOURCES}

The objective of evaluating and characterizing seismic sources for the ground-shaking PSHA was to describe alternative seismotectonic models of the site region that expressed the seismic source teams' uncertainties in source geometries, earthquake recurrence, and maximum magnitudes. The evaluations involved identifying and characterizing the seismic sources capable of producing earthquakes significant for ground-shaking hazard computation at the site.

The teams used two types of interpretations to express their epistemic uncertainties in seismic sources: fault-specific sources and areal source zones. Faults were characterized when 
earthquake activity (either through paleoseismic evidence or historical seismicity) could be confidently associated with a specific fault or fault zone. Alternative total fault lengths, alternative fault dips, and possible linkages with other faults express uncertainties in the geometry of fault-specific sources. The approximately 100 faults or fault zones identified as potential seismic sources within the site region were evaluated by the seismic source teams and incorporated into their interpretations (Stepp et al., 2001).

Areal seismic source zones were used to represent distributed seismicity not apparently associated with known specific faults or to model groups of faults interpreted to have the same earthquake potential, at sufficiently large distances from the site such that the details of the individual faults are not significant for hazard calculation. Uncertainties in areal seismic source zones were expressed by weighted alternative interpretations of source boundaries. The teams interpreted the spatial distribution of earthquakes within areal source zones to be either homogeneous or nonhomogeneous.

\section{GROUND MOTION EVALUATION AND CHARACTERIZATION}

Strong motion data from the Basin and Range Province, even when combined with the limited data from analog tectonic environments are insufficient to adequately constrain empirical attenuation models for normal faulting earthquakes. Consequently, a key issue with respect to characterizing ground motion attenuation in the Yucca Mountain region was the applicability to the Basin and Range Province of western U.S. empirical attenuation models, which are based on relatively large data sets. Most empirical attenuation relations in the western U.S. are based primarily on recordings in California from strike-slip and reverse-slip earthquakes. Because strong motion recordings of normal faulting earthquakes are sparse, separate style-of-faulting factors typically have not been estimated for normal faulting.

The seven ground motion experts estimated median ground motion, aleatory variability (standard deviation), and epistemic uncertainties for a matrix of earthquake magnitudes, source-to-site distances, and faulting styles (normal and strike-slip) and for a suite of spectral frequencies. The ground motions were defined at Point A. These estimates were based on empirical and numerical simulation-based models and on combinations of conversion factors. The experts classified proponent models as empirical attenuation relations, hybrid empirical, point-source numerical simulations, finite-fault numerical simulations, and blast models.

Differences exist in the seismic source, regional crustal path, and shallow site properties for the Yucca Mountain region compared to those properties represented in the western U.S. strong motion data set. Since these attenuation relations are primarily based on California strong motion data, the ground motion experts evaluated the need to modify them (median and/or standard deviation) to account for differences between California and the Yucca Mountain site region. Alternative sets of conversion factors were developed to convert the California attenuation relations to conditions appropriate for the Yucca Mountain site region. The ground motion experts then evaluated which, if any, of the conversion factors should be applied to estimate the ground motion at Yucca Mountain.

A ground motion model estimates the median ground motion as a function of magnitude and distance and the aleatory variability (standard deviation) about the median. Both the median 
estimate and the standard deviation are uncertain. The experts used logic trees to characterize this epistemic uncertainty in their ground motion evaluations. Each ground motion expert evaluated the alternative models individually and developed his/her own composite model for their best estimates of the median and standard deviation for a given set of earthquake magnitudes and source distances. Thus, the experts' ground motion estimates consisted of four values for each magnitude-distance pair: median, aleatory standard deviation, epistemic uncertainty for the median, and epistemic uncertainty in the aleatory variability.

The ground motion experts' point estimates of the ground motion were parameterized by the ground motion TFI as attenuation equations for use in the hazard calculations. Each ground motion expert defined the distance measure used in the regression analyses for his/her point estimates. In addition, the experts evaluated the degree of ground motion saturation at large magnitude and close distances.

\section{GROUND MOTION HAZARD RESULTS}

The ground motion hazard at Yucca Mountain was computed at Point A (Figure 1). The calculation was conducted in three steps. For each seismic source expert team, the calculation was performed for each seismic source for each combination of attenuation and seismic source parameters, resulting in an appropriately weighted aleatory hazard curve for each combination. The total hazard across sources was then aggregated for each team to obtain the teams' mean and fractile hazard curves. The integrated hazard across all seismic source teams was obtained by combining the expert teams' mean and fractile hazard curves giving each team equal weight. A minimum magnitude of $\mathbf{M} 5.0$ was used as the lower bound for integrating the earthquake recurrence relationship in the hazard calculations. The aleatory uncertainty (the variability about the ground motion experts' median attenuation) in the ground motion attenuation equations was modeled using the unbounded lognormal distribution (no upper bound was assumed).

Ground motion hazard was calculated for the ground motion measures peak horizontal ground acceleration (PGA), peak horizontal ground velocity, and spectral accelerations at $0.3,0.5,1,2$, 5,10 , and $20 \mathrm{~Hz}$ structural frequencies. The computations were based on equal weighting of the six seismic source expert teams' interpretations and the seven ground motion experts' interpretations. The results are presented in the form of summary hazard curves, which depict the mean, median, and $15^{\text {th }}$ and $85^{\text {th }}$ fractiles of the calculated aleatory hazard curves. The mean and median convey the central tendency of the hazard results while the separation between the $15^{\text {th }}$ and $85^{\text {th }}$ fractile curves conveys the epistemic uncertainty on the calculated exceedance frequency. Figure 2 shows summary hazard curves for PGA. At small annual exceedance frequencies $\left(<10^{-6}\right)$, the mean values exceed $3 \mathrm{~g}$ 's.

\section{GROUND MOTION HAZARD SENSITIVITY RESULTS}

Extensive evaluations to determine the sensitivity of the hazard results to assessed input parameters were performed (Stepp et al., 2001). The largest contributor to uncertainty in ground motion hazard was found to be uncertainty in ground motion attenuation. Specifically, experts' uncertainties about the median ground motion attenuation and the standard deviation of motion about the median, in that order, are the largest contributors. Expert-to-expert epistemic uncertainty is a smaller contributor to total hazard uncertainty. 


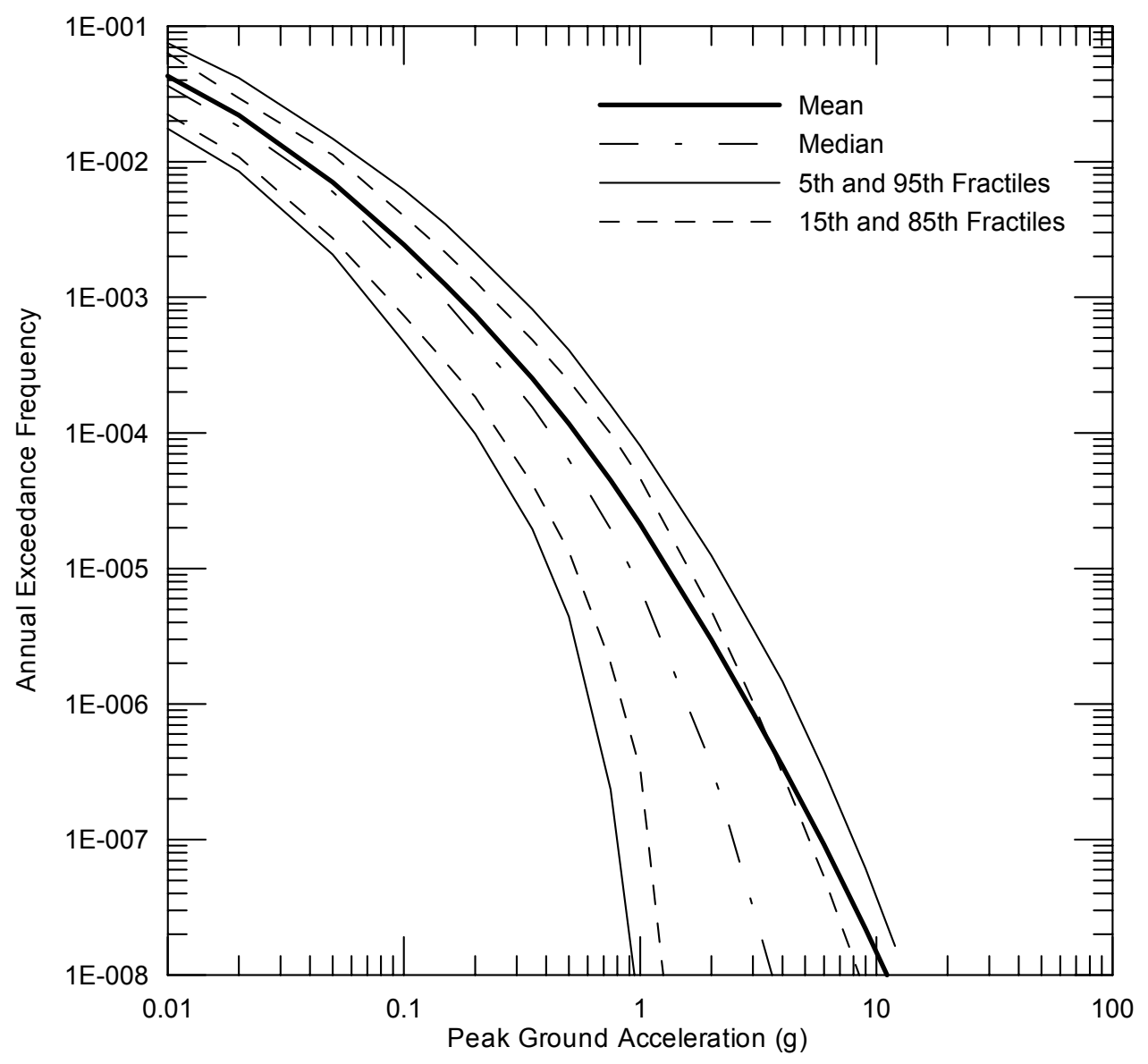

Figure 2. Summary hazard curves for horizontal PGA.

The composite mean hazard was deaggregated on magnitude, distance, and ground motion variability to determine controlling earthquakes and provide engineering insights for development of design basis spectra. Deaggregation of the mean hazard for an annual exceedance frequency of $10^{-7}$ shows that at intermediate frequencies (5 to $10 \mathrm{~Hz}$ ), the ground motion hazard is dominated by earthquakes smaller than M 7.0 at distances less than $15 \mathrm{~km}$ (Figure 3). The sources of these earthquakes are the Paintbrush Canyon - Stagecoach Road and Solitario Canyon faults (or alternative interpretations of coalesced fault systems that include these faults) and the host areal seismic source zone. Dominant earthquake sources for lowfrequency ground motions (e.g., 1 to $2 \mathrm{~Hz}$ ) display a bimodal distribution with significant contributions to the total hazard from large nearby earthquakes, the three sources mentioned above, and from $\mathbf{M} 7$ and larger earthquakes beyond distances of $50 \mathrm{~km}$ and ground motion variability larger than two standard deviations. The latter contribution is mainly from the comparatively active Death Valley and Furnace Creek faults. 


\section{E-7 Hazard, 5-10 Hz Horizontal}

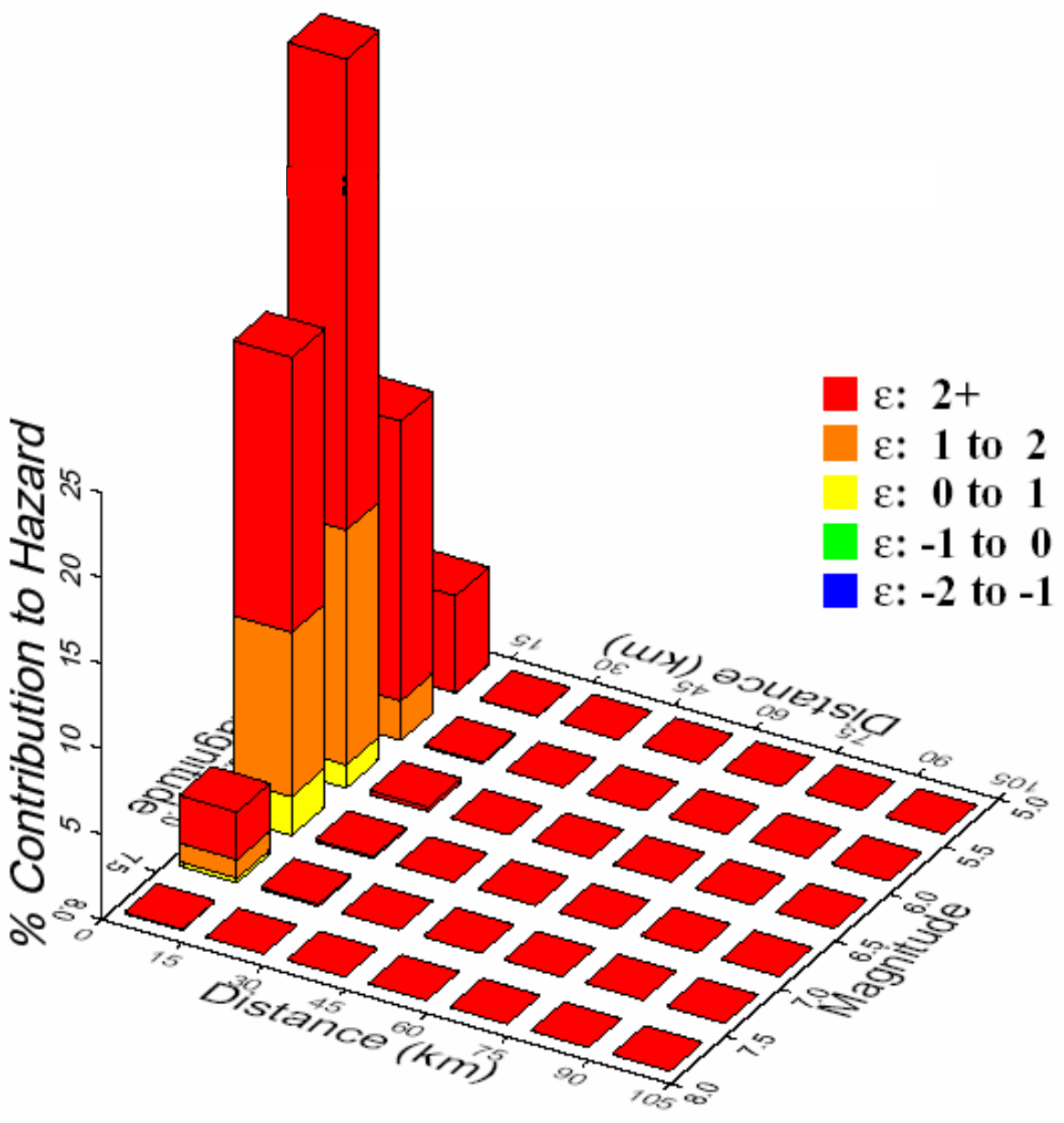

Figure 3. Contribution to mean hazard by magnitude, distance, and epsilon $(\varepsilon)$ for the $5-10 \mathrm{~Hz}$ horizontal ground motions, $10^{-7}$ annual exceedance frequency.

\section{REFERENCES}

Senior Seismic Hazard Analysis Committee (SSHAC), 1997, Recommendations for probabilistic seismic hazard analysis-guidance on uncertainty and use of experts: U.S. Nuclear Regulatory Commission NUREG/CR-6372, variously paginated.

Stepp, J.C., Wong, I., Whitney, J., Quittmeyer, R., Abrahamson, N., Coppersmith, K., Toro, G., Youngs, R., Savy, J., Sullivan, T., and Yucca Mountain PSHA Project Members, 2001, Probabilistic seismic hazard analyses for ground motions and fault displacement at Yucca Mountain, Nevada: Earthquake Spectra, v. 17, p.113-151. 
Ground Motion Methods and Results for the 1998 PSHA

Norman A. Abrahamson

\section{Ground Motion Characterization}

The 1998 PSHA use seven experts to develop the ground motion models for the spectral acceleration, peak acceleration, and peak velocity for both the horizontal and vertical components. To allow the ground motion experts to account for the different distance measures, the ground motion experts developed estimates of the median $(\mu)$ and aleatory standard deviation $(\sigma)$ for discrete magnitude distance and style-of-faulting cases. Parameteric models were then fit to the expert's point estimates to give the attenuation relations that are used in the PSHA.

The experts also provided estimates of the epistemic uncertainty for the median and the aleatory variability. The epistemic uncertainty in the median is denoted $\sigma_{\mu}$ and the epistemic uncertainty in the aleatory standard deviation is denoted $\sigma_{\sigma}$. Parametric models were used for both $\sigma_{\mu}$ and $\sigma_{\sigma}$. The experts were allowed to use asymmetric models for the epistmic uncertainty, but all seven experts chose to use symmetric models for simplicity.

\section{Expert Model Development}

The experts developed their models by selecting candidate models from available empirical ground motion models and from numerical simulations conducted for the sites and source conditions at Yucca Mountain (point A). In general, the empirical models were not developed for the site and source conditions at Yucca Mountain. To account for the differences in site and source conditions between the empirical strong motion data and Yucca Mountain, adjustment factors were applied to the empirical ground motion models. These adjustment factors accounted for three main factors: (1) the hard-rock condition at point A (shallow Vs and the kappa), (2) stress-drop for normal faulting earthquakes, and (3) the geometrical spreading in the Basin and Range (crustal velocity structure).

An example of the plots provided to the ground motion experts showing the estimates from the different models is shown in Figure 1 for peak acceleration on the horizontal component.

In addition to the ground motion models, the experts also considered the constraints on ground motions close to large normal faulting earthquakes provided by precarious rock data. The precarious rocks indicated that the median ground motion close to large normal faulting earthquakes should be much lower than predicted by the empirical models. Only one of the seven ground motion experts considered the precarious rock information to be developed enough to be considered: Anderson broadened his epistemic uncertainty in the median ground motion at short distances to account for precarious rock constraints.

To develop the weights for their models, the experts assigned weights to the candidate models. Most of the experts first assigned weights to model classes: empirical models, 
point source simulation models, and finite source simulation models. Weights were then assigned to the models within a class representing the relative strengths of the altenative models within each class. The total weight for a model was given by the product of these two weights. The weights for both the model classes and the individual models within a class varied as a function of magnitude and distance.

The weights were applied to the ground motion point estimates. The purpose for using point estimates rather than just assigning weights to the models was to have the experts consider the values of the ground motions predicted by the models and not just the merits of the models. Simple parameteric models were then fit to the expert's point estimates for use in the PSHA. The experts reviewed the fitting to be sure that it accurately represented their point estimates.

\section{Feedback and Model Revisions}

The experts received three rounds of feedback on their ground motion models during the project. This feedback focused on comparisons of the mu, sigma, sigma-mu, and sigmasigma values for the point estimates given by the experts. Feedback was also provided on the hazard values, but this focused on return periods in the 10,000 year range.

The feedback lead to three rounds of revisions of the ground motion models. The experts were allowed to make changes until they turned in their final model. One expert, Anderson, made significant changes to his model in the last round of revisions. He significantly increases his epistemic uncertainty for the median ground motion at short distances. This increase was based on the discrepancy between the empirical models and the precarious rock data, and on the uncertainty training that emphasized the tendency to underestimate uncertainties. In particular, he considered that the existing numerical simulation models may not be correct and that significant changes could occur in future developments of numerical simulations. Since these revisions came at the end of the project, they were not reviewed by the other experts. As a result, Anderson's model has much larger epistemic uncertainty than the other expert's models.

\section{Use of Parameteric distributions of Epistemic Uncertinaty}

In the 1998 PSHA, parameteric models were used for the epistemic uncertainties. This approach may lead to ground motion models that are outside the range of any existing models (in terms of the median and aleatory sigma). This was an intentional choice by the TFI. If the experts are restricted to available models, then the epistemic uncertainty will tend to increase as more models become available. That is, as more studies are conducted, the estimate of the uncertainty increases, which is contrary to the concept that epistemic uncertainty should decrease as additional data are collected.

The advantage of this approach is that it does not limit the ground motions to the available models. In this sense, it could be providing a more accurate assessment of the true scientific uncertainty. The disadvantage of this approach is that it can lead to ground motion models that predict much higher ground motions than are supported by the existing data. 
As an example, the epistemic uncertainty in the median PGA from Anderson and Boore are shown in Figures 2 and 3. This difference in the epistemic uncertainty has a large impact on the hazard at the $1 \mathrm{E}-8$ level.

\section{Maximum Ground Motions}

No limits on the ground motion or on the applicability of the log-normal distribution at high numbers of standard deviations were elicited. The feedback at the workshop focused on the 1E-4/yr hazard, not on the 1E-8/yr hazard. As a result, the ground motion experts did not review their models for the 1E-8/yr hazard level. If they had feedback focused on the $1 \mathrm{E}-8$ hazard level, then there would likely have been additional revisions to their models. 
case $33, M=6.5$, shallow, $x d=5 \mathrm{~km}$, SS, $100 \mathrm{~Hz}, \mathrm{HOR}, 6 / 10 / 97$, Rev 2

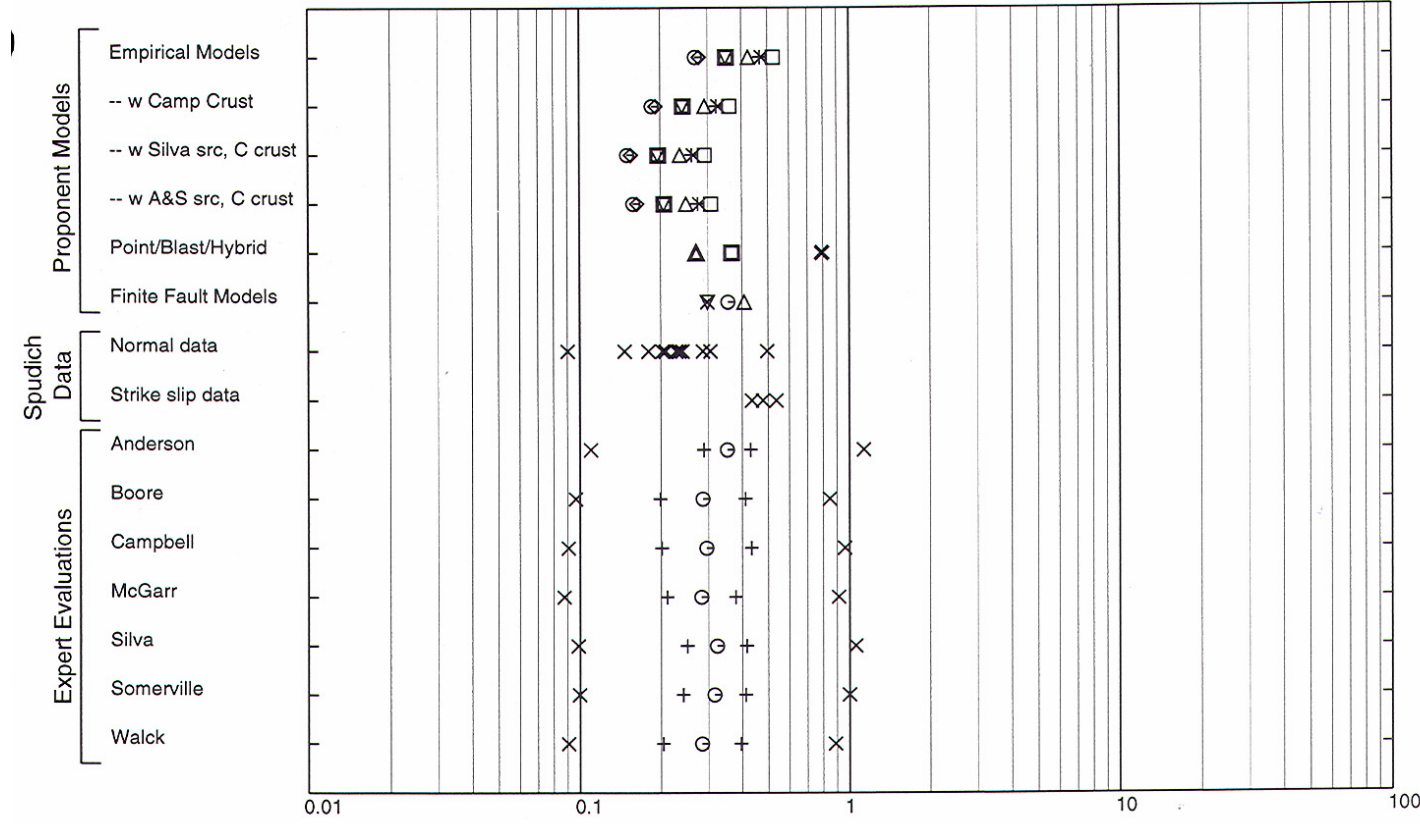

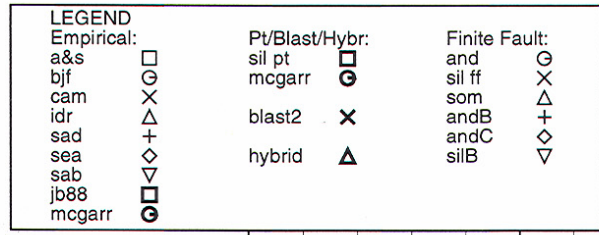

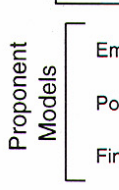

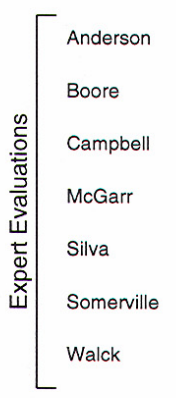

Spectral Acceleration (g)

Then
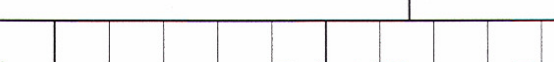
int/Blast/Hybrid nite Fault Models

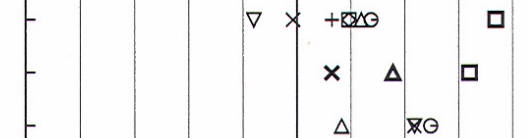


Anderson Rev 3, (Pt Est Rev3a), 7/11/97

Normal Faulting Attenuation, Horizontal Comp

Frequency $=100.0 \mathrm{~Hz}$
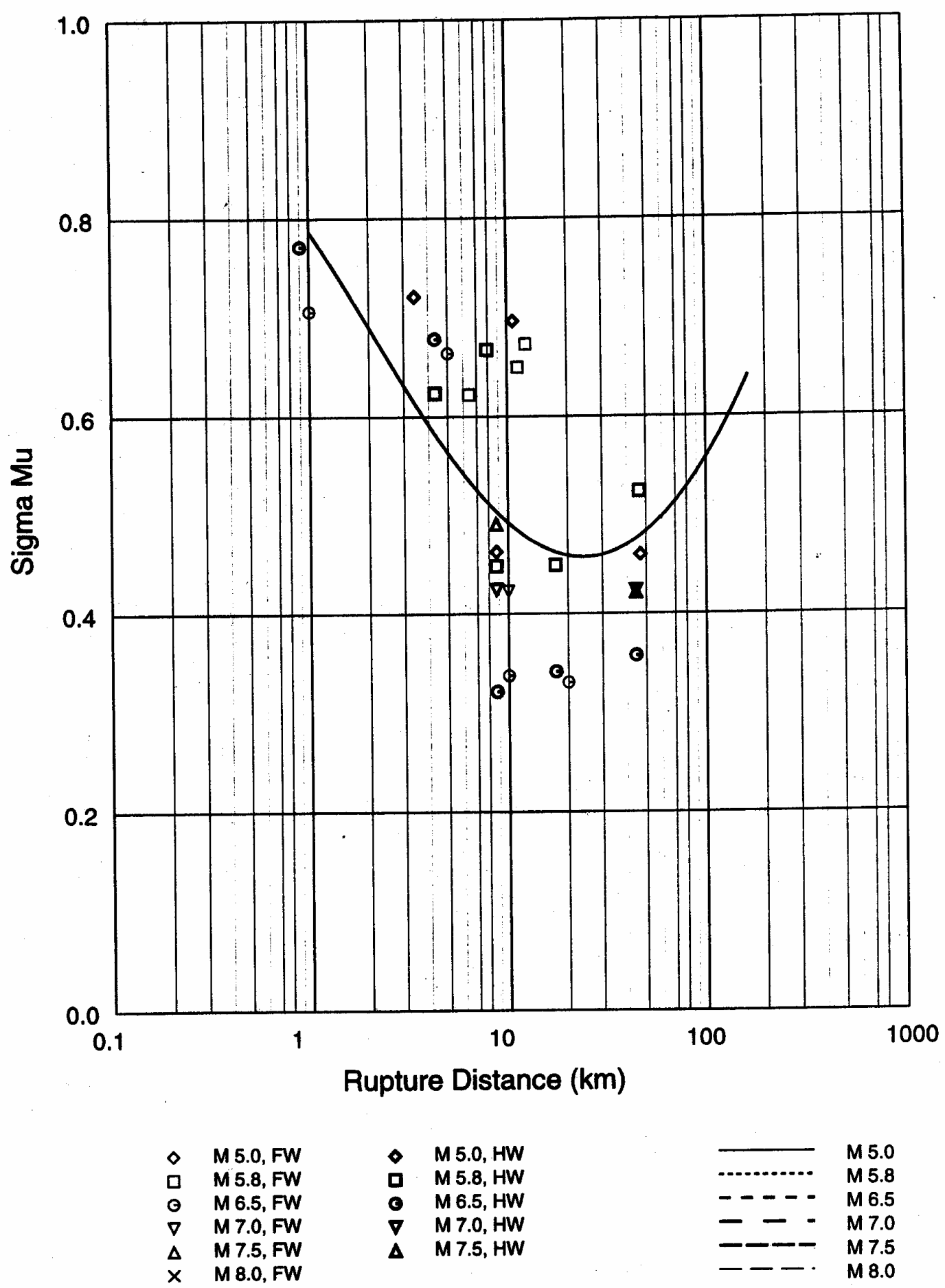

Figure 2. Example epistemic uncertainty in the median PGA from Anderson's model. 
Boore Rev 3, (Pt Est Rev2a), 7/4/97

Normal Faulting Attenuation, Horizontal Comp

Frequency $=100.0 \mathrm{~Hz}$

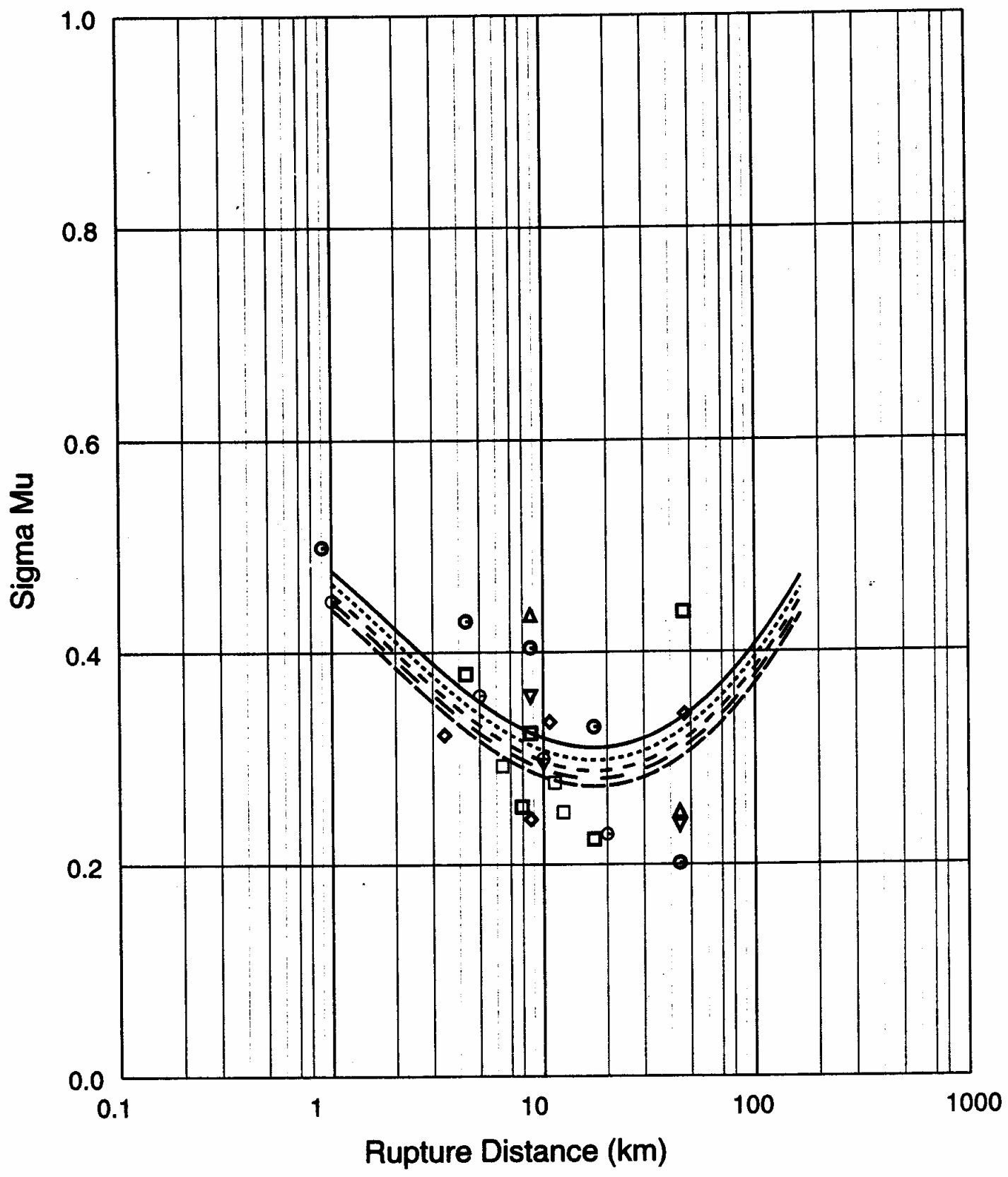

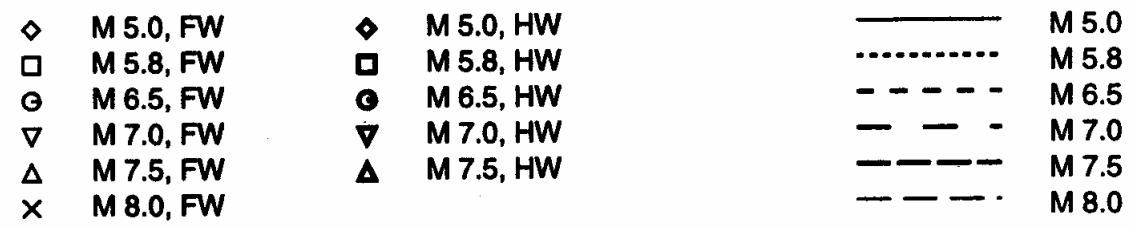

Figure 2. Example epistemic uncertainty in the median PGA from Boore's model. 


\title{
Seismic Hazard de-Aggregation and
}

\section{Ground-Motion Sensitivities for Yucca Mountain}

\author{
by Gabriel R. Toro, Risk Engineering, Inc.
}

\section{Introduction}

This report summarizes the results of additional de-aggregation and sensitivity calculations performed on the Yucca Mountain seismic-hazard models and results documented in CRWMSM\&O (1998, the YMPSHA) and in Toro (2003). The objective is to provide further insights into the seismic sources and expert models that control seismic hazards at very low exceedence probabilities.

These calculations consider peak ground acceleration (PGA) and peak ground velocity (PGV), for annual exceedence probabilities ranging from $10^{-4}$ to $10^{-8}$ (which are associated with PGAs of 0.5 and $11 \mathrm{~g}$ and with $\mathrm{PGVs}$ of 50 to $1300 \mathrm{~cm} / \mathrm{s}$, respectively). The first value represents the range of interest for the design of surface facilities; the second represents the range of interest for for performance assessment of the repository. For the sake of brevity, this report contains only the most salient graphical results; the complete set of results is contained in the Powerpoint file from the August 23 presentation, which will be distributed by the USGS.

\section{De-Aggregation of Seismic Hazard}

These results use finer magnitude and distance resolutions, and extend to lower probabilities, than the de-aggregation results in the YMPSHA. The objective is to provide additional insights into the magnitude-distance-epsilon combinations that dominate seismic hazard for low exceedence probabilities.

Results in the YMPSHA and in the presentation materials indicate that the seismic hazard for $10^{-4}$ comes from the various seismic-source classes considered (i.e., local faults, local area sources, and regional faults), especially from the first two. For $10^{-8}$, on the other hand, most of the hazard comes from local faults.

Figure 1 shows the de-aggregation of the mean PGA hazard for $10^{-4}$ and $10^{-8}$, in the form of joint and marginal distributions. The marginal distributions for $10^{-8}$ are shown separately for each ground-motion expert. Examining the hazard contributions by magnitude, we observe that the hazard at both $10^{-4}$ and $10^{-8}$ comes from the same broad range of magnitudes and that the modal value slightly above magnitude 6 . Examining the hazard contributions by distance, we observe that the most of the hazard for $10^{-4}$ comes from distances between 0 and $10 \mathrm{~km}$. The two spikes at $0.5^{1}$ and $3.5 \mathrm{~km}$, which are associated with the contributions to hazard from the Solitario Canyon and Paintbrush faults ${ }^{2}$, are approximately equal. For $10^{-4}$, the contribution from Solitario is much greater than the contribution from Paintbrush. This is true for all ground-motion experts

\footnotetext{
${ }^{1}$ The contribution shown at a distance of $0.5 \mathrm{~km}$ corresponds to contributions from the first distance bin, which extends from 0 to $1 \mathrm{~km}$. All distances shown are closest distance to the rupture (the distance metric used by all YMPSHA attenuation equations).

${ }^{2}$ The YM site is located on the foot wall of Solitario and on the hanging wall of Paintbrush
} 

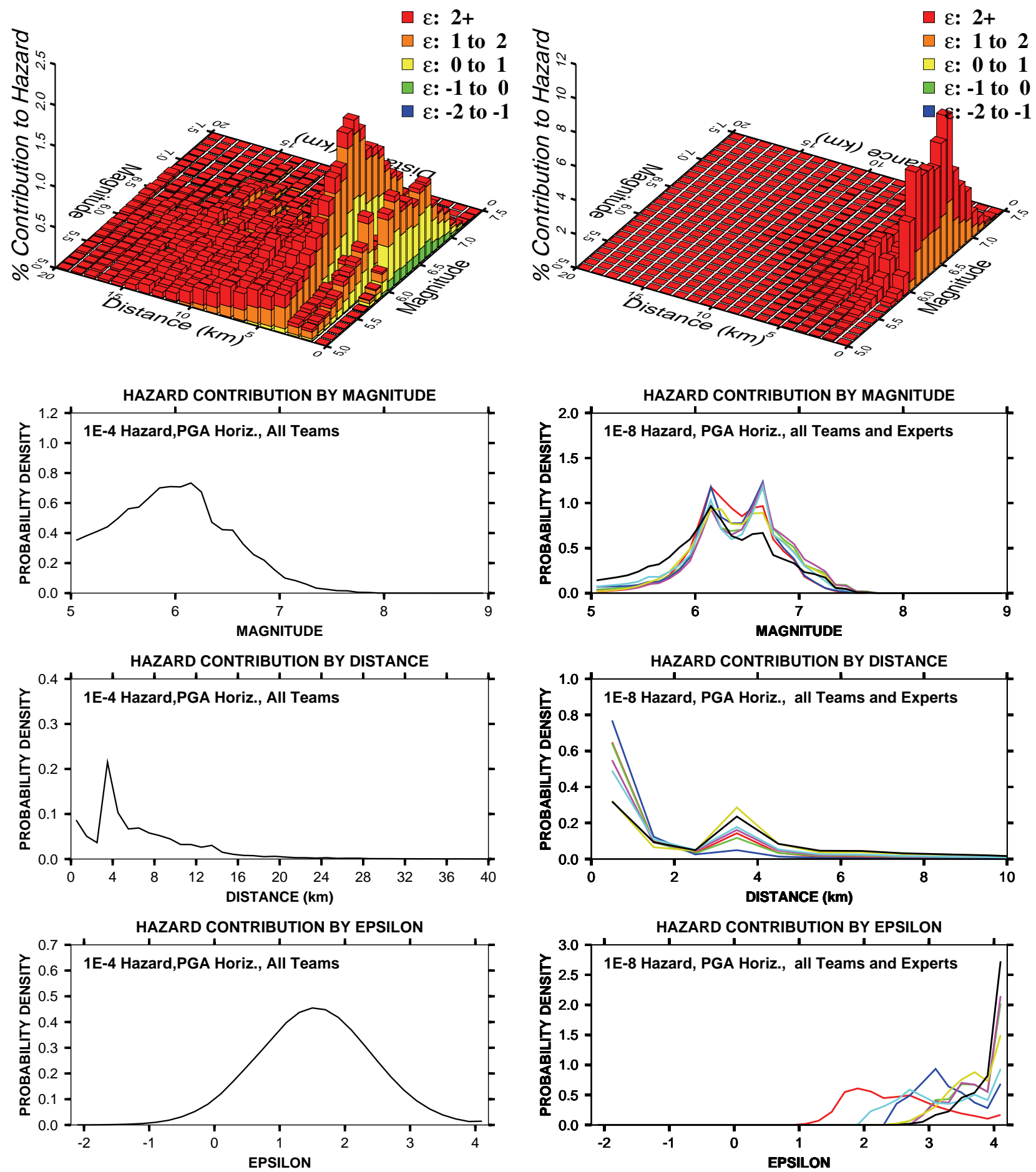

Figure 1. Joint and marginal de-aggregation results for the PGAs with annual exceedence probabilities of $10^{-4}$ (left, $\mathrm{PGA}=0.5 \mathrm{~g}$ ) and $10^{-8}$ (right; $\mathrm{PGA}=11 \mathrm{~g}$ ). The marginal results for $10^{-8}$ are presented separately for each expert (red, Anderson; green, Boore; blue, Campbell; magenta, McGarr; yellow, Silva; cyan, Somerville; black, Walck). 
except Silva and Walck. Examining the hazard contributions by epsilon ${ }^{3}$, we notice that the contributing epsilons shift to higher values as the exceedence probability varies from $10^{-4}$ to $10^{-8}$. For $10^{-8}$, we see large differences among ground-motion experts.

In summary, the de-aggregation results for PGA indicate that most of the $10^{-4}$ hazard comes from earthquakes in the Solitario Canyon and Paintbrush faults, while most of the $10^{-8}$ hazard comes from earthquakes in the Solitario Canyon fault. Results for PGV (not shown here) exhibit similar trends, except that there are moderate contributions from magnitudes 7 to 8 .

\section{Sensitivity to Ground-Motion Experts}

Figures 2 and 3 show the mean hazard calculated using the models specified by each groundmotion expert. These results differ from those in the YMPSHA in that they extend to $10^{-8}$ and that they are averaged over all source-characterization teams.

Each ground-motion expert specified a median attenuation equation, a value of $\sigma$, and the expert's estimates of the uncertainty in the median $\left(\sigma_{\mu}\right)$ and uncertainty in $\sigma\left(\sigma_{\sigma}\right)$. All of these quantities were allowed to vary with magnitude and distance.

For PGA, and to a lesser degree for PGV, Anderson's results are significantly higher than those of the other experts. Results for the other experts show moderate scatter, except for Boore's PGV results, which are significantly lower than the others. At $11 \mathrm{~g}$ (corresponding to $10^{-8}$ annual exceedence probability), Anderson contributes $70 \%$ of the mean seismic hazard.

Examination of the figures in Section 6 of the YMPSHA suggests that the main reason for Anderson's higher results is his estimate of $\sigma_{\mu}$, particularly at short distances (see Figures 6-7 through 6-10 of YMPSHA) ${ }^{4}$.

Other results, not shown here, indicate that the effect of $\sigma_{\mu}$ on amplitudes for a given exceedence probability (averaged over all ground-motion experts) is approximately $25 \%$ for $10^{-4}$ and $50 \%$ for $10^{-8}$. The effect of $\sigma_{\sigma}$ is approximately $5 \%$ for $10^{-4}$ and $50 \%$ for $10^{-8}$. The latter effect is roughly the same for all ground-motion experts.

In summary, the model specified by one of the ground-motion experts leads to much higher estimates of seismic hazard than the other experts. This difference is due mainly to that expert's estimate of uncertainty in mean hazard $\left(\sigma_{\mu}\right)$. For an exceedence probability of $10^{-8}$, the effect of

\footnotetext{
${ }^{3}$ Epsilon represents the difference between $\ln [$ actual ground-motion amplitude] and $\ln [$ predicted (median) groundmotion amplitude], expressed in units of the ground-motion standard deviation $\sigma$, Thus, if we take a $\sigma$ value of 0.5 (which is typical of PGA), an epsilon of 3 implies that the PGA is $\exp [0.5 \times 3]=4.5$ higher than the predicted PGA. In figure 1 , the $\varepsilon=4$ value contains the contributions from $\varepsilon \geq 4$.

${ }^{4}$ The effect of $\sigma_{\mu}$ on the mean amplitude for a given exceedence probability is approximately a factor of $\exp \left[1 / 2 \kappa \sigma_{\mu}{ }^{2}\right]$ (relative to the result that would be obtained by ignoring uncertainty in the median), where $\kappa$ is the slope of the hazard curve in log-log space (typically 3 to 4 at the amplitudes of interest). Therefore, $\sigma_{\mu}=0.78$ (Anderson's value for $1-\mathrm{km}$ distance) implies a factor of 2.5 in amplitudes for a typical slope of $\kappa=3$. In contrast, $\sigma_{\mu}=0.4$ (a value typical of all experts except Anderson and Campbell) for $1 \mathrm{~km}$ ), implies a factor of 1.3. The approximation used here is based on equations in Appendix A of NUREG/CR-6769.
} 
uncertainty in sigma is as important as the effect of uncertainty in the median. The results for PGV show similar trends.

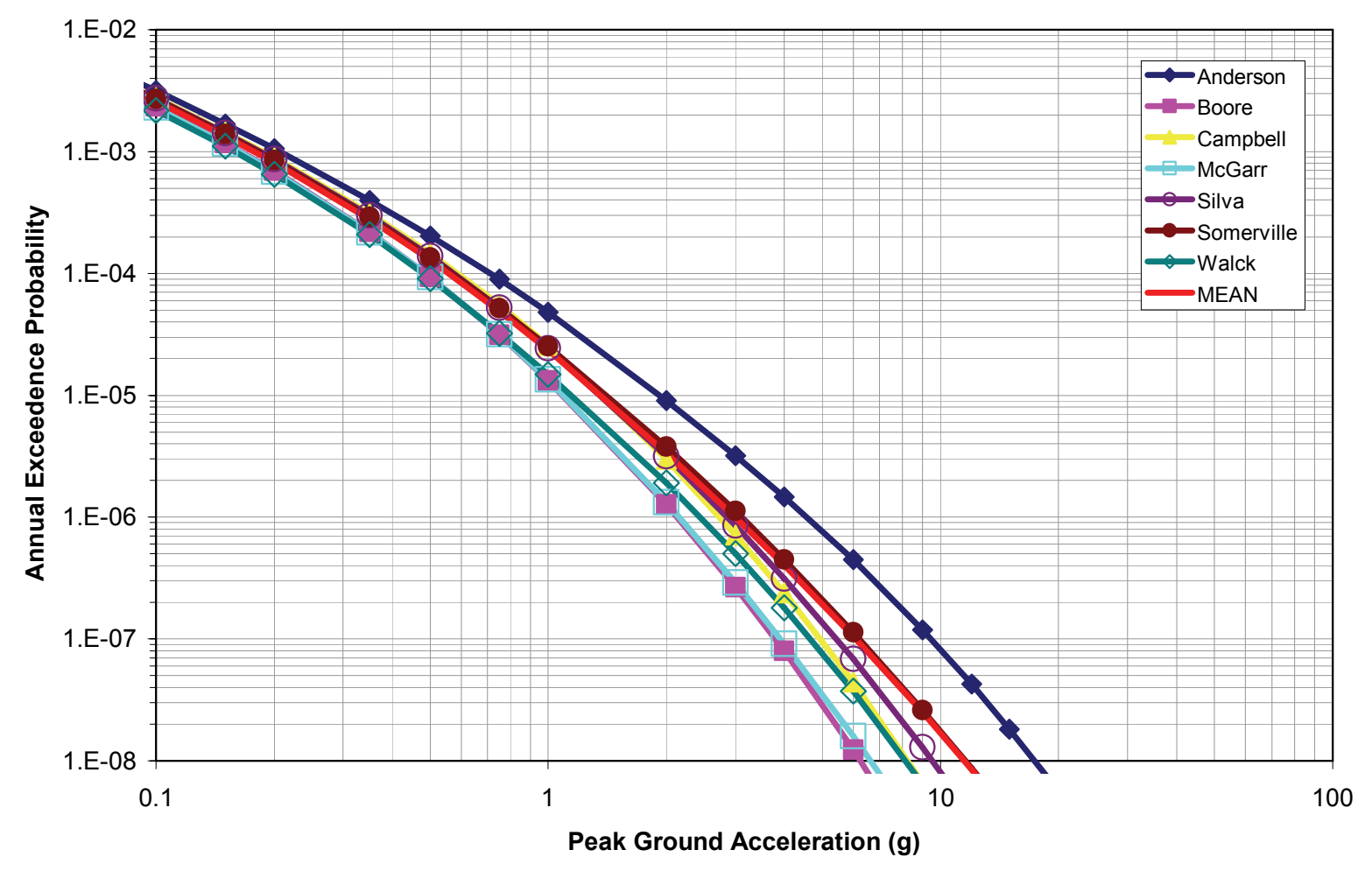

Figure 2. Mean PGA hazard by ground-motion expert.

\section{Recommendations}

The first lesson from these results is that SSHAC level-IV PSHA studies need additional feedback to the experts because the effects of unintended differences between expert models may have very large effects on the hazard results for very low exceedence probabilities. In fact, we have extracting additional insights from the de-aggregation information as part of this exercise. All these insights should have been available to the source-characterization and ground-motion experts as part of the feedback.

The high epsilons obtained in the $10^{-8}$ de-aggregation, together with existing results on the spatial variation of peak ground motions (e.g., Abrahamson and Sykora, 2003), imply that these peak motions may only occur in a small fraction of the repository area.

Ground-motion modelers can take the following two approaches in their effort to improve their inputs to low-probability PSHAs: (1) focus on maximum motions and try to define the maximum motions using physical constraints, or (2) improve their overall models (perhaps including the mechanisms that control maximum motions), in an effort to reduce the aleatory and epistemic uncertainties. The first approach is the one taken by PEGASOS, and may be viewed as the development of attenuation equations for the maximum possible motion (this is likely to be much more difficult than defining an attenuation equation for the median amplitude). The second approach may be more fruitful in the long term, but will probably require a significant research effort. It will also require a shift in emphasis from "getting the median right" (which may turn 


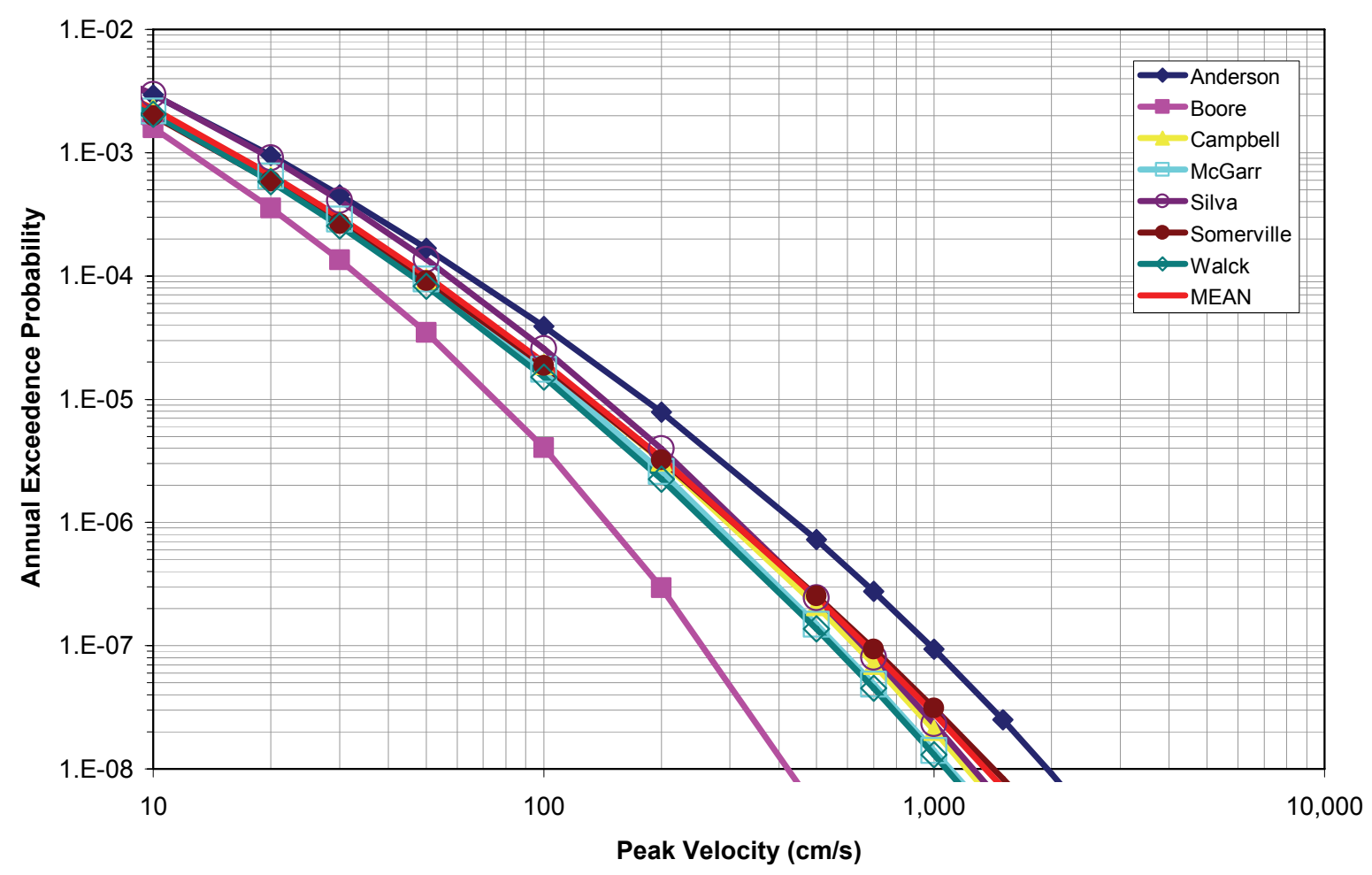

Figure 3. Mean PGV hazard by ground-motion expert.

out to be the easy part) to "getting the uncertainties right." Part of this effort may include the introduction of new explanatory variables. The de-aggregation results presented here indicate that the experts need to concentrate on earthquakes at very short distances ( $5 \mathrm{~km}$ or less).

Information about past ground motions or lack thereof ("Paleseismometric data") may be a very useful tool in our effort to obtain more realistic estimates of seismic hazard. It is important, however, to investigate alternative explanations for these observations and to quantify the associated uncertainties in both the age of the feature and the maximum ground motion that the feature has experienced during its existence. The spatial variability of ground motions (and its physical causes) may also have to be considered. Most of these "observations" provide information in "hazard space," not directly in terms of attenuation equations or source characteristics. Bayes' Theorem provides a rigorous framework for combining existing hazard results with Paleseismometric data, including the associated uncertainties and should be explored. There are precedents in the application of similar techniques to flood analysis (e.g., O'Connell et al., 2002).

The effect of non-ergodic ground-motions (i.e., the lack of independence between the groundmotion residuals of repeated characteristic events; see Anderson and Brune, 1999) should also be considered. Non-ergodic effects may be important in the Yucca Mountain performance assessment as a result of the long performance period. The YMPSHA and Anderson-Brune have explored both end members; reality lies somewhere in between and we should explore the hazard implications of partial ergodicity. 


\section{References}

Anderson, J.G. and J.N. Brune (1999). Probabilistic hazard analysis without the ergodic assumption, Seism. Res. Lett. 70, 19-23.

CRWMS-M\&O (1998). Probabilistic seismic hazard analyses for fault displacement and vibratory ground motion at Yucca Mountain, Nevada. I. Wong and C. Stepp, report coordinators. Prepared for the U.S. Geological Survey.

McGuire, R.K, Silva, W.J, and Costantino, C. (2001). Technical Basis for Revision of Regulatory Guidance on Design Ground Motions-- Development of Hazard-and Risk-consistent Seismic Spectra for Two Sites. Nuclear Regulatory Commission, NUREG/CR-6769.

O’Connel, D.R.H, Ostenaa, D.A., Levish, D.R., and Klinger, R.E. (2002). Bayesian flood frequency analysis with paleohydrologic bound data. Water Resources Research, 38, 16-1-1614.

Toro, G.R. (2003). PSHA Calculations for Annual Exceedence Probabilities as low as 1E-9. Scientific Notebook SN-M\&O-SCI-038-v1. Yucca Mountain Project. 
Bounds on PGV at the Yucca Mountain Repository Based on Earthquake Source Constraints

\section{A. McGarr}

Summary of presentation at Workshop on Extreme Ground Motions at Yucca Mountain on Monday, August 23, 2004

According to the PSHA for the nuclear repository at Yucca Mountain, summarized by Stepp et al. (2001), the design level PGV's for AEP's of $10^{-7}$ and $10^{-8}$ are about $7 \mathrm{~m} / \mathrm{s}$ and $13 \mathrm{~m} / \mathrm{s}$, respectively at Point $\mathrm{A}$. It seems to be generally agreed that the most likely source of such high PGV is an earthquake of M6.5 to M7 on the Solitario Canyon fault, which crops out along the western edge of Yucca Mountain.

Because this fault crops out immediately west of the repository, the maximum ground motion affecting the facility would presumably be that associated with the adjacent fault slip rate. Here I argue that the maximum slip rate is unlikely to exceed $4 \mathrm{~m} / \mathrm{s}$ and so the corresponding bound on PGV, half the peak slip rate, is $2 \mathrm{~m} / \mathrm{s}$. The basis for this argument is the observation that maximum PGV's worldwide are associated with nearfault ground motion. The peak slip rate, in turn, is related to the stresses loading the fault to cause seismic slip. Interestingly, the peak slip rate and the near-fault PGV are independent of earthquake magnitude or moment (McGarr and Fletcher, 2003).

Figure 1 shows near-fault PGV as a function of seismic moment. As seen here, over many orders of magnitude, there is no systematic variation in $\mathrm{PGV}$ with $\mathrm{M}_{0}$. The highest point, $2.6 \mathrm{~m} / \mathrm{s}$ for the Chi-chi earthquake (Silva and Wong, 2003) is the highest PGV ever recorded, but this datum is probably not relevant the assessment of PGV's that might affect Yucca Mountain because the recording site, TCU068, is on the immediate hangingwall of a thrust fault. The ground motions for the other three major earthquakes were all recorded within several $\mathrm{km}$ of the causative fault where substantial surface slip was observed. In each case, the fault parallel displacement, from the twice-integrated accelerograms, is close to half the nearby observed fault slip. The near-fault PGV for Izmit is probably an underestimate because the fault normal (north) component of the accelerograph was not functioning at the time of the earthquake.

The near-fault PGV for the M4.4 mining-induced earthquake is based on the velocity seismogram shown in Figure 2 together with the observation that the maximum slip along the causative fault, several km below the recording site, was $0.2 \mathrm{~m}$. The $\mathrm{S}$ wave velocity pulse is well approximated by a single cycle of sine wave of duration of $0.16 \mathrm{~s}$, especially as seen on the vertical component (Figure 2). Dividing this duration (rise time) into the maximum slip gives a lower bound for the average slip rate of $1.25 \mathrm{~m} / \mathrm{s}$ and a peak slip rate of $2.5 \mathrm{~m} / \mathrm{s}$, or a near-fault PGV of $1.25 \mathrm{~m} / \mathrm{s}$ (Figure 1). This estimate is a lower bound because the duration of the $\mathrm{S}$ pulse (Figure 2) may be representative of a broader portion of the fault zone than the high-slip patch, which might have had a shorter rise time.

Stick-slip event 9 was typical of the experiments reported by Lockner and Okubo (1983) and was emphasized by McGarr and Fletcher (2003). As seen in Figure 3 of Lockner 
and Okubo (1983), the maximum slip rate for event 9 is $0.1 \mathrm{~m} / \mathrm{s}$. To relate this maximum slip rate to those anticipated for crustal earthquakes we multiply by a stress adjustment factor of 41 , which is based on the differences between the stresses loading the laboratory granite sample and the deepest available in situ stresses, which were measured at a depth of $6.8 \mathrm{~km}$ at the KTB site, Germany (Brudy et al., 1997). This adjustment procedure was described in detail by McGarr and Fletcher (2003). It turns out that the adjusted peak slip rate for an equivalent crustal earthquake is predicted, from event 9 , to be $4.1 \mathrm{~m} / \mathrm{s}$ and so the adjusted PGV is half of this, or $2.05 \mathrm{~m} / \mathrm{s}$ (Figure 1). The stress-adjusted seismic moment of event 9 is $3.2 \times 10^{10} \mathrm{~N}-\mathrm{m}$ (McGarr et al.. 2004).

The main conclusions are:

1) The near-fault PGV is controlled by the loading stresses.

2) The near-fault PGV is independent of $M$ or $M_{0}$.

3) The laboratory results and earthquake observations covering a broad range of earthquake magnitude suggest that near-fault PGV exceeding $2 \mathrm{~m} / \mathrm{s}$ in the extensional tectonic regime of Yucca Mountain (Point A) is quite unlikely.

4) The PSHA results for postclosure AEP's should be revisited.

Recommendations:

1) More laboratory experiments to simulate near-fault PGV's under controlled conditions.

2) Investigate earthquakes for which one can infer slip rise time and the maximum fault slip to estimate lower bounds on near-fault PGV's

3) Compare ground motion recorded in deep boreholes to slip models developed for the same nearby earthquakes. 
Figures

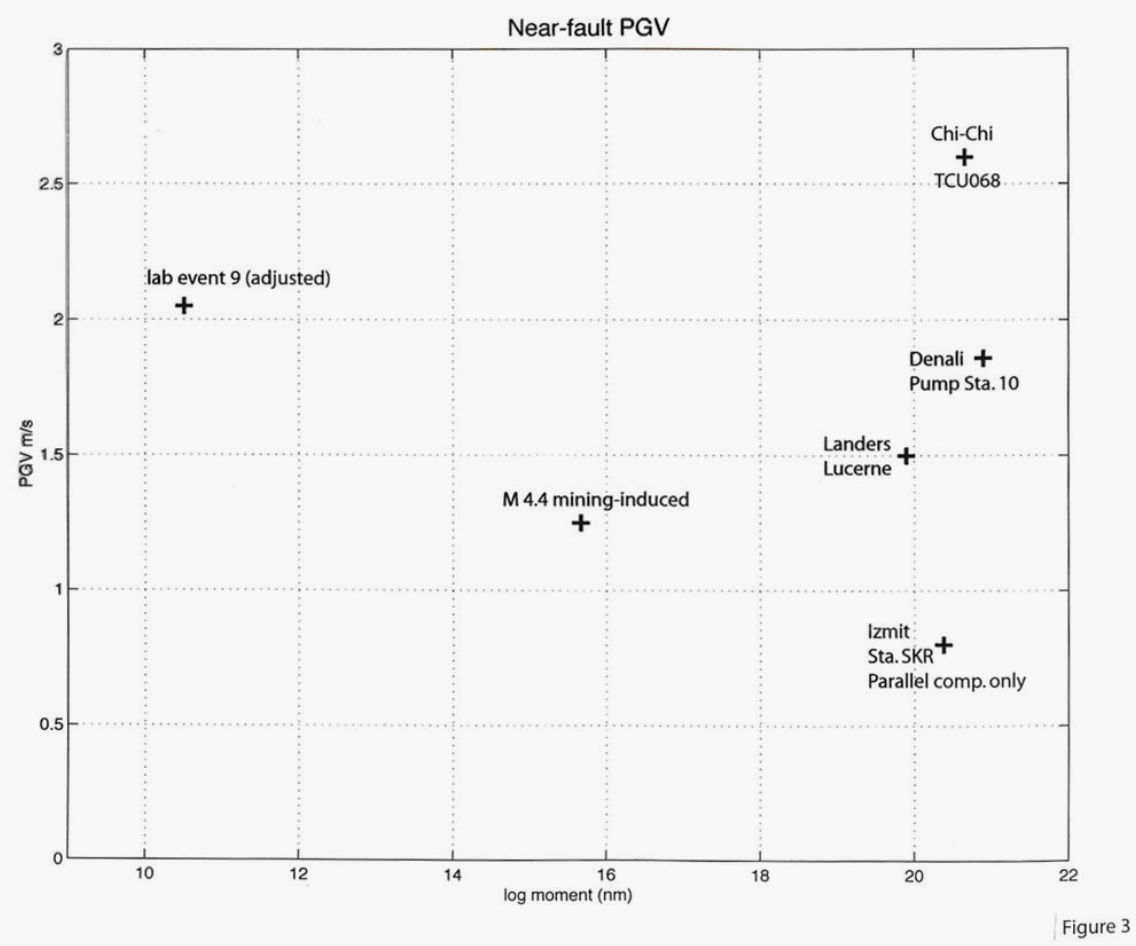

Figure 1. Peak ground velocity (PGV) as a function of seismic moment measured or inferred adjacent to the causative fault.

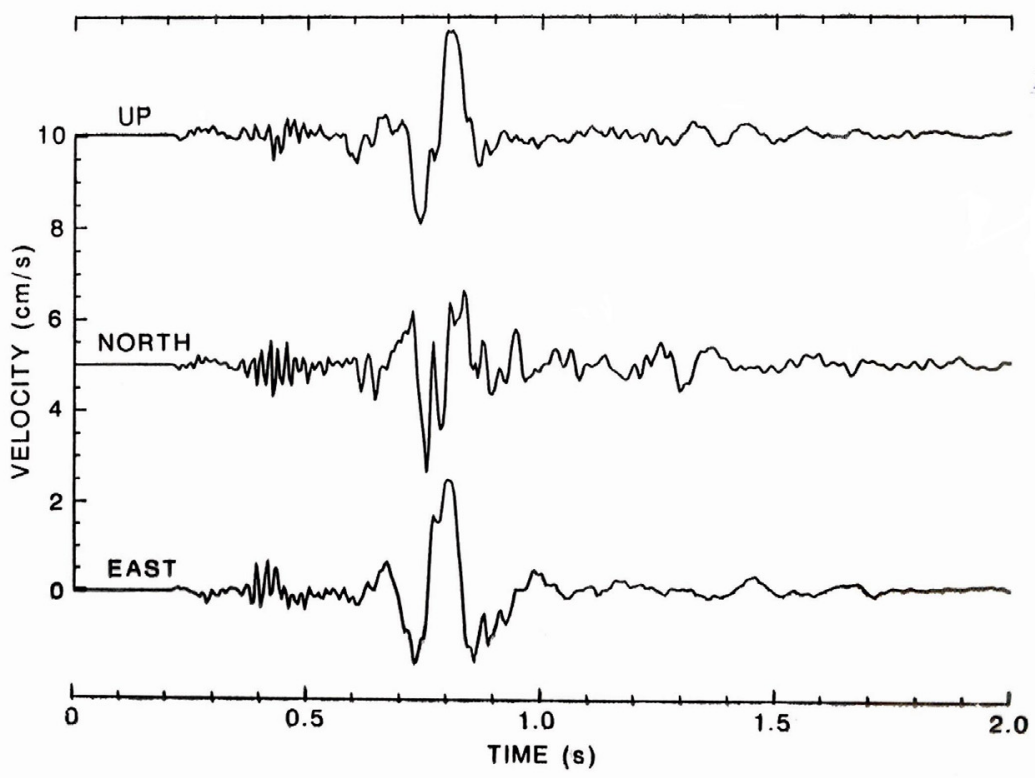

Figure 2. Ground velocity recorded at a bed rock site on the surface about $2 \mathrm{~km}$ above a M 4.4 mining-induced earthquake. 


\section{References}

Brudy, M., M. D. Zoback, K. Fuchs, F. Rummel, and J. Baumgartner, Estimation of the complete stress tensor to $8 \mathrm{~km}$ depth in the KTB scientific drill holes: implications for crustal strength, J. Geophys. Res., 102, 18,453-18,475, 1997.

Ellsworth, W. L., M. Celebi, J. R. Evans, E. G. Jensen, D. J. Nyman and P. Spudich, Processing and modeling of the Pump Station 10 record from the November 3, 2002, Denali fault, Alaska earthquake, preprint $11^{\text {th }}$ International Conference on Soil Dynamics \& Earthquake Engineering, Berkeley, CA, January 7-9, 2004.

Lockner, D. A. and P. G. Okubo, Measurements of frictional heating in granite, $J$. Geophys. Res., 88, 4313-4320, 1983.

McGarr, A., Observations constraining near-source ground motion estimated from locally recorded seismograms, J. Geophys. Res., 96, 16,495-16,508, 1991.

McGarr, A. and J. B. Fletcher, Maximum slip in earthquake fault zones, apparent stress, and stick-slip friction, Bull. Seismol. Soc. Am., 93, 2355-2362, 2003.

Sekiguchi, H. and T. Iwata, Rupture process of the 1999 Kocaeci, Turkey, earthquake estimated from strong motion waveforms, Bull. Seismol. Soc. Am.,92, 300-311, 2002.

Silva, W. and I. G. Wong, Proposed ground motions for postclosure analysis, presented to Nuclear Waste Technical Review board, Joint Meeting of the Natural system and Engineered System Panels, Los Vegas, NV, 24 February, 2003.

Somerville, P. G., N. F. Smith, R. W. Graves and N. A. Abrahamson, Modification of empirical strong ground motion attenuation relations to include the amplitude and duration effects of rupture directivity, Seismol Res. Lett. 68, 199-222, 1997.

Stepp, J. C., I. Wong, J. Whitney, R. Quittmeyer, N. Abrahamson, G. Toro, R. Youngs, K. Coppersmith, J. Savy, T. Sullivan and Yucca Mountain PSHA Project Members, Probabilistic seismic hazard analyses for ground motions and fault displacement at Yucca Mountain, Nevada, Earthquake Spectra, 17, 113-151, 2001. 


\section{NWTRB Perspective on Extreme Ground Motions}

By

Leon Reiter

Senior Professional Staff

U.S. Nuclear Waste Technical Review Board

\section{BACKGROUND}

On February 24, 2003, the Nuclear Waste Technical Review Board's (NWTRB) Panel on the Natural System and Panel on the Engineered System held a joint meeting in Las Vegas devoted to seismic issues. The NWTRB was set up by the Nuclear Waste Policy Amendments Act of 1987. Its defined purpose is to evaluate the technical and scientific validity of activities undertaken by the Department of Energy (DOE) with respect to various aspects of high-level waste and spent nuclear fuel. It consists of 11 members chosen by the President from a slate provided by the National Academy Science and reports at least twice a year to Congress and the Secretary of Energy. The NWTRB has no regulatory authority.

The Board was interested in the very high ground motions being considered for the evaluation of the proposed nuclear waste repository at Yucca Mountain, Nevada. In order to help in its evaluation, the NWTRB hired four consultants; Alfred (Skip) Hendron (geotechnical engineer-University of Illinois), Peter Kaiser (mining engineer-Laurentian University), Art McGarr (seismologist-U.S. Geological Survey), and Anestis (Andy) Veletsos (Civil EngineerRice University). The Board's analysis of the material presented to it by the DOE at the February 2003 meeting, including its perspective on extreme ground motions, was communicated to the DOE in a letter dated June 27, 2003. My presentation at the August 23-25, 2004, workshop is based on that letter, which can be found on the NWTRB web page, http://www.nwtrb.gov, under the heading of "correspondence. Portions of this write-up are taken directly form the NWTRB letter. The individual consultant reports and meeting transcripts can be found on the same web page under the heading of "meetings."

\section{RESULTS OF THE YUCCA MOUNTAIN PSHA}

The Yucca Mountain conducted a state-of-the-art probabilistic seismic hazard analysis (PSHA) for ground motion and fault displacement at the proposed Yucca Mountain waste repository. This effort, completed in 1998 and summarized in the professional literature in Stepp et al (2001), was the most extensive PSHA carried out until that time. Originally envisioned as primarily serving as a means for determining seismic design, problems arose when it became apparent that the PSHA would have to be extended to very low probabilities of exceedance $(<10$ ${ }^{6}$ per year). These low probabilities were needed because the regulations required that events, whose probabilities were as low as one chance in 10,000 over the regulatory lifetime of 10,000 years $\left(10^{-8}\right.$ per year), have to be considered in assessing the long-term performance of the repository. The ground motions at these low probabilities were extremely large and mean values (the metric of primary interest) reached as high as $11 \mathrm{~g}$ for peak ground acceleration (PGA) and $1300 \mathrm{~cm} / \mathrm{sec}$ for peak ground velocity (PGV) for a hypothetical rock outcrop (see Figure 1). PGV is the primary measure used in evaluating the safety of the underground repository.

The Board views these low probability estimates, which are outside the limits of existing worldwide seismic records or experience, as being generally unrealistic and possibly physically unrealizable. These ground motions may require unrealistic source characteristics (e.g., stress 
drops) and unrealistic strains, which may exceed the ability of the rock to sustain without fracturing.

In addition, real records used in the seismic consequence analysis (seismic evaluation) were scaled to reach target levels such as $535 \mathrm{~cm} / \mathrm{sec}$ PGV at $10^{-7}$ per year. These target levels were based upon extending the results from the PSHA and modifying them to take local site conditions into account. The scaling technique involved randomly picking one of the two horizontal components, determining how large a scaling factor is needed to reach the target level, and then scaling both horizontal components (regardless of whether it is the larger or smaller of the components) using the same scaling factor. Some of the actual ground motion recordings used were scaled up (increased) by factors higher than 100 to reach the target level of ground motion. In some cases this method of scaling yielded PGA's and PGV's (for example, $20 \mathrm{~g}$ PGA and $1790 \mathrm{~cm} / \mathrm{sec}$ PGV at $10^{-7}$ per year) well above already unrealistic target levels. Many DOE and DOE contractors at the February 24, 2003 meeting shared the NWTRB's views about the unrealistic nature of the low probability ground motion estimates. However, as discussed below differences of opinion between the NWTRB and the DOE existed on how to proceed given this lack of realism.

\section{TREATMENT OF UNCERTAINTY}

Another possible source of error in the ground motion estimates has to do with the treatment of uncertainty in the ground motion models. Anderson and Brune (1999) have questioned the use of the ergodic assumption, i.e., that the distribution of a random variable in space can be treated the same as the distribution of that same random variable at a single point when sampled as a function of time. In ground motion regression analysis this means that the standard deviation from the misfit of multiple earthquake can be assumed to be aleatory (random) uncertainty. If this uncertainty is due to differences in earthquake sources that are not present around the site being analyzed, it could result in overestimating the ground motion at low probabilities, where assumptions about the tails of the distribution control ground motions. In support of this hypothesis, James Brune and his colleagues at the University of Nevada have argued that observations of precarious rocks and other formations in the vicinity of Yucca Mountain imply that ground motions during the past 10,000,000 years, have been substantially less than those estimated in the PSHA.

\section{RECOMMENDATIONS}

The NWTRB made several recommendations to the DOE.

1. The very low probability ground motions need to be bounded on the basis of sound physical principles.

2. The results of the DOE studies should be subjected to external peer review. Estimating physical bounds on ground motion will be challenging. Aside from a study in Switzerland, the NWTRB was not aware of any other systematic attempt to address this issue. 
3. The DOE should evaluate and consider the work on precarious rocks and its implications.

\section{IMPLICATIONS OF TOO MUCH CONSERVATISM}

Finally the NWTRB was concerned that the DOE may find the highly conservative (erring on the side of safety) and physically unrealistic assumptions and results used in addressing seismic issues an attractive option because they can still show regulatory compliance. In this approach, studies carried out to define limits on ground motions would be used to show conservatism rather than as a means of modifying the ground motion estimates themselves. There are inherent problems associated with this approach.

1. High levels of conservatism can lead to a skewed understanding of repository system behavior. This is particularly important when many types of events are considered and priority is determined according to the risk they pose.

2. High levels of conservatism can introduce consideration of events for which there is little or no understanding such as predicting the effects of physically unrealistic ground motions.

3. Compounding conservative assumptions does not always lead to conservative results. For example, the worst case for tunnel stability is not when the horizontal and vertical stresses are both very high.

4. High levels of conservatism may lead to unreasonably high costs and may have a serious effect on the eventual design.

5. Conservatism stemming from a lack of understanding can undermine confidence in the scientific basis of the process under consideration. Physically unrealistic results, inappropriately extrapolated from physically real databases and analyses, could cast unwarranted doubt on much of the truly excellent work carried out this area.

6. If "unacceptable" consequences develop later as a result of the use of unrealistic or unduly conservative ground motion estimates, it may be difficult to justify subsequent reductions in ground motions to make them more realistic.

\section{ADDED NOTE}

It is important to note that subsequent to this letter, the DOE embarked upon a serious program (both short and long term) to derive more realistic ground motion estimates and has begun to modify the high ground motion estimates for their use in seismic consequence analysis. 


\section{REFERENCES}

Anderson, J.G. and J.N. Brune (1999). Probabilistic seismic hazard analysis without the ergodic assumption, Seismological Research Letters, 70, 19-28.

Stepp J.C., I. Wong, J. Whitney, R. Quittmeyer, N. Abrahamson, G. Toro, R. Youngs, K. Coppersmith, J. Savy, T. Sullivan, and Yucca Mountain PSHA Project Members (2001). Probabilistic seismic hazard analyses for ground motions and fault displacement at Yucca Mountain, Nevada, Earthquake Spectra, 17, 113-151.

Stepp, J. C. and I.G. Wong, (2003). Probabilistic seismic hazard analysis for Yucca Mountain. Presentation to the Nuclear Waste Technical Review Board, February 24, 2003.

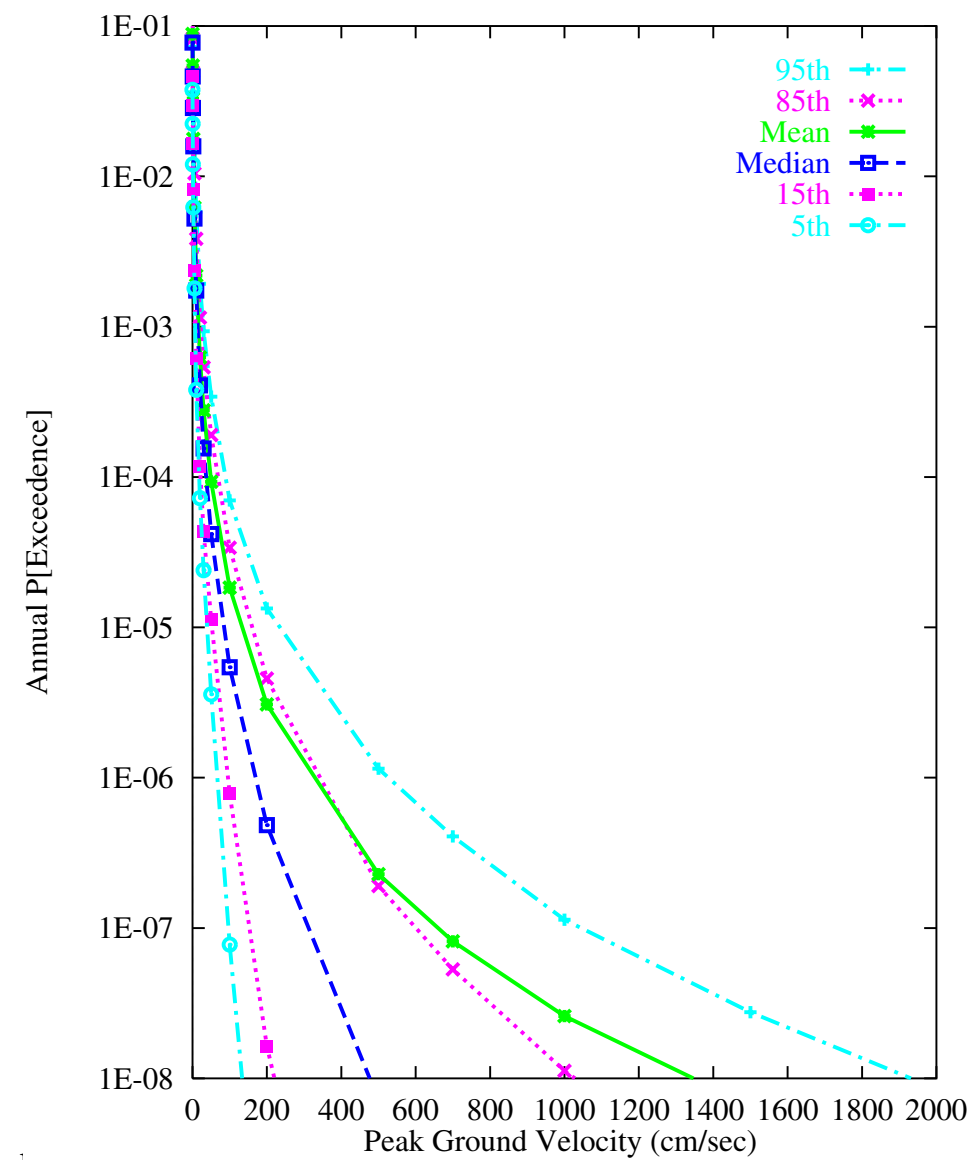

Figure 1. Ground motion nazara results (norizontal $r \mathrm{UV}$ ) Irom tne y ucca Mountain PSHA (Stepp and Wong, 2003) 
The PEGASOS Project, Methods and Results

Norman A. Abrahamson

\section{Introduction}

The PEGASOS project was a SSHAC level 4 seismic hazard study conducted for Swiss nuclear power plants. Mulitple experts developed models for the PSHA inputs: source characterization, rock ground motion, and sites response. Based on the Yucca Mountain experience, PEAGSOS required that the characterization included maximum ground motions on rock and and soil. The rock maximum ground motions were regional values, whereas the soil maximum ground motions were site specific.

\section{Rock Ground Motion Characterization}

The PEGASOS project had five ground motion experts. They developed ground motion models for spectral acceleration for hard-rock site conditions (Vs=2000 m/s). A kappa value was not specified for the site. The experts assigned weights to the candidate models, rather than point estimates as was done for Yucca Mountain. The weights were assigned to the median and the aleatory variability. The epistemic uncertainty was determined by the distribution of weights. In general, the distribution is asymmetric.

The maximum ground motions were considered in two ways: absolute threshold which is a function of magnitude and distance, and a deviation of the shape of the log-normal distribution.

To reduce the number of branches in the logic tree, a composite model was developed for each expert. The epistemic uncertainty in the median ground motion and the aleatory variability was discretized into seven discrete levels: $-3 \sigma,-2 \sigma,-1 \sigma, 0 \sigma, 1 \sigma, 2 \sigma$, and $3 \sigma$.

An example of the epistemic uncertainty in the median ground motion for peak horizontal acceleration for a magnitude 6 earthquake is shown in Figure 1. An example of the epistemic uncertainty in the standard deviation for a magnitude 6 earthquake at a distance of $10 \mathrm{~km}$ is shown in Figure 2.

\section{Approaches to Maximum Ground Motions}

Four approaches to estimating the maximum ground motions were considered in the PEGASOS project: statistical truncation (e.g. deviation from log-normal), maximum historical observations, limits on seismic source properties, and limits due to wave propagation and site response. Geologic observations were not used in PEGASOS.

For the rock ground motions, maximum values were developed as a function of magnitude and distance, rather than a single limiting value. For the soil ground motions, the maximum values were developed in terms of single limiting values based on the strength of the soils.

Empirical studies were conducted to find the largest historical ground motion at a given magnitude and distance and to evaluate any deviations from a lognormal distribution. The empirical studies are summarized in Bommer's presentation. Numerical simulations were conducted to find the limits due to source effects and soil strengths. 


\section{Maximum Ground Motions on Rock}

The ground motion experts had to provide a technical basis for their maximum ground motions. To provide this technical basis, the primary approach used for limiting the ground motion on rock is numerical simulations. In this approach, the "limiting: source properties are used and the ground motion is simulated at a range of sites distributed around the source. The difficulty is determining the limits on the source properties.A key issue is the combination of the source parameters. Are there combinations of source parameters that are physically impossible? This was a recurring difficulty faced in the PEGSOS project.

In this past, numerical modelers have focused on modeling past earthquakes and on modeling "median" future earthquakes. They had little experience with extreme cases and were uncomfortable with some of the results. In some cases, the ground motion experts forced the modelers to consider source parameters combinations that the modelers felt were "extreme". This lead to a recurring difficulty: what is a maximum ground motion in contrast to a very rare ground motion. For example, when the ground motion experts asked if a certain combination of source parameters was possible, the modelers replied, "yes, but it is "very unlikely" or "extremely unlikely". Table 1 lists some of the words used by the modelers and a rough definition. While the ground motion experts asked for the maximum ground motions, the modelers provided estimates of "very unlikely" ground motions.

Table 1. Terminology for "Maximum"

\begin{tabular}{|l|l|}
\hline \multicolumn{1}{|c|}{ Term } & \multicolumn{1}{c|}{ Meaning } \\
\hline Unreasonable ground motion & $\begin{array}{l}\text { Small chance of a larger ground motion } \\
\text { occurring }\end{array}$ \\
\hline Unlikely ground motion & $\begin{array}{l}\text { Very small chance of a larger ground } \\
\text { motion occurring }\end{array}$ \\
\hline Very unlikely ground motion & $\begin{array}{l}\text { Very very small chance of a larger ground } \\
\text { motion occurring }\end{array}$ \\
\hline Extremely unlikely ground motion & $\begin{array}{l}\text { Really small chance of a larger ground } \\
\text { motion occurring }\end{array}$ \\
\hline Maximum ground motion & $\begin{array}{l}\text { Zero chance of a larger ground motion } \\
\text { occurring }\end{array}$ \\
\hline
\end{tabular}

\section{Maximum Ground Motions on Soil}

Quantifying the maximum ground motion on soil sites was a much easier problem than quantifying the maximum ground motion on rock sites. Soil strength limits the ground motion that can be transmitted. This is a straight forward problem for geotechnical engineers since soil failure is a common problem. While the limited soil strengths can limit the ground motions, it implies soil failure which leads to other problems that must be addressed: e.g. what are the consequences of the soil failure? 


\section{Summary}

The maximum ground motion means that the probability of a larger value occurring is zero, not that it is unlikely. Maximum ground motions require a physical basis, not a statistical basis, but statistics can be used to constrain the rate of occurrence of very large ground motions. Other than soil failure, this is difficult to defend using currently available models.

Maximum ground motions should be addressed in the context of probability. That is, focus on the probabilities of extreme source parameter combinations, rather than absolute limits on the source parameters. The distribution of the rock ground motion should be modified based on the joint distribution of source parameters and wave propagation. 


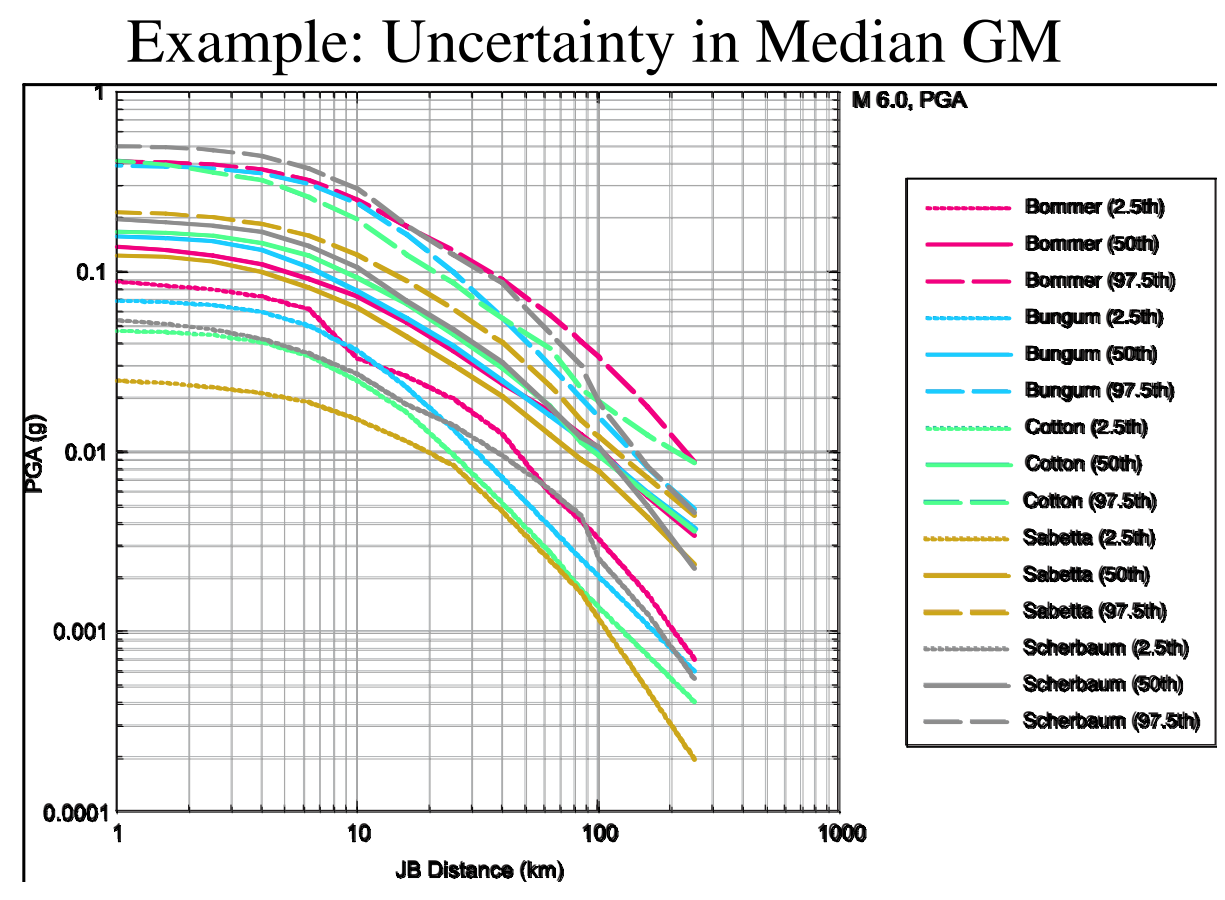

Figure 1. Example of the epistemic uncertainty in the median ground motion: $M=6$, PGA.

\section{Uncertainty in Aleatory Variability}

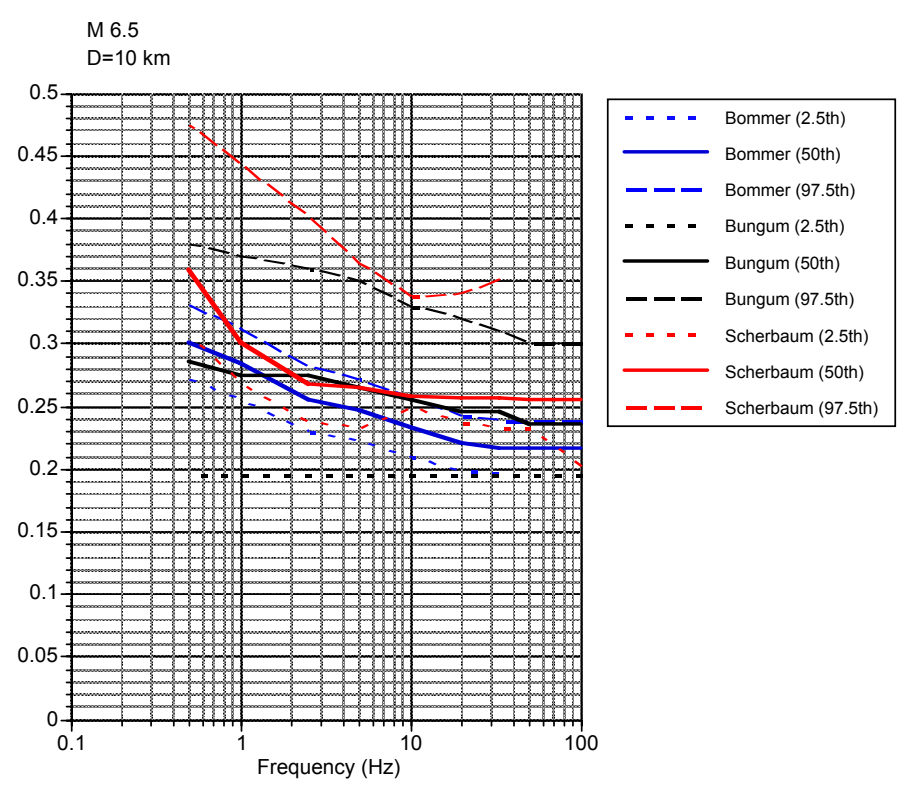

Figure 2. Example of the epistemic uncertainty in the aleatory variability: $M=6, R=10$ $\mathrm{km}$. 


\title{
The Use of Empirical Data, Numerical Simulation and Expert Judgment to Define Upper Bounds on Ground Motions: Insights from the PEGASOS Project
}

\author{
Julian J. Bommer \\ Dept. of Civil \& Environmental Engineering, Imperial College London, SW7 2BU, UK
}

\section{Introduction}

This document briefly summarizes the methodological approaches to defining upper bounds on earthquake ground motions in rock employed in the PEGASOS Project (Abrahamson et al., 2002).

\section{Upper Bounds in the PEGASOS Project}

The PEGASOS Project had the benefit of hindsight in coming after the Yucca Mountain seismic hazard assessment had been completed (Stepp et al., 2001) and the participants were aware of the need to consider upper bounds on ground motions since the hazard was to be calculated to annual frequencies of exceedance as low as $10^{-7}$ (Abrahamson et al., 2002).

The members of the expert panel for sub-project 2 (SP2) on ground-motion models had the benefit of knowing that the issue of upper bounds on ground motion was likely to arise, but the resources available to help constrain their estimates were limited. The experts were required to provide estimates of upper bounds on rock site spectral accelerations over a range of response frequencies as functions of magnitude and distance. A logic-tree approach was adopted with each expert assessing possible levels and assigning them relative weights.

The most important resource made available at the request of the panel of ground-motion experts was two sets of simulations performed by URS Corporation (Arben Pitarka and Paul Somerville) and OGS Trieste (Enrico Priolo and colleagues) to generate extreme ground motions for a few selected magnitude-distance pairs. The input to these models were reviewed by Professor Raúl Madariaga and only one set of simulations - using super-shear rupture velocities - was unambiguously judged to be unphysical and hence that set of results were disregarded by the experts.

Other resources at the disposal of the authors included the following: existing empirical ground-motion prediction equations; a large databank of strong-motion records; and previous studies proposing upper bounds on earthquake ground motions. The latter were 
mostly published more than 20 years ago (see review in Bommer et al., 2004) and although of historical interest these were generally not considered to be particularly useful resources for the solution of the problem.

Examination of the residuals in a number of strong-motion data sets reveals that the largest outliers are consistently at least at the $3 \sigma$ level (Bommer et al., 2004). Defining the upper bounds in terms of a number $(\varepsilon)$ of standard deviations rather than absolute values of spectral acceleration was not the favored approach in the PEGASOS project for two simple reasons: (1) the bounds, if they exist, are physical rather than statistical measures, and (2) if the bounds were defined in terms of $\varepsilon$, then in a logic-tree formulation this would create the illogical result of different absolute values for each ground-motion prediction equation.

In the PEGASOS project, a third expert panel - in addition to those on seismic sources and on ground motions - was established for site response, and they were also charged with defining upper limits on ground motions as imposed by the finite strength of nearsurface materials (e.g. Pecker, 2003, 2004). However, since this issue is not relevant to the Yucca Mountain project, it is not discussed in the presentations.

\section{Expert Estimates of Upper Bounds}

The five ground-motion experts in SP2 were charged with providing estimates of upper bounds on spectral accelerations in hard rock sites at various response frequencies for a range of distances (up to $100 \mathrm{~km}$ ) and for magnitudes from $M_{w} 5.5$ to $M_{w} 7.5$. The approaches adopted by the experts varied but in each case the experts produced a range of estimates, reflecting the large epistemic uncertainty in the upper bounds, and weighting these accordingly.

Expert 1 used five different criteria, each weighted according to his confidence in their reliability: the two sets of numerical simulations, the largest amplitudes in the empirical dataset multiplied by a factor of 1.5 , and the $2.5 \sigma$ and $3.0 \sigma$ levels from a particular groundmotion prediction equation; the highest weighting was given to the URS "Max1" simulations. These options and weights were then used to infer mean, minimum and maximum estimates of upper bounds. Experts 2 and 3 used similar criteria, but without a formal weighting scheme, using the empirical data without adjustment, and considering much higher exceedances from existing empirical equations (up to $+4 \sigma$ ). Experts 1, 2 and 3 all used a similar format to express their estimates of the upper bounds: adding certain numbers (not necessarily integers) of standard deviations to the median estimates from a particular attenuation equation - either Ambraseys et al. (1996) or Abrahamson \& Silva (1997). It is important to emphasize that these numbers were not assigned any particular statistical significance: this was simply a tool of convenience, equivalent to changing the 
constant term in the equations, to obtain estimates of the upper bounds over a range of magnitudes and distances.

Expert 4 used a different approach, starting with an anchor point, inferred from the simulations and the empirical data, of PGA equal to $3.0 \mathrm{~g}$ for an $M_{w} 7$ earthquake at $1 \mathrm{~km}$. The response spectral shape and the scaling of all ordinates with magnitude and distance were obtained directly from the equations for central and eastern US by Somerville et al. (2001). This provided the best estimates: upper and lower estimates of the upper bounds were then obtained by multiplying these values by 2.0 and 0.5 .

Expert 5 used another approach, with estimates based primarily on the simulations with sub-shear rupture velocities. The bounding values were interpolated for various magnitudes and distances using the stochastic model of Bay (2002) for Switzerland, with values of the stress parameter $\Delta \sigma$ high enough to match the estimates from the numerical simulations. Estimates of the upper bounds were found using values of 150, 200 and 250 bars for $\Delta \sigma$.

Figure 1 compares estimates of upper bounds on PGA for a particular scenario from the five experts, with the relative weighting assigned by the expert to each estimate. The difference between the lowest and highest estimates is almost one order of magnitude. It can also be observed that in some cases the ranges of estimates proposed by different experts were mutually exclusive. Recalling the objective of a SSHAC Level 4 seismic hazard assessment (Budnitz et al., 1997) to produce estimates that "must be the composite distribution of views represented in the appropriate scientific community", it is reasonable to conclude that the estimates of upper bounds have effectively captured "the centre, the body, and the range of technical interpretations that larger informed technical community would have if they were to conduct the study". The wide range of the estimates is simply a reflection of the large epistemic uncertainty associated with these estimates, for which there is currently little empirical or theoretical evidence. If one accepts the principle that estimates should encompass the space within which future estimates, based on increased data and improved knowledge, will fall, then it is likely that the SP2 experts in PEGASOS achieved this aim.

The SP2 experts were also required, as mentioned earlier, to provide estimates on the upper bounds for vertical ground motions. In the PEGASOS project, models for vertical ground motions were not provided independently but rather experts were required to provide models for the ratio of vertical-to-horizontal $(\mathrm{V} / \mathrm{H})$ motions. Experts 1 and 5 estimated the upper bounds on vertical ground motions by multiplying their estimates for upper bounds on horizontal motions by the median $\mathrm{V} / \mathrm{H}$ ratios. Expert 4 provided his estimate as the horizontal upper bounds multiplied by $2 / 3$. Expert 3 estimated the vertical upper bounds in the same way as for the horizontal motion, using the URS simulations 
and the vertical components of the empirical data. Expert 2 assumed that the upper bounds on the vertical motion would be equal to those on the horizontal motion.

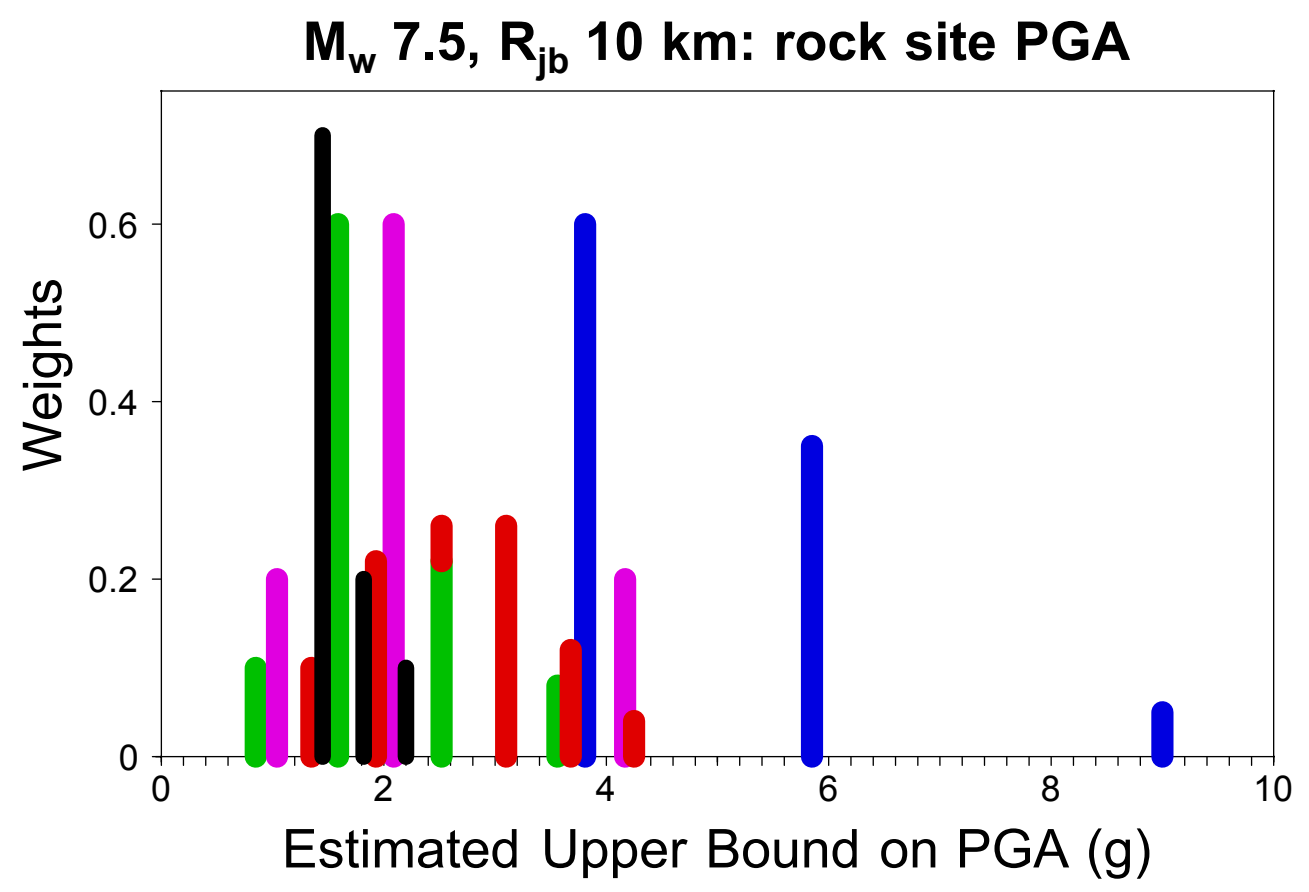

Figure 1. Estimated upper bounds on horizontal peak ground acceleration for a specific earthquake scenario, with associated weights, proposed by the five SP2 experts.

\section{Conclusions}

The issue of upper bounds on earthquake ground motions was addressed in the PEGASOS project because of the very low annual frequencies of exceedance considered for the PSHA and also because of the experience of the Yucca Mountain project.

- The general view of the experts charged with estimating upper bounds on rock motions was that the empirical data is not sufficient to provide reliable indications of the upper tails of the distribution of residuals in ground-motion prediction equations and at best can indicate lower bounds on the upper bounds.

- The most promising generic tool for obtaining reliable estimates for upper bounds is numerical simulations but the key factor will be defining the extreme but physically realizable combinations of source parameters (stress drop, rise time, rupture velocity, etc.) for the simulations, which can probably only be determined using dynamic models.

- Although the view of the SP2 experts in PEGASOS was that the upper bounds should be defined physically rather than statistically, it may only prove possible in 
the short- or medium-term to define the joint probability distributions of earthquake source parameters and then to obtain probabilistic estimates of extreme motions.

\section{Acknowledgements}

The author would like to first express thanks to Tom Hanks and the other members of Extreme Ground Motions at Yucca Mountain committee for the invitation to participate in this workshop. The author also thanks the other members of the PEGASOS expert panel on ground motions with whom he has enjoyed - and continues to enjoy - many long and stimulating discussions on upper bounds, and many other aspects of seismic hazard assessment: Hilmar Bungum, Fabrice Cotton, Fabio Sabetta and Frank Scherbaum. Particular thanks are due to Norm Abrahamson, Technical Facilitator Integrator of the ground motion panel, for his constant guidance and patient correction of our mistakes. I am also grateful to the organizers of the PEGASOS project for the opportunity to explore these issues and also for generously allowing Fleur Strasser, whose PhD thesis is addressing the issue of upper bounds on earthquake ground motions, to participate as an observer in several of the project workshops.

\section{$\underline{\text { References }}$}

Abrahamson, N.A., Birkhauser P., Koller, M., Mayer-Rosa, D. Smit, P., Sprecher, C., Tinic, S. and Graf, R. (2002). PEGASOS - a comprehensive probabilistic seismic hazard assessment for nuclear power plants in Switzerland. $12^{\text {th }}$ European Conference on Earthquake Engineering, London, Paper No. 633.

Abrahamson, N.A. and Silva, W.J. (1997). Empirical response spectral attenuation relations for shallow crustal earthquakes. Seismological Research Letters 68(1), 94-127.

Ambraseys, N.N., Simpson, K.A. and Bommer, J.J. (1996). Prediction of horizontal response spectra in Europe. Earthquake Engineering \& Structural Dynamics 25, 371-400.

Bay, F. (2002). Ground motion scaling in Switzerland: implications for hazard assessment. PhD Thesis, ETH, Zurich.

Bommer, J.J., Abrahamson, N.A., Strasser, F.O., Pecker, A., Bard, P-Y., Bungum, H., Cotton, F., Fäh, D., Sabetta, F., Scherbaum, F. and Studer, J. (2004). The challenge of defining upper bounds on earthquake ground motions. Seismological Research Letters 75(1), 82-95.

Budnitz, R.J., Apostolakis, G., Boore, D.M., Cluff, L.S., Coppersmith, K.J., Cornell, C.A. and Morris, P.A. (1997). Recommendations for probabilistic seismic hazard analysis: guidance on uncertainty and use of experts. US Nuclear Regulatory Commission Report NUREG/CR6372.

Pecker, A. (2003). An estimate of maximum ground motion. Comptes Rendus Mecanique 331, 661-666.

Pecker, A. (2004). An estimate of maximum ground surface motion for non zero surface velocity. Comptes Rendus Mecanique 332, 725-730.

Somerville, P., Collins, N., Abrahamson, N., Graves, R. and Saika, C. (2001). Ground motion attenuation relations for the Central and Eastern United States. USGS Report. Award \#99HQGR0098.

Stepp, J.C., Wong, I., Whitney, J., Quittmeyer, R., Abrahamson, N., Toro, G., Youngs, R., Coppersmith, K., Savy, J., Sullivan, T. and Yucca Mountain PSHA Project Members (2001). Probabilistic seismic hazard analyses for ground motions and fault displacements at Yucca Mountain, Nevada. Earthquake Spectra 17(1), 113-151. 


\title{
Peak Ground Velocities for Seismic Events at Yucca Mountain, Nevada
}

\author{
Jerry King, Bechtel SAIC Company, LLC \\ Kevin Coppersmith, Coppersmith Consulting, Inc. \\ Richard Quittmeyer, Integrated Science Solutions, Inc.
}

The objective of this study is to bound credible peak horizontal ground velocities (PGV) for the repository waste emplacement level at Yucca Mountain. Results are presented as a probability distribution for horizontal PGV to represent uncertainties in the analysis. The analysis is used in conjunction with a probabilistic seismic hazard analysis (PSHA) and ground motion site-response modeling to provide input to an abstraction of seismic consequences. The abstraction input consists of values of horizontal PGV at the waste emplacement level for various annual probabilities of exceedance, based on the PSHA and site-response modeling, and a bound to horizontal PGV from this analysis. The seismic consequence abstraction, in turn, feeds the seismic scenario class of the total system performance assessment (TSPA).

The bound on horizontal PGV at the repository waste emplacement level developed in this analysis complements ground motions developed from PSHA results. In the PSHA, ground motion experts characterized the epistemic uncertainty and aleatory variability in their ground motion interpretations. To characterize the aleatory variability they used unbounded lognormal distributions. As a consequence, as seismic hazard calculations are extended to lower and lower annual exceedance probabilities, the ground motion level increases without bound, eventually reaching levels that are not credible. To provide credible seismic inputs for TSPA, in accordance with 10 Code of Federal Regulations (CFR) 63.102(j), this complementary analysis is carried out to determine reasonable values of horizontal PGV at the waste emplacement level for very low annual exceedance probabilities. For each realization of the TSPA seismic scenario, the results of this analysis provide a constraint or bound on the values sampled from the horizontal PGV hazard curve for the waste emplacement level.

This analysis depends largely on predictions of rock deformation that would be caused by large ground motions at the waste emplacement level at Yucca Mountain and the fact that such deformation is not observed. The lack of such deformation is used to conclude that lithophysal rocks of the Topopah Spring Tuff have not experienced ground motions large enough to cause the predicted deformation during the approximately 12.8 million years since their deposition. Analysis limitations include the following:

- The 12.8 million years age of the Topopah Spring Tuff does not preclude the possibility that ground motions large enough to cause rock deformation occurred at the Yucca Mountain site prior to its deposition. 
- The lack of observations of the type of rock deformation that would be expected if Yucca Mountain had experienced large ground motion levels is limited to those portions of the mountain that are exposed in the Exploratory Studies Facility (ESF) and the Enhanced Characterization of the Repository Block (ECRB) cross-drift.

- Geologic studies of fracture distribution, genesis, and characteristics in the ESF and ECRB cross-drift were not carried out specifically to look for deformation predicted to be associated with large ground motion levels.

- Testing of lithophysal rock samples to provide information on the shear strains associated with fracture generation is carried out on laboratory-scale samples. It represents an approximation to in situ behavior.

- Shear strains at which lithophysal rock of the Topopah Spring Tuff exhibits systematic macro-scale fracturing is modeled using a two-dimensional particle flow code.

- Modeling to determine the shear strains that would be induced in the rock at the waste emplacement level by large ground motions employs a one-dimensional equivalent-linear approach.

Because of uncertainties in the data, analyses, and modeling, and the limitations listed above, the value for bounding horizontal PGV is provided as a probability distribution.

Rock testing data, geologic data, and ground-motion site response data are combined to determine the bounding distribution. The analysis consists of four steps. First, laboratory testing and numerical simulations of lithophysal rock deformation are used to determine the shear-strain threshold for rock failure. Second, the results of the numerical simulations are combined with geologic observations in the ESF and ECRB cross drift to conclude that the Topopah Spring lithophysal zones have not experienced shear strains exceeding the threshold for failure. Third, ground-motion site response data are used to assess the level of horizontal PGV that would be required to generate shear strains exceeding the shear-strain threshold for failure. Fourth, it is concluded that such a level of horizontal PGV has not been reached at Yucca Mountain since the rocks were deposited 12.8 million years ago.

Given the uncertainties in the available data, the bounding horizontal PGV is expressed as a probability distribution. Two approaches are taken. In one, a distribution on the bound to horizontal PGV is assessed directly. In the second approach, a probability distribution is assessed for shear-strain threshold, which is then transformed into distributions for horizontal PGV on the basis of the ground-motion site-response modeling results.

Based on laboratory test results, rock mechanics modeling, and the site-response modeling, the first approach characterizes the bound to horizontal PGV at the waste emplacement level as a uniform probability density function. The lower and upper limits 
for the distribution are assessed at 150 and $500 \mathrm{~cm} / \mathrm{sec}$, respectively, based on the range of shear-strain increments from the combined laboratory testing and numerical simulations and the corresponding horizontal PGV values. This is the distribution used in the seismic consequence abstraction for the seismic scenario class of the TSPA.

For the second approach, the testing and modeling results are used to assess a triangular probability density function for shear-strain threshold, with maximum and minimum values of $0.09 \%$ and $0.25 \%$, respectively, and a modal value of $0.16 \%$. (Note: The distribution illustrated in the workshop presentation has a maximum value of $0.35 \%$. It was reassessed following the workshop and now has a lower maximum value.) The range is based on the range of peak strains determined from the laboratory testing results. The mode is assessed on the basis of the mean values determined for the laboratory samples with length-to-diameter ratios greater than 1.5 , which are considered to provide the most representative results. The range and mode determined from the laboratory testing results are consistent with the results from the numerical simulations.

To translate the triangular shear-strain threshold probability distribution into a distribution for horizontal PGV at the waste emplacement level, the results of the groundmotion site-response modeling are used to determine PGV levels that correspond to specified peak shear strains. Using this relationship, the assessed distribution on shearstrain failure threshold is mapped to a distribution on PGV. Eight bounding horizontal PGV distributions are developed to account for the epistemic uncertainty in site-response modeling and the use of two response-spectrum frequency ranges. The resulting distributions for horizontal PGV depart slightly from a triangular shape because the relation between shear-strain threshold and horizontal PGV is not linear. These distributions fall into two groups, depending on the assumed dynamic properties of the tuff rock that comprises Yucca Mountain. For the case where the tuff is assumed to respond with a high degree of nonlinearity (i.e., with considerable strain softening and increased damping) to the input ground motions), the PGV distributions range from about 100 to $250 \mathrm{~cm} / \mathrm{sec}$ and have a mode of about $175 \mathrm{~cm} / \mathrm{sec}$. In the second group, in which little nonlinearity is assumed, the distributions range from about 200 to $500 \mathrm{~cm} / \mathrm{sec}$ and have a mode of about $335 \mathrm{~cm} / \mathrm{sec}$. (Note: The workshop presentation shows a combined average of the two groups.) The directly assessed uniform distribution that was used as input to the TSPA conservatively brackets the high end of the range of these results.

It is recognized that the lack of rock-failing ground motions in the last 12.8 millions years does not prove that such ground motions would not occur in 100 million years and, therefore, that they have less than one chance in 10,000 of occurrence over 10,000 years, the threshold for exclusion from the TSPA per $\S 63.102(\mathrm{j})$. However, as there is no evidence that rock-failing ground motions can or will occur at Yucca Mountain, the 12.8 my geologic record is considered to provide a reasonable basis for identifying what earthquakes are credible at Yucca Mountain. Specifically, it is reasonable to consider that earthquake ground motions that exceed what has been experienced in the last 12.8 my are not credible and can reasonably be excluded from the Yucca Mountain TSPA. 


\section{FUNDAMENTAL CONSIDERATIONS \\ RELATING TO THE STRENGTH OF ROCK*}

\section{Charles Fairhurst**}

\subsection{THE STRENGTH OF ROCK}

Whether the aim be to prevent collapse or to promote it, rock strength is an important factor in many practical problems of rock mechanics. The property of 'strength' of a rock derives, as with all solids, from various types of inter-atomic and intermolecular bonds, some strong and others relatively weak, that exist within the rock. To break the rock, it is necessary to break enough bonds to separate it into at least two pieces.

A bond between a pair of atoms (or molecules) is formed as a result of two forces - one an attraction, the other a repulsion. The force-intensity versus atomic-separation relationship differs for the two forces such that the resultant force between the atom-pair for various spacings is as shown in Figure 1.

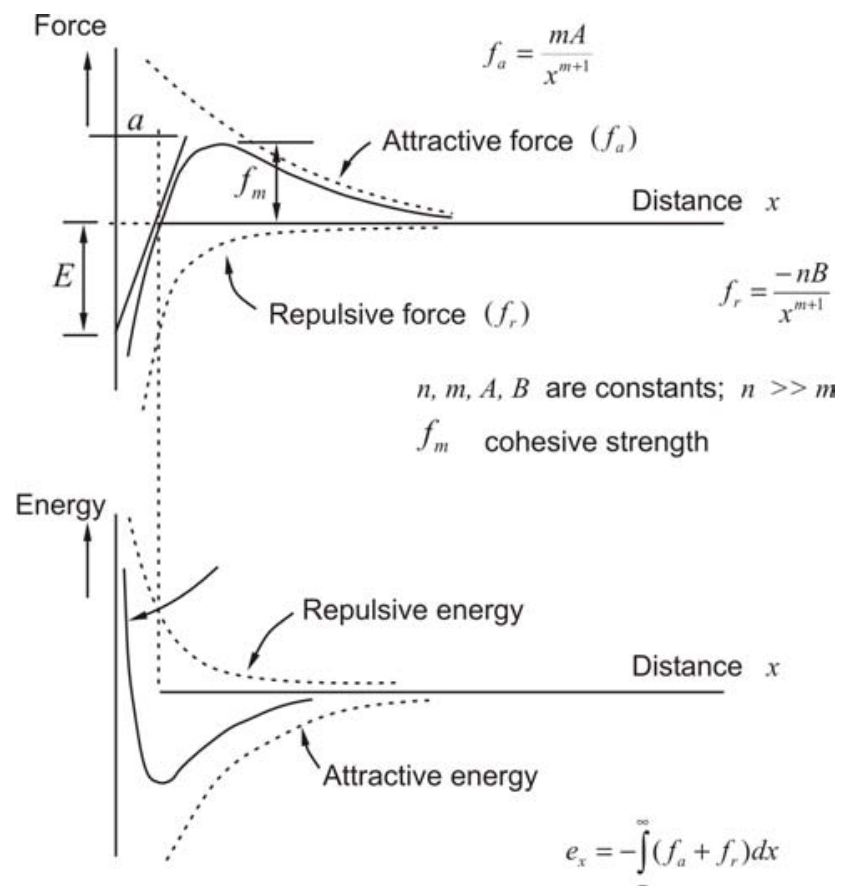

Figure 1 Schematic representation of (i) forces; (ii) potential energy trough between atoms (after Houwink, 1958 p.23)

* Originally presented at the Colloquium on Rock Fracture, Ruhr University, Bochum, Germany, April 1971, (and revised from original, published in Veröff. Inst. Bodenmechanik und Felsmechanik (Karlsruhe), 55, 1-56.)

** Now (2004) Professor Emeritus, University of Minnesota; Senior Consultant, Itasca Consulting Group, Inc., 111,Third Avenue South, Suite 450, Minneapolis, MN 55401, USA. [E-mail fairh001@umn.edu ] 
Both forces increase as the inter-atomic spacing is reduced, with the compressive (i.e., repulsion) force becoming very dominant at small spacings. The value of the exponents $m$ and $n$ in Figure 1 vary depending on the nature of the bond so that the force and spacing scales will change, but the general shape of the net-force vs. spacing curve remains the same - i.e., there is always a tensile or cohesive limit, a decrease in net force at large spacing, and a rapid increase without limit at small spacings.

Application of external compression forces will reduce the inter-atomic spacing (i.e., cause the solid to contract) in accordance with the net force-spacing relationship; application of external tension will increase the spacing. Release the external loads and the spacing will return to the zero net force value. The slope of the curve in the vicinity of the zero-force value represents the elastic modulus of the material.

Careful distinction must be drawn between the physical reality of discrete bond forces and the mathematical construct of stress. The mathematical, continuum, concept of 'stress at a point' has no direct physical meaning. Because it is, however, common to determine stresses, and to compute stress-strain behavior from the physical response of solids to applied forces, it is convenient to indicate the analogy at the atomic level. ${ }^{1}$

If we assume that, over a small planar element of area $\Delta A$, in the solid, all $n$ possible bonds are fully active normal to the element, then we may define an average inter-atomic normal 'stress' $(\sigma)$ across the plane $\triangle A$ as

$$
\sigma=\frac{n F}{\Delta A} \quad \Delta A \rightarrow 0
$$

where $F$ is the inter-atomic force per bond.

We may similarly define an intrinsic ${ }^{2}$ elastic modulus, $E$, for small displacement $(x)$ about the equilibrium spacing $(a)$.

1 Filonenko-Borodic explains the situation as follows: “... it is sometimes said that the theory of elasticity is based on the hypothesis of the continuous structure_of solids. It must be borne in mind, of course, that this hypothesis is but a working hypothesis; it is dictated by the adopted mathematical method of investigation and does not intrude into the branches of physics that are directly concerned with the problems of body structure."

2 'Intrinsic' in that the deformation from which the strain is computed results entirely from deformation (extension or compression) of the bonds. Macroscopically observed moduli in rocks will include additional deformations [e.g., due to pre-existing cracks ('zero-modulus bonds') and will tend to be less than this intrinsic value. 
Thus, defining the inter-atomic 'strain' $\varepsilon$,

$$
\varepsilon=\frac{x}{a}
$$

we obtain

$$
E=\frac{\sigma a}{x}
$$

\subsection{COHESIVE STRENGTH}

We may now obtain a rough estimate of the value of the cohesive strength as a (maximum)tensile stress $\left(\sigma_{m}\right)$. (Joffé et al. 1935). Assuming that the form of the inter-atomic stress-spacing curve is sinusoidal (see Figure 2) for extensional displacements $x$ from the equilibrium position in the range, $0<x<a-$ i.e.,

$$
\sigma=\sigma_{m} \sin \frac{2 \pi x}{\lambda}
$$

where $\sigma_{m}$ is the inter-atomic cohesive strength, and

$\lambda \quad$ is a separation parameter in the direction of $x$, which describes the range of interatomic force interaction (see Figure 2).

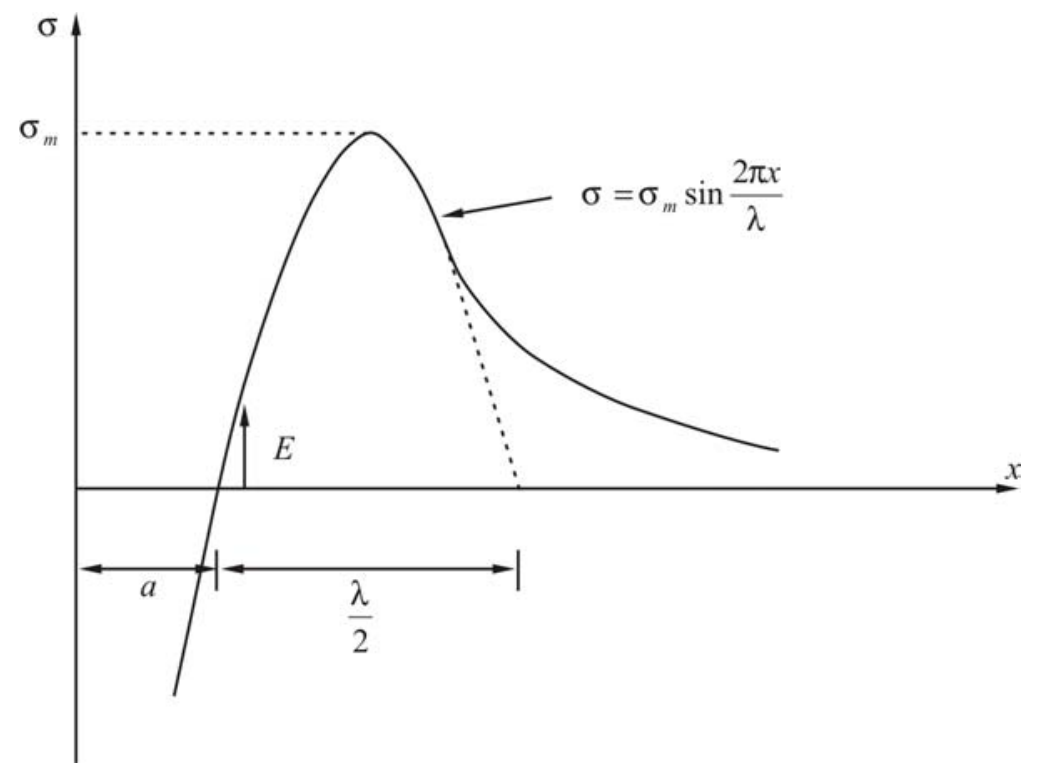

Figure 2 Inter-atomic stress spacing curve 
Differentiating (4) with respect to $x$, we have

$$
\begin{aligned}
\frac{d \sigma}{d x} & =\frac{2 \pi}{\lambda} \sigma_{m} \cos \frac{2 \pi x}{\lambda} \\
& =\frac{2 \pi}{\lambda} \sigma_{m}, \text { for small } \mathrm{x}
\end{aligned}
$$

Substituting in (5) from (3), we have

$$
\frac{E}{a}=\frac{2 \pi \sigma_{m}}{\lambda} \text { or } \sigma_{m}=\frac{E \lambda}{2 \pi a}
$$

For an 'order-of-magnitude' estimate, we will consider $\lambda / 2$ to be approximately equal to $a$. Hence, from (6) we obtain

$$
\sigma_{m}=\frac{E}{3}
$$

Alternatively, if we assume that the work done to create unit area of surface

[i.e., to separate the atomic bonds acting across a unit area of the solid to the point where the bonds are 'broken', or no longer attract each other. This is effectively to separate them to infinite spacing]

reappears entirely as the 'surface energy' $2 \gamma$, where $\gamma$ is the specific energy for each of the two (upper and lower) surfaces created, then we avoid the necessity of assigning a value to $\gamma$.

Noting that the work done per unit area of new surface $(2 \gamma)$ equals the shaded area in Figure 2, which we will assume to be roughly twice the area under the half-sine wave, we may then write

$$
\int_{o}^{\frac{\lambda}{2}} \sigma_{m} \sin \frac{2 \pi x}{\lambda} \cdot d x=\gamma \quad \text { or } \quad \frac{\lambda \sigma_{m}}{\pi}=\gamma
$$

Substituting for $\gamma$ from (6), we obtain

$$
\sigma_{m}=\sqrt{\frac{E \gamma}{2 a}}
$$

The values for the theoretical cohesive strength indicated by (7) and (9) are orders of magnitude larger than the observed tensile strengths of most solids. For granite, for example, the typical elastic modulus (E) in tension may be of the order of $5 \times 10^{6} \mathrm{lb}$. per sq. in.; according to (7), the cohesive strength should then be of the order of $2 \times 10^{6} \mathrm{lb}$. per sq. in. A tensile strength of $2 \times 10^{3} \mathrm{lb}$. per sq. 
in., or three orders of magnitude smaller, is closer to the value usually observed. Similar discrepancies, although not as great, exist for other materials.

The hypothesis presented by Griffith in 1921 was an attempt to explain the discrepancies. It will be discussed in some detail below. Before leaving the topic of atomic interaction, however, several points of interest should be noted.

1. A solid can only be ruptured by exceeding the cohesive strength. This requires "stretching" of the inter-atomic bonds, either by direct extension or by shearing. Tension and shear are thus the two basic modes of causing rupture. There is no fundamental compression mechanism of rupture.

2. Rupture of a solid occurs when all bonds have been broken across (as a minimum) a continuous plane of separation traversing the solid. To 'break' a bond, it is necessary to separate the atoms to such a spacing (effectively to 'infinity' on an inter-atomic scale) that the atoms no longer attract each other. Each atom forms a new (surface) equilibrium with its neighbors in the absence of the previously unbroken bond. If the rupturing force is released at any value of spacing less than that necessary to break down inter-atomic attraction, even though the extension be beyond that corresponding to that at the cohesive strength, the atoms will attract each other back to the equilibrium spacing. In other words, the complete energy of separation - the total area under the extension portion of the inter-atomic force-spacing curve (shaded in Figure 2) must be supplied before rupture will occur.

In short, rupture involves two conditions. Both are necessary for rupture to occur but, together, they are also sufficient to ensure rupture. The two are:

(1) a 'stress' condition (The inter-atomic cohesive stress must be exceeded.); and

(2) an energy condition. (The energy necessary to form two distinct surfaces through the solid must be supplied.)

\subsection{GRIFFITH THEORY OF RUPTURE}

Griffith recognized the need to satisfy the two conditions for fracture. He advanced the hypothesis that the average applied stress did in fact produce stresses to the cohesive-strength value because of intense stress concentrations produced at the tips of the sub-microscopic micro-cracks. He then demonstrated that, once a certain stress level had been reached, the supply of energy necessary to produce rupture would indeed become available. Although Griffith limited his analysis to an explanation of the strength of brittle solids, it will be seen later that the general principles upon which his Theory is based are applicable to a variety of practical situations. 
$\sigma$

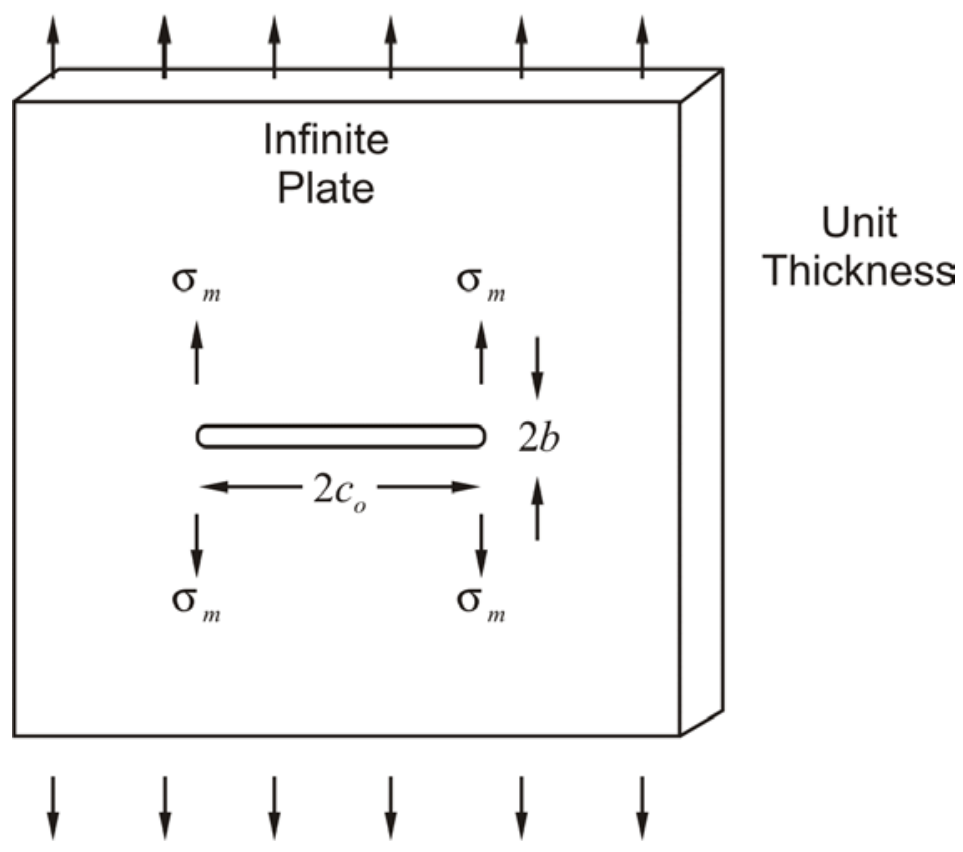

Figure 3 Plate model analyzed by Griffith

Griffith considered the conditions necessary for rupture of a thin, linearly elastic, isotropic, infinite plate loaded in plane stress by a 'dead-weight' tension, $\sigma$ (i.e., the tension did not change with displacement of the boundary), into which was introduced a single thin slit, or 'flaw', of length $2 c$, and having a radius of curvature $\rho$ at each tip. The stress, $\sigma_{m}$, developed at the tip of the crack (considered as an ellipse of major axis $2 c$, minor axis $2 b$ ) due to the applied stress $\sigma$ is given by the expression

$$
\sigma_{m}=\sigma_{o}\left(1+\frac{2 c}{b}\right)
$$

or, for sharp cracks,

$$
\sigma_{m} \cong \sigma_{o} \sqrt{\frac{c}{\rho}}
$$

Thus, provided the ratio $c / b$ or, equivalently $\sqrt{c / \rho}$, is very large (i.e., the cracks are very narrow and considered as degenerate ellipses), the required stress, $\sigma_{m}$, equal to the cohesive strength, may be achieved with only moderate applied stress, $\sigma$.

To establish the energy condition necessary for the cracks to start to spread (i.e., for rupture to begin), Griffith invoked the Theorem of Minimum Potential Energy, which may be stated as 
The stable equilibrium state of a system is that for which the potential energy of the system is a minimum

For the particular application of this theorem to rupture, Griffith added the statement

[T] he equilibrium position, if equilibrium is possible, must be one in which rupture of the solid has occurred, if the system can pass from the unbroken to the broken condition by a process involving a continuous decrease of potential energy.

The process of passing "from the unbroken to the broken condition" occurs by the progressive lengthening of the crack across the plate. Therefore, in order to proceed with the mathematical formulation of the energy criterion for rupture, we must consider the energy changes that occur when the crack lengthens. We will do this by first considering the energy change produced by introducing a crack into the plate, and then examining the effect of changing the crack length.

There are three parts of the system which contribute to the energy changes due to crack extension:

(1) potential energy of the applied forces $(W)$;

(2) strain energy of the loaded plate $(U)$; and

(3) surface energy of the crack surfaces $(S)$.

Other energies in the system (e.g., the surface energy of the faces and outer (infinite) boundary of the plate) are assumed not to change with crack extension and therefore can be neglected. We will consider the three energies in turn.

\subsection{Potential Energy of Applied Forces $(W)$}

It may be shown (Love 1927) that, when a linearly elastic body is deformed by constant forces applied at the outer boundary, the potential energy of these forces is reduced by an amount $(\Delta W)$ equal to twice the increase in strain energy $(\Delta U)$ of the body produced by the deformation. ${ }^{3}$ Thus,

${ }^{3}$ An elementary example of this is the energy change that occurs when an elastic solid is loaded in uniaxial tension by a constant force $\mathrm{F}$. The loss in potential energy $(\Delta \mathrm{W})$ of the applied force $\mathrm{F}$ due to the elastic deformation $\mathrm{u}$ is $\mathrm{Fu}$. [See Fig. a1]. The gain in strain energy $(\Delta \mathrm{U})$, equal to the area under the linear elastic force-deformation curve, is $1 / 2 \mathrm{Fu}$. Thus,

$$
\Delta W=-2 \Delta U
$$

Figure al Loss in Potential Energy ( $\triangle P$ ) and Gain in Strain Energy ( $\Delta U)$ of a Solid Loaded By a Constant Force

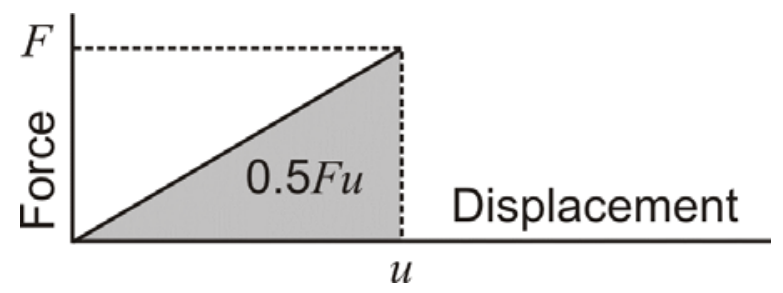




$$
\Delta W=2 \Delta U
$$

\subsection{Strain Energy of the Loaded Plate}

Griffith demonstrated that the strain energy of the infinite plate increased by an amount $\left(\pi c^{2} \sigma^{2} / E\right)$, where $E$ is the elastic modulus of the plate material by introduction of a crack, length $2 c$. This result was confirmed subsequently by Sneddon (1946) and by Irwin (1954)

$$
\Delta U=\frac{\pi c^{2} \sigma^{2}}{E}
$$

\subsection{Surface Energy of the Crack Surfaces}

If we designate the specific surface energy as $\gamma$, then, as the crack is of length $2 c$, and of unit thickness, the total increase in surface introduced is

$$
\Delta S=2 \cdot 2 c \cdot \gamma=4 c \gamma
$$

\subsection{Change in Potential Energy of the System ( $\triangle P$ )}

The total change in potential energy of the system $(\Delta P)$ produced by introduction of the crack may now be calculated. Thus,

$$
\Delta P=\Delta W+\Delta U+\Delta S
$$

Substituting from equation (11) we obtain

$$
\Delta P=\Delta S-\Delta U
$$

Substituting from equations (12) and (13), we find

$$
\Delta P=4 c \gamma-\frac{\pi c^{2} \sigma^{2}}{E}
$$

This relationship is plotted in Figure 4 for various crack lengths $(2 c)$ and two stress levels, $\sigma_{a}, \sigma_{b}$, with $\sigma_{b}$ a greater tension than $\sigma_{a}$.

\footnotetext{
${ }^{4}$ See the appendix.
} 


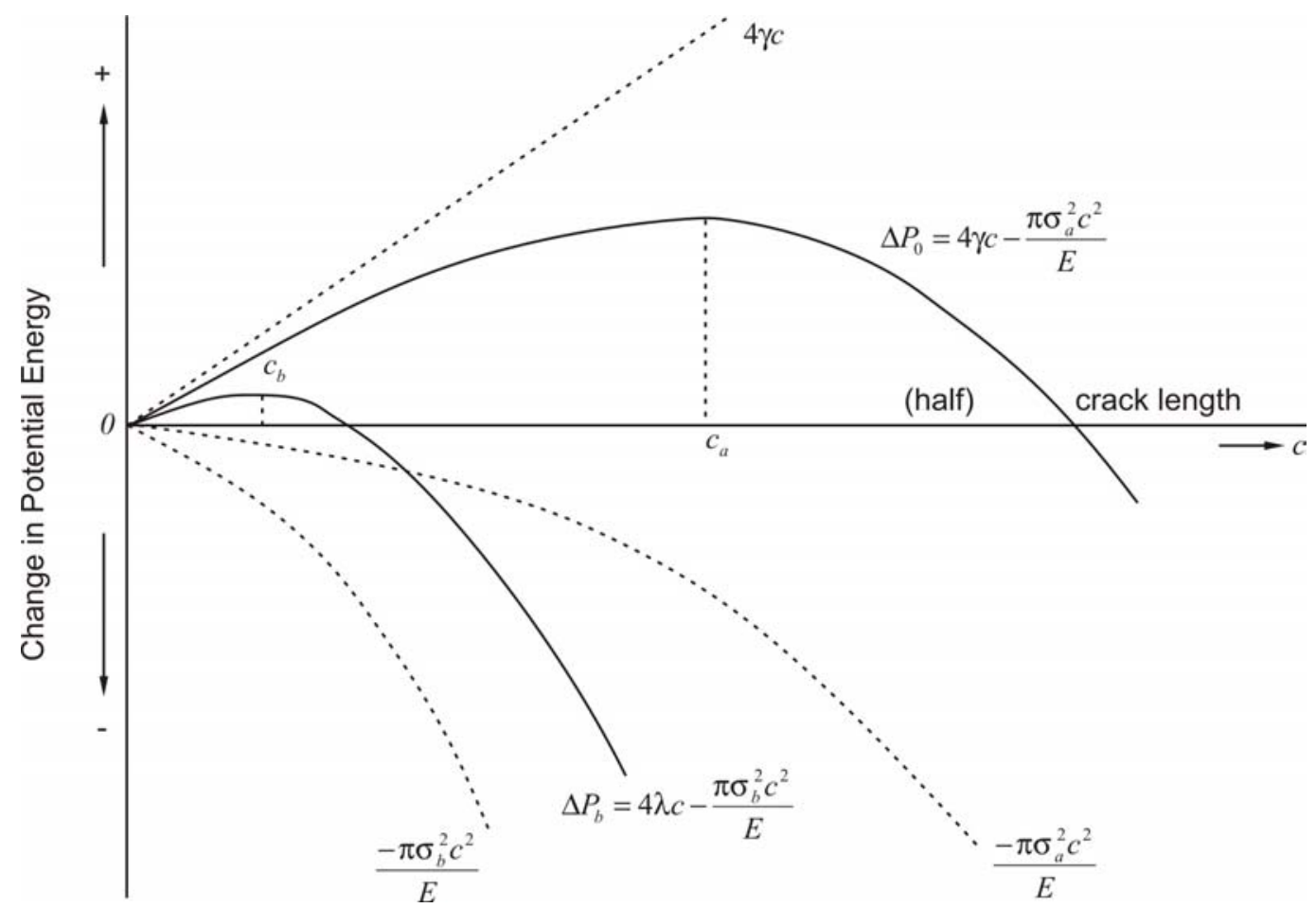

Figure 4 Change in potential energy (AP) of the plate-load system shown in Figure 3 due to the introduction of a crack of variable length $2 c$ Ior, equivalently, variation in $\triangle P$ with 'extension' of a crack under constant load]. N.B. The crack would actually 'extend' only on the right-hand (instability) side of $\triangle P$ maximum.

According to Griffith's energy instability hypothesis of crack extension, cracks of length less than $2 c_{a}$ would not extend at an applied stress level $\sigma_{a}$, as crack extension would require an increase $(\Delta P)$ in the potential energy of the system. The same is true for cracks less than $2 c_{b}$ in length at an applied stress $\sigma_{b}$. Conversely, introduction of a crack longer than $2 c_{a}$ or $2 c_{b}$ would immediately result in crack extension, at stress levels $\sigma_{a}$ and $\sigma_{b}$, respectively, since $\partial(\Delta P) / \partial \leq 0$ for these lengths.

The Griffith energy criterion for tensile rupture is thus satisfied whenever $(\partial / \partial c)(\Delta P) \leq 0$, and rupture will begin when

$$
\frac{\partial(\Delta P)}{\partial c}=0
$$

Applying this criterion to (16), we find the tensile stress $\left(\sigma_{g}\right)$ at which rupture begins. Thus, 


$$
\begin{aligned}
& 4 \gamma-\frac{2 \pi c \sigma_{g}^{2}}{E}=0 \quad \ldots \ldots \text { (a) } \\
& \text { or } \\
& \sigma_{g}=\sqrt{\frac{2 E \gamma}{\pi c}} \quad \ldots \ldots \text { (b) }
\end{aligned}
$$

Thus, according to the Griffith criterion, $\sigma_{g}$ is the tensile strength of a plate loaded in uniaxial (plane stress) tension.

Analysis of the corresponding plane-strain problem reveals that $E$ in (18) is replaced by $E /\left(1-v^{2}\right)$, where $v$ is Poisson's ratio for the material. It has also been shown (Sack 1946) that, when the line crack is replaced by a 'penny-shaped' crack in a solid, the criterion is modified such that $2 / \pi$ in (18) is replaced by $\pi / 4\left(1-v^{2}\right)$. In all of these cases, the numerical factors associated with $\sqrt{E \gamma / c_{o}}$ are of similar magnitude. This indicates that the geometry of the crack is probably not very influential on the tensile strength.

There are several points that should be noted concerning the Griffith tensile strength $\left(\sigma_{g}\right)$ as represented by (18).

1. There is no fundamental significance to the value $\sigma_{g}$. It is not the tensile strength of the plate material, but, rather, the stress at which spontaneous extension of the crack $2 c$ will occur in the uniaxially loaded plate of Figure 3 . The fundamental criterion for rupture is that given by (17) - i.e., the onset of energy instability. As will be seen later, the stress at which (17) is satisfied may differ appreciably for different loading systems and 'specimen' geometries.

2. The appearance of the length dimension $\left(c_{o}\right)$ in (17) is a consequence of the fact that the change in energy stored in the system [second term in (16)] is proportional to the volume of the solid affected by the crack whereas energy absorbed by the system depends on the area of the crack. Any linear, elastic, instability criterion will result in a rupture condition of the general form

$$
\sigma_{t}^{2} d=\text { const. }
$$

where $\sigma_{t}$ is the tensile strength of the solid, and

$d$ is a length that characterizes the dimensions of those critical 'flaws' in the solid responsible for the onset of tensile rupture.

The value of the constant in (19) will depend on the geometry of the flaws and the manner in which energy is absorbed during flaw growth. 


\subsection{INFLUENCE OF STIFFNESS OF APPLIED LOAD ON THE GRIFFITH CRITERION}

In the above analysis, it was assumed that the plate was loaded by a perfectly soft system - i.e., the tension forces applied at the boundary were constant independent of displacement of the boundary. This was the situation assumed by Griffith. It may readily be shown, however, that the tensile rupture criterion is not affected by the load-deformation (or 'stiffness') characteristics of the applied load.

This is most conveniently done by considering the force and displacement changes that will occur, simultaneously, at the plate boundary when the crack is introduced. We will consider the plate loaded to a force $F$ through a spring attached to a (rigid) end grip, as shown in Figure 5.

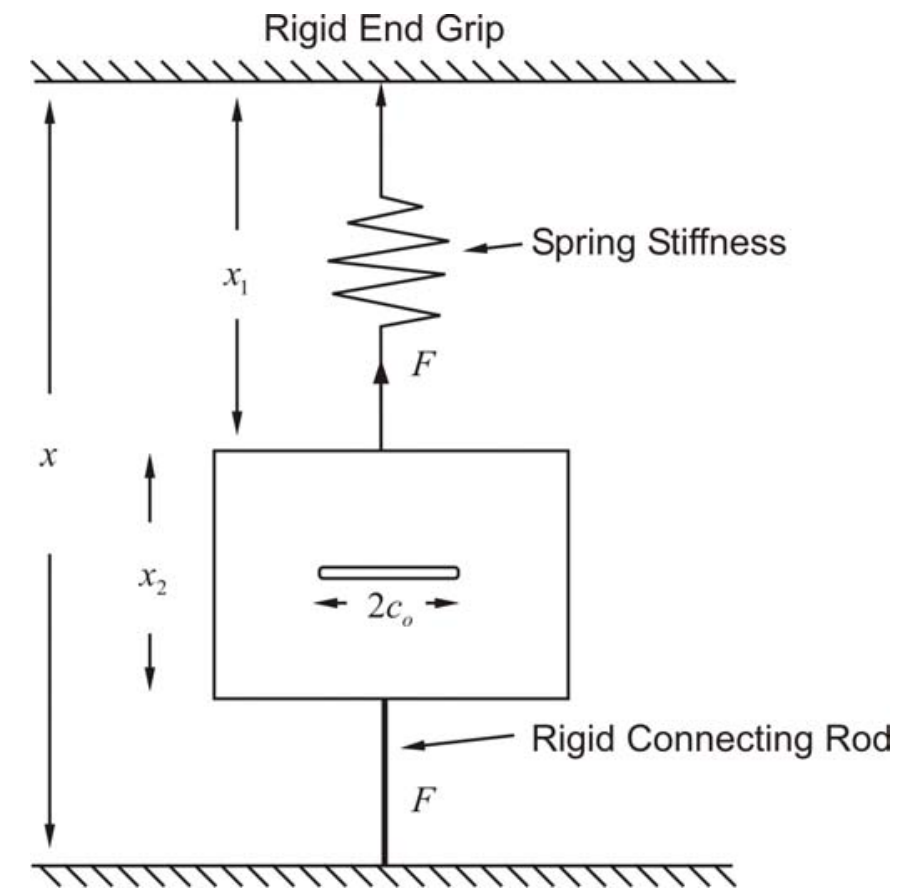

Figure 5 Griffith plate stretched through a non-rigid applied load

The strain energy $(V)$ stored in the system (i.e., plate and spring) at the force level $F$ is

$$
V=\int_{o}^{F} x \cdot d F=\frac{[M(K)+M(c)] F^{2}}{2}
$$

where $M(K)$ is the (constant) elastic compliance of the applied load (i.e., the reciprocal of the spring stiffness $K$ ) (Thus, $x_{1}=M(K) F_{x_{1}}$, where $x_{1}$ is the spring extension at load $F_{x_{1}}$ ), and $M(c)$ is the (variable) elastic compliance of the specimen. $(M(c)$ will increase with crack extension $\left(x_{2}=M(c) F\right)$. 
The differential $d V$ of the elastic energy when both $F$ and $c$ [or, equivalently, $M(c)$ ] change simultaneously is

$$
d V=\frac{F^{2}}{2} d[M(c)]+[M(K)+M(c)] \cdot F d F
$$

As the crack lengthens (and, hence, $x_{2}$ changes), the total extension $(x)$ between the rigid end grips remains constant

$$
x=x_{1}+x_{2}=\text { constant }
$$

or

$$
x=[M(K)+M(c)] \cdot F=\text { constant }
$$

Therefore,

$$
d x=[M(K)+M(c)] d f+F . d[M(c)]=0
$$

or

$$
[M(K)+M(c)] d f=-F . d[M(c) 0]
$$

Substitution of (23) into (21) yields

$$
d V=\frac{-F^{2}}{2} \cdot d[M(c)]
$$

That is, the change in strain energy of the system $(d V)$ is independent of the compliance $[M(K)]$ or the stiffness of the applied load.

Note that $d V$ is equal to the sum $(\Delta U+\Delta W)$ in the earlier derivation of the Griffith criterion.

It is important to recognize that, so far, we have considered the onset, or 'initiation', of rupture. Stiffness of the loading system can play a part in fracture propagation, as will be shown below. We have established the important point that the tensile strength of a solid that behaves as a Griffith material (i.e., a cracked plate) should not depend on the particular direct tensile testing system used.

\subsection{STRESS-STRAIN BEHAVIOR OF A GRIFFITH MATERIAL IN TENSION}

It is useful to consider the macroscopic "stress-strain" behavior of the Griffith plate system loaded in tension [see Figure 2]. The analysis below follows that presented by Berry (1961). 
The Griffith plate is assumed to be of unit thickness and large cross-sectional area A.

The total strain energy of the plate before introduction of the crack $=\frac{A \sigma^{2}}{2 E}$.

Increase of strain energy of the plate due to introduction of a crack, length $2 c$,

$$
\frac{\pi c^{2} \sigma^{2}}{E}
$$

$\therefore$ Strain energy of the cracked plate $=\frac{\sigma^{2}}{2 E}\left[A+2 \pi c^{2}\right]$.

If we define an average elastic modulus $E^{\prime}$ of the cracked plate such that

$$
\frac{\sigma^{2}}{2 E}\left[A+2 \pi c^{2}\right]=\frac{\sigma^{2} A}{2 E^{\prime}}
$$

we have

$$
E^{\prime}=\frac{A E}{A+2 \pi c^{2}}+\frac{E}{1+\frac{2 \pi c^{2}}{A}}
$$

From (18) we have

$$
\sigma^{2} g=\frac{2 E \gamma}{\pi c}
$$

However, for a linearly elastic material

$$
\sigma_{g}=E^{\prime} \varepsilon_{g}
$$

where $\varepsilon_{g}$ is the average $^{5}$ axial strain in the plate at rupture.

Substituting in (26) for $\sigma_{g}$ from 18(a), and for $E^{\prime}$ from (25), we obtain

$$
\varepsilon_{g}=\frac{\sigma_{g}}{E}+\frac{8 E \gamma^{2}}{A \pi \sigma_{g}{ }^{3}}
$$

(27) is the locus in stress-strain space of the Griffith criterion for rupture in direct tension. See Figure (6).

\footnotetext{
${ }^{5}$ Obviously, the strain will not be uniform in the vicinity of the crack
} 


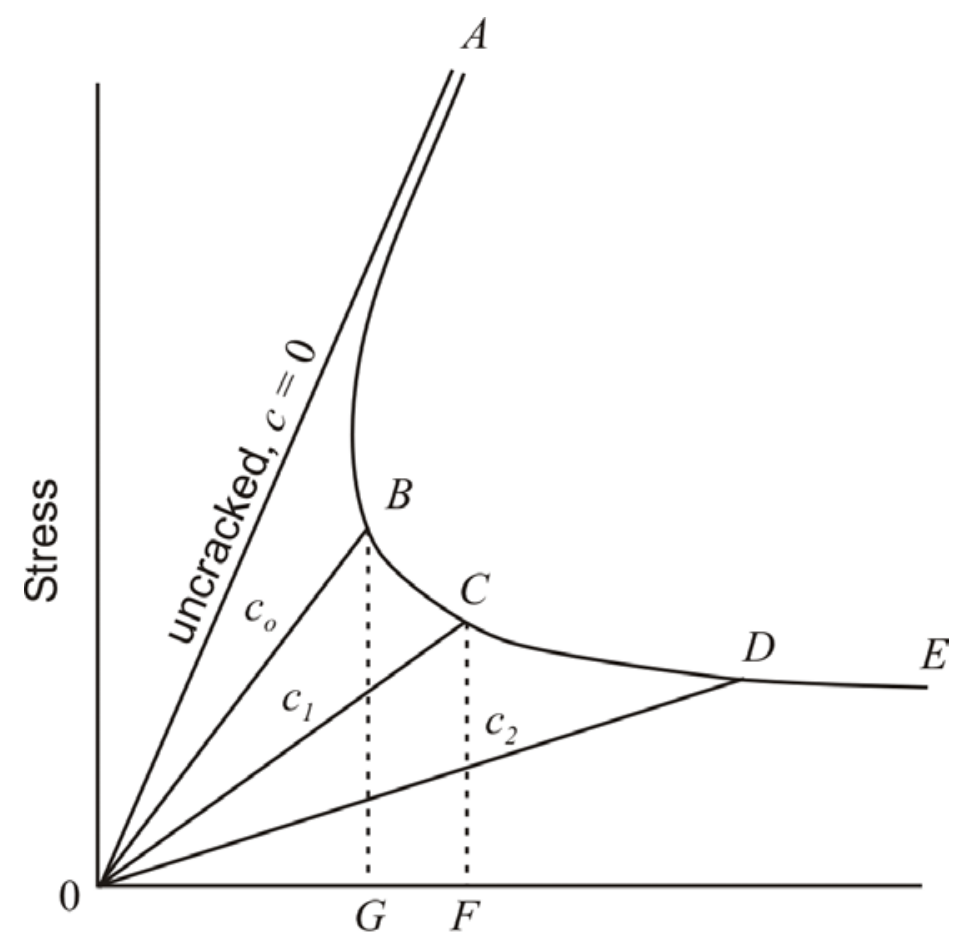

Strain

Figure 6 Locus of the Griffith criterion for rupture in direct tension

It is seen that the locus is asymptotic to the slope $\tan ^{-1} E$, where $E$ is the modulus of elasticity of the uncracked plate, for which, according to Griffith, the strength would equal the theoretical cohesive strength. For a plate with an initial crack of length $2 c$, the loading path would follow OB. At B, the crack would start to lengthen, and the overall plate would 'strain' accordingly. If the applied load were reduced with crack extension so as to follow the locus BCDE, the crack would be slowly extended to traverse the plate - i.e., the Griffith criterion $\partial P / \partial c=0$ is continuously just satisfied, with no excess energy to allow onset of the rapid instability condition $\partial P / \partial c<0$. At loading condition $\mathrm{B}$, the plate contains a crack length $2 c$ about to extend, and strain energy proportional to the area OBF. At $\mathrm{C}$, the crack has lengthened to $2 c_{1}$, and the plate contains strain energy proportional to the area OCG. As the energy input to the plate in extending the crack from $2 c_{0}$ to $2 c_{1}$ (i.e., from $\mathrm{B}$ to $\mathrm{C}$ ) is proportional to the area $\mathrm{BCGF}$, it follows that the area $\mathrm{OBC}$ is proportional to the increase in surface energy, $4 \gamma\left(c_{1}-c_{0}\right)$, of the crack. Similarly, area OBD is proportional to the new surface energy, $4 \gamma\left(c_{2}-c_{0}\right)$. It is seen that the total surface energy of a crack is proportional to the area enclosed by the asymptote OA, the locus, and the slope representing the crack length. 


\subsection{INFLUENCE OF STIFFNESS OF APPLIED LOAD ON CRACK EXTENSION}

It has been shown that the stiffness of the load application system does not influence the Griffith criterion for (the onset of) crack extension. The stiffness of the applied load does affect fracture propagation. Assume, for example, as did Griffith, that the applied load is independent of plate boundary displacement when crack extension occurs. If the initial crack length was $2 c_{O}$, then the load, on reaching B, in Figure 7, would follow the path BB'B". At an extension corresponding to $\mathrm{OG}$, then the energy supplied to the plate by the applied load during crack extension is proportional to the area $\mathrm{FBB}^{\prime} \mathrm{G}$; the energy required for slow crack extension to an average plate strain of OG is proportional to $\mathrm{FBCG}$; the excess energy, proportional to $\mathrm{BB}$ ' $\mathrm{C}$, will produce crack acceleration, the kinetic energy of the system increasing with crack extension, leading rapidly to rupture of the plate. If the plate is loaded through a system of stiffness $K$, as in Figure 5, then the applied load will decrease with crack extension.

Assume then that the applied load decreases along BHDJ. At a crack extension corresponding to average strain $\mathrm{OG}$, the excess energy is proportional to area $\mathrm{BHC}$, considerably less than for the 'dead-load' system, but also causing crack acceleration. With such a loading system, the crack would continue to accelerate as it extended, generating maximum kinetic energy at the crack length $2 c_{2}$ corresponding to the line OD. The crack would continue to grow as the applied load fell along DJ, but since the energy released by the load in region DJ is less than that required to satisfy the criterion for fracture, kinetic energy is abstracted from the system until the crack eventually stops at condition $\mathrm{J}$, at a length $2 c_{3}$ corresponding to the line $\mathrm{OE}$. At the point $\mathrm{J}$, the kinetic energy BCD has been transformed into the surface energy, DJE, necessary to establish the crack length $2 c_{3}$. For further crack propagation, the load must be raised along OJ to E, adding the strain energy JELK necessary to satisfy the fracture criterion. With such a system, the crack would initially propagate unstably, but would eventually come to rest before rupturing the plate. Rupture would involve successive re-loading of the plate.

With an applied load of high stiffness such as represented, for example, by the slope BM, any crack propagation immediately causes the applied load to fall to a value below that required for further propagation (i.e., points on the locus $\mathrm{BCDE}$ ). If the load drops to $\mathrm{M}$, for example, an amount of energy proportional to the area BCM must be added to the system before the crack will extend to the length $2 c_{I}$ (point $\mathrm{C}$ on the locus). In such a high stiffness system, in effect, the crack will propagate only if the necessary energy is added to the system by outward displacement of the rigid boundary under load. Thus, while the stiffness of the applied load does not influence initiation of fracturing in a Griffith material, it can have a marked effect on propagation of fracture. 


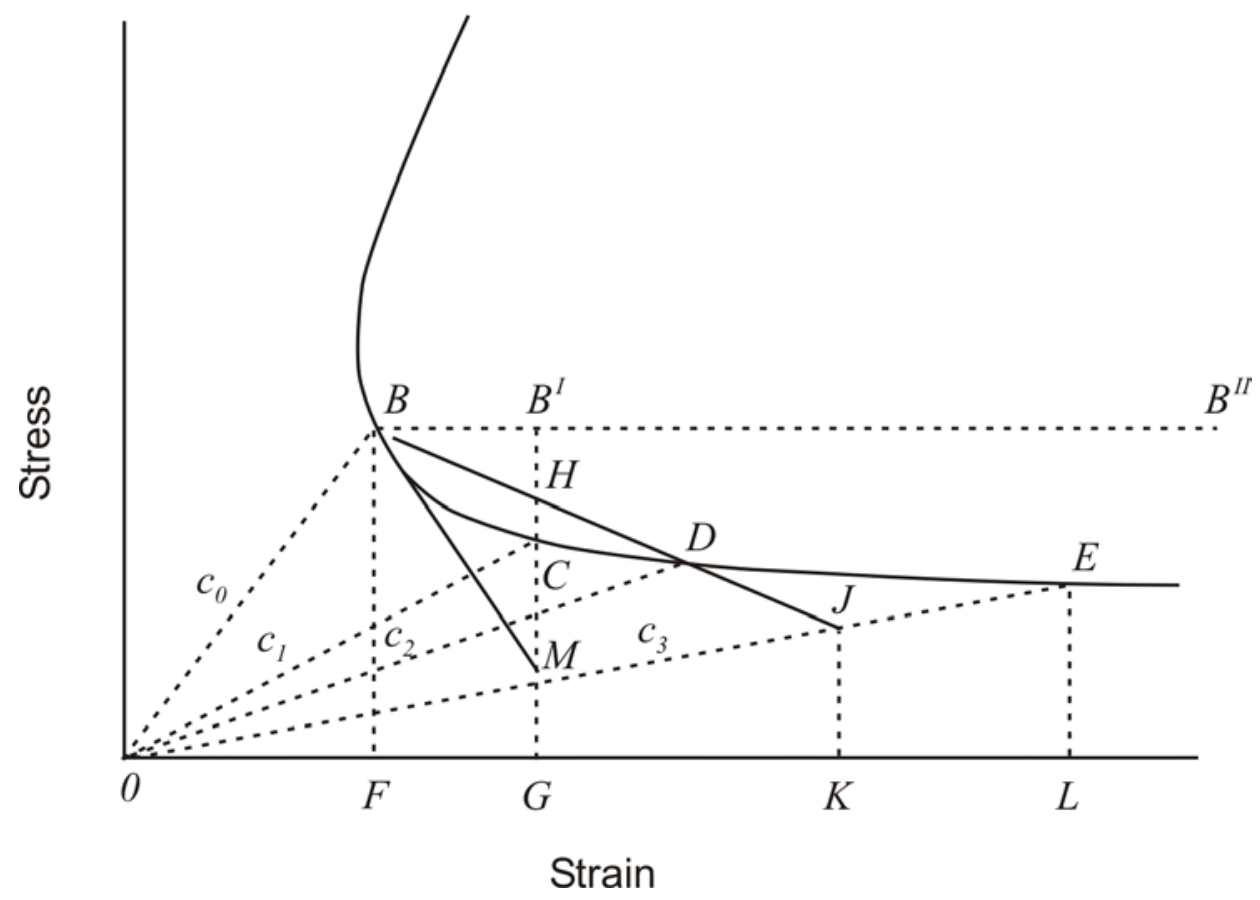

Figure 7 Influence of loading system on crack propagation

\subsection{VELOCITY OF FRACTURE PROPAGATION IN A GRIFFITH MATERIAL}

As indicated above, analysis of a propagating crack must involve consideration of the kinetic energy of the material associated with the advancing crack. The potential energy equation (16), modified for the case of a moving crack, becomes, after Mott (1948),

$$
\Delta P=4 c \gamma-\frac{\pi c^{2} \sigma^{2}}{E}+\frac{k \rho c^{2} v^{2} \sigma^{2}}{2 E^{2}}=\text { constant }
$$

The last term of (28) represents the kinetic energy associated with a crack (instantaneous) length $2 c$, moving with a velocity $v \cdot p$ is the density of the material. The constant $k$ is an (unspecified) numerical factor. Other parameters are as defined previously. Mott (1948) derived the kinetic energy term from dimensional considerations, as outlined in the appendix. For a given stress level, $\sigma, \Delta P$ (the increase in potential energy above the initial ground state of the uncracked plate) is now a constant, as it includes all the energy components of the conservative system.

Dulaney and Brace (1960) have derived the crack velocity $\left(\mathrm{v}_{O}\right)$ - (half) crack length (c) relationship as follows:

At the onset of fracture propagation, when the crack had the initial length $2 c_{O}$, the static Griffith criterion was satisfied. Thus, from (18), with $c=c_{0}$,

$$
4 \gamma=\frac{2 \pi c_{0} \sigma^{2}}{E}
$$


Substituting from (29) for the first term in (28), we obtain

$$
\Delta P=\frac{2 \pi c_{0} c \sigma^{2}}{E}-\frac{\pi \sigma^{2} c^{2}}{E}+\frac{k \rho c^{2} \mathrm{v}^{2} \sigma^{2}}{2 E^{2}}
$$

A boundary condition for the velocity is

$$
\mathrm{v}\left(=\frac{d c}{d t}\right)=0, \text { when } c=c_{0}
$$

Application of the boundary condition to (30) gives

$$
\Delta P=\frac{2 \pi \sigma^{2} c_{0}^{2}}{E}-\frac{\pi \sigma^{2} c_{0}^{2}}{E}+0=\frac{\pi \sigma^{2} c_{0}^{2}}{E}=\text { constant }
$$

Substituting (31) into (30), we obtain

$$
\frac{\pi \sigma^{2} c_{0}^{2}}{E}=\frac{2 \pi c_{0} c \sigma^{2}}{E}-\frac{\pi \sigma^{2} c^{2}}{E}+\frac{k \rho c^{2} v^{2} \sigma^{2}}{2 E^{2}}
$$

Re-arranging, collecting terms, etc., (32) yields the following expression for v:

$$
\begin{gathered}
\mathrm{v}=\sqrt{\frac{2 \pi E}{k \rho}}\left[1-\frac{c_{0}}{c}\right] \\
\mathrm{v}=\mathrm{v}_{m}\left[1-\frac{c_{0}}{c}\right]
\end{gathered}
$$

As the crack length $(c)$ becomes much larger than the initial length $\left(c_{o}\right)$, the velocity tends to the maximum value $\left(\mathrm{v}_{m}\right)$, where

$$
\mathrm{v}_{m}=\sqrt{\frac{2 \pi E}{k \rho}}
$$

In this case (34) becomes

$$
\mathrm{v}_{m}=0.38 \sqrt{\frac{E}{\rho}}
$$

Thus, a Griffith crack propagating across a plate, as shown in Figure 3, will attain a maximum velocity of the order of one-third of the velocity of sound, $(\sqrt{E / \rho})$, in the medium. 
Figure 8 shows the crack velocity as a function of crack half-length, as predicted by 33(a).

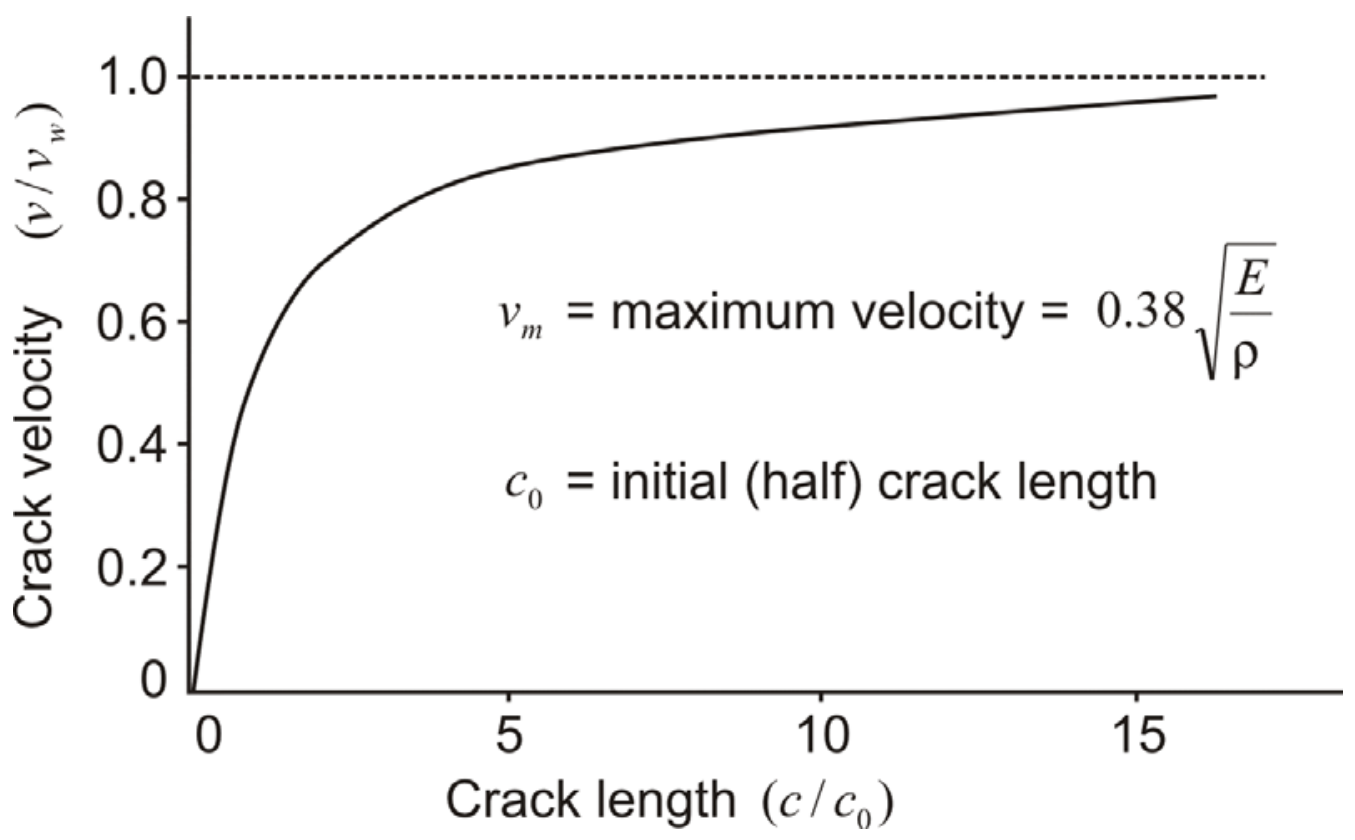

Figure 8 Crack velocity as a function of crack half-length

The crack velocity rapidly approaches a high value (e.g., $\mathrm{v} \cong 0.6 \mathrm{v}_{m}$ for $\left.c=2.5 c_{0}\right)$. For a material with a sonic velocity around $12,000 \mathrm{ft}$. per second, the velocity will reach a value of almost $3000 \mathrm{ft}$. per second when the crack has extended only 2.5 times its original length. At such velocities, the time interval between crack initiation and complete tensile rupture of a specimen of 3-4 inches in diameter would be of the order of 100 microseconds only.

Berry (1960) has also derived (33) for the Griffith crack. He points out $(1960,1961)$ that there is a fundamental inconsistency in the crack-velocity analysis as outlined above, in that the Griffith criterion 18(a), to (29), represents an (unstable) equilibrium condition. The crack velocity, in fact, will remain identically zero for all crack lengths if the applied stress is sufficient only to reach the equilibrium condition. In other words, it is incorrect to assume that the third term of (28) exists unless the Griffith stress is (infinitesimally) exceeded, so as to generate an excess of energy over that required for (unstable) static equilibrium. Berry demonstrates, however, that (33) is the correct limiting expression for the velocity, when the Griffith stress is infinitesimally exceeded. If the load is applied so that the Griffith stress is instantaneously exceeded to a greater degree, then the crack acceleration is somewhat greater - to the same limiting value, $\mathrm{v}_{m}$, of (35).

It will be shown later that there are important differences between the velocity behavior of the ideal Griffith material and that of many real materials. 


\subsection{MODIFICATION OF THE GRIFFITH CRITERION FOR REAL MATERIALS}

The original Griffith criterion considered the highly idealized situation in which a single, critically stressed, crack begins to extend and propagate throughout the solid. It is implicitly assumed that there are no other cracks in the material or, equivalently, that any other cracks remain elastic (i.e., do not propagate) and, hence, do not contribute to the incremental energy changes of the system.

This assumption does not hold for real materials, and it is necessary to modify the original criterion to obtain a more valid description of actual behavior. Real materials contain many 'flaws' and stress raisers that play the role of Griffith cracks (i.e., to raise the stress intensity sufficiently to overcome inter-atomic or intermolecular bonds and to serve as a source of potential energy instability). The onset of unstable crack extension at one location does not necessarily imply that the same crack will continuously extend to total rupture.

Consider, for example, the situation depicted in Figure 9, in which a major crack, AA, is extending under a mean applied tension $\sigma$ through a material containing a large number of smaller, initially non-propagating cracks. It may be shown from elastic theory that the highly stressed region ahead of the crack tip increases in extent as the main crack extends.

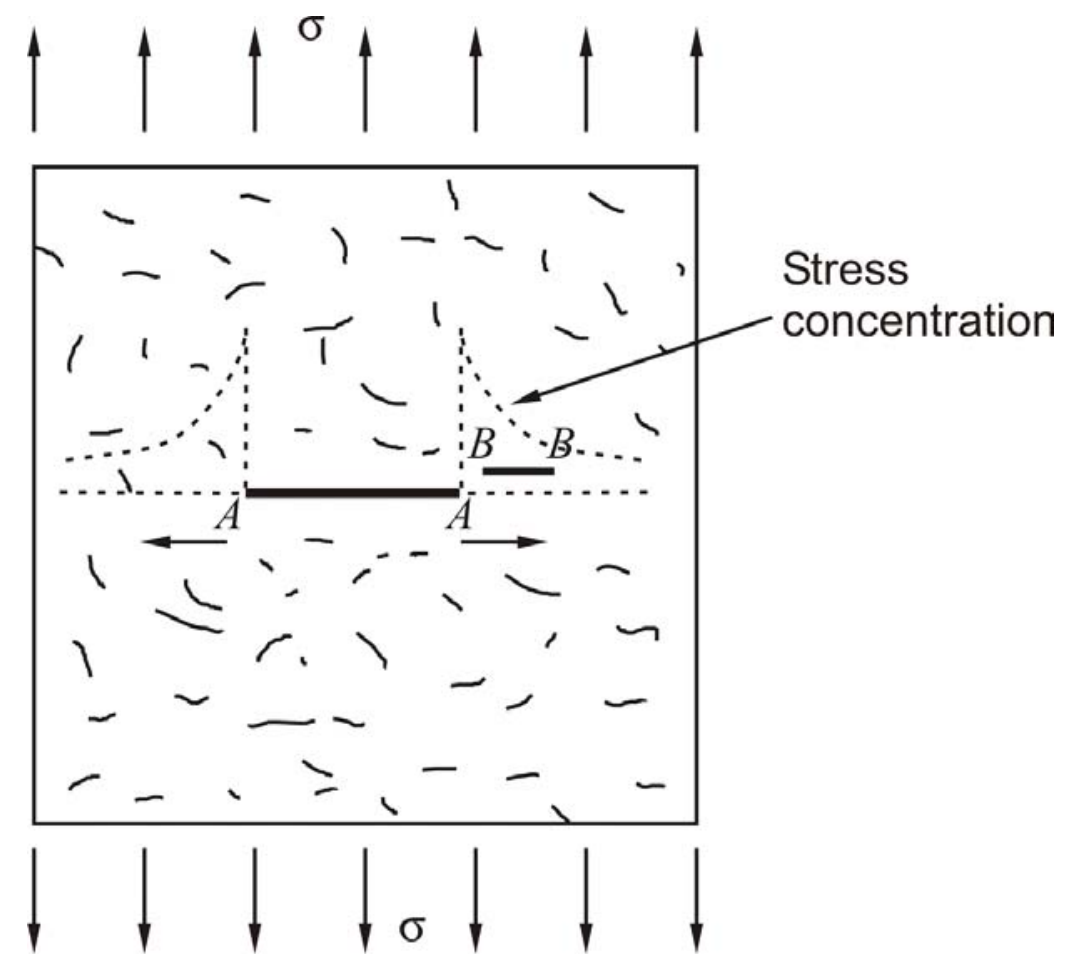

Figure 9 Crack propagation in an extensively pre-cracked material

Thus, small cracks in the path of the main crack are subjected to increasingly high stresses as it approaches. At a given instant, for example, a small crack BB may be subjected to a mean stress, $\bar{\sigma}_{B}$, high enough to start extension of the crack, both away from and toward the main crack. The small crack may be located off the axis of the main crack, resulting in a 'step' in the rupture path 
when the two intersect. In addition, there will be many such cracks ahead of the main crack, and their number will increase with growth of the overall rupture path. Each mini-crack instability contributes to the energy balance equation, affecting both the surface-energy-demand term and the strain-energy-release term.

Glücklich and Cohen (1967) have suggested that, in the plane stress case, the two terms are modified as follows:

$$
\begin{gathered}
\Delta S_{m c}=4 \gamma c+4 \gamma \sum_{i=1}^{n=s v} b_{i} \\
\Delta U_{m c}=\frac{\pi \sigma^{2} c^{2}}{E}+\frac{\pi \sigma^{2}}{E} \sum_{i=1}^{n=s v} b_{i}^{2}
\end{gathered}
$$

where $\Delta S_{m c}, \Delta U_{m c}$ are the changes in surface energy, and stored energy of the loaded (precracked) plate, respectively, for the multiple-crack-growth situation,
$b_{i}$
$n$
is the (typical) half-length of the small cracks that propagate,
$v$
is the number of the small cracks,
is the volume ahead of the main crack within which the stress is sufficient to cause propagation of the small cracks, and
$s=n / v \quad$ is the density of small cracks.

Other terms are as defined earlier for the simple single-crack Griffith analysis. [E, the overall modulus of elasticity of the plate, will have a value appropriate to that for an extensively cracked plate. It is assumed that this value does not change significantly due to cracking in the region ahead of the main crack.]

The increase in energy release is proportional to $\sum b_{n}{ }^{2}\left[\right.$ not to $\left.\left(\sum b_{n}\right)^{2}\right]$ - i.e., the sum of the energies released by growth of all the small cracks is much less than the energy released by a single long crack of the same total length. The increase in surface energy demand, being proportional to $\sum b_{n}$ is the same for the multitude of small cracks as for a single long crack of equivalent length. As the volume, $v$, over which minor cracking develops, increases with main crack length, the phenomenon of pre-cracking ahead of a main crack results in a rapidly increasing energy demand, while having relatively little effect on the energy released. The energy demand term may be represented approximately in the non-linear form

$$
\Delta U_{m c}=4 \sigma c^{\alpha(c)}
$$

where the exponent $\alpha$ increases progressively with main-crack growth, from the value $\alpha \cong 1$ at initiation of the main crack. Figure 10 outlines the energy changes for multiple cracking crackgrowth under a constant mean applied tension. Comparing Figure 10 with Figure 2, depending on the exponent $\alpha$, major instability may not immediately result from the start of main crack extension. At the stress level, $\sigma_{a}$, a crack of half-length $c_{a}$, will extend unstably to the half length $c_{a}$, beyond which it is no longer unstable and will quickly cease to propagate. If the higher mean stress, $\sigma_{b}$ is applied, then a crack would remain unstable to a greater half-length $\left(c_{b^{\prime}}\right)$. 


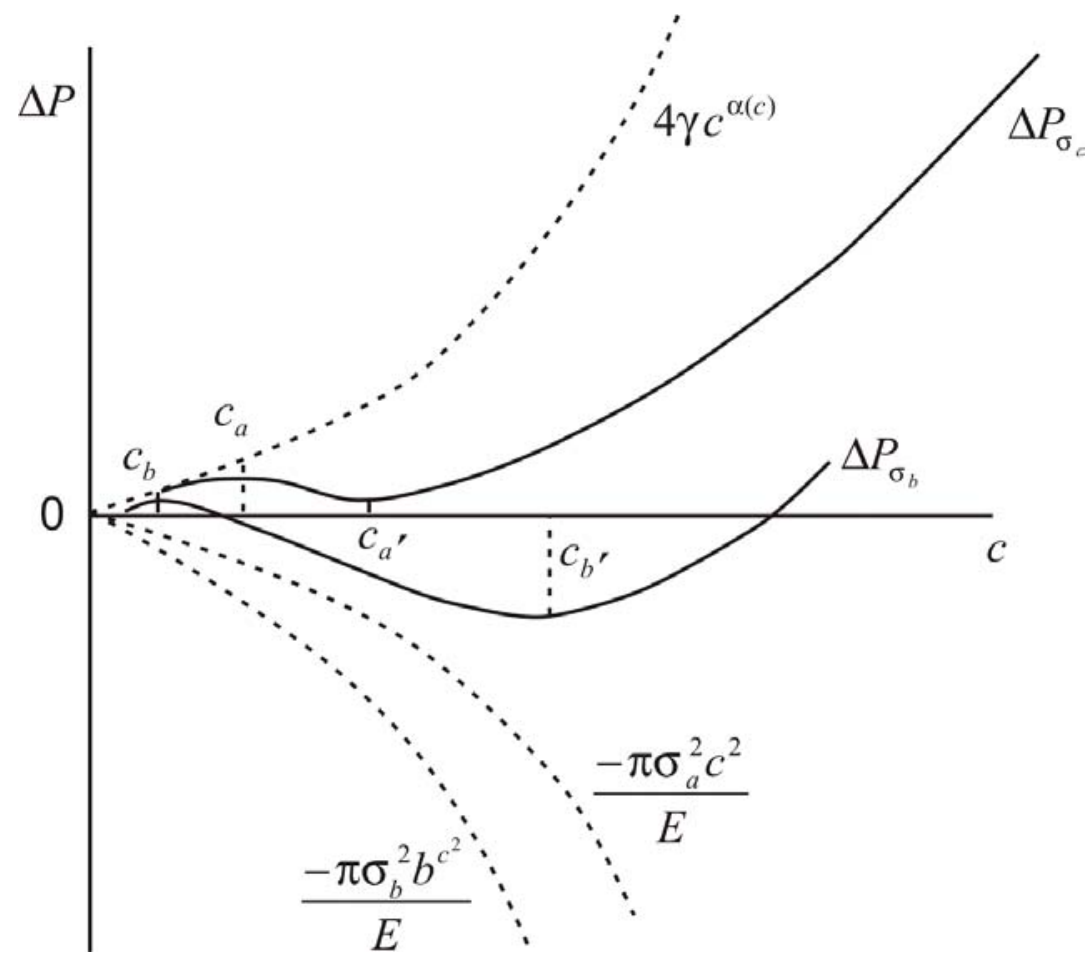

Figure 10 Change in potential energy of a pre-cracked Griffith plate model with growth of a crack, length $c$

Thus, to continue unstable crack extension beyond $c_{a}$, it would be necessary to increase the mean applied stress. A material that is extensively 'pre-cracked' (or, equivalently, that contains a high density of stress-raisers) thus can exhibit the phenomenon of 'stable crack-growth'. The solid does not rupture spontaneously as soon as a critical stress is reached; instead, the crack may grow slowly as a series of transient instabilities under increasing load.

The stable crack-growth model shown in Figure 10 predicts that the applied load must be increased continuously without limit for continued crack growth - i.e., no macroscopic instability will ever occur. In an infinitely large solid, this may be true; in reality, several effects may intervene to cause unstable rupture.

Thus, with a test specimen of finite length, as the crack approaches the outer edges, growth of the pre-cracking volume becomes limited, and the mean stress in the volume rises rapidly. This has the effect of placing an upper limit on the exponent $\alpha$ in (38) and causing a more rapid increase in the energy-release rate. Together, these two effects will produce a major instability.

It may be conjectured that the surface energy term, $\gamma$, could exhibit some form of 'rate-of-loading' dependence. Thus, as the applied load is increased, the amount of excess energy released during the transient instabilities may tend to increase. In turn, this tends to result in more rapid rate of crack extension during the instability. If the processes of energy absorption during generation of the new surfaces are such that the energy required is the lower the more rapidly created the surfaces, in effect 
this will reduce exponent $\alpha$. Beyond a critical size of main crack and a critical rate of applied-load increase, the exponent could fall to a value where major instability results.

The mechanisms of stable crack growth are not well understood and probably differ for different materials. Nevertheless, all involve the common requirement that the energy absorbed by the processes of crack extension increases more rapidly than the energy released by the same crack extension.

Figure 11 illustrates an alternative representation of the potential energy changes for the extending Griffith crack shown in Figure 4. Whereas Figure 4 represents (16), Figure 11 represents 18(a), the derivative with respect to crack length (c) of (16).

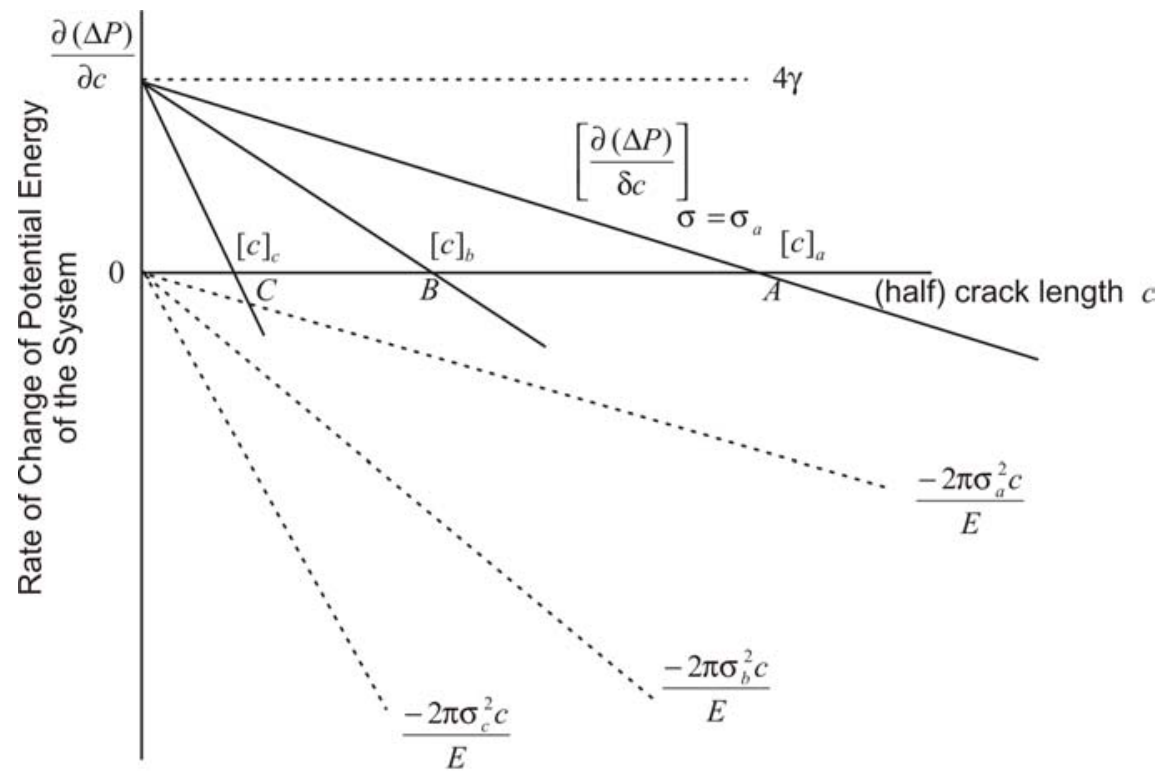

Increasing Stress Level, $\sigma_{c}>\sigma_{b}>\sigma_{a}$

Figure 11 Variation in the rate of change in potential energy $[\partial(\Delta P) / \partial c]$ of the plate-load system of Figure 3 with variation in crack length $[\partial(\Delta P) / \partial c]$

The point at which the net curve crosses the abscissa corresponds to the crack length at which instability occurs. The region above the abscissa corresponds to stable conditions, the region below to unstable conditions. Thus, at a constant mean-applied-stress of $\sigma_{b}$, all cracks equal to or greater than $2 c_{b}$ in length will extend unstably. To follow the Griffith crack locus shown in Figure 6 (i.e., to slowly extend a Griffith crack, or to constantly remain on the point of instability) is equivalent to changing the applied stress level such that the crack extension condition continuously follows the abscissa, $[\partial(\Delta P) / \partial c=0]$, in Figure 11 . 
For the stable crack growth situation shown in Figure 10, the zero slope straight line, $4 \gamma$, of Figure 11 , is changed to a line of continuously increasing slope, up to a (half) crack length, say, of $c_{d}$, at which the pre-cracked volume becomes limited, as shown in Figure 12. It is assumed, as in Figure 10 , that the strain energy terms are negligibly affected.

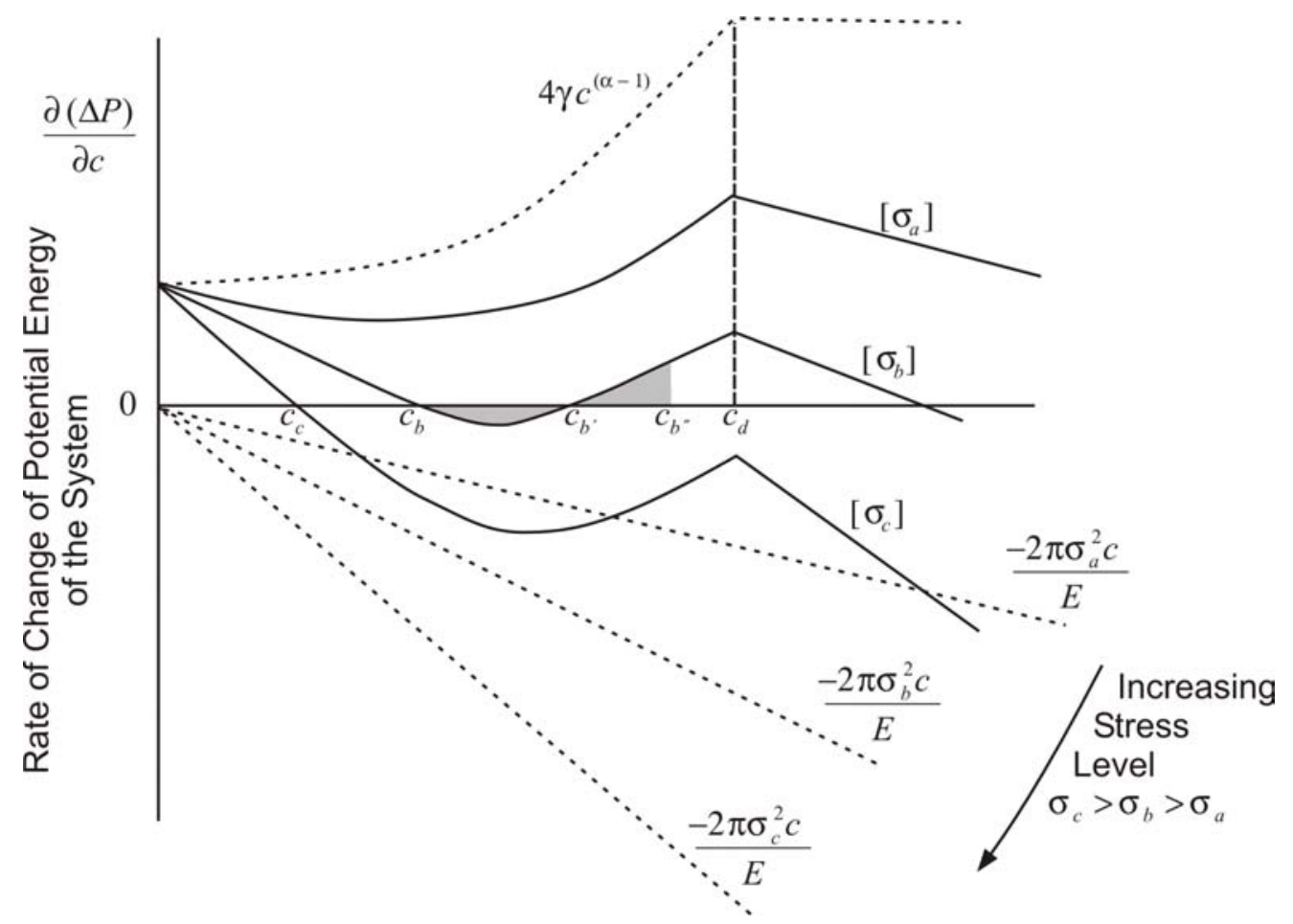

Figure 12 Variation in the rate of change in potential energy with variation in crack length for a pre-cracked plate system

In the case shown in Figure 12, at a stress level of $\sigma_{a}$, the system is stable for all crack lengths (i.e., the solid line marked $\left[\sigma_{a}\right]$ is positive everywhere); hence, no crack growth occurs. At the higher stress level, $\sigma_{b}$, (See solid line marked $\left[\sigma_{b}\right]$ ), a crack of (half) length $c_{b}$ would start to extend, accelerating to (half) length $c_{b^{\prime}}$ and continuing, at a decelerating rate, to (half) length $c_{b^{\prime \prime}}$. At this point, the crack would stop. [The excess energy released over the length range $\left(c_{b}-c_{b^{\prime}}\right)$ would be used to supply the energy deficiency over the range $\left(c_{b^{\prime}}-c_{b^{\prime \prime}}\right)$, i.e., the shaded areas above and below the abscissa $[\partial(\Delta P) / \partial c=0]$ are equal. $\}$ There is insufficient energy available to extend the crack further - the specimen does not break. At the still higher stress $\sigma_{c}$ (see solid line marked $\left[\sigma_{c}\right]$ ), the system is unstable for all (half) crack lengths greater than $c_{c}$. The specimen would rupture 'spontaneously' if it contained cracks of (half) length $c_{c}$ or greater. 


\subsection{INFLUENCE OF INHOMOGENEITIES ON FRACTURE PROPAGATION}

Most rocks consist of more than one mineral constituent, with grains of variable orientation and pores between the grains. Tensile rupture by crack propagation in rocks is consequently considerably more complex than even the pre-cracked model a crack may start at A in Figure 13, for example, and may traverse the specimen along a very irregular path.

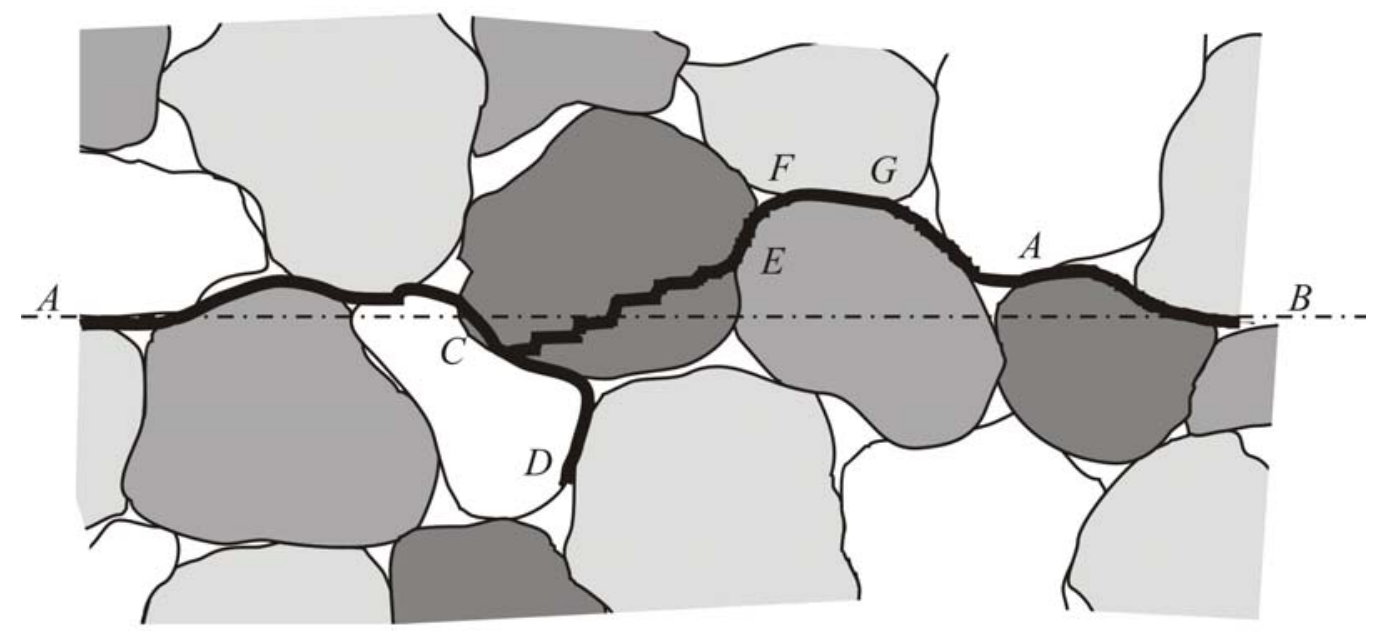

Figure 13 Irregular crack paths in rock loaded in tension

Propagation along the direct path $\mathrm{AB}$ would involve cleavage through grains of various orientations, requiring higher 'surface energy' than required to propagate the same projected length along a more tortuous path. At $\mathrm{C}$, for example, the crack may tend to follow a grain boundary, say to D. Further propagation along the boundary would require a higher stress than that required to restart the crack at $\mathrm{C}$, traversing the grain along $\mathrm{CE}$. A new crack may then start, say at $\mathrm{G}$, running toward $\mathrm{F}$, leaving the step EF, a pore space may be intersected, etc. In such a complicated fracture process, the term 'surface energy' tends to be an inadequate description for the multitude of energy-absorbing mechanisms that can develop as tensile rupture propagates through rock. 'Work of Fracture' $\left(\mathrm{W}_{\mathrm{F}}\right)$, one of the alternative terms used frequently, seems more appropriate. It may be defined as "the energy required to extend rupture by unit length along the mean plane of rupture" - $\mathrm{AB}$ in Figure 13.

The rate of variation of $\mathrm{W}_{\mathrm{F}}$ per unit advance in the direction $\mathrm{AB}$ may appear as shown by the solid line d...M in Figure 14.

The rupture path is assumed to have extended stably to the projected length $c_{d}$, at which point it encounters a pore space or pre-existing crack such that no energy is required to extend the length to $c_{e}$. With a constant stress or dead weight loading system, the rupture would accelerate quickly from $c_{d}$ to $c_{e}$, generating kinetic energy represented by the shaded area $d c_{d} c_{e} e$. [The constant appliedstress (energy-release) line is shown dotted.] Immediately beyond the pore space, the rupture encounters a 'hard' or 'strong' grain. Over this increment, $W_{F}$ is appreciably in excess (by the shaded area $e f g$ ) of that released by the constant stress system. The deficiency (efg) is abstracted from the kinetic energy of the rapidly advancing rupture - i.e., the rupture slows down. 


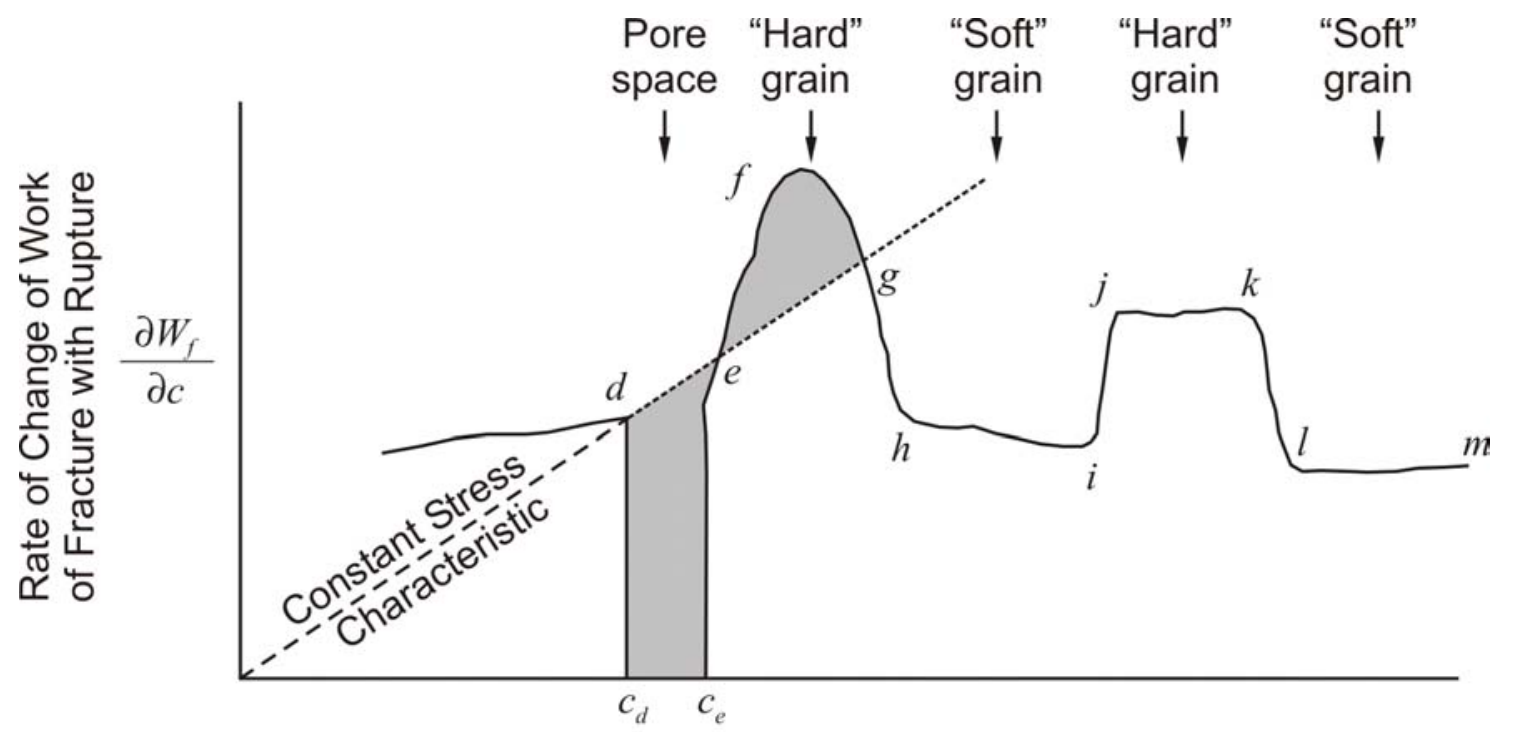

Projected Extent $(c)$ of Rupture in Direction $A B$

\section{Figure 14 Energy release - Work of Fracture: Interaction during tensile rupture of a rock specimen loaded by a constant stress system}

If the deficiency exceeds the total kinetic energy (i.e., if area $d c_{d} c_{e} e>$ area $e f g$ ), then the rupture will stop, and it will be necessary to add energy to the system - i.e., raise the applied stress level to further propagate the fracture. If the reverse is true, then the rupture will slow down prior to accelerating again, toward rapid disintegration over the relatively 'soft' (i.e., low $\mathrm{W}_{\mathrm{F}}$ ) regions ghiklm.

If the work of rupture is supplied through a perfectly rigid loading system, then, by definition, the applied load always will be exactly equal to that required for rupture propagation - i.e., the energy released by the loading system exactly balances the work of fracture at all stages of rupture. In Figure 14, the energy-release-rate curve everywhere overlies the work of the fracture curve. Rupture proceeds at precisely the applied displacement rate of the loading system.

Actual rupture of real systems generally falls between the above two extreme idealizations. Even where a specimen is loaded through rigid grips, for example, the unfractured portions of the specimen release stored energy when rupture is initiated. This can result in significant fracture propagation if, for any reason, $\mathrm{W}_{\mathrm{F}}$ tends to decrease after initiation.

The behavior of real systems is illustrated by Figure 15 


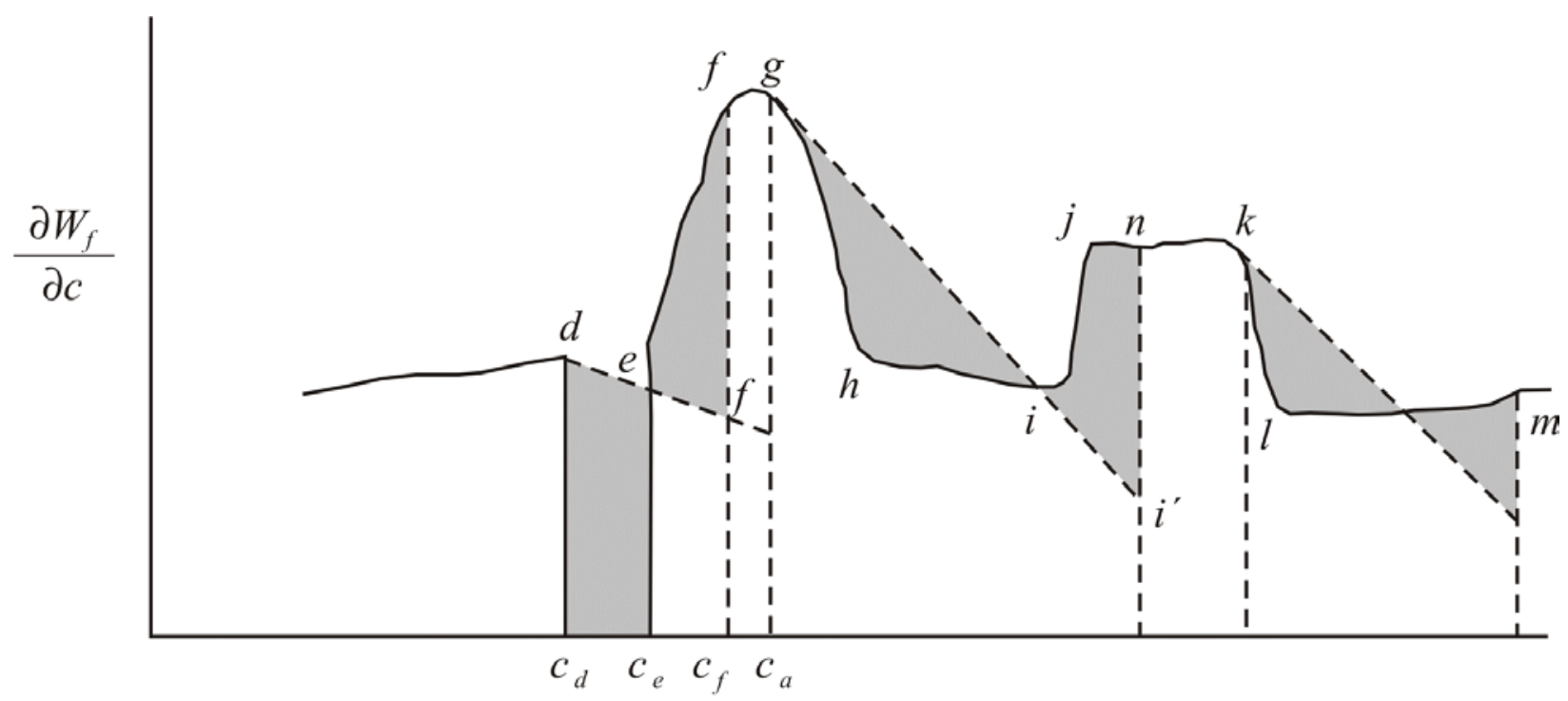

Projected Rupture Length $(c)$

Figure 15 “Energy Release-Work of Fracture" interaction during tensile rupture of a rock specimen under realistic loading conditions [same specimen as in Figure 14]

As with the dead-load system, the rupture encounters a pore-space or pre-existing crack at $d$. The excess energy release, shaded area $d c_{f} c_{e} e$ is now somewhat lower because the applied load decreases with fracture extension, due to the finite stiffness of the applied load. The fracture accelerates to a length $c_{e}$, then starts to decelerate, reaching a length $c_{f}$, at which the deficiency of energy release, the shaded area eff', balances the excess generated over the extension $c_{d}-c_{e}$. The applied force then is increased to further extend the fracture through the hard grain, from $c_{f}$ to $c_{g}$. At this point, the system again becomes temporarily unstable, developing kinetic energy equivalent to the shaded area ghi, as the applied load drops less rapidly with fracture extension than the rate of change in $\mathrm{W}_{\mathrm{F}}$. Again, the fracture decelerates and eventually halts, at length $c_{n}$, such that the area ghi equals area $i i^{\prime} n j$. The sequence is again repeated when the length $c_{k}$ is reached. Eventually (not shown in Figure 15), as the edges of the specimen are approached, a macroscopic instability ensues, and the specimen ruptures.

The excess energy released by a 'soft' loading system may be sufficient to propagate a fracture through 'hard' zones, for example, to the point where total disintegration may occur, without increase in the applied load. With a relatively stiff loading system, the corresponding excess energy may be sufficiently lower that the fracture is arrested at a shorter length. The applied load would then need to be further increased to produce final disintegration. Glücklich and Cohen (1967) suggest that this loading stiffness effect could be sufficient to cause significant differences between the 'strengths' of a given material measured in a soft and a stiff system. There is yet little evidence to indicate the importance of the effect in rock testing. 


\subsection{ROCK FRACTURE IN COMPRESSION}

Many of the practical problems of rock mechanics involve disintegration or structural collapse of the rock due to the application of compressive loads. As mentioned earlier, however, compressive disintegration results from the action of tension and shear forces generated within the loaded rock by the applied compression.

Griffith (1924) attempted to extend his theory of rupture to explain the observed strength of brittle materials in compression by assuming that tensions equal to the cohesive strength $\sigma_{\mathrm{m}}$ (Figure 1) were generated locally at the 'flaws' within the material. Accepting the Griffith hypothesis that the uniaxial tensile strength of a brittle solid is determined by flaws within the solid, then if, as in an isotropic material, the strength is the same for all directions through the solid, the flaws must be randomly distributed through it. In direct tension, the most critical orientation of a flaw (assumed to be representable as an elliptical crack) is normal to the applied tension, as this produced the greatest amplification, or 'concentration', of the applied stress, allowing the theoretical cohesive strength to be reached.

If the Griffith crack is located within a compressive stress field, localized tension around the crack is possible only:

(1) when the crack is oriented at an angle to the principal directions of applied stress; and

(2) when the applied stress field is not hydrostatic.

Using the analytical solution by Inglis (1913) for stresses around an elliptical crack in a uniformly loaded plate, Griffith examined the tensions generated around the crack tip. Assuming that the crack remained open in the compressive field, he noted that the magnitude of the tension changed both with position along the crack edge and with orientation (see Figure 16) of the crack axis to the direction of maximum applied compression $\left(\sigma_{1}\right)$. Specification of the required tension stress (i.e., the cohesive strength $\sigma_{m}$ ) for fracturing posed a fundamental problem, as both the real value of $\sigma_{m}$ and the actual shape of the 'flaws' were unknown. [In the original analysis of the tensile rupture, Griffith had, in effect, merely demonstrated that any value of $\sigma_{m}$ could be achieved with a realistic value of applied tension, provided the flaw (i.e., crack) was sharp enough. He did not specify any required dimensions or cohesive strengths.]

To overcome this difficulty, he assumed that the [inclined] critical flaw in the compression field was of the same [unknown] shape and size as the [normal] critical flaw in the direct tension field. For this case, the ratio between the maximum tension around the compression crack and that around the direct tension crack is independent of the crack shape. Assuming, then, that the same value of $\sigma_{m}$ must be achieved in both cases, he could express the condition for the onset of crack initiation in compression in terms of the tensile rupture criterion expressed by 10(a) and 10(b). Proceeding in this way, he derived the two-part condition for the onset of rupture as follows. 


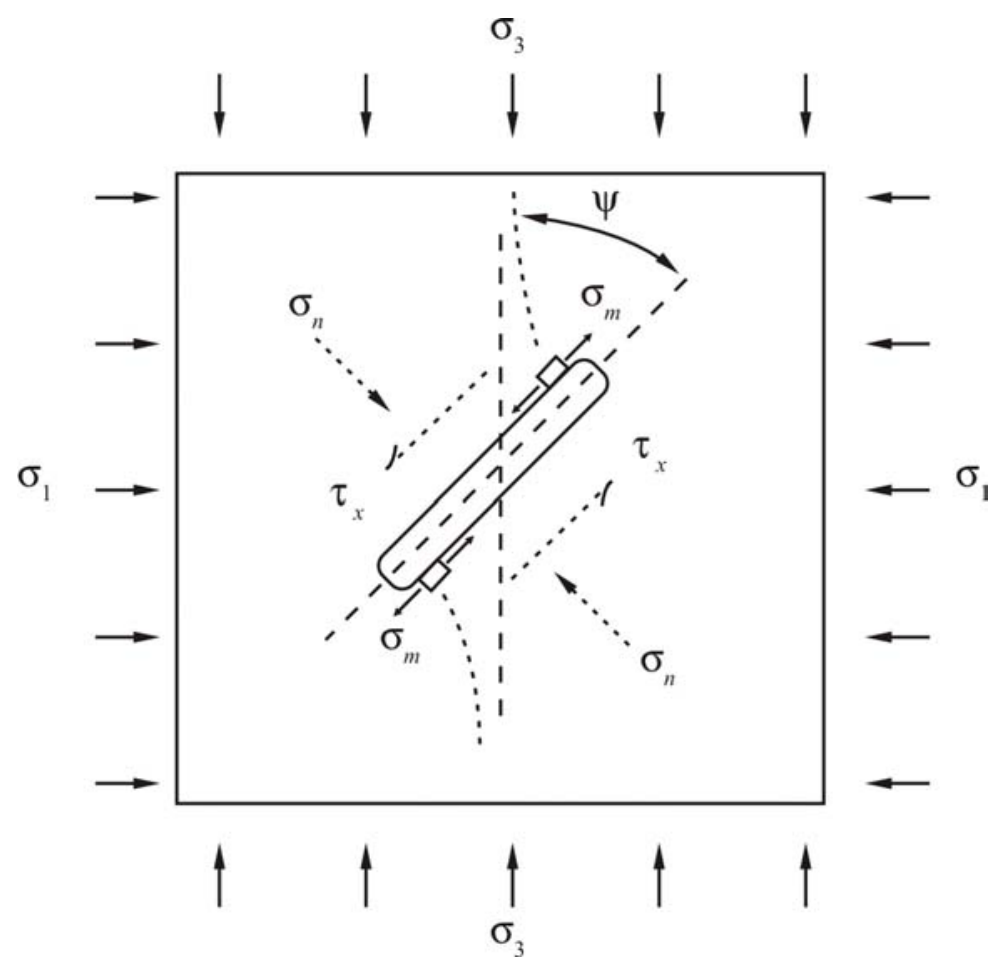

Figure 16 Griffith crack in a compression stress field

Rupture begins

(i) when $\left(\sigma_{1}-\sigma_{3}\right)^{2}+8 \sigma_{0}\left(\sigma_{1}+\sigma_{3}\right)=0$; if $3 \sigma_{1}+\sigma_{3}>0$

In this case, the plane of the initial crack is oriented to the direction of $\sigma_{3}$ at angle $\psi$, where

$$
\psi=\frac{1}{2} \cos ^{-1} \frac{\sigma_{1}-\sigma_{3}}{2\left(\sigma_{1}+\sigma_{3}\right)}
$$

(ii) when $\sigma_{1}=\sigma_{0}$; if $3 \sigma_{1}+\sigma_{3}>0$

In this case, the initial crack orientation is

$$
\psi=\frac{\pi}{2}
$$

In (39), tensile stresses are assumed positive, $\sigma_{1}>\sigma_{3} ; \sigma_{o}$ is the uniaxial direct tension strength of the material; and $\psi$ is the orientation of the crack (along which rupture starts) to the direction of $\sigma_{1}$. 
The criterion expressed in (39) includes the tensile rupture criterion, as the limiting case of (39b). It also indicates that, for a range where the major principal stress $\left(\sigma_{l}\right)$ is tensile and the minor principal stress $\left(\sigma_{3}\right)$ is compressive, but less than one-third of the absolute value of $\sigma_{1}$, then rupture will occur as in direct tension - i.e., the relatively small compressive stress has no influence. It is interesting that the criterion indicates that the rock will begin to rupture in uniaxial compression $\left(\sigma_{1}=0\right)$ when the applied compression $\left(\sigma_{3}\right)$ reaches a value 8 times as high as the direct tensile strength $\left(\sigma_{0}\right)$. Although somewhat low, the ratio is of the correct order of magnitude. [Compression strength values for rock specimens usually range from 15-20 times the direct tension strength.]

The fact that (unequal) applied compressions produce tensions close to the tips of an inclined crack can be readily understood by noting that the shear stresses ( $\tau_{\psi}$ in Figure 16$)$ produced parallel to the crack axis by the compressions will tend to cause displacement of each side of the crack in the opposite sense (left-hand side downward, right-hand side upward in Figure 16). This will result in a tensile 'tearing tendency' slightly off each tip.

\subsection{CRITICISM OF GRIFFITH COMPRESSION CRITERION}

Surprisingly, in deriving the Compression Fracture criterion, Griffith did not consider at all the question of the energetics, or stability, of compression fracture. It seems he implicitly assumed that, once initiated, compression fracture extension would be an unstable process, leading directly to collapse (although he intimated that the situation might need more study when noting that the compression fracture may not propagate along the plane of the major crack).

Subsequent work (Brace and Bombolakis 1963; Hoek 1968) has demonstrated that, indeed, the compression criterion of (30) is a crack initiation criterion only, which does not result in energy instability. Thus, failure to examine stability considerations has led to an erroneous fracture criterion - by the very person who introduced the concept of fracture as due to an energy instability!

It must be said, however, that study of energy stability for the compression situation (i.e., as shown in Figure 16) is considerably more complicated than for the direct tension situation. The compressive crack is not initiated along the axis of the pre-existing crack, and it has been found (Brack and Bombolakis 1963; Hoek and Bieniawski 1966) that it changes orientation continuously as it is propagated [under increasing stress difference $\left(\sigma_{1}-\sigma_{3}\right)$ ]. The extending crack tends to align itself parallel to the direction of maximum applied compression (see dotted lines in Fig. 16); this is the most stable orientation (i.e., the one for which the compressive stress field produces the least tension at the extending crack tip) for a crack. Wawersik (1965) has shown that the tensile stress concentration produced by crack extension parallel to an applied principal compression tends, in the limit, to zero. Thus, although tension cracking in a compressive stress field can occur in the manner indicated by Griffith, it does not lead to an unstable energy situation. Compression collapse cannot occur by this mechanism alone. Hoek and Bieniawski (1965) have studied experimentally the propagation of cracks from an open elliptical crack in a glass plate. The results are reproduced in Figure 17. 


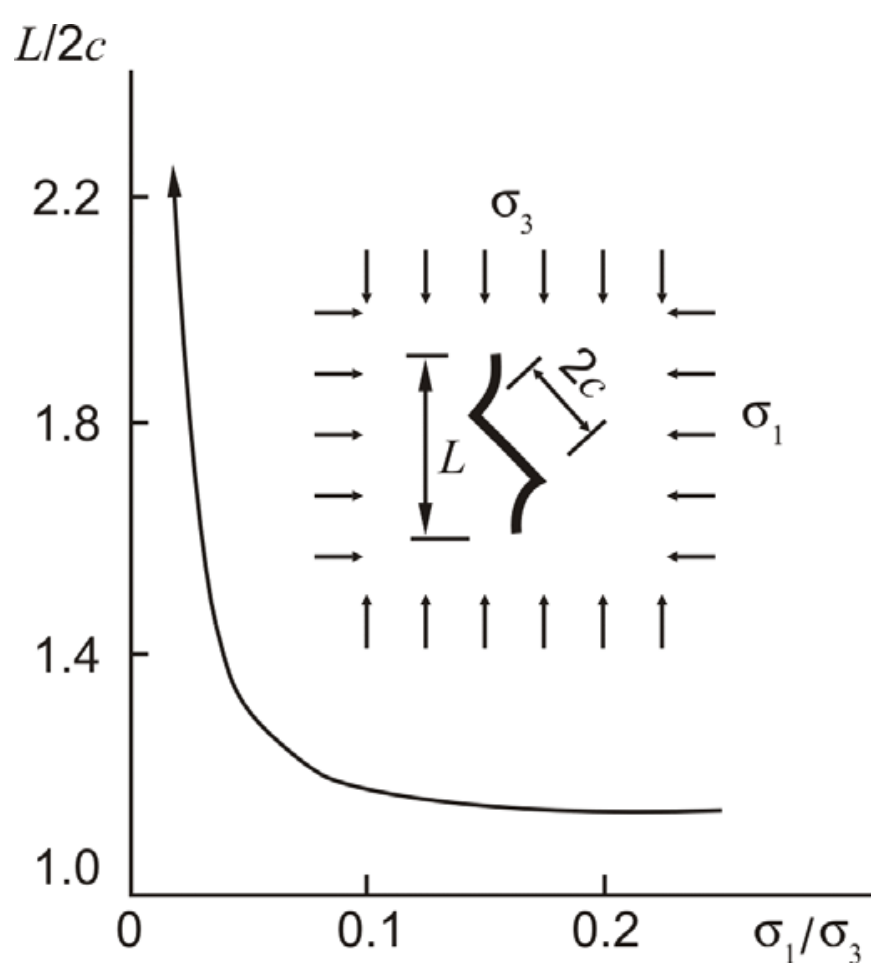

Figure 17 Length of stable crack propagated from an open elliptical flaw under compressive stress conditions (after Hoek and Bieniawski 1965)

These results confirm the conclusion that the crack extension is a stable process. They also reveal how effectively a small minor compressive stress $\left(\sigma_{l}\right)$ suppresses crack extension due to the compressive stress concentration effect of $\sigma_{l}$ at the tip of the extending crack.

A second important objection to the Griffith compression criterion is the assumption that the original (included) crack will remain open. It seems obvious that it will tend to close in the compressive stress field. McClintock and Walsh (1962) have examined theoretically the significance of crack closure. It is apparent that, if the closed crack is subjected to a normal stress, $\sigma_{n}$ (Figure 16), then shear stress $\tau_{\psi}$, tending to produce the tangential tension $\sigma_{m}$, will be counteracted by a frictional shear resistance $\left(\tau_{r}=\mu \sigma_{n}\right)$, where $\mu$ is the coefficient of friction across the closed crack surfaces. The shear stress effective in producing tension will then be $\left(\tau_{\psi}-\mu \sigma_{n}\right)$. The net result is that, for the compression region of the Griffith criterion, as represented by (39a), the parabolic condition is replaced by a linear criterion, which is essentially equivalent to the Coulomb criterion of failure. The McClintock-Walsh (1962) modification does not consider the problem of stable crack propagation. The crack will still extend essentially as in the Griffith compression criterion, albeit at a still higher stress level.

The Griffith crack is but one example of an inhomogeneity in the rock. Pore spaces, soft inclusions in a hard matrix, and hard grains (inclusions) in a soft matrix are other examples. In all of these, it seems that the stress field produced by the inhomogeneity is such as to promote tensile cracking essentially parallel to the major applied compressive stress. In addition, in all cases, the cracks are stable and tend to propagate for a short distance only from the point of initiation. It is not surprising, 
therefore, that extensive short-range cracks, all more or less parallel to each other within grains or from grain boundaries, are frequently observed in rock specimens. The condition is often present in rocks as they are taken from the field before any loads are imposed in the laboratory. If, as in the case of laboratory tests, or in the field where rock is either adjacent to a free surface or confined by compression, the rock is not subjected to an overall tension $\left(\sigma_{1}\right)$, normal to the major applied compression $\left(\sigma_{3}\right)$ [Note: tension stresses positive], then the sum of the local tensions (in the direction of $\sigma_{3}$ ) by the inhomogeneity (or flaw) must be balanced by equal local compression forces acting in the same direction, as shown along AB in Figure 18. (The same is true across any vertical section) in order to be in equilibrium with the free surface stress $\sigma_{1}=0$. [Addition of a confining pressure $\sigma_{1} \neq 0$ will merely bias the local stresses so that the resultant force is in equilibrium with $\left.\sigma_{1}\right]$. This, again, indicates that the tensions induced by inhomogeneities or flaws situated in a compression crack extension result in stable crack extension. In cases where end-loading conditions (i.e., across surfaces CAD, EBF) are non-uniform, the tension region may extend continuously over a large central region of the specimen, the 'balancing compression' being concentrated close to the ends. [See, for example, the tangential tension stress distribution for the Brazilian test situation.] In such cases, axial cracking parallel to $\sigma_{3}$ may extend much farther. It could accelerate and penetrate into the compression region before stopping, much as described earlier for unstable transient crack growth in tension. Axial splitting of compression test specimens, which is so frequently observed, is probably the result of the development of non-uniform axial loading during the test.

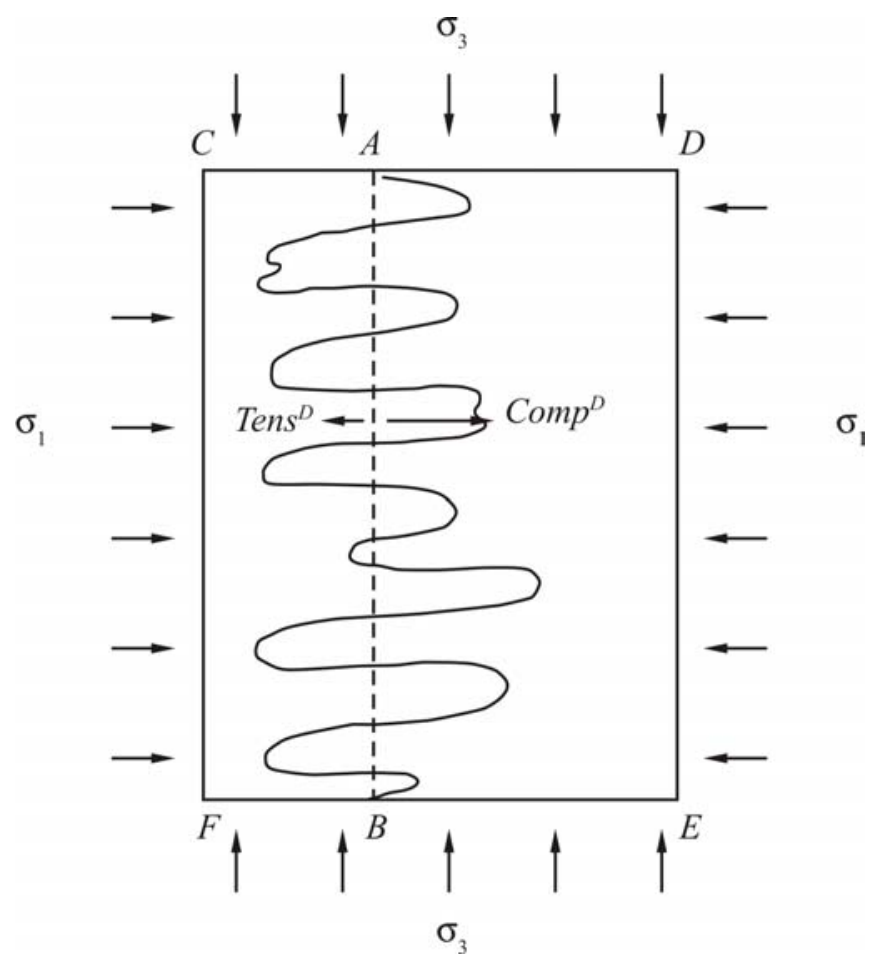

Figure 18 Schematic distribution of localized tension and compression forces along a vertical section of a laterally unconfined specimen loaded vertically in compression 
In summary, then, axial cracking parallel to the direction of major compression is likely to occur in most rocks. The extend of such cracking in macroscopically uniform compressive loading system is likely to be limited, and is rapidly attenuated in the presence of confining stress. Axial cracking will not produce unstable collapse in uniform compressive stress fields. Some other mechanism must be responsible for collapse in compression. Axial shortening due to shear displacement along planes inclined to the major compression is an obvious possibility, assuming shear displacement is possible.

Cook (1965) has considered the problem of unstable propagation of a shear crack in a uniform compressive stress field. The procedure parallels that used by Griffith in the analysis of tensile rupture. It is implicitly assumed that the shear stress developed at the tip of the crack is sufficient to exceed the cohesive strength $\sigma_{m}$ by shearing.

Starr (1928) showed that the increase in strain energy $(\Delta U)$ in a plate due to the introduction of a crack that undergoes shear displacement in the applied plan (shear) stress field is given by

$$
\Delta U=\frac{\pi \tau^{2} c^{2}}{E}
$$

where $\tau$ is the shear stress parallel to the frictionless crack,

$c$ is the half-length of the crack, and

$E$ is the modulus of the plate material.

It is assumed in (40) that there is no discontinuity of normal stress across the shear crack.

Cook (1965) modified (40) to take account of friction along the crack in compressive shearing, replacing $\tau$ in (40) by $\tau_{\text {eff, }}$, the effective shear stress, given by

$$
\tau_{\text {eff }}=\tau-\mu \sigma_{n}
$$

where $\sigma_{n}$ is the compressive normal stress, and

$\mu$ is the coefficient of friction between crack surfaces.

Equation (40) then becomes

$$
\Delta U=\frac{\pi\left(\tau-\mu \sigma_{n}\right)^{2} \sigma^{2}}{E}
$$

Proceeding as with the original Griffith criterion, we have

$$
\Delta S=4 c \gamma_{s}
$$

where $\gamma_{s}$ is the "Work of Fracture in Shear". 
Unstable shear fracture will occur when

$$
\frac{\partial}{\partial c}\left(4 c \gamma_{s}-\frac{\pi\left(\tau-\mu \sigma_{n}\right)^{2} c^{2}}{E}\right) \leq 0
$$

That is, instability develops when

$$
\left(\tau-\mu \sigma_{n}\right)=\sqrt{\frac{2 E \gamma_{s}}{\pi c}}
$$

The criterion of (44b) will be reached first at the crack orientation for which, in a given applied compression field, $\left(\tau-\mu \sigma_{n}\right)$ is a maximum. This orientation is shown to be given by the expression

$$
\psi=\frac{1}{2} \tan ^{-1} \frac{1}{\mu}
$$

where $\psi$ is the angle between the crack axis and the direction of major compression, as in Figure 16. $\tau$ and $\sigma_{n}$ can, of course, be expressed in terms of $\sigma_{l}$ and $\sigma_{3}$, and $\psi$ (or, equivalently, $\mu$ ). The shear criterion (44b) again is equivalent to the Coulomb criterion, differing from the McClintock-Walsh criterion and the original Coulomb criterion only in the value of the constant - i.e., the right-hand side term in $(44 b)$.

The value of $\gamma_{s}$, the Work of Fracture in Shear, probably is dependent on several factors and is unlikely to be a constant. Thus, in unconfined compression, axial splitting, by developing 'ligaments' in the rock, will tend to reduce the resistance to shear. With the addition of confining pressure and elimination of splitting, the work of fracture in shear may increase rapidly. At still higher confining pressures, some rocks may develop some form of plastic deformation at the crack tip, which may reduce the work of fracture. Variation of $\gamma_{s}$ in this way could explain the 'less than linear' increase in compressive 'strength' with increase in confinement, particularly at high values of confining pressure. Cook (1965) has expressed the shear failure criterion of (44b) in terms of a stress-strain curve in compression in essentially the same way as did Berry for the Griffith Tensile Rupture Criterion. The same form of fracture locus is obtained.

Complete load-deformation curves have been obtained experimentally for compression tests on rock specimens. In general, the curves tend to have the characteristic appearance shown in Figure 19. Examination of sectioned specimens removed from tests at various stages during the complete loaddeformation event indicates that the sudden drop in load-bearing capability exhibited in all tests up to quite high confining pressure is associated with microscopic shear fracture along essentially a single planar zone. The major shear is preceded in

(a) unconfined tests, by axial splitting, slabbing of edges, grain rotation, and minor shears distributed through the rock; and 
(b) confined tests, mainly by shears distributed throughout the specimen. Axial cracks and slabbing are generally absent.

Detailed interpretation of the compressive load-deformation curve is difficult, particularly as the peak load is approached. The rock tends to dilate appreciably at loads above $50 \%$ of the peak, indicating inelastic deformations. (The dilation is accompanied by micro-seismic activity; see Fig. 19. $)^{6}$ The dilation usually is restricted in the vicinity of the loading platens, so that the applied load must become non-uniformly distributed to an increasing extent.

It appears that no simple quantitative meaning can be assigned to the peak load in compression, which is often referred to as "the compressive strength".

Disintegration in compression tests proceeds in a very heterogeneous way, often being concentrated along a central shear zone located between more or less intact parts of the specimen at each end, adjoining the loading platens. Reduction of the data to average 'stress-strain curves' is very misleading and should be avoided. It is preferable to record the load-deformation response, noting the specimen dimensions, and the mode of disintegration.

\subsection{GENERALIZATION OF ENERGY INSTABILITY CONCEPT OF FRACTURE AND COLLAPSE}

Although details of the Griffith approach to fracture may be of uncertain validity, the general view of fracture (and eventual collapse) as the result of energy instability in the system can be a very fruitful one. It seems that Griffith's high-stress condition can always be achieved in brittle rocks and so can be taken for granted. The deformation behavior of any system can be examined in terms of the Energy Supply (or Release) Rate and the Energy Demand Rate at all stages. When supply exceeds demand, the system becomes unstable, either temporarily or permanently. In the latter case, the system will collapse.

The advent of high-speed digital computers, and the associated development of approximate numerical methods of analysis in mechanics, facilitates application of the energy instability approach to many situations for which it previously had been impractical. This is particularly true of situations involving complicated geometry.

Hardy (1971), for example, has analyzed the so-called Brazilian test, an indirect tension-test used on rocks, as an energy instability problem. The same approach has been used on other indirect tension tests, such as the beam test and the ring test. It is well known that computation of the 'tensile strength' on the basis of the peak stress generated in the various tests results in a wide variation (up to $600 \%$ ) of strength values. This suggests that the calculated peak stress developed prior to fracture (usually computed on the basis of linear elasticity) is not a meaningful quantity. Test results

\footnotetext{
6 The onset of microseismic activity corresponds, in principle, to the start of the (stable) crack growth predicted by the Griffith Criterion for the 'strength' of brittle materials in uniaxial compression, as discussed in connection with Figure 16. If we assume that the actual strength is 16 20 times greater than the uniaxial tensile strength, and that the Griffith uniaxial 'strength' in compression is 8 times the tensile strength, then microseismic activity should start at about $40 \% \sim 50 \%$ of the peak load in uni-axial compression. This compares well with observations on specimens in laboratory tests.
} 
correlated based on an energy instability analysis provide more consistent values for the rock 'strength'. The adoption of Fracture Toughness in preference to tensile strength as a relevant engineering measure in metals technology is a development along these lines, stemming from Irwin's (1958) adaptation of Griffith's theory of rupture.

(a)

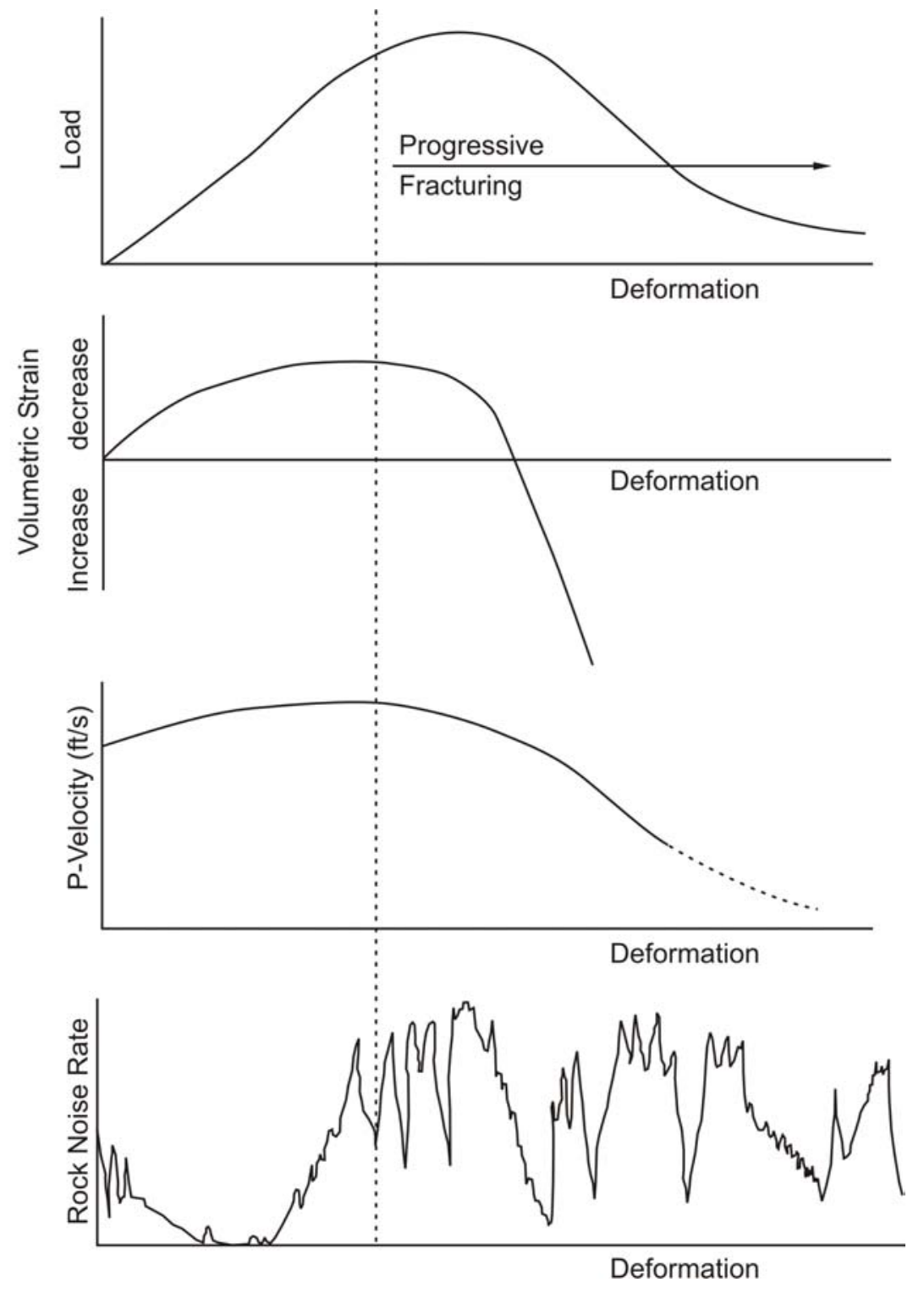

Figure 19 Typical behavior of a cylindrical specimen of rock compressed to disintegration in a controlled laboratory test: (a) complete loaddeformation curve; (b) volumetric strain-deformation curve; (c)seismic velocity (transverse to axis of loading) - deformation curve; (d) seismic noise rate- deformation curve (All curves relate to tests on the same specimen.) 
The energy-instability approach is not limited to microscopic events. It can be used, for example, in the analysis of slabbing around tunnels (Fairhurst and Cook 1966), tunnel stability (Daemen and Fairhurst 1971), crater formation in blasting (Porter and Fairhurst 1971) and, indeed, any situation involving rupture.

\subsection{SIZE-STRENGTH RELATIONSHIPS FOR ROCK}

As noted earlier, relationships (19), and (40), of the general form

$$
S^{2} d=\text { constant }
$$

where $S$ is the rupture stress, or 'strength' in compression, and

$d$ is a parameter with dimensions of length that characterizes the critical flaw size

are a consequence of the type of elastic instability assumed to govern structural collapse (or rupture). The 'energy supply' is released from a volume proportional to $d^{2}$ (per unit thickness).

Thus, if the size of the critical flaw increased at a rate directly proportional to the size (linear dimension $L$ ) of the test 'specimen', the strength $(S)$ should be related to the size, for geometrically similar specimens and applied load distributions, as follows:

$$
S^{2} L=\text { constant }
$$

This relationship appears to be approximately confirmed from test data on coal (Holland 1964; Salamon and Munro 1967) - i.e., the strength $S$ decreases as $L^{-0.5}$. Coal is an extensively cracked brittle material, and it is reasonable to presume that coal specimens and coal mine pillars will contain flaws just as large as the pillar size will allow.

If, however, the critical flaw size is a constant (i.e., does not increase with specimen size), then it may be expected that, provided the specimen is large enough to accommodate a reasonably large number of critical flaws, the strength will be independent of size. Limited tests on the bending strength of granite beams, ranging from $1 \mathrm{ft}$. long x 1 inch thick to $30 \mathrm{ft}$. long x 12 inches thick, indicate a virtually constant strength for all sizes. Laboratory compression tests on homogeneous limestones and marbles from $1 / 2$ inch to 6 inch in diameter also tend to indicate a size-independent strength. In such rocks, it appears that the 'flaw size' is determined by the maximum grain size.

If tests are conducted on a scale such that the region critically stressed is limited to a size approaching that of the 'flaws' themselves, then the general concept of a flaw located within a relatively large (constant modulus) energy supply zone is no longer valid. In an extreme case, the critically stressed region may lie entirely within a ('hard') single grain; in a repeat test, it may lie, although with lower probability, entirely adjacent to a weak grain boundary. On this small scale, test results are likely to be quite erratic, usually exhibiting markedly increased strengths. The scale is then too small, and, as in the case of single atom-pairs, notions (and formulae) from classical continuum mechanics are simply not applicable. 


\subsection{REFERENCES}

Berry, J. P. (1960) "Some Kinetic Considerations of the Griffith Criterion for Fracture. I. Equations of Motion at Constant Force," J. Mech. Phys., Solids, 8, 194-206. (See also "II Equations of Motion at Constant Deformation," J. Mech. Phys. Solids, 8, 207-216 (1960).

Berry, J. P. (1962) "Velocity Behaviour of a Moving Crack: Some Comments on the Paper by Dulaney and Brace," J. Appl. Phys., 33(1), Letters to the Editor, 226-227.

Brace, W. F. and E. G. Bombolakis. (1963) “A Note on Brittle Crack Growth in Compression," J. Geophys. Res.,68,3709-3713.

Cook, N.G.W. (1965) “The Failure of Rock,” Int. J. Rock Mech. Min. Sci., 2, 389-403.

Daemen, J., and C. Fairhurst. (1971) "Influence of Failed Rock Properties on Tunnel Stability," in Twelfth Symposium on Rock Mechanics. Rolla, Missouri, November 1970, pp. 855-875. G. B. Clark, Ed. New York: SME/AIMMPE.

Dulaney, E.N. and W. F. Brace. (1960) "Velocity Behavior of a Moving Crack," J. Appl. Phys., 31(12), 2233-2236.

Fairhurst, C., and N.G.W Cook. (1966) "The Phenomenon of Rock Splitting Parallel to the Direction of Maximum Compression in the Neighborhood of a Surface," in Proceedings of the First Congress of the International Society of Rock Mechanics. Lisbon, September-October, Vol. 1, pp. 687-692, J. G. Zeitlen, Ed. Lisbon: LNEC.

Filonenko-Borodich, M. Theory of Elasticity. English translation by M. Konajeva. Moscow, 378 p.

Glücklich, J., and L. J. Cohen. (1967) "Size as a Factor in the Brittle-Ductile Transition and the Strength of Some Materials," Int. J. Fract. Mech.,3, 278-289.

Griffith, A. A. (1921) "The Phenomena of Rupture and Flow in Solids," Phil. Trans. Roy. Soc. Series A, 221, 163-198.

Hardy, M.P. (1971) "Derivation of the 'Griffith Locus' for Indirect Tensile Strength Tests," University of Minnesota, Mineral Resources Res. Cent., Rept. No. 24, pp. 123-129, April.

Hoek, E., and Z. T. Bieniawski. (1966) "Fracture Propagation Mechanism in Hard Rock," in Proceedings of the First Congress of the International Society of Rock Mechanics. Lisbon, September-October, Vol. 1, pp. 243-249, J. G. Zeitlen, Ed. Lisbon: LNEC.

Hoek, E. (1968) "Brittle Failure of Rock," in Rock Mechanics in Engineering Practice, Ch. 4, pp. 99-124. K. G. Stagg and O. C. Zienkiewicz, Eds. London: Wiley.

Holland, C. T. (1964) "The Strength of Coal in Mine Pillars," in Proceedings of the Sixth Symposium on Rock Mechanics. University of Missouri, Rolla. 
Houwink, R. (1958) Elasticity, Plasticity, and Structure of Matter, 2nd ed. New York: Dover.

Inglis, C. E. (1913) "Stresses in a Plate Due to the Presence of Cracks and Sharp Corners," Trans. Inst. Naval Arch., London, 55(1),219-141.

Irwin, G. R. (1958) Fracture, Hanbuch der Physik, Vol. VI. Vienna: Springer.

Joffé A, A Smekal, E. Orowan (1935) International Conference on Physics, (London) Vol. II

Love, A.E.H. (1927) A Treatise on the Mathematical Theory of Elasticity, 4th Ed. New York: Dover.

McClintock, F. A. and J. B. Walsh. (1962) "Friction on Griffith Cracks in Rocks under Pressure," in Proceedings of the Fourth Congress of Applied Mechanics, pp. 1015-1022. Lisbon, September-October, Vol. 1, pp. 243-249, J. G. Zeitlen, Ed. Lisbon: LNEC.

Mott, N. F. (1948) “Brittle Fracture in Mild Steel Plates," Engineering, 164, 16-18.

Porter, D. D., and C. Fairhurst. (1971) "A Study of Crack Propagation Produced by the Sustained Borehole Pressure in Blasting," in Dynamic Rock Mechanics. Proceedings of the 12th Symposium on Rock Mechanics, University of Missouri, Rolla, November 1970, pp. 497-515, G. B. Clark, Ed. New York: SME/AIMMPE.

Roberts, D. K., and A. A. Wells. (1954) “The Velocity of Brittle Fracture,” Engineering, 171, 820821.

Sack, R. A. (1946) “Extension of Griffith's Theory of Rupture to Three Dimensions," Proc. Phys. Soc., London, 68, 55-67.

Salamon, M.D.G., and A. H. Munro. (1967) "A Study of the Strength of Coal Pillars," J. S. Afr. Inst. Min. Metall., 68, 55-67.

Sneddon, I. N. (1946) "The Distribution of Stress in the Neighborhood of a Crack in an Elastic Solid," Proc. Roy. Soc., London Series A, 187, 229-60.

Starr, A. T. (1928) "Slip in a Crystal and Rupture in a Solid Due to Shear," Proc. Camb. Phil. Soc., $24,489-500$.

Wawersik, W. R. (1968) Detailed Analysis of Rock Failure in Laboratory Compression Tests, Ph.D. Thesis, University of Minnesota; or Wawersik, W. R., and C. Fairhurst. (1970) "A Study of Brittle Rock Fracture in Laboratory Compression Experiments," Int. J. Rock Mech. Min. Sci., 7(5), 561-575. 


\section{APPENDIX}

\section{Change in Strain Energy of a Plate Due to Introduction of a Crack}

A simple derivation of the change in strain energy of the plate with and without the crack has been presented by Irwin (reported as Appendix 1 of the paper by Roberts and Wells(1954). Using Westegaard's solution for the displacement around a crack in a biaxially loaded plate in plane stress, he shows that the displacement ' $v$ ' of the crack edges from the major crack axis $(y=0)$ due to a stress $\sigma$ applied on the outer boundary of the infinite plate is given by the expression:

$$
\mathbf{v}=\frac{2 \sigma \sqrt{c^{2}-x^{2}}}{E}
$$

where $+c \geq x \geq-c$.

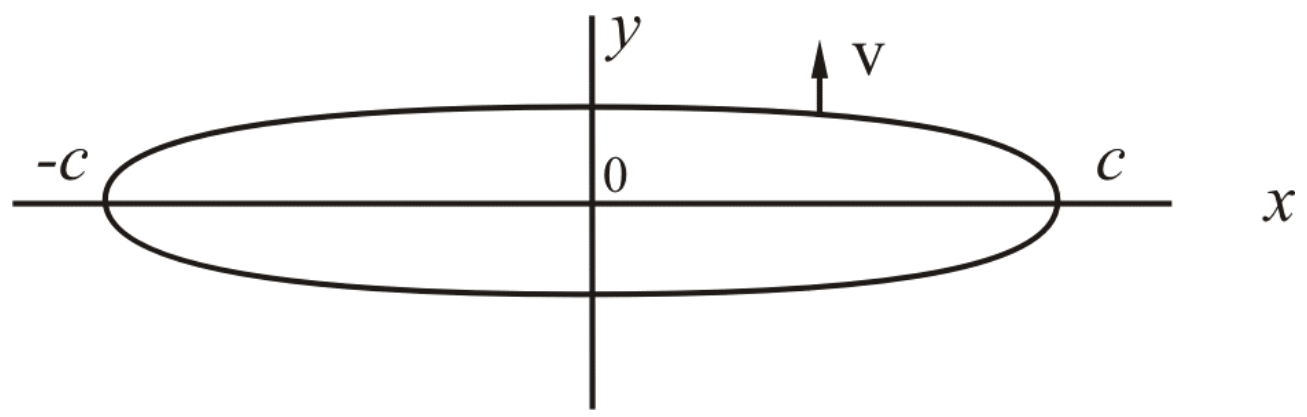

Figure A1 Opening of a Line Crack Due to Constant Stress $\sigma$ at Infinity

To close the crack it would be necessary to apply a uniform tension normal to the crack surfaces. Since the plate is assumed to be linearly elastic, the crack will close uniformly with increase in the crack tension, until the latter reaches the stress $\tilde{\sigma}$. At this value the crack surfaces will meet and the crack, in effect, will no longer exist i.e. the plate is everywhere under homogeneous tension $\sigma$.

If the volume of the fully open crack is V per unit thickness, then the work (W) done in closing the crack will be

$$
W=1 / 2(V \sigma)
$$


Noting the symmetry of the crack edge displacement 'v' (Figure A1), we may write

$$
W=2 \sigma^{2} \int_{o}^{c} v d x
$$

From A2, we have

$$
W=\frac{2 \sigma}{E} \int_{0}^{c} \sqrt{c^{2}-x^{2}} d x=\frac{\pi c^{2} \sigma^{2}}{E}
$$

Thus, the difference between the strain energy of the plate with and without the crack is $\left(\pi c^{2} \sigma^{2}\right) / E$.

This method of computation, based on the recognition that the energy change can be computed by considering displacements at the crack edges only (rather than throughout the plate), is very useful, particularly when finite plates are considered. Irwin's method allows easy numerical computation of energy changes.

\section{Kinetic Energy of a Moving Crack}

Consider the planar crack, length $2 c$, (as in Figure A2) moving with the instantaneous velocity, $v_{O}$, along the $\mathrm{x}$-axis. An arbitrary element $\mathrm{dxdy}$ has been displaced by an amount $u$, as shown. The kinetic energy of the element, mass $\rho$, is given by

$$
\begin{aligned}
& \frac{1}{2} \rho d x d y\left(\frac{d u}{d t}\right)^{2} \\
& =\frac{1}{2} \rho d x d y\left(\frac{d c}{d t}\right)^{2}\left(\frac{d u}{d c}\right)^{2} \\
& =\frac{1}{2} \rho \mathrm{v}^{2}\left(\frac{d u}{d c}\right)^{2} d x \cdot d y
\end{aligned}
$$

The total kinetic energy (KE) of the (infinite) plate is then

$$
K . E=\frac{1}{2} \rho \mathrm{v}^{2} \int_{-\infty}^{+\infty} \int_{-\infty}^{+\infty}\left(\frac{d u}{d c}\right)^{2} d x . d y
$$

Mott then reasons "The value of $u$ near the surface of the crack is of order $\sigma_{c} / E$ and, thus, the integral is, on dimensional grounds, a multiple of $c^{2}(\sigma / E)^{2}$; the numerical factor could easily be calculated." Hence, the kinetic energy is 


$$
K . E=\frac{1}{2} k \rho c^{2} \mathrm{v}^{2}\left(\frac{\sigma}{E}\right)^{2}
$$

where $k$ is the numerical factor. Its value has been computed by Roberts and Wells (1954) ( $k \cong 45$ for a material with Poisson's ratio $v=0.25$ ).

Roberts and Wells (1954) have determined that, for a material for which Poisson's ratio $v=0.25$

$$
\sqrt{\frac{2 \pi}{k}} \cong 0.38 \text {. }
$$

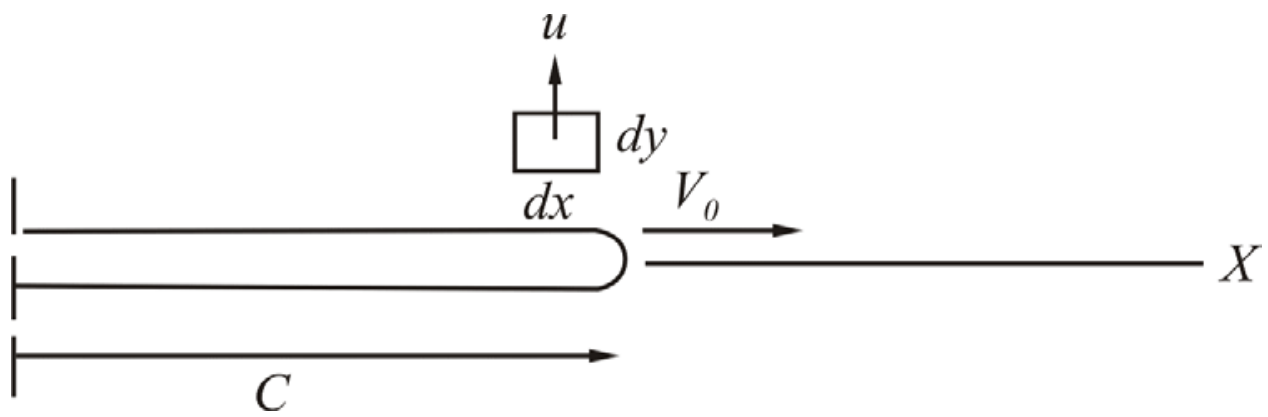

Figure A2 Planar crack, length 2c, moving at velocity $V_{o}$ 


\section{Deterministic Modeling of Physically-Limited Ground Motion}

\section{J. Andrews, U.S. Geological Survey, Menlo Park, CA}

When predicting ground motion at critical structures for very low probability of exceedance, Probabilistic Seismic Hazard Analysis can yield values much larger than any ground motion that has actually been observed in an earthquake. Are there physical limits that can constrain such predictions? Two physical principles can be applied: (1) maximum stress drop available at the source, and (2) strength of material through which waves propagate. These two principles are applied in this work to deterministic forward modeling of an earthquake on the Solitario Canyon fault near the Yucca Mountain repository. A schematic diagram of the site is shown in Figure 1.

Strength of material provides a physical constraint on ground motion. Particle velocity propagated in an $\mathrm{S}$ wave is limited to shear strength divided by shear impedance, which effectively limits short-period motion, even though velocity can increase further as waves reverberate in a layer. Non-elastic response near the earth's surface constrains shortperiod motion. In addition, non-elastic response near a rupture front increases fracture energy and limits particle velocity at the source.

To establish physical limits on earthquake ground motion, we need to use non-linear calculational methods. The demonstration calculation shown here is done in twodimensional plane strain. I propose to generalize the computer code to three dimensions in the coming year.

The state of stress in the crust, at least at shallow depths, has been determined from borehole measurements by Zoback and others. The least compressive principal stress is horizontal, and its ratio to the vertical stress is consistent with a coefficient of Coulomb friction of 0.6 on a normal fault dipping 60 degrees. The fluid pressure is hydrostatic below the water table, which is about $600 \mathrm{~m}$ below the surface. I assume that this stress state extends to a depth of $10 \mathrm{~km}$. Shear stress on the fault in this initial stress state is shown as a cyan curve in the left panel of Figure 2.

Unfortunately, we know little about limits on stress drop. Complete stress drop may be possible. Thermal pressurization of pore fluid from frictional heating can produce nearcomplete stress drop in large events in sufficiently impermeable material. The character of ground motion near the northern part of the rupture of the Chi-chi earthquake suggests that thermal pressurization may have occurred there. In this work I arbitrarily assume that friction drops to a value of 0.1 after the initiation of slip. Slip starts when shear stress rises to a level corresponding to static friction of 0.7 .

Results from a dynamic elastic calculation done with these stress assumptions are shown in Figure 2. Final slip resulting from the assumed stress drop is $15 \mathrm{~m}$. Geologic evidence suggests that slip greater than $3 \mathrm{~m}$ has very small probability on the Solitario canyon fault. In future work the large stress drop used here might be confined to small patches, which would limit slip but not reduce the intensity of shorter-period motion.

The calculation is repeated using the Mohr-Coulomb yield condition shown in Figure 3. The cohesion of $1 \mathrm{MPa}$ is a compromise between larger cohesion measured in the welded tuff units and very small cohesion on fractures and joints. The final plastic strain 
distribution is shown in Figure 4. The along-fault component of plastic strain is extensional in the down-thrown block, and is compressive at the site of the repository.

Figure 5 compares velocity at the repository site between the elastic and non-elastic calculations. Yielding reduces peak horizontal velocity, and it significantly reduces spectral response velocity shown in the lower right panel.

Yielding is not as effective in reducing ground motion in this calculation as it would be in a more realistic case. Because of the large stress drop over the entire fault surface, the rupture propagates at the $\mathrm{P}$-wave speed. The large initial motion at the site is a $\mathrm{P}$ wave, and no yielding occurs until a reflection arrives from the surface. If large stress drop occurred only on small patches, rupture velocity would be slower, and motion at the site would be primarily shorter-period $\mathrm{S}$ waves. For these reasons yielding would be much more effective in reducing the motion. In future work large stress drop will be confined to patches, such that slip conforms to geologic evidence.

Conclusions are (1) strength of geologic materials sets limits on ground motion; (2) nonelastic calculations are required. Methods for non-elastic calculations are well-established outside the disciplines of seismology and engineering seismology. I have knowledge and experience to apply such methods to seismological problems.

\section{Proposed work:}

A. Code development. A 3D non-elastic code, appropriate to dynamic fault rupture, will be developed. Features will include topography, structure varying across faults, initial stress in equilibrium with topography and density structure, Coulomb yielding, tensile failure, spall, and compaction. Time required: one to two man-years.

B. Running calculations. Sources and material properties must be varied in a comprehensive study to maximum physical ground motion. Time required: one to two man-years.

Tasks A and B can be concurrent if more than one person is supported. First results can be available in less than a year. 


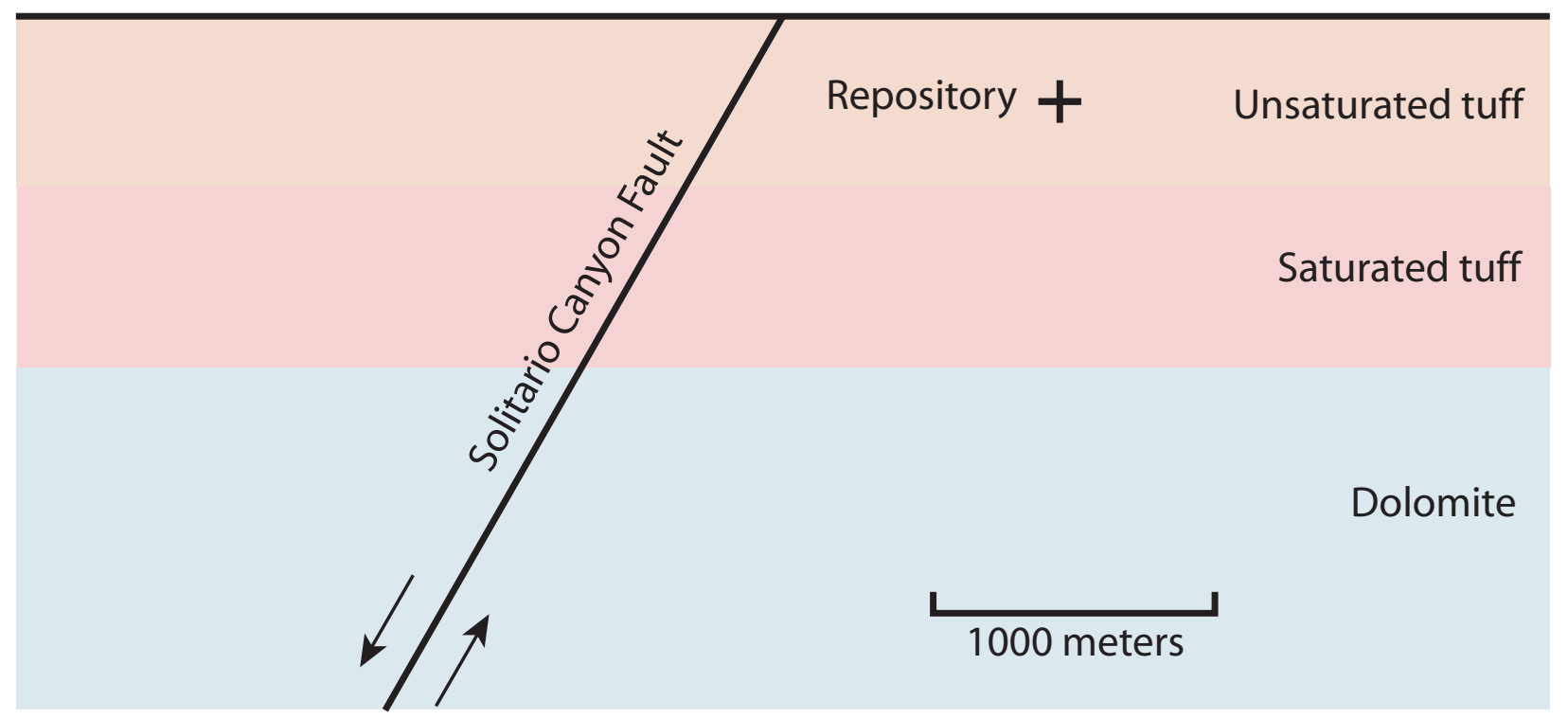

Figure 1. Demonstration 2D calculation of rupture on Solitario Canyon fault.

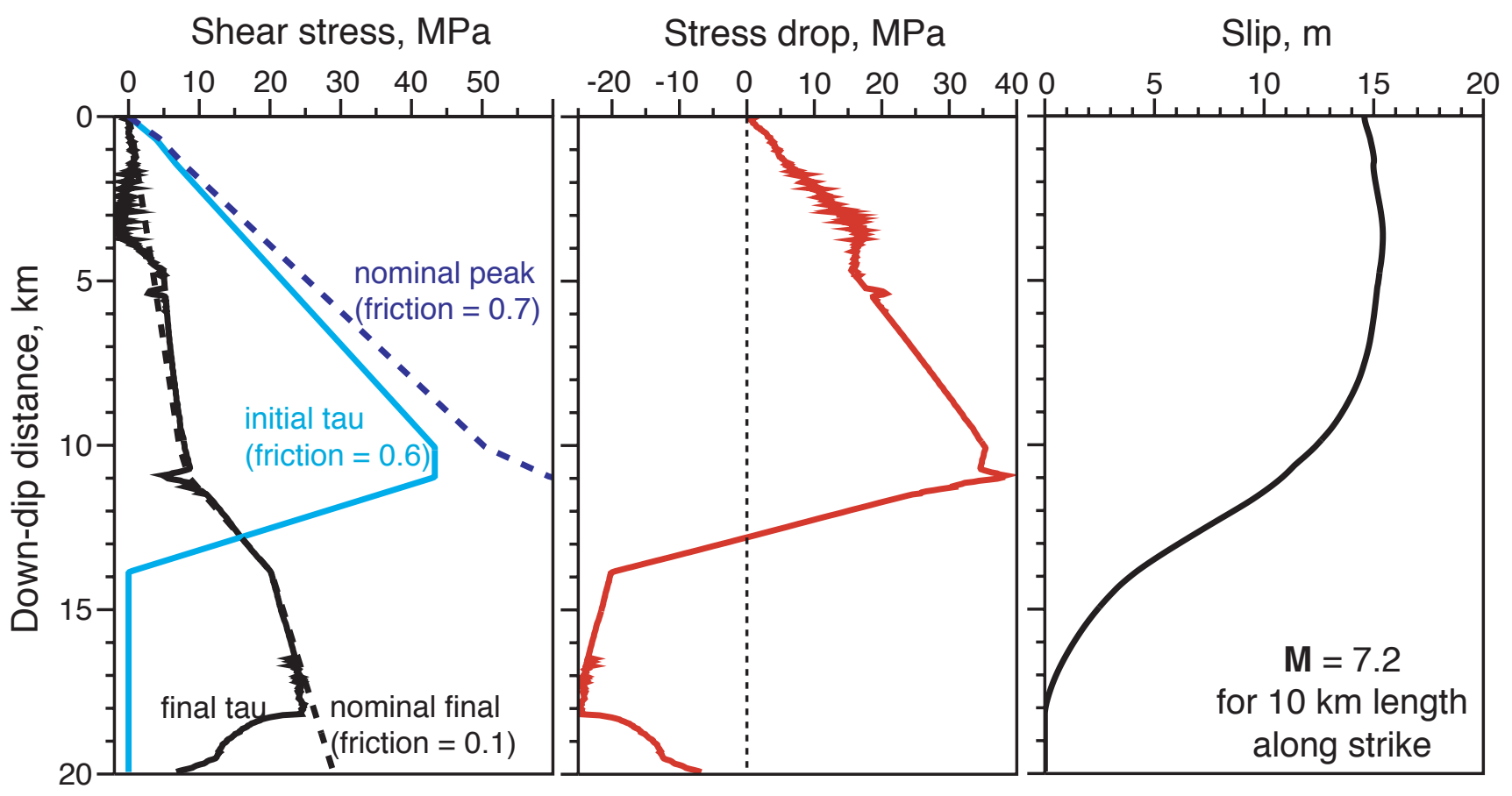

Figure 2. Modeled stress and slip on Solitario Canyon Fault in 2D plane strain. 
Figure 3. Mohr-Coulomb yield condition. Internal friction $=1.0$, angle of friction $=45$ degrees, cohesion $=1 \mathrm{MPa}$.
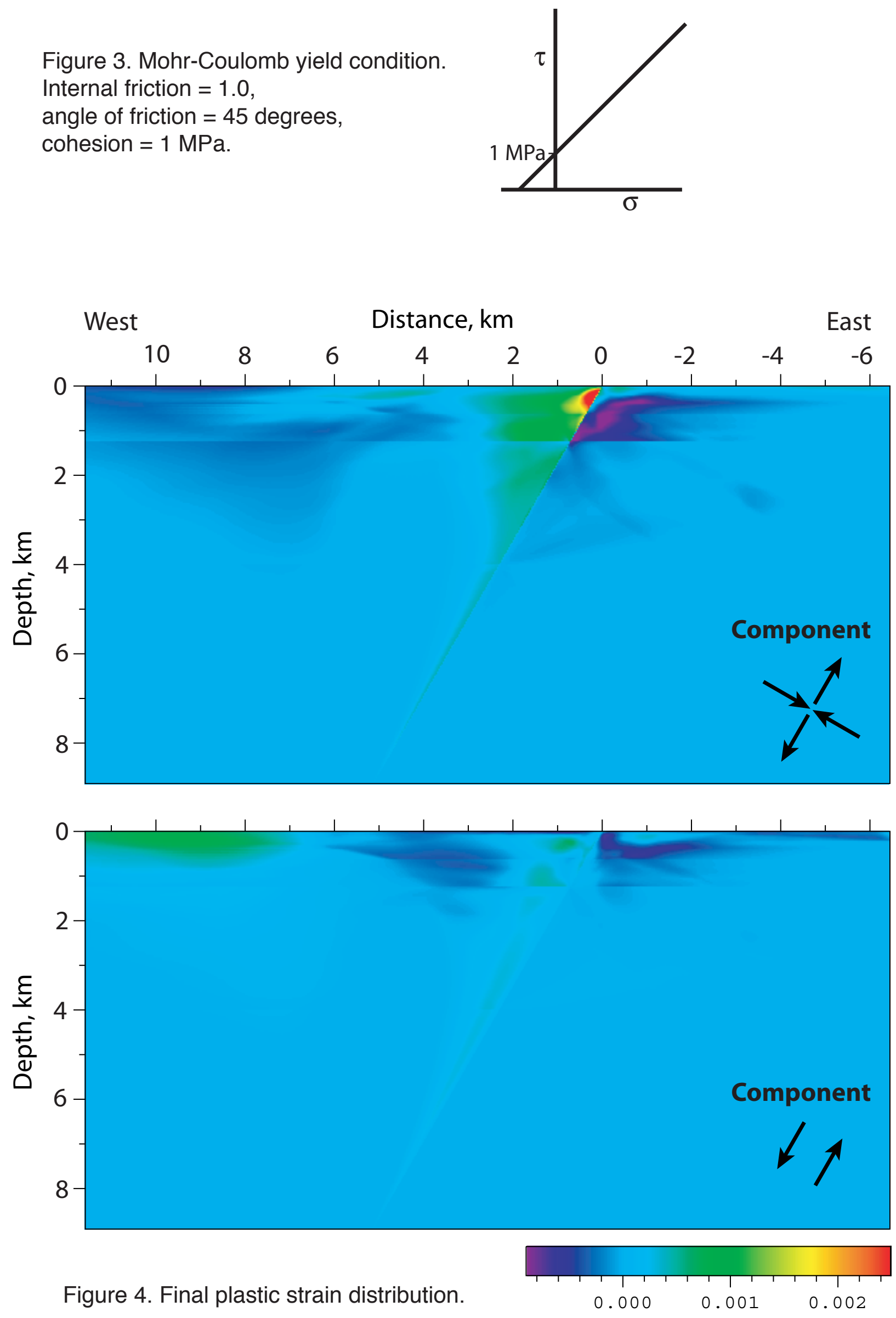

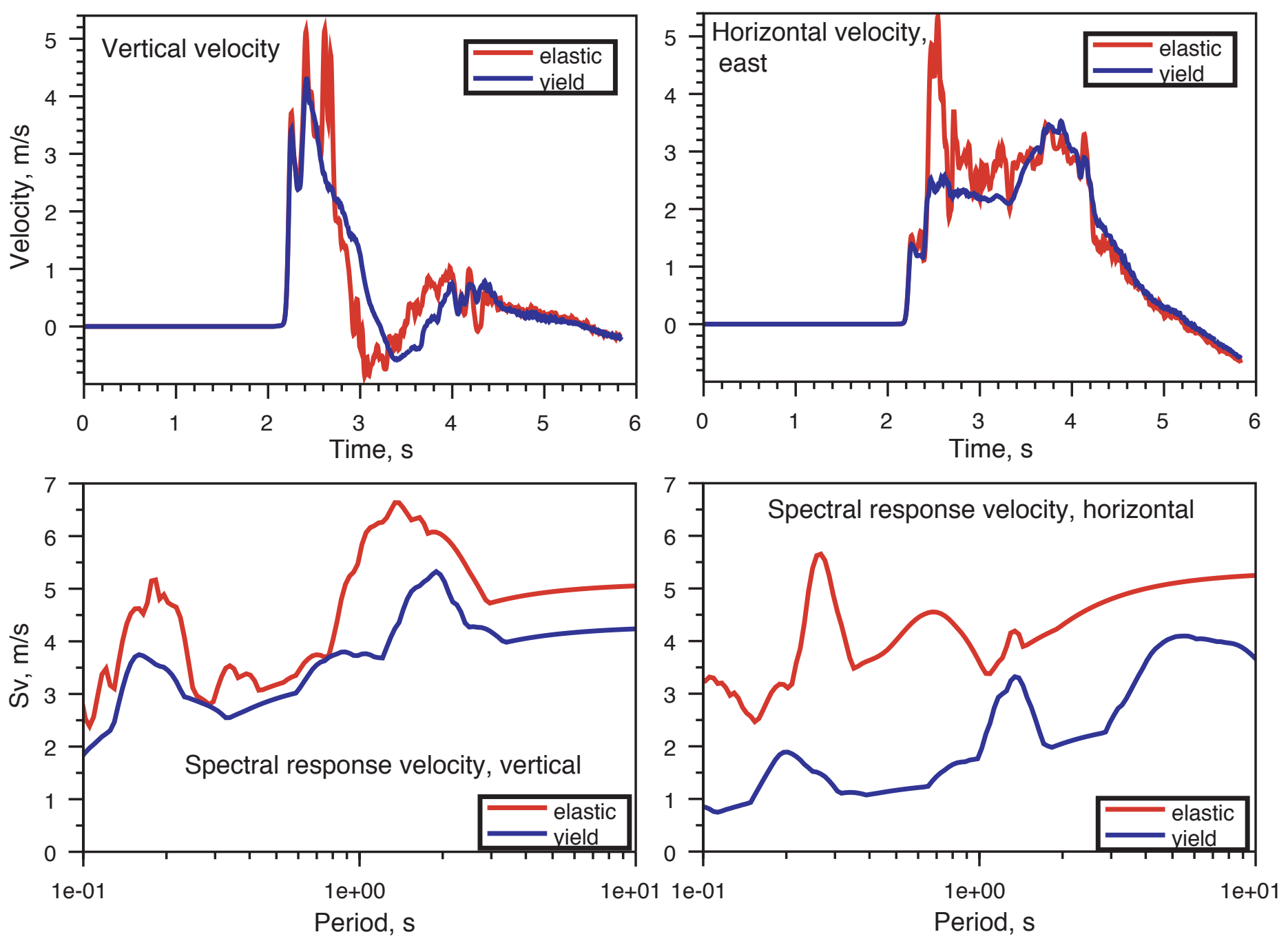

Figure 5. Comparison of velocity at repository site between the elastic calculation and the calculation with Coulomb yielding. Top: velocity; bottom: spectral response velocity; left: vertical component; right: horizontal east component. 


\section{Branko Damjanac, Peter A. Cundall and Terje Brandshaug \\ Itasca Presentations at the Menlo Park Workshop, August 23-24, 2004 BACKGROUND}

This memorandum presents summaries of presentations by Drs. Peter Cundall and Branko Damjanac at the Workshop on Extreme Ground Motions at Yucca Mountain, Menlo Park, California, August 23-24, 2004. The two presentations are summarized in Sections 2 and 3, respectively.

\subsection{FULLY NON-LINEAR MODELING OF DYNAMIC TRANSMISSION IN ROCK}

The currently accepted methodology for calculating the transmission of seismic motion from source to site is the equivalent linear method (ELM), which is an approximate method, described as follows.

A series of linear analyses is performed, with constant (but different) values of damping ratio and shear modulus at various locations in the model. The observed maximum cyclic shear strain in each element is used to determine values for damping and modulus for the next analysis using laboratory-derived curves - "degradation curves." The process is repeated several times, until there is no further change in properties. At this point, it is said that "strain-compatible" values of damping and modulus have been found.

The method has been found to give reasonable results for ground motions commonly considered in Civil Engineering (e.g., less than $1 \mathrm{~g}$ ), but it is unknown if the method is good enough for very high amplitude motions. To be rigorous, we should compare the results of ELM analyses with full, nonlinear simulations (FNL), for high-amplitude wave propagation. Itasca recently received an S\&T contract to study this topic in detail; we simply present here some background and preliminary results (because the work has only just started). A comparison of the treatment of effects and mechanisms of the two methods is shown in Table 1.

\section{Table 1 Comparison between equivalent-linear and fully non-linear methods}

\begin{tabular}{|l||l|}
\hline \multicolumn{1}{|c||}{ Equivalent-linear method (ELM) } & \multicolumn{1}{c|}{ Fully non-linear method (FNL) } \\
\hline $\begin{array}{l}\text { Properties are constant over time - e.g., } \\
\text { overdamped in quiet periods; underdamped } \\
\text { for periods of strong-motion. }\end{array}$ & $\begin{array}{l}\text { Damping and modulus appropriate to ampli- } \\
\text { tude at all times. }\end{array}$ \\
\hline $\begin{array}{l}\text { Interference \& mixing between frequencies } \\
\text { absent. }\end{array}$ & Interference \& mixing occur naturally. \\
\hline \begin{tabular}{l} 
Irreversible strains not modeled directly. \\
\hline $\begin{array}{l}\text { Stress and strain increments coaxial in elas- } \\
\text { tic law. }\end{array}$
\end{tabular} & $\begin{array}{l}\text { Proper flow rule: independent strain incre- } \\
\text { ment. }\end{array}$ \\
\hline $\begin{array}{l}\text { Shape of hysteresis law (an ellipse) is built } \\
\text { in. }\end{array}$ & Any form of hysteretic law may be used. \\
\hline $\begin{array}{l}\text { No coupling between P and S wave compo- } \\
\text { nents. }\end{array}$ & $\begin{array}{l}\text { Full, non-linear coupling between P \& S (e.g., } \\
\text { change in shear strength due to P wave). }\end{array}$ \\
\hline
\end{tabular}




\subsection{Direct Comparison Between ELM \& FNL for Modest Strains}

The equivalent-linear code SHAKE was compared with FLAC (a continuum FD code), using the example found on the SHAKE web site (a series of soil layers, of increasing modulus with depth). Details of the comparison are found in the FLAC user's manual (Itasca, 2004). The Loma Prieta horizontal acceleration record was used, scaled to various maximum acceleration levels. FLAC used a fully non-linear law (with memory of reversal points): an example of the stress/strain path at the middle of the soil profile is reproduced in Figure 1. The comparison of surface acceleration amplification-factor (between SHAKE and FLAC) is shown in Figure 2, for base excitation up to $1 \mathrm{~g}$. There is reasonable agreement between the ELM and FNL method for this case.

\subsection{Simple Example of the Effect of Simultaneous P-Wave and S-Wave Propagation}

The ELM does not include the coupling effects of shear and compressional strains, which may be important - for example, if a momentary reduction of normal stress leads to increased shear yielding. Using the same seismic history as the previous example, a $1 \mathrm{Km}$-high column of MohrCoulomb, perfectly plastic material is used. There is a Gaussian standard deviation of friction angle $=7.5^{\circ}$, with a mean of $30^{\circ}$. This produces a quasi-continuous yield function for the ensemble. $\mathrm{P}$-wave input also is applied, of varying magnitude. This time history is the time-reversed S-wave history (to give the same spectrum, but almost zero time correlation). 0 shows the effect (on the horizontal surface acceleration) both with and without simultaneous P-wave excitation.

The effect of a simultaneous P-wave excitation is to increase the mean horizontal motion during the quiet period and decrease it during the strong-motion period, but the mean acceleration and mean energy transmission are almost unchanged. 


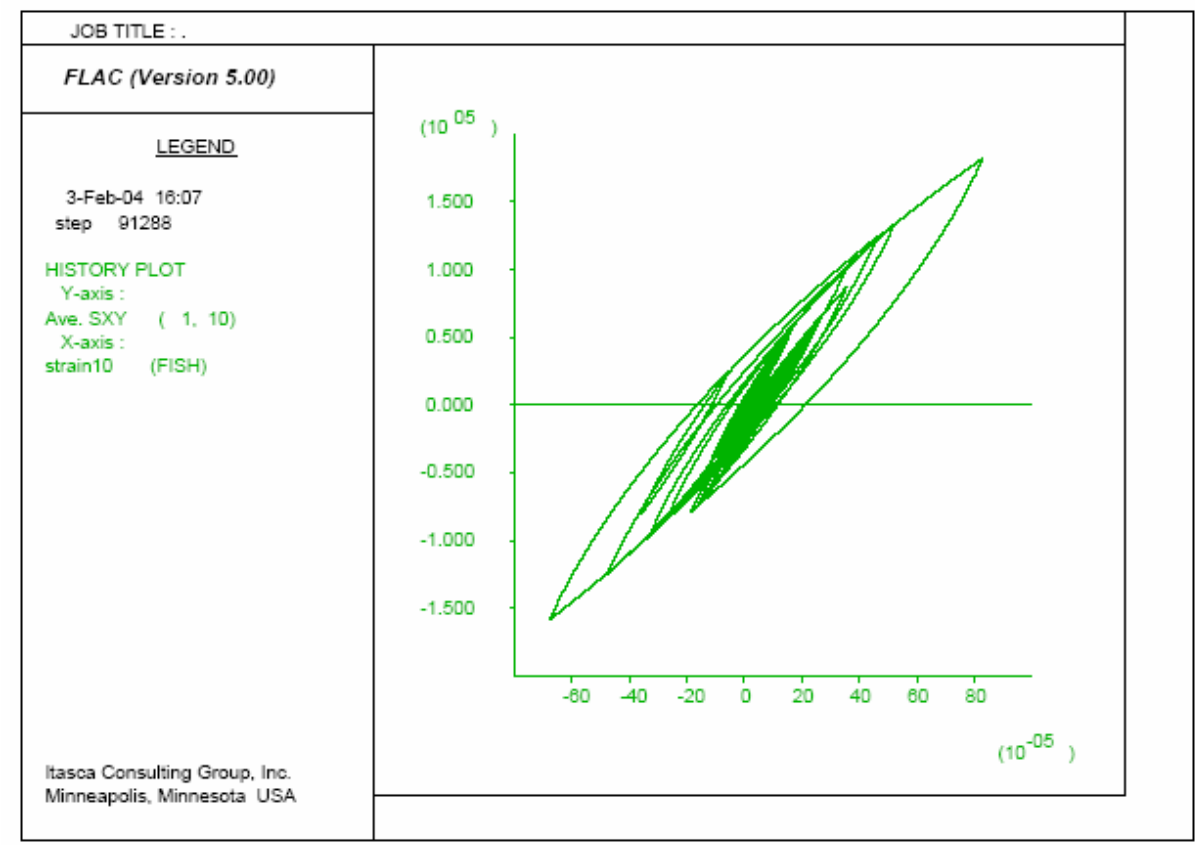

Figure 1 Shear stress/strain path in the middle of the soil profile

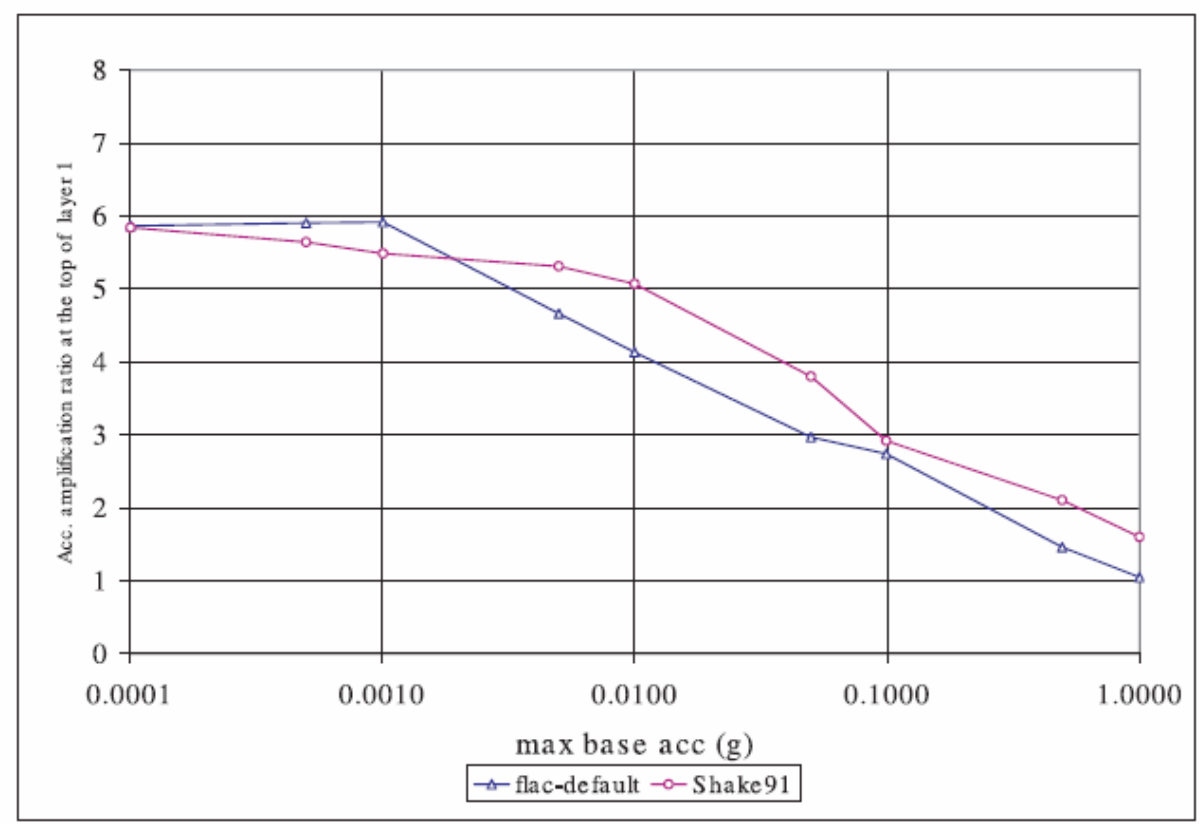

Figure 2 Amplification factor (for surface acceleration) versus base acceleration 
Surface horizontal acceleration vs time: Left, zero P-wave amplitude; Right, equal P-and S-wave
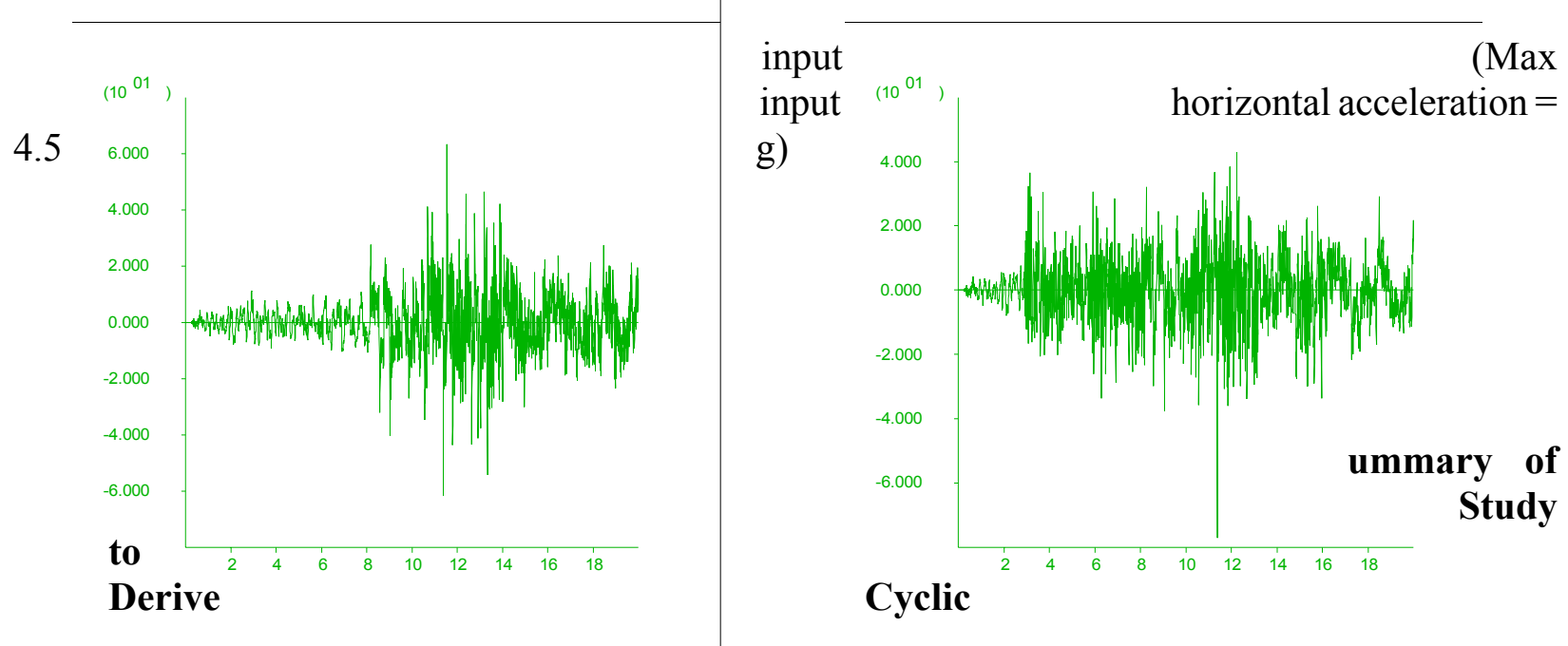

\section{Response of Large-Scale Rock Units at Yucca Mountain (Degradation Curves)}

It is impossible to determine, experimentally, the appropriate cyclic degradation response for the major geological units. First, these units are in the order of $10 \mathrm{~m}$ to $100 \mathrm{~m}$ thick, and, second, the large-strain response is needed for strong-motion propagation calculations. We have constructed numerical models of the jointed rock units, based on all available geological and laboratory data (e.g., fracture maps, joint shear tests and intact rock tests). These models are exercised by cyclic loading, and degradation curves are derived from steady-state hysteresis loops. Figure 3 shows a typical joint structure for the Prow Pass unit (modeled with code $U D E C$ ) and the resulting hysteresis loops. The lower plots show stress tensors and open joints at the extreme points on the steady-state hysteresis loop: it is notable that shear strain alone causes tensile separation. Although the tests were performed on a "sample" with sinusoidal excitation, the same methodology could be applied to the propagation of synthetic seismic histories through the complete transmission path at the site.

\subsection{Dynamic Wave Propagation through Jointed Rock at the Yucca Mountain Site}

Itasca has performed many simulations of the response of the rock around the repository to supplied seismic motion. Several cases were repeated, for the $10^{-6}$ probability level, but with the repository opening omitted - i.e., the new simulations represent wave propagation through non-linear rock. Space precludes the inclusion of all the results, but, as an example, Figure 5 shows the final rock state after the passage of the S-wave alone; the magenta lines represent fractures that have yielded or opened. Figure 4 illustrates the stress paths followed for three cases. As noted previously, tensile cracking occurs during cyclic shear loading only. (The addition of $\mathrm{P}$-wave loading increases the area of cracking). 

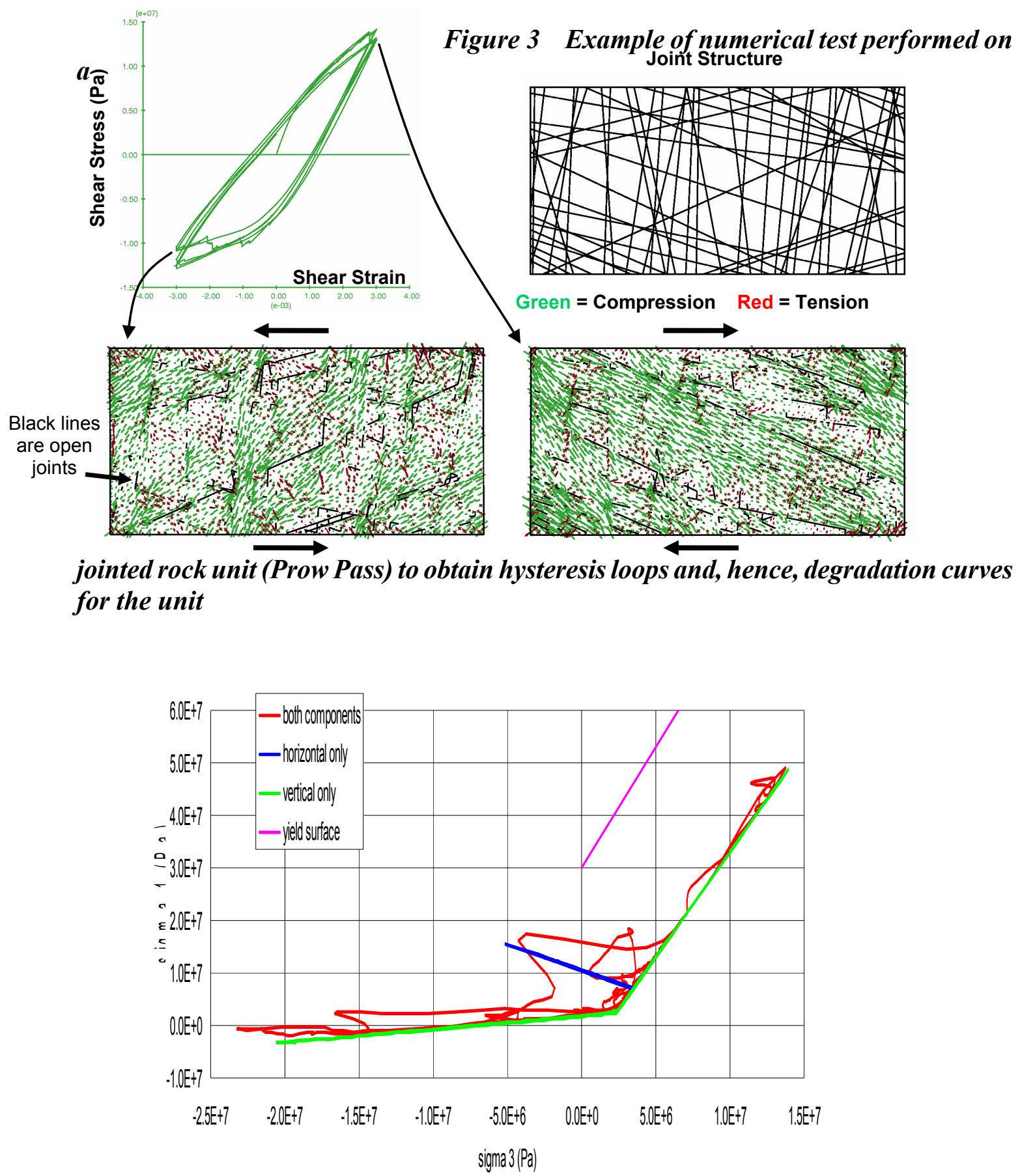

Figure 4 Stress paths followed during the seismic histories used in dynamic wave propagation through site rock (major principal stress vs minor principal stress) 


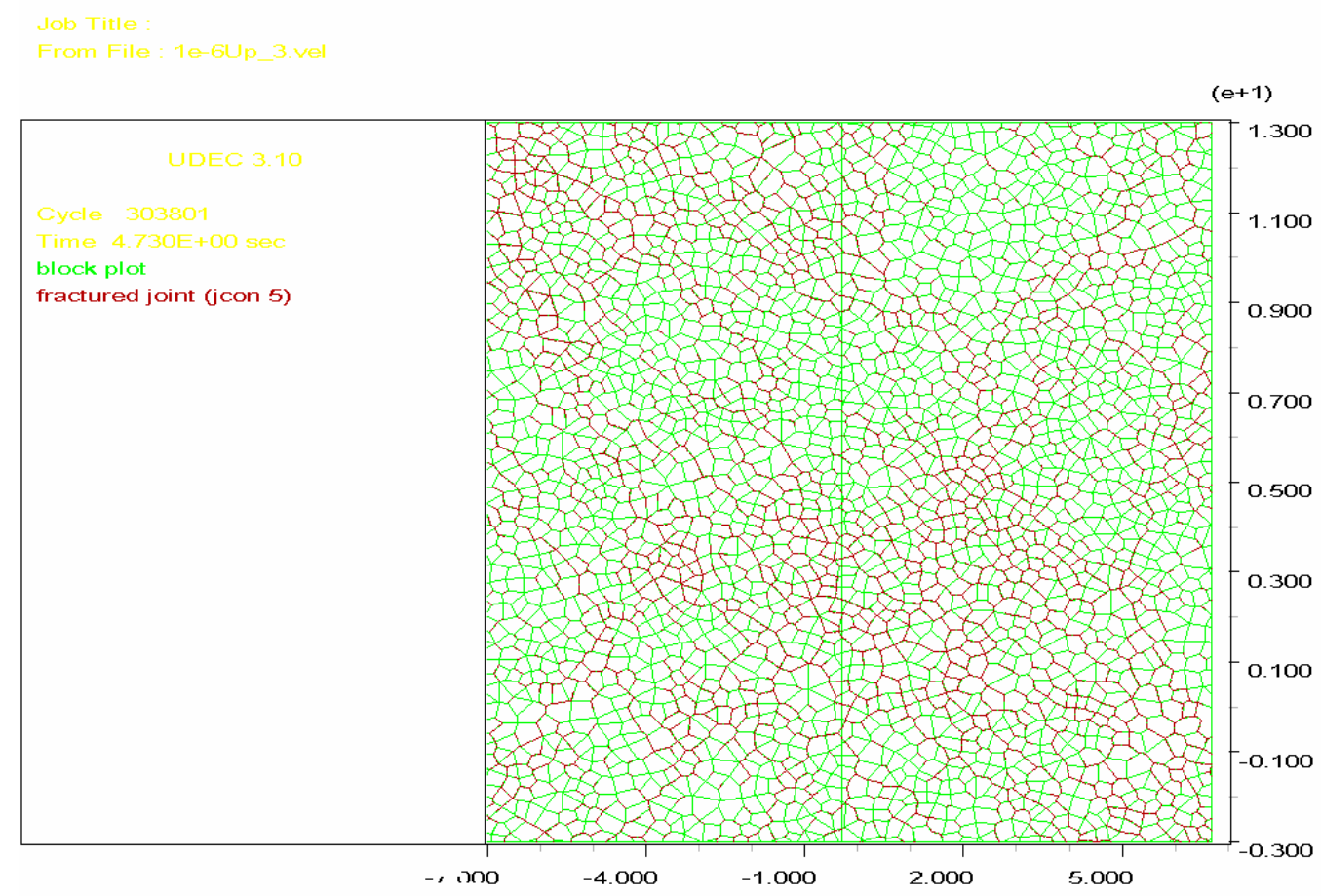

Figure 5 Final rock state after passage of seismic $P$-wave $\left(10^{-6}\right.$ probability level): magenta lines indicate yielded or open fractures

\subsection{Conclusions}

We have demonstrated that the means exists to perform fully non-linear simulations of wave propagation through — and below - the site. Some simple examples have been presented to indication the nature of such simulations, but a systematic study should be made of nonlinear wave transmission from source to site in order to validate (or not) the currently used equivalent-linear method (ELM), which is being applied well outside of its normal range of strain level. Preliminary results (for a few simple cases) indicate that the ELM is surprisingly good, even at high levels of motion.

\subsection{ROCK MECHANICS ANALYSIS OF ABSENCE OF SEISMIC DAMAGE IN LITHOPHYSAL UNITS}

The only credible way to provide limits to the maximum peak ground velocity (PGV) of the synthetic time histories used as input to seismic analyses for the Yucca Mountain Project is to estimate the maximum PGV that could have been experienced at the site in the geological past. To make this estimate, at least two pieces of evidence are necessary:

(1) observations of strain-induced fractures around lithophysae (or lack of such fractures); and

(2) data on the mean strain necessary to initiate fracturing around lithophysae and slip on joints.

Evidence in the first category is available from observations in the Exploratory Study Facility (ESF) and Enhanced Characterization of Repository Block(ECRB) Cross-Drift that indicate that the major- 
ity of the fractures in the lithophysal and nonlithophysal units are induced thermally. To supply evidence in the second category, and to determine the upper bound to the seismically induced strain experienced by the Topopah Spring tuff since it has cooled off, the shear strain increments required to cause fracturing of the lithophysal rock mass were calculated based on results of the laboratory experiments (for units in which the proper test results are available) and results of the PFC and UDEC numerical micro-mechanical models.

The numerical results of PFC and UDEC, based on and calibrated to results of laboratory tests, were used to extrapolate experimental results to wider ranges of lithophysal porosity and different loading conditions that could not be tested in the laboratory (e.g., laboratory tests were conducted for unconfined conditions only). The numerical models also were used to establish the relation between different states of damage evolution and strain. Only the strain at peak stress could be determined from the laboratory results.

\subsection{Damage States in Lithophysal Tuff}

First, a decision must be made about the damage state (limiting state) at which fracturing would be observable in the field. Clearly, the state at which the first micro-cracks appear would be an underestimate (even though it is recorded in the numerical test), because a few unconnected cracks would be unnoticed in both the field and in the laboratory. Three states were considered: (a) the state at which the volumetric strain rate reverses (from compaction to expansion); (b) the onset of systematic fracturing (OSF); and (c) the state at which the peak stress occurs (i.e., the strength of the sample).

Figure 6 illustrates typical fracturing (at the point when the sample is strained beyond the peak stress) that occurs in a PFC sample in which lithophysal holes are represented as circular voids. There usually is considerable damage (e.g., blue fractures in Figure 6) at the peak stress point. Note that most of the stress-induced fractures connect lithophysae, so it should be possible to distinguish them - in underground observations - from other types of fractures, such as cooling fractures. The state at the peak stress is certainly an upper bound to a strain for which the fractures connecting lithophysae would be visible in the ESF and the ECRB cross-drift. The state at volumetric strain reversal is associated with significant damage, as the sample ceases to behave as an elastic continuum. (Structural change, due to cracks, is the reason for volumetric expansion.) The strain at volumetric strain reversal is less than the strain at the peak stress. The strain at the peak stress can be determined from the data collected during the laboratory test. Unfortunately, the collected information during the tests is insufficient to determine strain at the volumetric strain reversal or any other damage state (except at the peak stress).

One of the advantages of numerical tests on synthetic models of rock is the ability to monitor evolution of damage much more precisely and at finer detail (at practically no additional cost) than is possible in the laboratory. Numerical models allow determination of OSF by direct monitoring of formation and propagation of macro cracks by coalescence of micro cracks. An algorithm for monitoring the evolution of microcracks has been developed and used in PFC simulations of uniaxial compressive tests on the lithophysal rock mass. These results justify use of the states at peak stress and volumetric strain reversal as conservative estimates of the damage state at which fracturing would be observable in the field. 


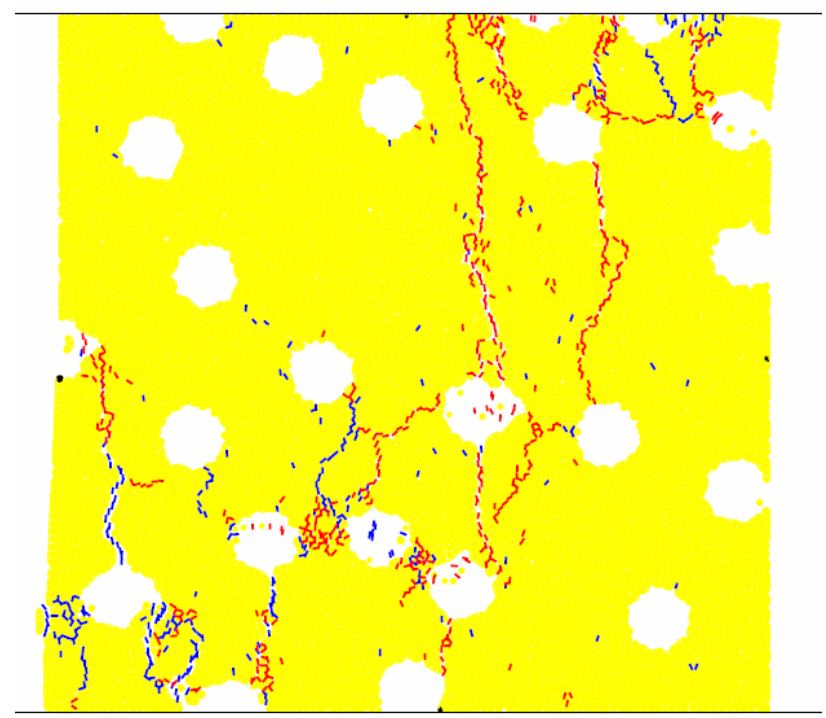

Figure 6 Fractures developed in lithophysal sample (blue $=$ pre-peak, red $=$ post-peak)

\subsection{Methodology for Calculation of Strain Increment}

The axial strain to a selected damage state (e.g., failure or state at peak stress, or OSF) cannot be used as the stain increment required to cause fracturing of lithophysal rock, because the axial strain measured in the laboratory corresponds to a certain uniaxial stress (and corresponding strain) path from the initial, unstressed state to the damage state. The rock mass exposed in the Yucca Mountain ESF and ECRB Cross-Drift is under an in-situ state of stress (strain) with a significant deviatoric component. (The horizontal principal stresses are between $30 \%$ and $60 \%$ of the vertical principal stress.) The shear-strain increment that causes stress change from an arbitrary initial stress state to a state on a surface (or line) in stress space that defines a limiting stress state (corresponding to a selected damage state) is calculated. The stress path from the initial stress state to the limiting damage state during a strong seismic ground motion can be arbitrary. In this analysis, the shear strain increment is calculated for the stress path in which the mean stress does not change (see Figure 7).

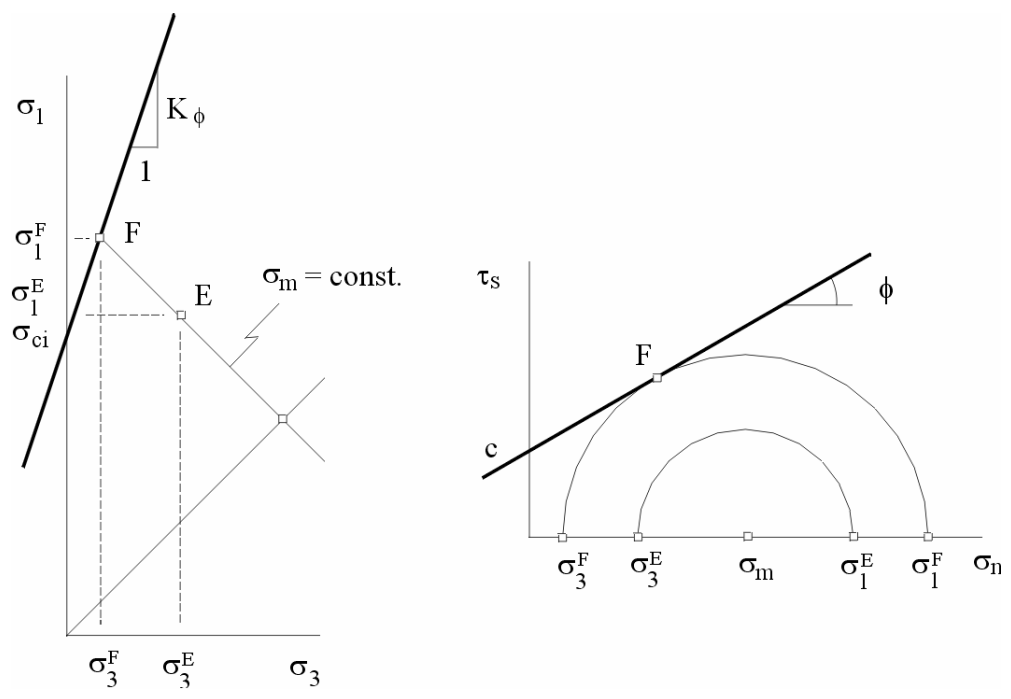




\section{Figure 7 Rock Mechanics Analysis of Absence of Seismic Damage in Lithophysal Units}

\subsection{Shear Strain Limits Estimated from Laboratory Results}

A large number of experiments was conducted on the samples from Topopah Spring tuff, both lithophysal and nonlithophysal. Testing of lithophysal tuff is particularly challenging because of lithophysal porosity, which makes preparation of the test samples very difficult. As expected, the mechanical properties of the lithophysal tuff exhibit strong size dependency. Therefore, the results obtained from the tests on the largest samples, 288-mm diameter cores taken from the ESF and ECRB Cross-Drift, are considered to be the best representation of the mechanical behavior of the lithophysal tuff. The shear strain increments were calculated for all laboratory results obtained on 288-mm diameter samples taken from the ESF and ECRB Cross-Drift. The experimental results were obtained for unconfined conditions only. A friction angle of $30^{\circ}$ was assumed in the calculation. This assumption is conservative, because the friction angle of the lithophysal rock is probably in the range of $40^{\circ}$, which results in smaller strain increment. The results for the $288-\mathrm{mm}$ diameter samples, divided into two categories based on height-to-diameter ratio $(H / D>1.5$ and $H / D \leq 1.5$ ), are shown in Figure 8 as a function of lithophysal porosity.

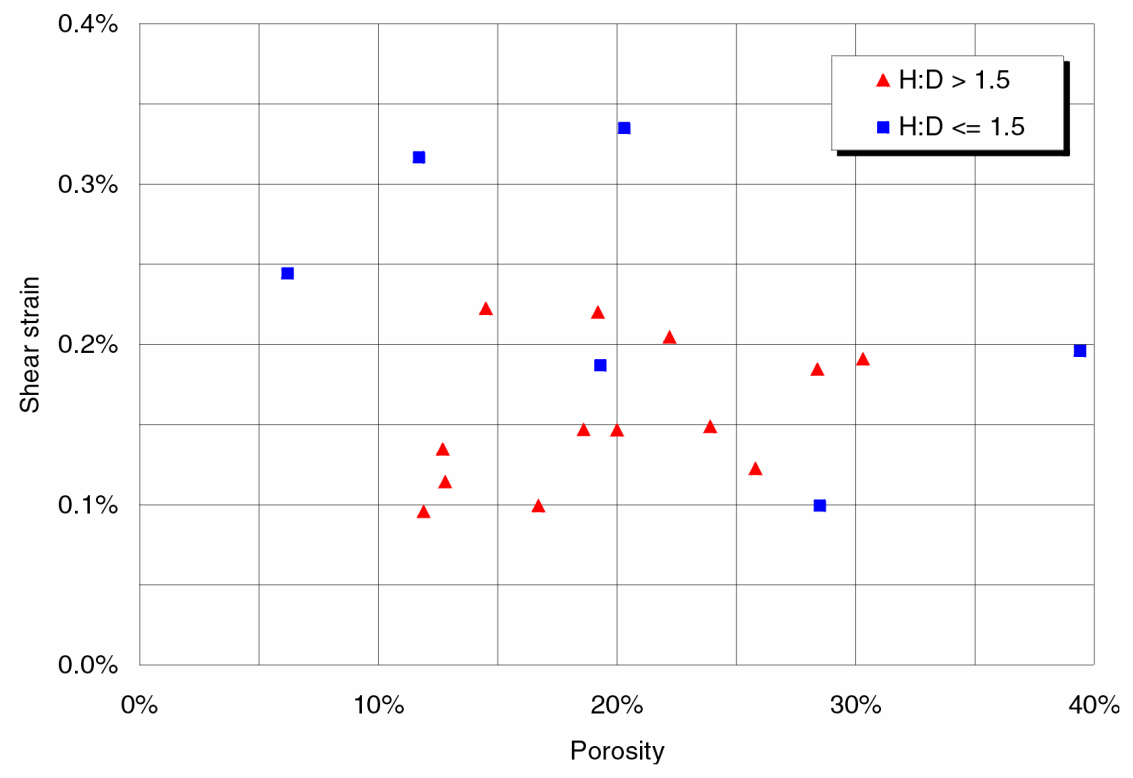

Figure 8 Calculated shear strain limit for 288-inch diameter samples

\subsection{Shear Strain Limits Estimated from Numerical Results}

The numerical models of the lithophysal rock mass first were calibrated to the results of the laboratory tests on samples with a certain lithophysal porosity. Subsequently, the effects of changing lithophysal porosity and shape of lithophysae were investigated. Thus, in the numerical analysis, it is assumed that lithophysal porosity and lithophysae shape are the only parameters affecting mechanical behavior of the lithophysal rock mass. This probably is the main reason the numerical results show less scatter than that observed in the laboratory tests. 
The shear strain increments are calculated for the state of volumetric strain reversal and the state at peak stress. The PFC samples were tested for unconfined conditions only. A friction angle of $30^{\circ}$ was assumed in calculating the shear strain increment based on PFC results. The UDEC samples were tested for both unconfined and confined conditions. The friction angle determined from the UDEC results was used in the calculating the shear strain increment based on UDEC results. The results for three types of 2D simulation are superimposed on each graph shown in Figure 9: (a) circular voids, modeled by PFC; (b) irregular (stencil) voids, modeled by PFC; and (c) circular voids, modeled by UDEC. The shear strain increments are calculated for two different levels of confining stress ( $250 \mathrm{~m}$ and $400 \mathrm{~m}$ of overburden) and two different assumptions about the damage state at which fracturing would be visible (reversal of volumetric strain rate or peak stress).

In Figure 9, the engineering shear strain (axial strain minus lateral strain) increment is plotted against lithophysal porosity for 400 overburden, and peak-stress criterion. On the figure, the three lines (and similarly colored points) correspond to the three types of model (PFC circular voids, PFC irregular voids and UDEC circular voids). Finally, "error" bars for \pm 1 standard deviation are plotted in the same color as the corresponding line.

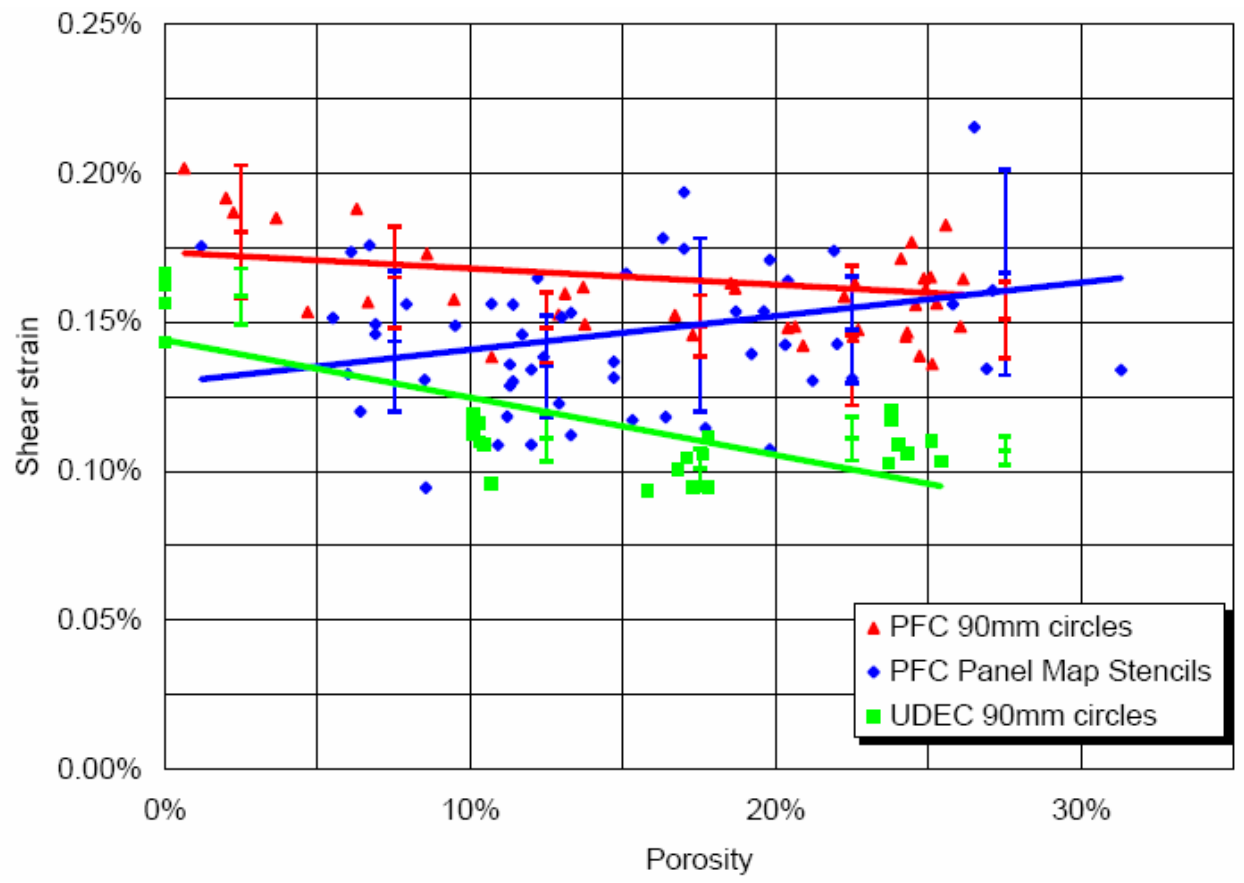

Figure 9 Shear strain vs porosity for peak-stress criterion; overburden $=400 \mathrm{~m}$

\subsection{Conclusions}

Re-analysis of the laboratory results and the results of numerical simulations has provided a correlation between the mean shear strain experienced by a rock mass and the damage on internal structures (lithophysae). Because it appears that no damage (i.e., systematic cracks around and between lithophysae) is observed at the site, then the maximum shear strain over geological time is likely to have been between $0.1 \%$ and $0.2 \%$. For the 288 -mm diameter samples (shown in Figure 8), which are probably the best representation of the mechanical behavior of lithophysal rock, the majority of the results are in the range between $0.1 \%$ and $0.2 \%$ of strain. 


\subsection{REFERENCE}

Itasca Consulting Group, Inc. (2004) FLAC (Fast Lagrangian Analysis of Continua), Version 5.0 User's Manual. Minneapolis: ICG. 


\title{
Strength of Faults and Maximum Stress-drops in Earthquakes
}

\author{
Christopher H. Scholz \\ Lamont-Doherty Earth Observatory, \\ Columbia Univ., Palisades, New York, 10964
}

\begin{abstract}
We investigate the strength of rock at the field scale and the maximum stress-drop that can occur within earthquakes by studying the displacement profiles of faults and earthquakes. The displacement to length ratio $\mathrm{D} / \mathrm{L}$ is in the range of $10^{-3}-10^{-2}$ for faults, indicating stress-drops in the range $1-10 \mathrm{~kb}$. These depend on lithology, with faults in sedimentary rocks at the lower end of the range and those in crystalline basement at the upper end. The $\mathrm{D} / \mathrm{L}$ range for large earthquakes is $10^{-5}-10^{-4}$, corresponding to stress-drops in the range 10 100 bars. Earthquakes and faults both tend to have linear displacement tapers near their tips. The magnitude of tip tapers indicate the rupture resistance near the propagating tip. For isolated faults and earthquakes the tip tapers (which are scale independent) have values that track with the $\mathrm{D} / \mathrm{L}$ ratios of the corresponding rupture. However, the tip tapers can be as much as an order of magnitude higher when the rupture tip interacts with the stress field of an adjacent rupture tip. For earthquakes, this indicates that stress-drops can locally be as high as a kb at such interacting regions as interior fault jogs, where the rupture encounters the end of the fault, or when the rupture tip enters the stress shadow of a previous earthquake.
\end{abstract}

\section{Introduction}

Two issues are addressed here, the strength of rock at the field scale and the maximum stress-drop that can occur within earthquakes. The approach is to study the displacement profiles of faults and earthquakes. The displacement amplitudes of faults scale linearly with length, the ratio of the two, D/L, is proportional to stress-drop, $\left(\sigma_{\mathrm{y}}\right.$ $\left.\sigma_{\mathrm{f}}\right)$, where $\sigma_{\mathrm{y}}$ is the yield strength of the rock and $\sigma_{\mathrm{f}}$ is the residual friction. The displacement gradients near the tips of earthquakes and faults are, generally, approximately linear. This feature is one of the predictions of the CFTT (critical fault tip taper) model, an elastic-plastic crack model that best agrees with fault observations (Scholz, 2002, pp. 16-17 and 115-121). In this model (the application to shear cracks of the CTOA model for Mode I cracks, see Kanninen and Popelar, 1985), the material in a volume around the fault tip is allowed to yield inelastically wherever the yield strength $\sigma_{\mathrm{y}}$ is exceeded. the CFTT is proportional to the stress-drop at the tip of the fault, and hence measures the local rupture resistance. In the case of an earthquake, D/L and CFTT are correspondingly proportional to the friction stress-drop $\left(\mu_{\mathrm{s}}-\mu_{\mathrm{d}}\right) \sigma_{\mathrm{n}}$. The CFTT, which measures a local stress drop, and $\mathrm{D} / \mathrm{L}$, which measures the mean stress drop, will not indicate the same stress drop value unless the rupture has propagated in uniform rock in a uniform stress field.

There are a number of predictions the model makes regarding CFTT. If the crack (fault or earthquake) propagated in a uniform rock and stress field, it would remain 
constant during propagation, i.e., CFTT is scale independent (see Newman et al., 2003). However, because strength depends on lithology but friction does not (Byerlee, 1978), CFTT should depend on rock type for faults but not for earthquakes.

\section{Mean Stress-drop of Faults and Earthquakes}

In both cases the scaling relationship between $\mathrm{D}$ and $\mathrm{L}$ is linear, as shown in Fig. 1 , but with very different scaling parameters. The $\mathrm{D} / \mathrm{L}$ ratio for large earthquakes range from $10^{-5}-10^{-4}$, corresponding to stress-drops of 10-100 bars. The primary systematics in this variation is between interplate and intraplate earthquakes, the latter having stressdrops averaging about 4 times higher than of the former (Scholz, 2002, p. 206-207). The faults have much higher $\mathrm{D} / \mathrm{L}$ ratios, in the range of $10^{-3}-10^{-2}$, corresponding to stressdrops of $1-10 \mathrm{~kb}$. These therefore represent lower bounds for the strength of rock at the field scale. In this case the variation correlates with lithology, the smaller D/L values are for small faults in sedimentary rocks and the larger ones for faults in crystalline basement. The conclusion is that the stress-drops for faults are typically two orders of magnitude greater than those for earthquakes. One of the questions we will ask is: can the local stress-drop within an earthquake be as high as the rock strength?

\section{Fault and Earthquake Tip Tapers and Local Stress-drops}

Figure 2 shows the displacement profiles for a number of isolated normal faults in the Volcanic Tablelands, eastern California, normalized to fault length. These faults range in length from 690-2200 m, and the good data collapse in Fig. 2 indicates that self-similarity extends to the entire profile, not just maximum displacement as indicated in Fig. 1. Notice that the tip taper is scaleindependent, as expected from the CFTT model.

FTTs (fault tip taper, the measured quantity, corresponds to CFTT only when it is measure along the centerline of a fault in a uniform rock type) are strongly dependent on stress interactions between faults and between earthquakes. For faults, the most common form of such interactions is when sub-parallel faults or fault segments overlap, such that the interacting tips lie within the stress shadows of the adjacent fault. The displacement profiles in such cases become asymmetric, in which the peak slip region is shifted towards the interacting tip and the FTT at that end becomes steeper than that of the distal end (Peacock, 1991; Peacock and Sanderson, 1993; Contreras et al., 2000). This occurs because the FTT at the interacting tip must overcome both the rupture resistance and the stress-drop of the adjacent fault (Willemse et al., 1996; Willemse, 1997; Scholz, 2002, p. 127-129). The degree to which FTTs can be augmented by such interactions is highly variable: it depends on the offset and separation of the fault tips (Gupta and Scholz, 2000). We are interested in this topic because earthquakes are often highly segmented, and segment boundaries are where strong interactions take place and the stress-drops are likely to be highest. We can investigate this by studying the earthquake tip taper of such interior segments.

Figure 3a shows the FTTs for the faults in the Bishop (welded tuff) in the Volcanic Tablelands (Dawers et al., 1963. These are all along the fault centerlines and hence true CFTTS (Scholz and Lawler, 2004). Average FTT for other isolated faults range from $1 \times 10^{-3}$ to $8 \times 10^{-2}$ and increase with rock strength. FTTs for interacting faults average $1.2 \times 10^{-1}$ with much more scatter. 
Table 1. Summary of tip taper data.

\begin{tabular}{c|cc} 
Rupture type & Ave.FTT & S.D. \\
\hline Isolated-all & $3.8 \mathrm{E}-2$ & $4.9 \mathrm{E}-2$ \\
Isolated-tuff & $5.1 \mathrm{E}-2$ & $2.1 \mathrm{E}-2$ \\
Isolated-granite & $8.0 \mathrm{E}-2$ & $7.6 \mathrm{E}-2$ \\
Isolated-seds. & $1.1 \mathrm{E}-2$ & $1.0 \mathrm{E}-2$ \\
Isolated-strikeslip & $5.0 \mathrm{E}-2$ & $4.5 \mathrm{E}-2$ \\
Isolated-normal & $3.6 \mathrm{E}-2$ & $4.9 \mathrm{E}-2$ \\
Interacting faults & $1.2 \mathrm{E}-1$ & $1.0 \mathrm{E}-1$ \\
Interior eqk & $1.4 \mathrm{E}-3$ & $1.3 \mathrm{E}-3$ \\
Exterior eqk. & $1.8 \mathrm{E}-4$ & $9.7 \mathrm{E}-5$
\end{tabular}

The CFTTs for large earthquakes (those with lengths $>30 \mathrm{~km}$, dashed line in Fig. $3 \mathrm{~b}$ ) are, like their $\mathrm{D} / \mathrm{L}$ ratios, about 2 orders of magnitude smaller than those of faults, averaging $1.8 \times 10^{-4}$. Interior tips of earthquake segments have FTTs about an order of magnitude steeper than the exterior tips of earthquakes. The steepest one we measured, for the Lone Pine segment of the 1872 Owens Valley earthquake, was 5x 10 ${ }^{-3}$, although that scarp was probably produced by three earthquakes (Lubitkin and Clark, 1988).

Examples of two types of earthquake interactions are shown in Figure 5. Figure 5a shows the slip distribution in the 1992 Landers earthquake on the Kickapoo fault, a 4 $\mathrm{km}$ long 'shunt' fault that runs obliquely through the extensional jog between the Johnson Valley fault and the Homestead Valley fault (Sowers et al., 1994). The strike-slip displacement goes to zero at each end of the Kickapoo fault and neither was mapped as touching the other two faults. This is thus an example of a strength barrier in which the rupture segment propagated to the ends of the fault, thereby encountering solid rock. The FTT at the north and south tip of the Kickapoo fault are 1.5 and $1.8 \times 10^{-3}$, respectively, a factor of 10 greater than the average value for non-interacting earthquake tips. The $\mathrm{D} / \mathrm{L}$ ratio for the Kickapoo fault was about $5 \times 10^{-3}$, about 10 times higher than for the Landers earthquake as a whole, also indicating a kb stress-drop there. The Landers rupture was impeded for several seconds at this point (Wald and Heaton, 1994), and dynamic modeling indicated an unusually high stress-drop there (Olson et al., 1997). A second example of this type of barrier is found in the 1959 Hegben Lake earthquake. This earthquake had two rupture segments. The western end of the west segment reached the end of the fault. It had a taper of $4 \times 10^{-3}$, ten times larger than three other tips (Whitkind, 1964).

The second type of earthquake interaction, a relaxation barrier, is shown in Fig. 5b, where the surface displacement distributions for the 1940 and 1979 Imperial Valley earthquakes are plotted. Inversions of geodetic and seismic data indicated that the slip at depth in the northern part of both events were somewhat higher than the surface values, about a meter for the 1940 and about half that for the 1979 event, but the deep slip at the southern end of the 1940 rupture was similar to the surface displacement profile (King and Thatcher, 1998). The potential slip accumulated on the Imperial fault between 1940 and 1979 is shown by the horizontal line, based on the estimate of $35 \pm 2 \mathrm{~mm} / \mathrm{yr}$ from GPS data (Bennett et al., 1996). Hence the 1940 stress-drop had by 1979 been recovered in the northern end of the rupture but not in the southern end, where the slip was greater than the accumulation line, indicating that a residual stress-drop existed in that region in 
1979. The 1979 earthquake ruptured the northern end of the 1940 rupture and then entered the stress shadow of the 1940 earthquake and abruptly stopped, with a high FTT of $1.6 \times 10^{-3}$, indicating the same type of interaction that has been observed for overlapping faults.

\section{Discussion}

The results above indicate that a minimum estimate for upper crustal strength is in the order of $10 \mathrm{~kb}$. Earthquake stress-drops can reach a factor of 10 higher than mean stress-drops in locally, at fault segment boundaries. Faults in the vicinity of Yucca Mtn. are intraplate faults, so should be expected to have stress-drips on the order of 100 bars, so local stress-drops within them can reach a $\mathrm{kb}$ or so.

There are seismological observations of $\mathrm{kb}$ stress drops as well. Munguia and Brune, 1984) found $\mathrm{kb}$ stress drop sub-events in the 1980 Victoria, Mexico earthquake (M 6.1). Mori and Shimazaki (1984) interpreted strong motion records of the 1968 Tokachi-oki M 7.9 earthquake as indicating several very high stress-drop subevents ( $4 \mathrm{~kb})$. A accelerometer at Cape Mendicino registered a high-frequency $2 \mathrm{~g}$ acceleration from the 1992 Petrolia (M 7) earthquake, whereas the nearby (6 km) station recorded a maximum of only $0.6 \mathrm{~g}$. Oglesby and Archuleta (1997), argued that this was a source effect and modelled it with as caused by the rupture of a high stress-drop asperity on this shallow dipping fault plane just below the Cape Mendicino station. They point out that this form of focusing can only occur along a normal from the fault plane connecting the asperity and station. Thus to determine whether of not such a focusing event can occur at Yucca Mountain, one needs to know the strike and dip of the nearby faults to see if a normal from the lower part of the fault plane (where such high strength features are likely to occur) can intersect the facility.

The results show that when earthquakes propagate to fault tips, their FTTs become an order of magitude larger than otherwise, but not the two orders of magnitude necessary to reach the rock strength there. However, faults grow incrementally, in earthquakes (Cowie and Scholz, 1993), as shown in a stepwise manner in Figure 6. At equilibrium the fault tip taper is CFTT (Fig. 6a). If an earthquake occurs on the fault and propagates to the fault's end, it will contribute its earthquake tip taper (ETT. Fig. 6b.). The fault responds by growing and increment $\Delta \mathrm{L}$ to restore the CFTT (fig. 6c.. There is no need for the ETT to be as large as the CFTT: the examples given above indicate that it is about a tenth of that. 


\section{Figures}

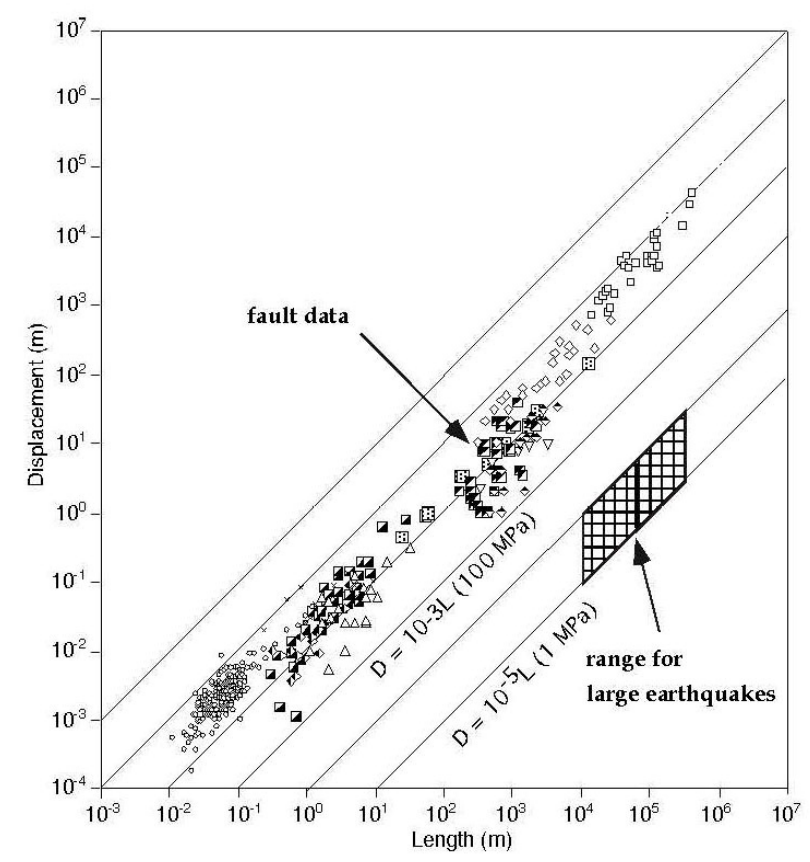

Figure 1. Scaling between displacement and length for earthquakes and faults. Fault data from Schlische et al., (1996).

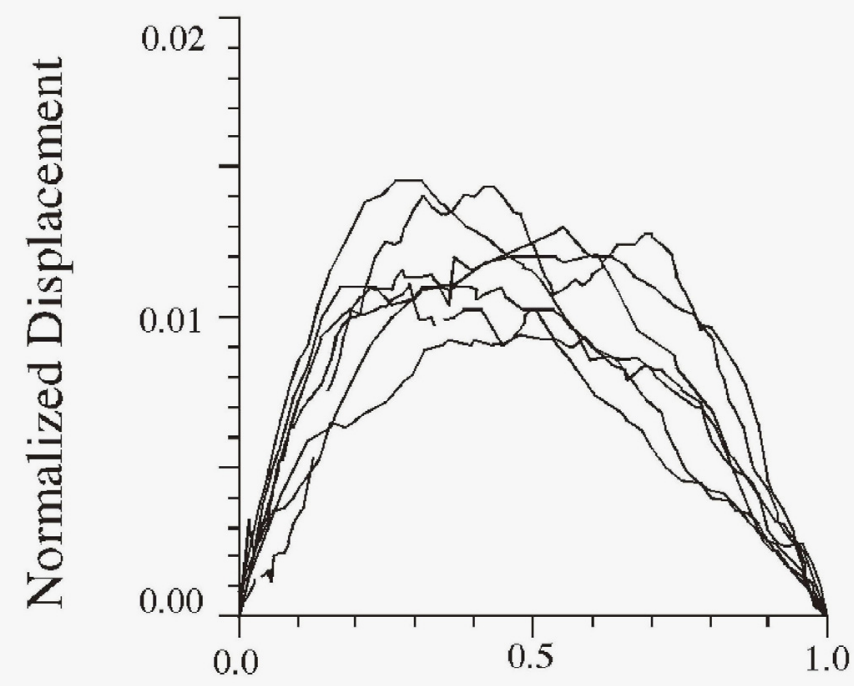

Normalized Distance Along Fault

Figure 2. Displacement profiles normalized to fault length for isolated faults with lengths from 690 to $2200 \mathrm{~m}$ in the Volcanic Tablelands, California. Data from Dawers et al. (1993). 

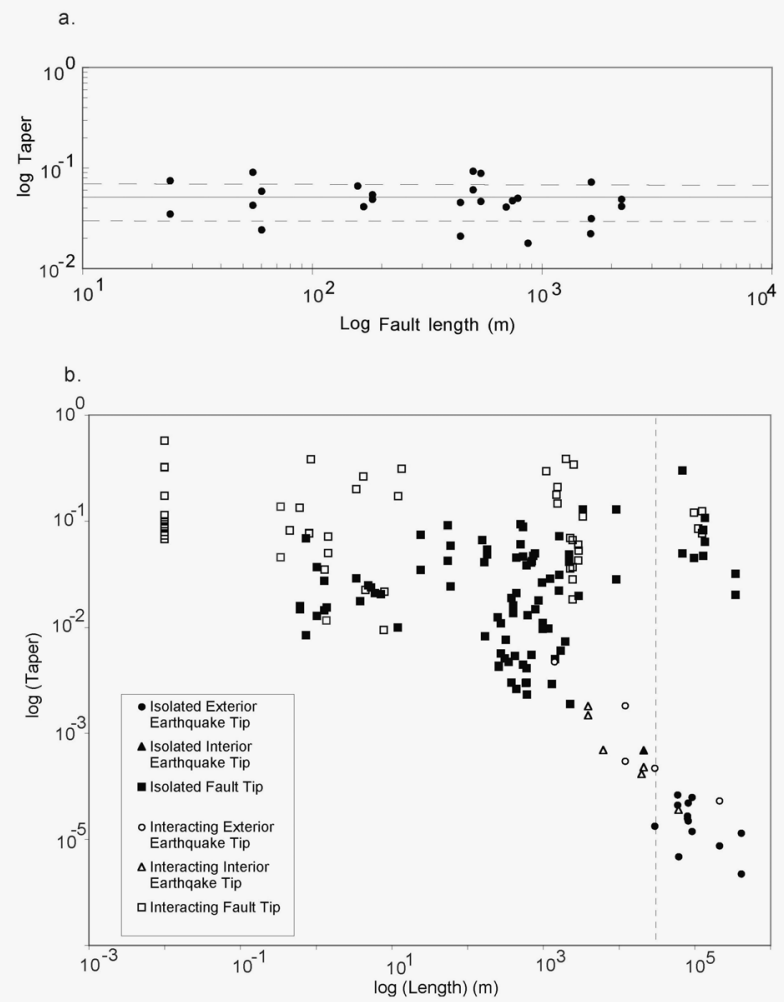

Figure 3. a) Fault tip tapers for a larger dataset of isolated faults in the Volcanic Tablelands (data from Dawers et al. (1993). b), tip tapers for a variety of faults and earthquakes (data from Scholz and Lawler, 2004).

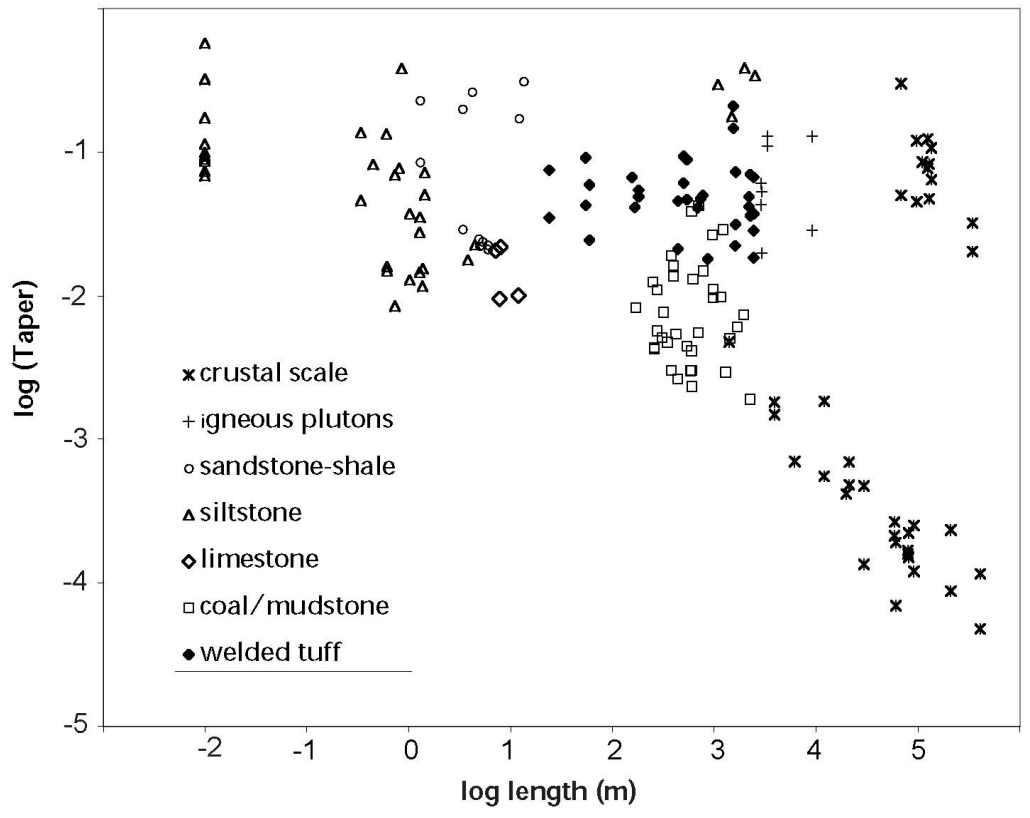

Figure 4. The same data as in Fig. 3b, sorted in terms of lithology (from Scholz and Lawler, 2004). 


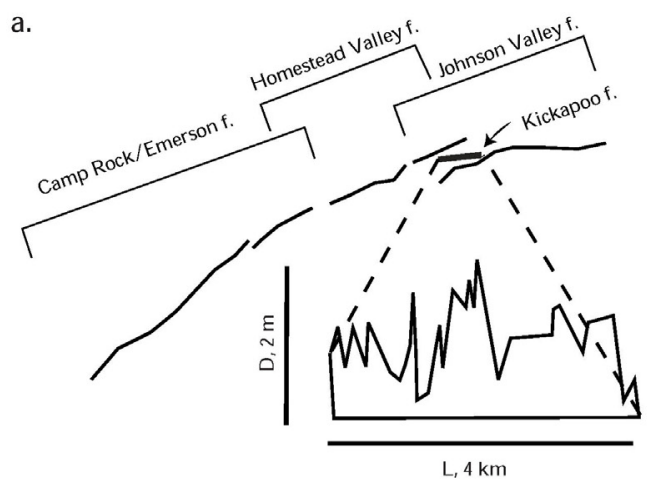

b.

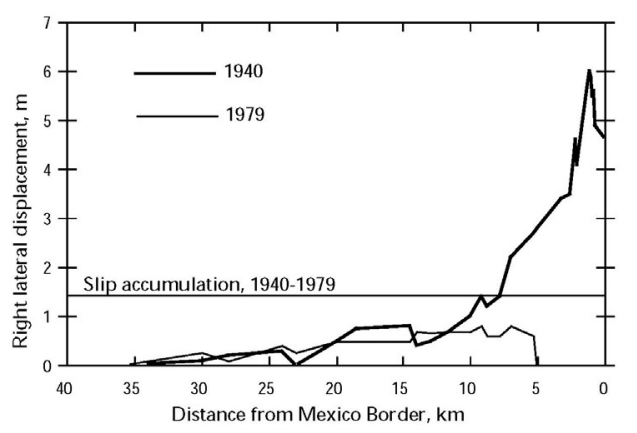

Figure 5. a) Slip distribution of the Kickapoo fault, linking the Johnson Valley faults and the Homestead Valley faults in the 1992 Landers earthquake (data from Sowers et al, 1994_.. b) Surface slip distributions in the 1940 and 1979 Imperial Valley earthquakes. (data from Sharp, 1982). 


\section{a}

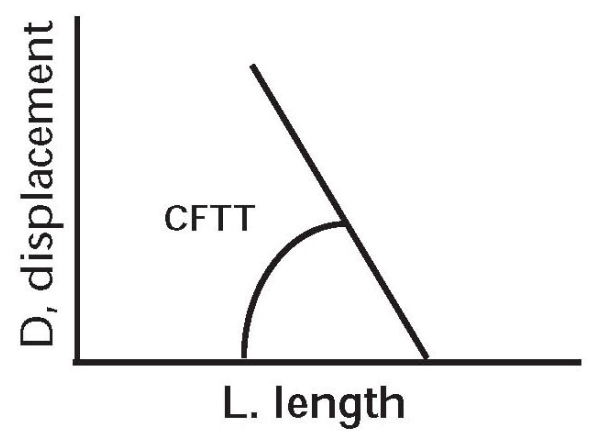

b
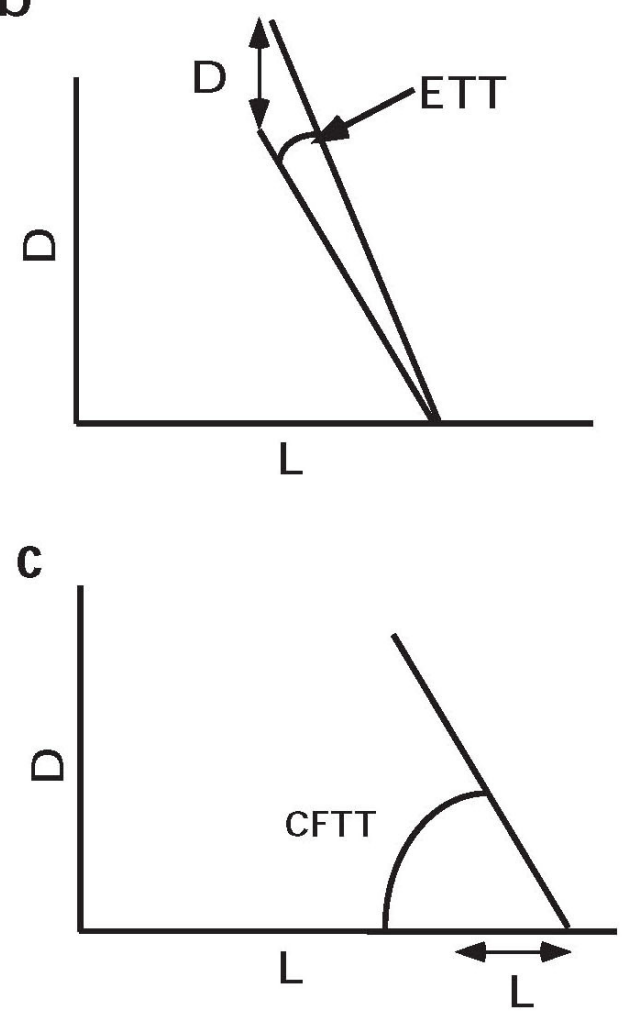

Fig. 6a shows the fault tip displacement taper at equilibrium, with the taper at the CFTT. In Fig. $6 \mathrm{~b}$, an earthquake has propagated to the end of the fault and added its increment of slip, D, and earthquake tip taper ETT. In response, the fault then grows an increment $\mathrm{L}$ to restore the taper to the CFTT. It is not necessary for the ETT to equal the CFTT (Cowie and Scholz, 1993). The ETT and its corresponding stress-drop is likely to be similar to what we have observed for interior earthquake segments, about a tenth of the rock strength. 


\section{References}

Bennett, R A., W. Rodi, and R.E. Reilinger, Global Positioning System constraints on fault slip rates in southern California and northern Baja, Mexico, J. Geophys. Res. , 101, 21,943-21,960, 1996.

Byerlee, J. Friction of Rocks. Pure and Applied Geophy. 116: 615-626, 1978.

Contreras, J., M. H. Anders, and C. H. Scholz, Growth of a normal fault system: observations from the Lake Malawi basin of the east African rift. J. Struct. Geol. 22, 159-1682000.

Cowie, P. A., and Scholz, C.H. Growth of faults by accumulation of seismic slip. J. Geophys. Res. 97(B7), 11085-11095 (1992b).

Dawers, N.H., M.H. Anders, and C.H . Scholz, Growth of normal faults: Displacement-length scaling. Geology 21: 1107-1110, 1993.

Gupta, A., and C.H. Scholz, A model of normal fault interaction based on observations and theory. J. Struct. Geol. 22: 865-879, 2000.

Kanninen, M. F. \& Popelar, C. H. Advanced Fracture Mechanics , Oxford Univ. Press, Oxford, 1985.

King, N.E., and W. Thatcher, The coseismic slip distribution of the 1940 and 1979 Imperial Valley, California, earthquakes and their implications, J. Geophys. Res, 103, 18,069-18,086, 1998.

Lubetkin, L. K. C., and M. M. Clark, Late Quaternary activity along the Lone Pine fault, eastern California, Geol. Soc. Amer. Bull. 100, 755-766, 1988.

Newman, J. C., M. A. James, and U. Zerbst, A review of the CTOA/CTOD fracture criterion, Eng. Fracture Mech. 70, 371-385, 2003.

Mori, J. and Shimazaki, K., High stress-drops of of short period sub-events form the 1968 Tokachi-oki earthquakes as observed on strong ground motion records, Bull. Seismo. Soc. Am., 74, 1529-1544, 1984.

Munguia, L., and J. N. Brune, Simulations of strong ground motions for earthquakes in the Mexicali-Imperial Valley, Geophys. J. R. Astron. Soc., 79, 747-771, 1984.

Oglesby, D. D. and R.J. Archuleta, A faulting model for the 1992 Petrolia earthquake: Can extreme ground acceleration be a source effect?, J. Geophys. Res., 102, 11,877-11,897, 1997.

Olsen, K. B., R. Madariaga, and R. J. Archuleta, Three-dimensional dynamic simulation of the 1992 Landers earthquake. Science 278, 834-838, 1997.

Peacock, D.C.P. Displacements and segment linkage in strike-slip fault zones. J. Struct. Geol. 13: 1025-1035, 1991.

Peacock, D.C.P., and D.J. Sanderson, Displacements, segment linkage and relay ramps in normal-fault zones. J. Struct. Geol. 13: 721-734, 1991.

Schlische, R.W., S.S. Young, , R.V. Ackermann,., and A. Gupta, Geometry and scaling relations of a population of very small rift-related normal faults, Geology 24:683686, 1996.

Scholz, C.H. 2002. The Mechanics of Earthquakes and Faulting, 2nd ed. Cambridge University Press:Cambridge, UK.

Scholz, C.H. and T.M. Lawler, Displacement tip tapers for faults and earthquake, sub. GRL, 2004.

Sharp, R.V. Comparison of 1979 surface faulting with earlier displacements in the Imperial Valley, in The Imperial Valley, California, earthquake of October 15, 1979, Geol. Surv. Prof. Paper 1254, p. 213-222, 1982. 
Sowers, J.M., J.R. Unruh, W.R Lettis, and T.D. Rubin, Relationship of the Kickapoo fault to the Johnson Valley and Homestead Valley faults, San Bernardino County, California. Bull. Seis. Soc. Am. 84: 528-536, 1994.

Wald, D.J. and T.H. Heaton, Spatial and temporal distribution of slip for the 1992 Landers, California, Earthquake. Bull. Seis. Soc. Am. 84: 668-691, 1994.

Whitkind, I.J., in The Hebgen Lake, Montana Earthquake of August 17, 1959, pp 37-50, USGS Prof. Pap. 435, 1964.

Willemse, E.J.M.. Segmented normal faults: Correspondence between three dimensional mechanical models and field data. J.Geophys.Res.-Solid Earth 102: 675-692, 1997

Willemse, E.J.M., D.D. Pollard, and A. Aydin, Three-dimensional analyses of slip distributions on normal fault arrays with consequences for fault scaling. J.Struct.Geol. 18: 295-309, 1996. 


\title{
PHYSICAL CONSTRAINTS ON UPPER BOUND GROUND MOTIONS
}

\author{
Paul Somerville and Arben Pitarka
}

URS Group Inc., Pasadena

\section{INTRODUCTION}

We examine two physical conditions that may place constraints on the upper bound levels of ground motions. First, we describe observations of weak ground motions from shallow faulting earthquakes. We also note that near-fault peak velocities may be bounded by the magnitude scaling of the period of the rupture directivity pulse. We then proceed to describe kinematic simulations of upper bound ground motions, using the inverse correlation between two strongly influential parameters, rupture area and rise time for a fixed magnitude event, to place bounds on the ground motions. We summarize the implications of these results for upper ground motions at Yucca Mountain, and suggest topics for further research.

\section{REDUCTION OF GROUND MOTIONS FROM SHALLOW FAULTING}

Earthquakes typically nucleate near the bottom of the seismogenic rupture zone in the crust. Large earthquakes usually break the surface, but small earthquakes usually do not. Over one-half of the earthquakes in the magnitude range of 6.0 to 6.5 do not break the surface; this fraction decreases to about one-third for the magnitude range of 6.5 to 7 , and about one-fifth of earthquakes in the magnitude range of 7.0 to 7.5 (Lettis et al., 1997). If it is assumed that all of the slip on a fault occurs during earthquakes, then larger earthquakes are characterized by relatively larger amounts of shallow slip than are smaller earthquakes.

These differences in the depth distribution of slip and are important, because it appears that the ground motions generated by earthquakes that do not have large shallow asperities are stronger than those of earthquakes that do. Recent large earthquakes having large surface slip, including the 2002 Denali, 1999 Kocaeli, and 1999 Chi-Chi events, have surprisingly weak ground motions at short and intermediate periods. These new observations are consistent with our finding from previous earthquakes that the strong ground motions of earthquakes that have shallow asperities (top of asperity is shallower than $5 \mathrm{~km}$ ) are weaker than the ground motions of events whose asperities are all deep (Kagawa et al., 2004; Somerville, 2003). The large differences in ground motion levels between these two categories of events are illustrated in Figure 1, which shows the response spectra of near-fault recordings of recent large earthquakes. The left panel shows recordings from four shallow earthquakes in the $\mathrm{M}_{\mathrm{w}}$ range of 7.4 to 7.9 , and the right panel shows recordings from two deep earthquakes of magnitude $M_{w} 6.7$ and 7.0. The response spectra of the deep earthquakes are much stronger than those of the larger shallow earthquakes for periods less than $1.5 \mathrm{sec}$.

Comparing the distribution of slip with depth, averaged along strike, in the top part of Figure 2, this difference in ground motions between shallow and deep events seems paradoxical because the shallow events have much larger near-surface displacements. However, slip velocity is a much more important determinant of strong motion levels than fault slip alone. The effective slip velocity is defined by Ishii et al. (2000) as the slip velocity averaged over the time in which the slip grows from $10 \%$ to $70 \%$ of its final 
value, and represents the dynamic stress drop. As shown in Figure 3, the distribution of effective slip velocity with depth for shallow events is quite different from the distribution of slip with depth. The shallow events have large near-surface displacements, but they do not have correspondingly large slip velocities. The slip velocities of the deep events are larger than those of the shallow events, causing larger ground motion levels because slip velocity is an important determinant of strong motion levels. Averaged over 9 shallow events and 8 deep events, the slip velocity of shallow events is about $70 \%$ that of deep events. This is true both for the fault as a whole and for the asperities on the fault. This difference in slip velocity between shallow and deep events is an important aspect of earthquake source characterization for the simulation of strong ground motion. For a given seismic moment, the rupture areas of shallow events are larger, and hence their static stress drops and smaller, than those of deep events, which may also contribute to the difference on ground motions (Kagawa et al., 2004).

The fracture energy and stress intensity factor are found to be large for surface faulting events, and small for subsurface faults. Large fracture energy events may produce mainly long period seismic radiation. This is consistent with surface faulting events producing weak high frequency ground motions. The features of rupture in the shallow part of fault $(0-5 \mathrm{~km}$ depth) are controlled by velocity strengthening, with larger slip weakening distance Dc, larger fracture energy, i.e. much energy absorbed from the crack tip, lower rupture velocity, lower slip velocity, and lower ground motions than buried faulting events.

\section{ESTIMATES OF UPPER BOUND GROUND MOTIONS IN THE PEGASOS PROJECT}

We performed kinematic strong motion simulations based on earthquake source models that use the source scaling relations of Somerville et al. (2001) for the central and eastern United States. In order to establish the upper limit ground motion level, we considered three earthquake mechanisms and performed a large number of ground motion simulations. For each event, parametric uncertainty in a set of source characteristics was applied using multiple representations. The source parameters that were varied include slip model (s), depth (d), rupture area (ra), slip contrast (sc), hypocenter location (hy), rupture velocity (rv), rise time (rt). Where single parameter values were involved, the randomness was represented using median (M), upper (U), and lower (L) bound values; these variations (e.g. Urt) are indicated along the horizontal axis of Figure 4. The effect of each source parameter on the ground motion was evaluated based on simulations in which one of these parameters was varied while the others were kept fixed at their median value. Median ground motion values were derived from simulations that used median values of the source parameters. Upper limit values of ground motions were derived from simulations that used combinations of upper bound values of source parameters that most strongly affected the ground motion. The rupture area and rise time as well as their combination with supershear rupture velocity most strongly affect the ground motion level over a broad frequency range. The combination of extremely small rupture area and short rise time gives rise to extremely large ground motions.

Constraints were placed on upper bound ground motions based on correlation of source parameters. The two source parameters that have the strongest influence on ground motions, rupture area and rise time, have an inverse correlation. Combinations of 
small rupture area and short rise time (Max2 in Figure 4) give rise to very large ground motions that are considered unphysical, because the small rupture area requires a large average displacement, which should be accompanied by a longer than median rise time, not shorter than median rise time. An even more extreme (and unphysical) set of scenarios adds supersonic rupture velocity to this combination of parameters (Extreme in Figure 4). These scenarios use combinations of small rupture area, small rise time, and super shear rupture time, together with the maximizing values of the other parameters (upper slip contrast, subsurface fault and reverse faulting mechanism). Because of the extremely low joint probability of occurrence of all of these extreme source parameters, we regard them as being unphysical.

\section{PHYSICAL FACTORS LIMITING GROUND MOTIONS AT YUCCA MOUNTAIN}

\section{Shallow Faulting}

Shallow faulting has low slip velocity and hence lower ground motions than buried faulting. We need separate ground motion models for shallow and buried faulting. These models might each have lower aleatory variability, and the shallow faulting model will have much lower median values. Ground motion amplitudes from shallow faulting earthquakes may have been overestimated in the Yucca Mountain PSHA

\section{Rupture Directivity}

Upper bound ground motions at Yucca Mountain are controlled by rupture directivity effects. The amplitude of the directivity pulse is controlled by the rupture velocity, which is limited to the Rayleigh wave velocity or to supershear values. The period of the pulse increases with magnitude, bounding the magnitude scaling of the peak velocity of the directivity pulse (Somerville, 2003).

\section{SUGGESTIONS FOR FUTHER RESEARCH}

\section{Rupture Dynamics}

- Use rupture dynamics to establish a physical basis for differences in source parameters between shallow and buried faulting earthquakes

- Examine correlation between source parameters such as rupture velocity and rise time in kinematic and dynamic rupture models of past earthquakes, including normal faulting earthquakes

- Develop the capability to model differences in ground motions between shallow and buried earthquakes

- Use dynamic rupture models of normal faulting earthquakes to identify physical bounds on source parameters and ground motions

\section{Probabilistic Seismic Hazard Analysis}

- Identify the depth of faulting of earthquakes on the Solitario Canyon fault

- Use separate ground motion models for shallow and buried faulting in YM PSHA - lower median value for shallow faulting

- lower variability about the median for both shallow and buried faulting 
- This may result in a reduction of this fault's contribution to the hazard at low probabilities

\section{Wave Propagation}

- The Yucca Mountain volcanics constitute a basin-like environment - trapping of body waves that enter the volcanics from their margins

- Triplications, caustics and focusing effects can potentially cause large amplification of ground motions

- Look for evidence of amplification or deamplification in Yucca Mountain strong motion recordings from local and regional earthquakes and NTS events

\section{REFERENCES}

Ishii, T., T. Sato and Paul G. Somerville (2000). Identification of main rupture areas of heterogeneous fault models for strong motion estimation. J. Struct. Constr. Eng., AIJ, No. $527,61-70$.

Kagawa, T., K. Irikura and P. Somerville (2004). Differences in ground motion and fault rupture process between the surface and buried rupture earthquakes. Earth, Planets and Space 56, 314.

Lettis, W.R., D.L. Wells, and J.N. Baldwin (1997). Empirical observations regarding reverse earthquakes, blind thrust faults, and quaternary deformation: are blind thrust faults truly blind? Bull. Seism. Soc. Am., 87, 1171-1198.

Pitarka, A. and P.G. Somerville (2002). Numerical Simulations for Evaluation of Median and Upper Limit Ground Motions in Switzerland. Report to September 15, 2002

Somerville, P.G. (2003). Magnitude scaling of the near fault rupture directivity pulse. Phys. Earth.Planetary.Int., 137, 201-212.

Somerville, P.G., N. Collins, N. Abrahamson, R. Graves and C. Saikia (2001). Earthquake source scaling and ground motion attenuation relations for the central and eastern United States. Report to the USGS.
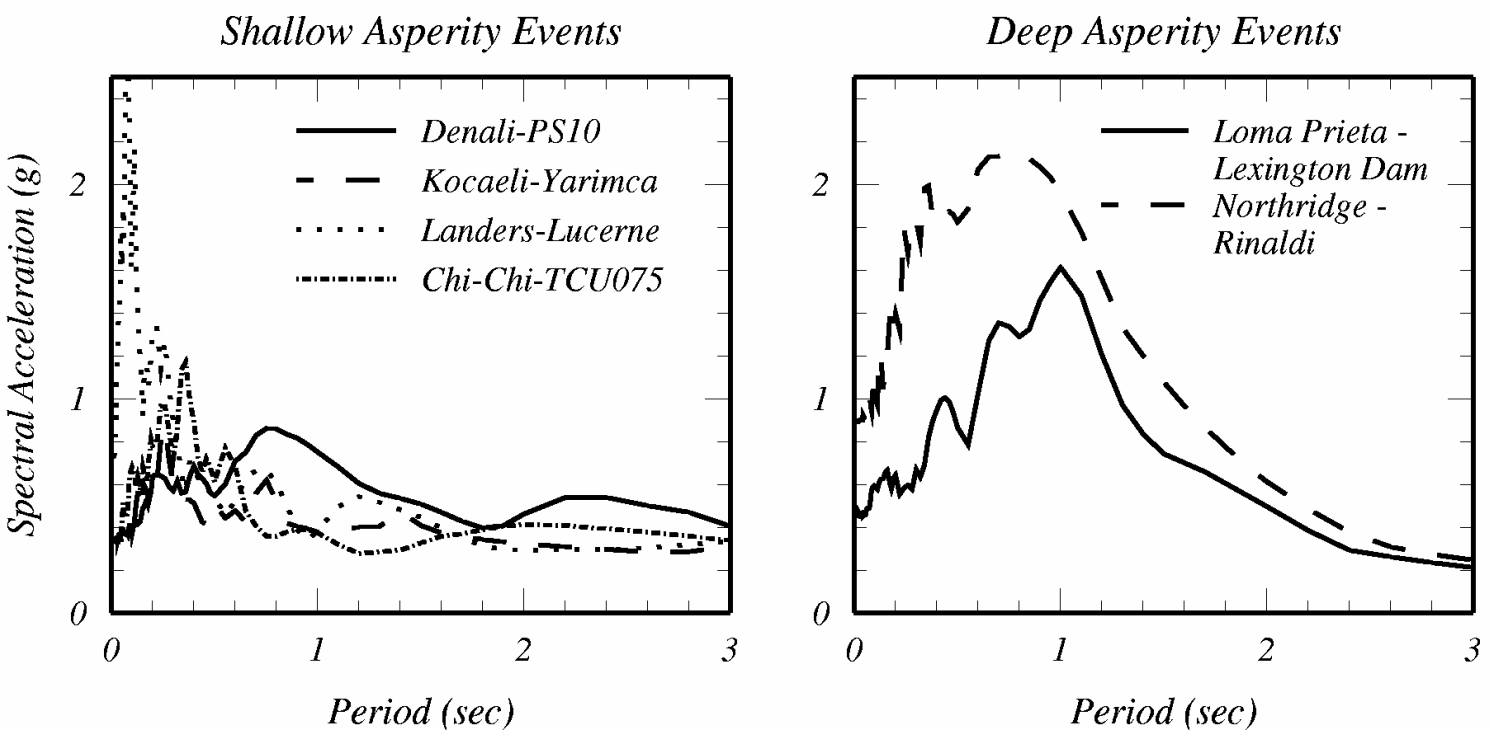

Figure 1. Near-fault response spectra of recent large earthquakes. Left: Four earthquakes, Mw 7.2 to 7.9, with shallow asperities and large surface faulting. Right: Two earthquakes, Mw 6.7 and 7.0, with deep asperities and no surface faulting. 


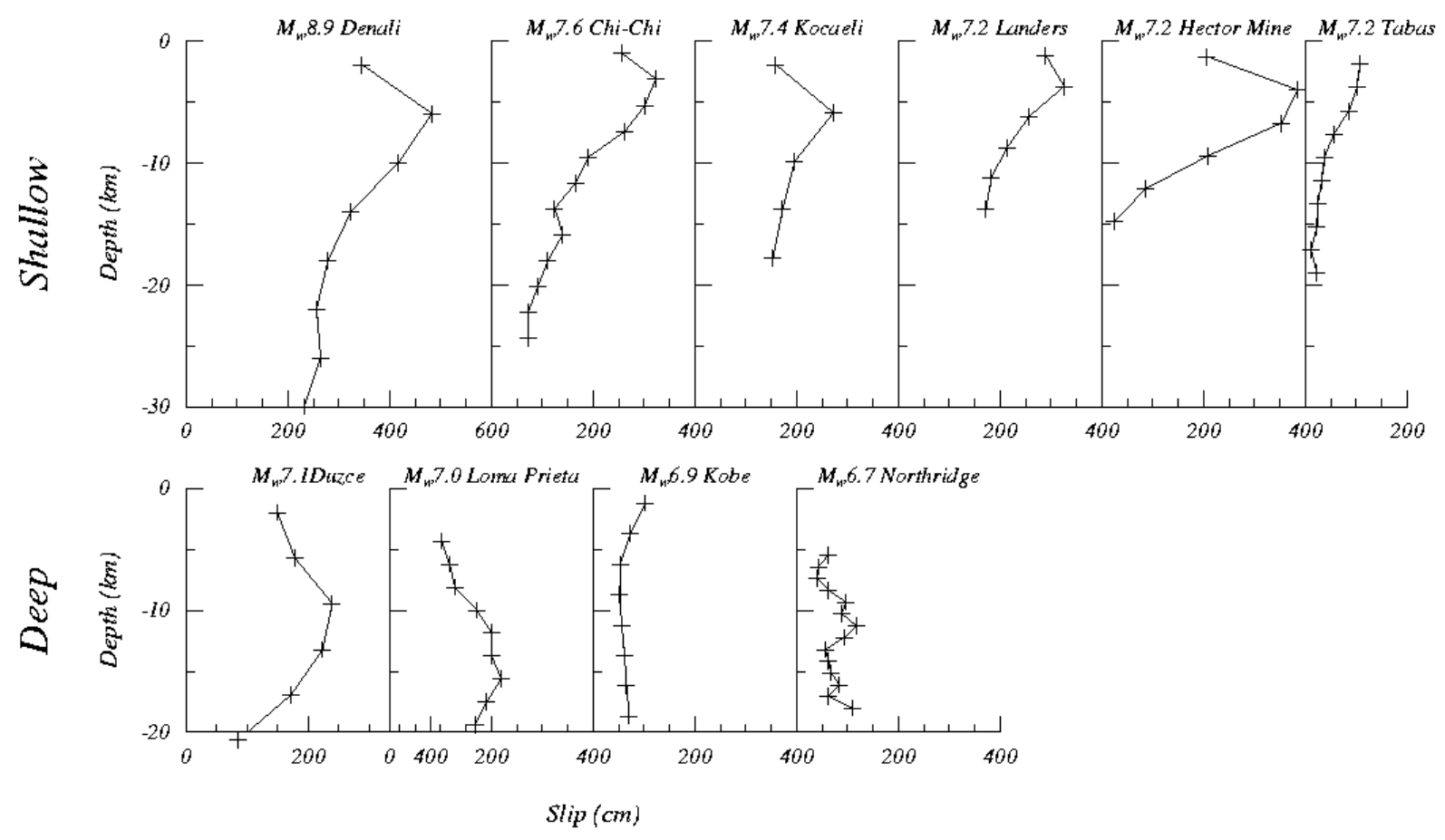

Figure 2. Distribution of slip for shallow (top) and deep (bottom) earthquakes.
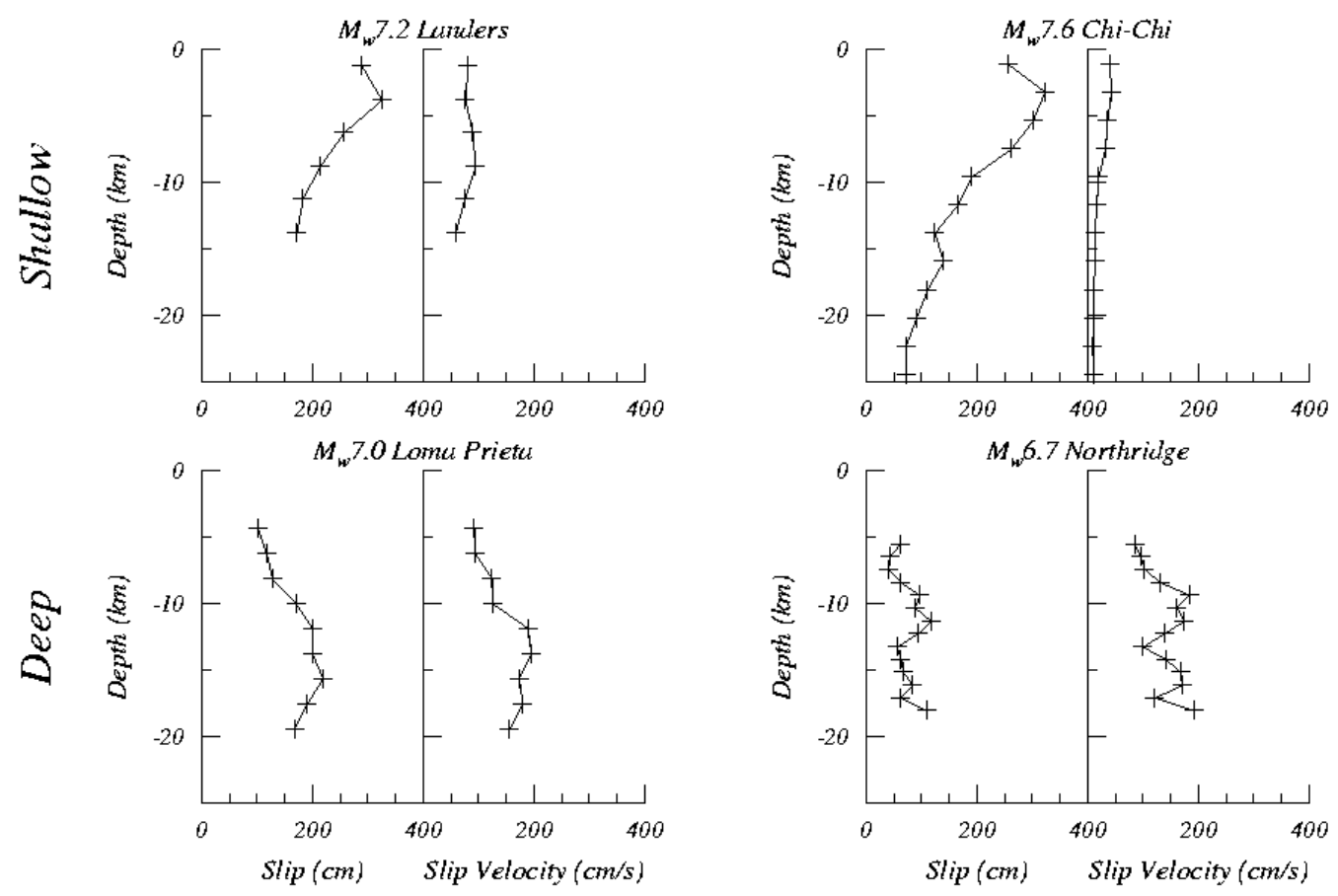

Figure 3. Distribution of slip (left) and slip velocity (right) for shallow (top) and deep (bottom) earthquakes. The left side shows two strike-slip earthquakes and the right side shows two thrust earthquakes. 


\section{M7.0,r05,Average Horizontal}

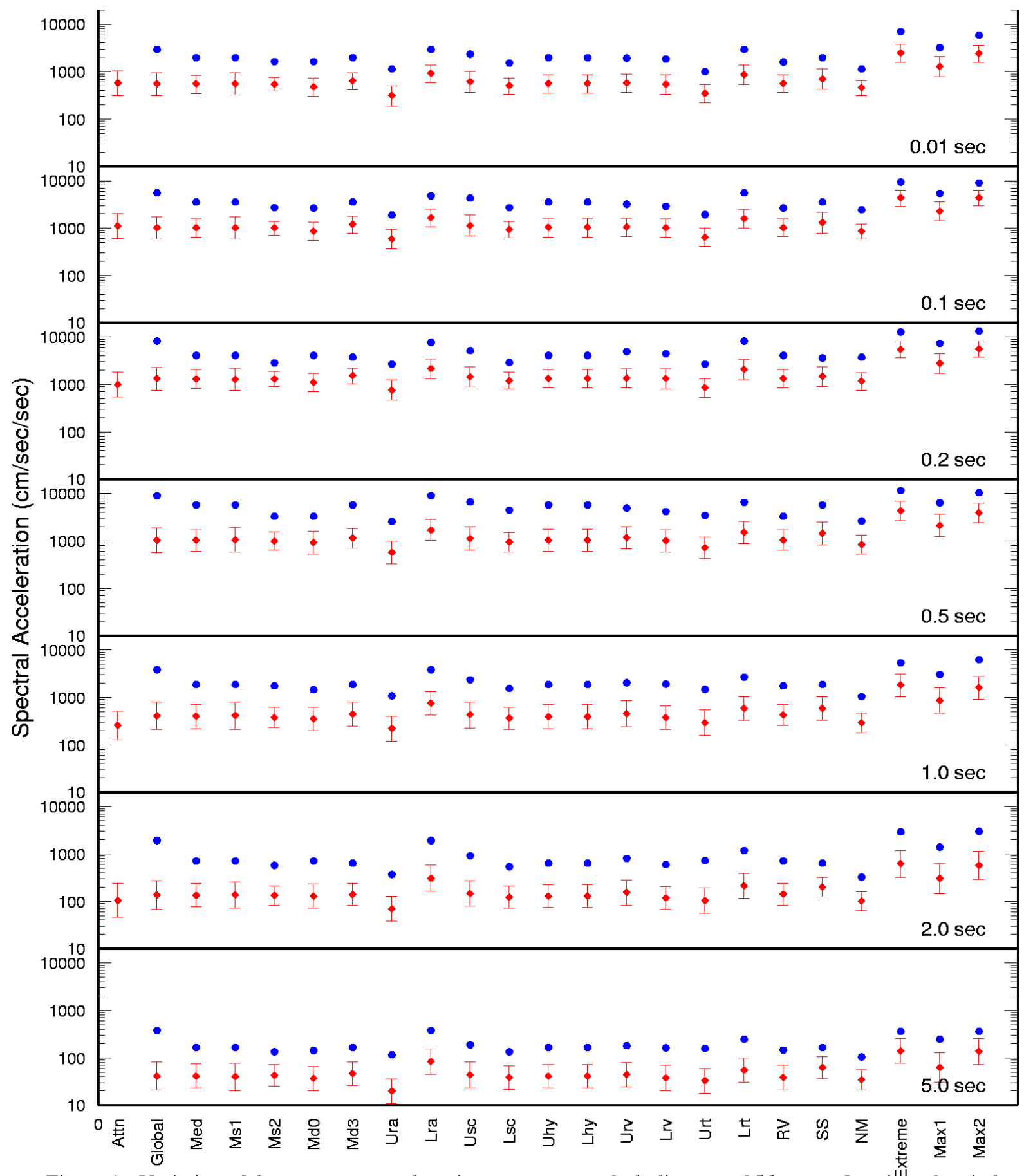

Figure 4a. Variation of the average ground motion response at a fault distance of $5 \mathrm{~km}$ as a functiơ of period calculted for M7.0 scenario earthquakes indicated at the bottom of the figure. The median $+/-$ one standard deviation, and maximum simulated ground motion levels are shown. For detailed explanation see text 
Workshop on Extreme Ground Motions at Yucca Mountain

August 23-25, 2004, Menlo Park, CA

\section{A STOCHASTIC APPROACH TO PREDICTING SOURCE EFFECTS ON EXTREME GROUND MOTION}

G. C. Beroza, Department of Geophysics, Stanford, CA, 94305-2215, beroza@geo.stanford.edu; P. Martin Mai, Department of Earth Sciences, Institute of Geophysics, ETH Hoenggerberg, CH-8093, Zurich, Switzerland, mai@sed.ethz.ch.

We propose a stochastic approach for predicting extreme strong ground motion at low hazard levels. Our approach builds on previous work to characterize the scaling (Mai and Beroza, 2000) and spatial variability (Mai and Beroza, 2002) of earthquake slip. These stochastic slip distributions are used to develop the temporal behavior of slip using physically consistent stochastic-dynamic earthquake source models (Guatteri et al., 2003) or pseudo-dynamic approximations to such models (Guatteri et al., 2004). The premise of our approach is that we may be able to gain useful bounds on extreme ground motion by systematically exploring source models that are consistent with past earthquakes, but that occur at low probability and exhibit especially pernicious source properties, such as locally very high stress drop.

\section{Source Parameter Scaling for Heterogeneous Slip Distributions}

A number of scaling-relations have been proposed to estimate source dimensions for given magnitude M (Wells and Coppersmith, 1994 (henceforth denoted WC), Hanks and Bakun, 2002; Mai and Beroza, 2000; Somerville et al., 1999), however only the latter two studies considered the effect of heterogeneous slip. The MB-relations and the WC-relations seem similar, but differ substantially if we focus on the lower tails of the fault-length, $L$, and fault-width, $W$, populations. This translates into very different average displacement, $D$, and hence a very different level of strong ground motion.

For the repository site, the closest fault capable of generating moderate to large earthquakes is the Solitario Canyon Fault, located approximately $1.5 \mathrm{~km}$ to the west. From geological maps, we estimate the total length of the fault to be $\sim 12 \mathrm{~km}$, potentially separated into 3 individual segments (North segment $\sim 5.4 \mathrm{~km}$; Central segment $\sim 2.6 \mathrm{~km}$, and Southern segment $\sim 4.0 \mathrm{~km}$ ).

We consider a $\mathbf{M}=6.75$ earthquake on this fault to assess the source characteristics for extreme ground-motion simulations. Using the above lower-tail estimate of fault width, we calculate the expected average slip for two different fault lengths: $L_{\text {surf }}=12 \mathrm{~km}$, the length of the visible surface-fault expression, and $L_{s u b s}=16 \mathrm{~km}$, the assumed sub-surface fault length based on Wells and Coppersmith, 1994). For $\mathbf{M}=6.75$, we obtain $D=3.0-4.0 \mathrm{~m}$ and $D=3.5-4.7 \mathrm{~m}$ for the WC- and MB-relations, respectively. These are very high values, leading to very high stress drops (Figure 1) and potentially very damaging near-source ground motions. A recent earthquake with somewhat similar source characteristics, however, is the $\mathbf{M}=6.6 \mathrm{Bam}$ earthquake in 2003 that occurred on a very short fault $(\mathrm{L} \sim 15 \mathrm{~km}$ ) with slip of 2-3 m locally (Jonsson et al., 2004), resulting in devastating ground motions and the destruction of the city of Bam. 


\section{Representing and Simulating Slip Variability with Random Field Models}

The variability of slip, slip-velocity, and rupture time maps directly into high frequency strong ground motions. It is therefore crucial to adequately model these source quantities in a self-consistent, physically constrained way. Our approach involves the characterization of spatially variable slip as a spatial random-field model (Mai and Beroza, 2002) that captures slip variability as observed in past earthquakes. In the second step, we model rupture time and rise time (peak slip-velocity) using principles of earthquake rupture dynamics.

The spatial random field can characterized in the spectral domain by its power spectral density, $P(k)$, where $k$ is the wavenumber. Mai and Beroza (2002) found that a von Karman autocorrelation function slip with magnitude-dependent correlation length best represents the observed power spectral decay of earthquake slip models. Analyzing the spectral behavior of 44 source models, Mai and Beroza (2002) found that the spectral decay at high wavenumbers occurs with Hurst exponent $H=[0.8-1.0]$, while the correlation lengths scale with magnitude roughly as $a_{x} \approx 2.0+1 / 3 L\left(\right.$ or $\left.\log \left(a_{x}\right) \approx-2.5+1 / 2 M_{w}\right)$, and $a_{z} \approx 1.0+1 / 3 W\left(\operatorname{or} \log \left(a_{z}\right) \approx-1.5+\right.$ $1 / 3 M_{w}$ ). Using such scaling relations ensures that our models will be statistically consistent with past earthquakes.

We use the static stress drop, $\Delta \tau$, associated with slip on the rupture plane, to develop the temporal slip evolution. We relate slip to stress using a convolutional integral (Andrews, 1980) expressed as a multiplication in the wavenumber domain, as $\Delta \tau(\boldsymbol{k})=-K(\boldsymbol{k}) \cdot D(\boldsymbol{k})$ where $\tau(\boldsymbol{k})$ and $D(\boldsymbol{k})$ denote the two-dimensional stress drop $\Delta \tau(x, z)$ and slip-function $D(x, z)$, respectively in the wavenumber domain, and $K(\boldsymbol{k})$ is the static stiffness function. Recent work has calibrated this method against analytical solutions (Okada, 1992) and the method by Bouchon, 1997), extending the Andrews-model to include both in-plane and anti-plane stresses (Ripperger and Mai, 2004).
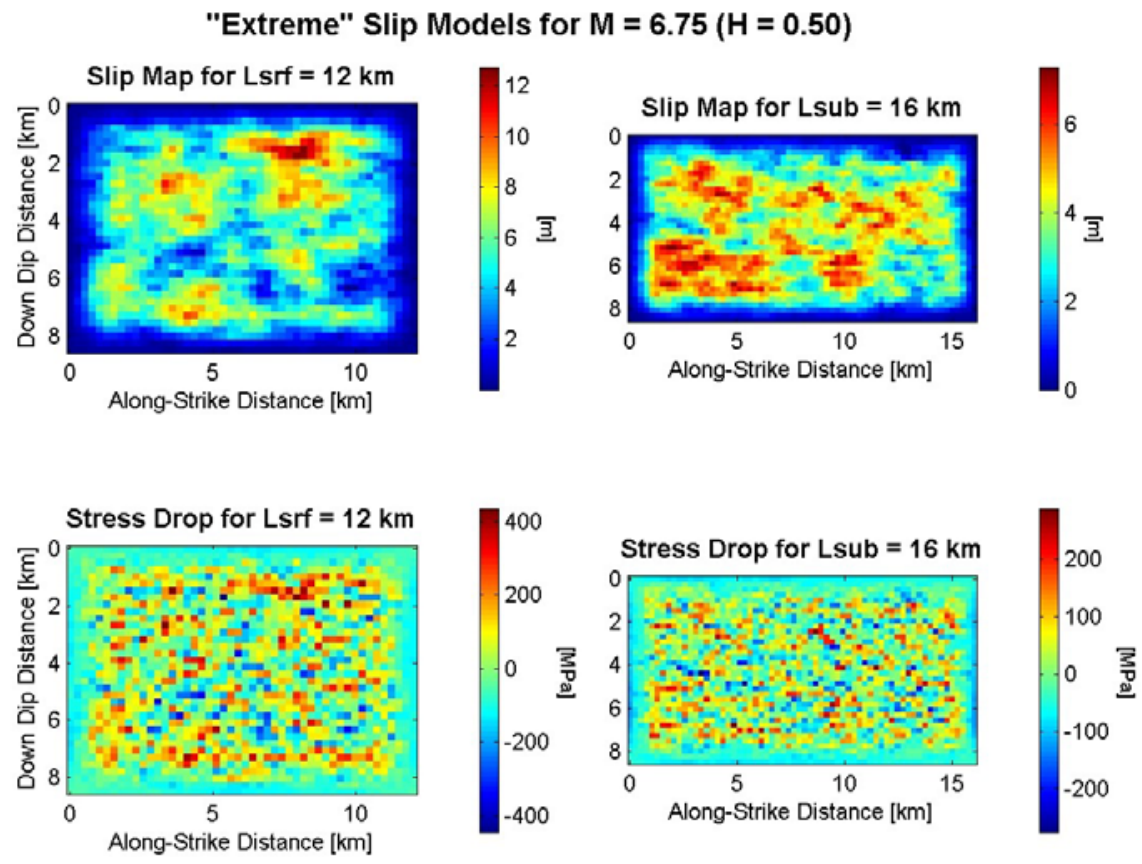

Figure 1. Slip (upper) and associate stress drop (lower) distributions for an Mw 6.75 earthquake on the Solitario Canyon fault under two assumptions of the extent of faulting (see text). Slip in the first model exceeds 10 meters and stress drops in both models are locally as high as several kilobars. 


\section{Physically Consistent Rupture Velocity and Rise Time}

With the above approach, we generate physically consistent slip distributions, but rather than assuming a purely kinematic rupture time distribution, we develop physically consistent rupture propagation and the slip durations. We follow Guatteri et al. (2004) to compute the temporal slip evolution using the pseudo-dynamic source modeling approach. From stochastic-dynamic modeling of dynamic rupture Guatteri et al., 2003) derived empirical relations linking fracture energy $G_{c}$ to the stress-intensity factor $\Delta \tau \cdot L_{c}{ }^{1 / 2}$, where $L_{c}$ denotes the crack length (taken as the distance to the hypocenter). Fracture energy and stress drop control rupture velocity as low fracture energy promotes fast rupture propagation, while high fracture energy decelerates rupture propagation. This behavior is given by a relationship between rupture velocity, crack length, and stress drop for an anti-plane crack (Andrews, 1976): $1-v^{2} / \beta^{2}=\pi^{2} \cdot\left(R_{c} / 2\right)^{2}$, where $R_{\mathrm{c}}$ is a dimensionless parameter: $R_{c}=\mu \cdot G_{c} /\left(\Delta \tau^{2} \cdot L_{c}\right), v$ is the rupture velocity, $\beta$ is the shear wave velocity, $\mu$ is the shear modulus, $\Delta \tau$ is the stress drop, and $L_{c}$ is crack length.

The slip duration at each point on the fault is controlled by healing phases coming from the fault edges as well as healing phases generated internally on the rupture plane due to the prevailing stress conditions. Guatteri et al., 2003) derived an empirical relationship that reflects such behavior of the rise time, using the previously computed rupture-onset time at each point and the total effective fault rupture duration.

The pseudo-dynamic source-modeling methodology is essentially kinematic, but it embodies a codification of relations between source parameters such as the joint variation of stress drop and rupture velocity in dynamic rupture models. The pseudo-dynamic approach allows us to efficiently generate a huge number of source models covering a wide parameter range, that are stochastically consistent with past earthquakes and have physically consistent rupture-velocity and rise-time distributions. It also allows us to explore strong-ground motions excited by extreme source models for which: (1) the source dimensions are chosen to be at the lower tails of faultlength/fault-width distributions; (2) average stress-drops as well as localized stress drops are on the order of kilobars; (3) rupture propagation velocity approach the local shear-wave velocity (or even become super-shear); (4) local slip-durations are very short, which in conjunction with large-slip will result in extreme peak-slip velocities.

\section{Conclusions and Recommendations}

(1) As currently formulated, our approach is based only on a small population of events that are predominantly either strike-slip or reverse faulting earthquakes. Moreover, while it reproduces the observed distribution of source parameters in past earthquakes, the constraints on slip are primarily statistical, rather than physical in nature.

(2) On the plus side, it may be that statistical bounds on the behavior of the source translate into tighter bounds on the source than are obtained through the application of the sort of "improbabilistic seismic hazard analysis" (the application of PSHA at extremely low probabilities of exceedence) that has been performed to date.

(3) Moreover, the pseudo-dynamic approach may be the ideal way to translate physical

bounds on source parameters and the correlations among them, into physical bounds on ground motion. 


\section{References}

Andrews, D.J., Rupture propagation with finite stress in antiplane strain, J. Geophys. Res., 81 (20), 3575-3582, 1976.

Andrews, D.J., Fault impedance and earthquake energy in the Fourier transform domain, Bulletin of the Seismological Society of America, 70 (5), 1683-1698, 1980.

Bouchon, M., The state of stress on some faults of the San Andreas system as inferred from near-field strong motion data, Journal of Geophysical Research-Solid Earth, 102 (B6), 11731-11744, 1997.

Guatteri, M., P.M. Mai, and G.C. Beroza, A Pseudo-Dynamic Approximation to Dynamic rupture Models for Strong Ground Motion Prediction, Bull. Seismol. Soc. Am (in press), 2004.

Guatteri, M., P.M. Mai, G.C. Beroza, and J. Boatwright, Strong ground-motion prediction from stochastic-dynamic source models, Bulletin of the Seismological Society of America, 93 (1), 301-313, 2003.

Hanks, T.C., and W.H. Bakun, A bilinear source-scaling model for M-log A observations of continental earthquakes, Bulletin of the Seismological Society of America, 92 (5), 1841-1846, 2002.

Mai, P.M., and G.C. Beroza, Source scaling properties from finite-fault-rupture models, Bulletin of the Seismological Society of America, 90 (3), 604-615, 2000.

Mai, P.M., and G.C. Beroza, A spatial random field model to characterize complexity in earthquake slip, Journal of Geophysical Research-Solid Earth, 107 (B11), art. no.-2308, 2002.

Okada, Y., Internal Deformation Due to Shear and Tensile Faults in a Half- Space, Bulletin of the Seismological Society of America, 82 (2), 1018-1040, 1992.

Ripperger, J., and P.M. Mai, Fast computation of static stress changes on 2D faults fromfinal slip distributions, submitted to Geophys. Res. Lett., 2004.

Somerville, P., K. Irikura, R. Graves, S. Sawada, D.J. Wald, N. Abrahmason, Y. Iwasaki, T. Kagawa, N. Smith, and A. Kowada, Characterizing crustal earthquake slip models for the prediction of strong ground motion, Seismological Research Letters, 70 (1), 59-80, 1999.

Wells, D.L., and K.J. Coppersmith, New empirical relationships among magnitude, rupture length, rupture width, rupture area, and surface displacement, Bulletin of the Seismological Society of America, 84 (4), 974-1002, 1994. 


\section{Large amplitude PGA's and PGV's and arms stress drop variability}

John Anderson

Nevada Seismological Laboratory

MS 174

University of Nevada

Reno, Nevada 89557

775-784-4265

jga@seismo.unr.edu

This paper reviewed and presented figures showing extreme accelerations and extreme velocities. Figure 1 shows the statistics of extreme accelerations, and Figure 2 shows the statistics of extreme recorded velocities. Figure 1 shows 35 records that have been identified with peak accelerations greater than $800 \mathrm{~cm} / \mathrm{s} 2$. Figure 3 shows about 25 records for which one or more component exceeded $75 \mathrm{~cm} / \mathrm{s}$. These are roughly the thresholds of extreme motions that we will investigate.

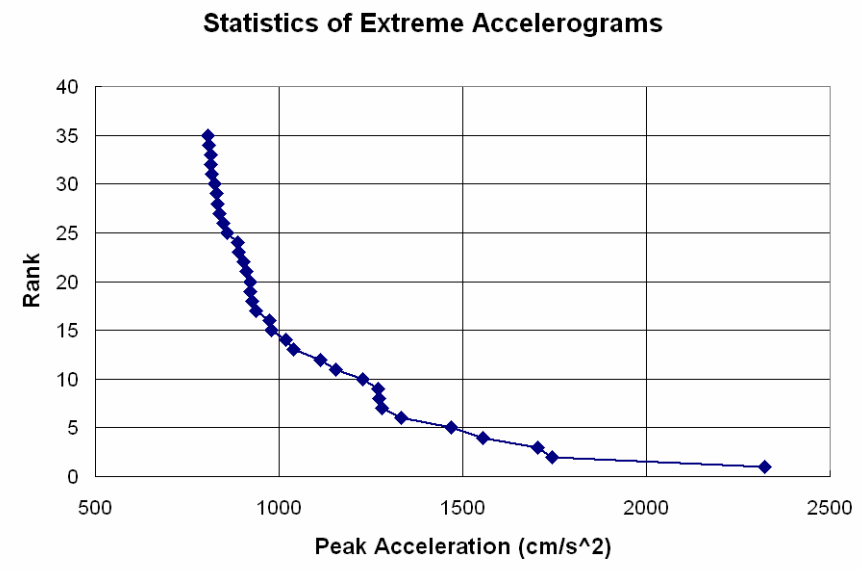

Figure 1. Extreme accelerations. The table with extreme records has been drawn from the COSMOS database. 
NGA Data v3.1

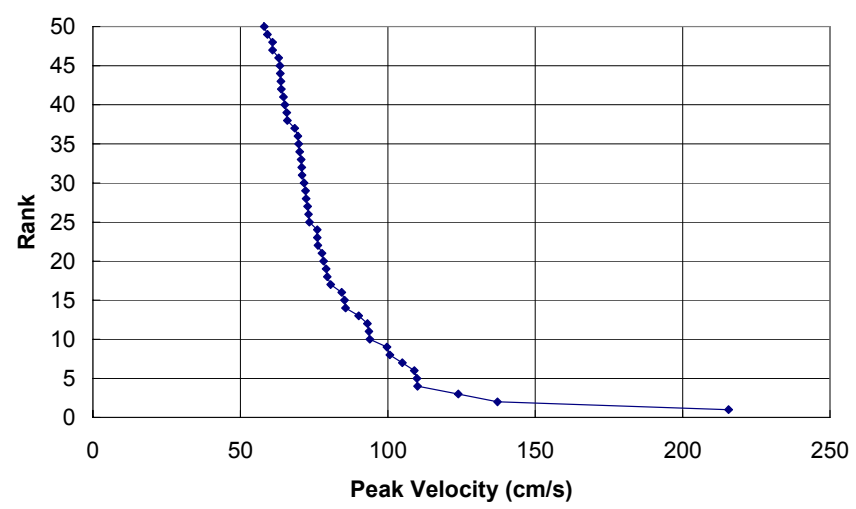

Figure 2. Extreme velocities. The table with extreme velocity records has been drawn from the PEER NGA database.

My presentation at the Workshop on Extreme Ground Motions at Yucca Mountain focused on the results of a preliminary review of some of these records. The very preliminary impression is that most of the extreme velocities are associated with nearfault pulses for earthquakes with $\mathrm{M}>6$. However, that remains to be examined in more details.

Several of the extreme accelerations are shown in Figure 3. Figure 3 shows horizontal components of the records, even if the maximum acceleration occurred on the vertical component, thus explaining why some of these records appear to have peaks that are smaller than $80 \%$ of gravity. The 36 accelerograms identified so far with peak acceleration in excess of $800 \mathrm{~cm} / \mathrm{s} 2$ come from 22 earthquakes, 1971-2003. Two earthquakes contribute six records each: Japan, 200, 3 May 26, MW=7.0 (HRV), Depth $=61 \mathrm{~km}$, and Northridge, 1994, MW=6.7, shallow. Of these records, 14 accelerograms from 12 earthquakes caused peak acceleration in excess of $1 \mathrm{~g}$. On $78 \%$ of the records, the horizontal component was the strongest.

A preliminary conclusion presented at the workshop is that all cases of extreme accelerations occur in one or more of the following limited set of conditions:

- Thrust faulting: $69 \%$

- Hanging wall: $47 \%$

- Not sure if this percentage is different from the distribution of mechanisms in the overall data set. The fact that none of these are from normal faulting may merely represent the lack of normal faulting data.

- Forward directivity: $\geq 33 \%$

- Dam abutments (Topographic amplification): 20\%

- Site Condition

- Soil site condition: $\geq 33 \%$

- Recognizable strong resonance: $6 \%$

- Deep source (perhaps very high stress drop): $20 \%$

- The parameter kappa is less than $30 \mathrm{~ms}$ on all but one of the records examined. 
- Several of the peaks occur in isolated spikes that are much greater than the rest of the record.

There was no obvious tendency for the extreme peak accelerations to occur more frequently with higher magnitude events. The preliminary study found more points in the magnitude 6.5-7 range than at higher magnitudes. However, most of the overall data set is also in that range, so I did not come to any conclusions yet on the statistical significance if any of that observation. Spectral amplitudes at high frequencies and rms acceleration showed a similar lack of magnitude trend.

The preliminary conclusions also examined a few records from Japan, where the extreme ground motions were recorded on the Kiknet stations with a downhole accelerogram also available. Record accelerations at the surface correspond to accelerations of under $20 \% \mathrm{~g}$ at $100 \mathrm{~m}$ depth at $4 / 5$ stations, and to accelerations of $300-600 \mathrm{~cm} / \mathrm{s} 2$ at the last station.

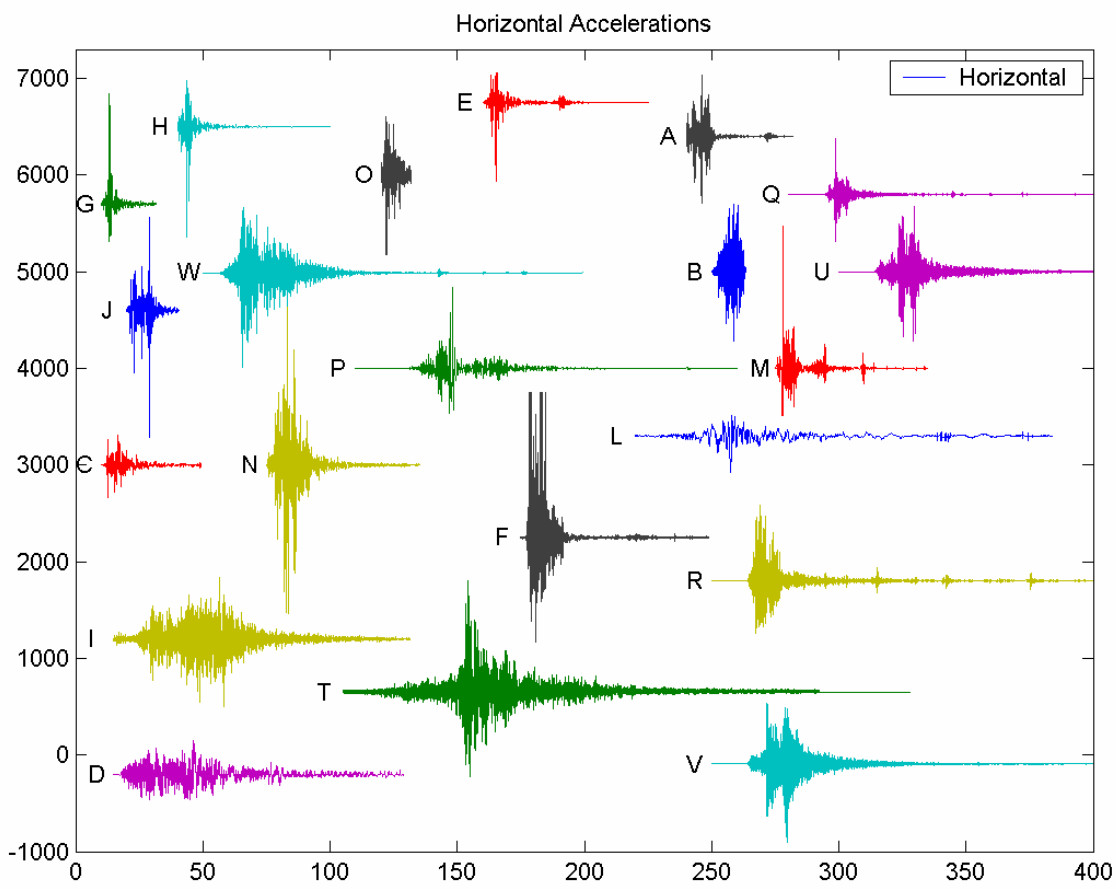

Figure 3. Several extreme accelerograms plotted on a common scale. 


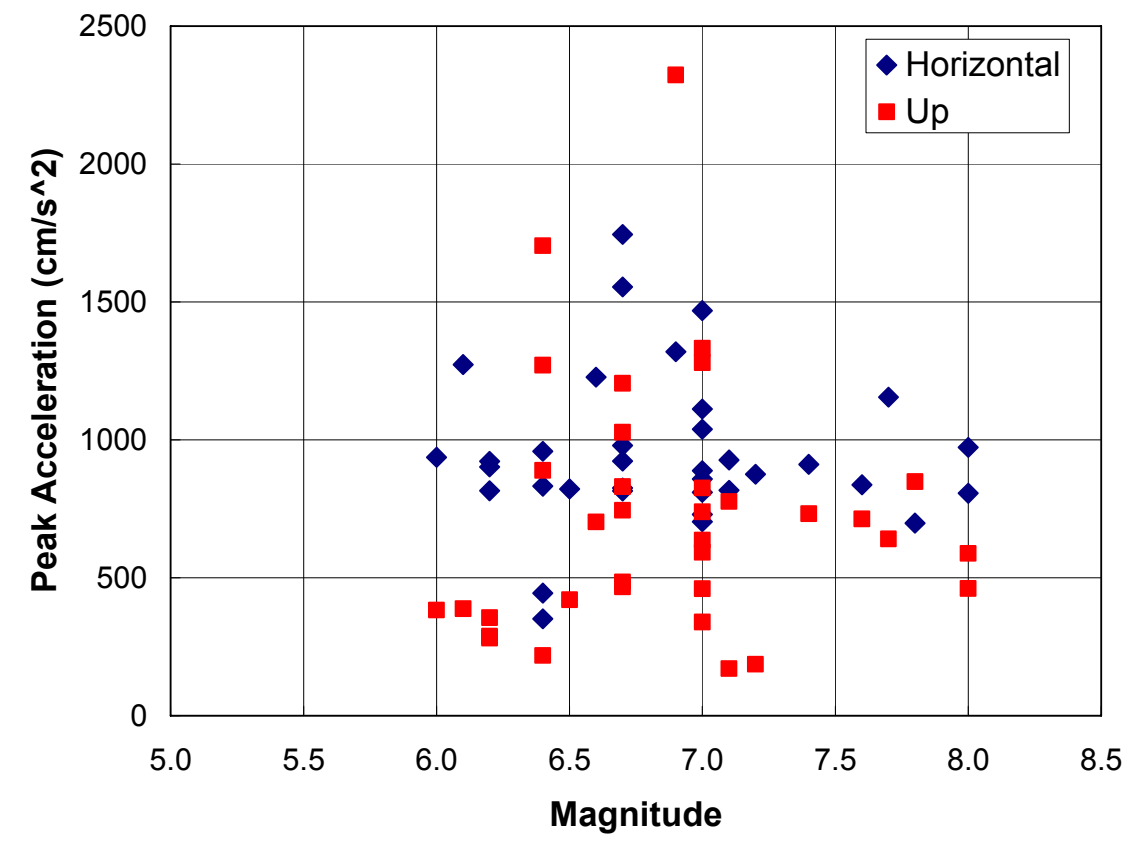

Figure 4. Peak accelerations as a function of the earthquake magnitude. The criteria for being included is that at least one of the components on the accelerogram exceeded 800 $\mathrm{cm} / \mathrm{s} 2$.

\section{Conclusions}

- Extreme velocities appear to have forward directivity or large earthquakes

- Extreme accelerations examined all have one or more of the following:

- Thrust,

- Forward directivity

- Soft site

- Abutment (topography)

- Deep source

- Caveat: : normal faulting is barely represented.

- Surface/downhole pairs for extreme accelerations are much stronger at the surface.

\section{Proposal:}

We suggest that completing this study is relevant for Yucca Mountain. All of thee preliminary results need to be carried out in a strict QA environment. A more detailed study would examine more thoroughly the conditions associated with all accelerograms that caused peak accelerations greater than $80 \%$ of gravity, and peak velocities greater than $75 \mathrm{~cm} / \mathrm{s}$. Based on these results, it will be possible to judge whether any of these conditions that contributed extreme ground motions exist at Yucca Mountain. The surface - downhole data from Kiknet can further inform the Yucca Mountain debate with data. 
Specific tasks. For each extreme accelerogram and each extreme velocity:

- Map of fault and station location

- Identify epicenter / directivity

- Focal mechanism

- Site condition

- Kappa, spectral amplitudes, arms

- Is this an isolated spike?

- Topography of the station

For KiKnet data with extreme accelerograms

- All of above

- Compare surface and downhole records on all of above points

Overview:

- Examine statistics.

- Put into perspective of scope of all data

- Conclusions for how this may be relevant for Yucca Mountain, considering how representative the conditions are of those near Yucca Mountain.

- Discussion of what combinations of conditions might cause the most severe accelerations and velocities.

The cost of this project is about one man-year. 


\section{$m b$ vs Mw in the search for High Stress-Drop Earthquakes James W. Dewey U.S. Geological Survey}

Theory predicts that high stress-drop earthquakes should tend to have high values of $m b$ (a measure of the short-period energy of the earthquake) compared to $M w$ (a measure of the long-period energy of the earthquake. There are a number of factors in addition to stress drop that can influence mb. It is possible, nonetheless, that stress drop is important enough an influence on $m b$ that $m b-M w$ values for cataloged earthquakes could be used to search for extremely high stress-drop earthquakes. Final identification of anomalously high stress-drop earthquakes would have to depend on detailed study of the candidate earthquakes.

At the USGS/NEIC, the $m b$ measurement is made from a signal that is narrow-band filtered with a central frequency near $1 \mathrm{~Hz}$ (fig. 1b). The measurement is made from the largest amplitude phase in the entire $\mathrm{P}, \mathrm{pP}, \mathrm{sP}$ waveform. The current practice, in effect since the early 1970's, differs from the practice used in the 1960's and early 1970's, when amplitudes were measured in the first few cycles of the P-wave train. From comparison of the unfiltered broad-band velocity signal (fig. 1a) with the filtered signal from which $m b$ is measured (fig $1 \mathrm{~b}$ ), it is clear that $m b$ cannot reflect the source-process of the entire earthquake except in some statistical sense. The hope is that $m b$ might reflect the source processes (breakage of high stress-drop asperities; stopping phases, etc.) that are most responsible for high-frequency ground-motions of engineering interest. "Stress drop" is used to characterize the efficiency of these processes.

Plotting $m b$ vs. $M w$ for earthquakes world-wide (Fig. 2) shows large scatter. If this scatter were due entirely to changes in the stress droop, it would imply a variation in stress drop of over three orders of magnitude. It is clear that $m b$ does depend on other factors besides stress-drop. For example (Fig. 2), a 500 bar $M w=6.0$ earthquake in a region of low upper-mantle attenuation (e.g. eastern U.S.) may produce a similar mb as a $5 \mathrm{kbar} M w=6.0$ earthquake in a region of high upper-mantle attenuation (e.g., western U.S.). Restricting attention to $m b$ vs. $M w$ from earthquakes in geographically limited source-regions should remove scatter due to differences in upper-mantle attenuation.

Figures 3 and 4 show different perspectives on $m b$ vs. $M w$ for the California-Nevada region. In any given $M w$ range there are some earthquakes that stand out as having high $m b$ vs. $M w$. The bottom-line question, which I have not yet been able to systematically investigate, is: are the shocks with high $m b$ vs. $M w$ in Figures 3 and 4 characterized by unusually high stress-drops? If so, $m b$ vs. $M w$ would appear to be a promising reconnaissance tool for searching for stress-drop extremes world-wide. 
Example of $\mathrm{mb}$ amplitude measurement for Indonesian earthquake of 2004/07/28, 03:56 UTC

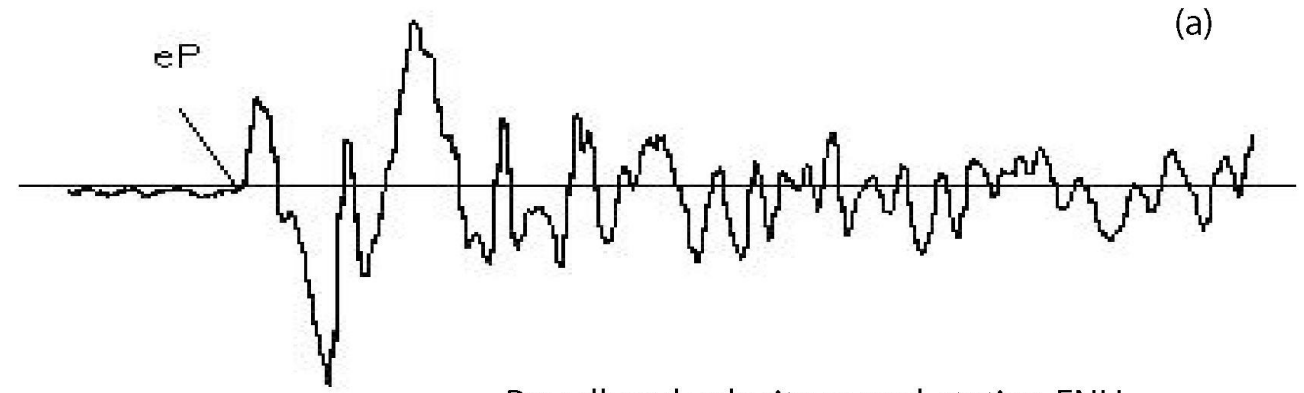

Broadband velocity record, station ENH
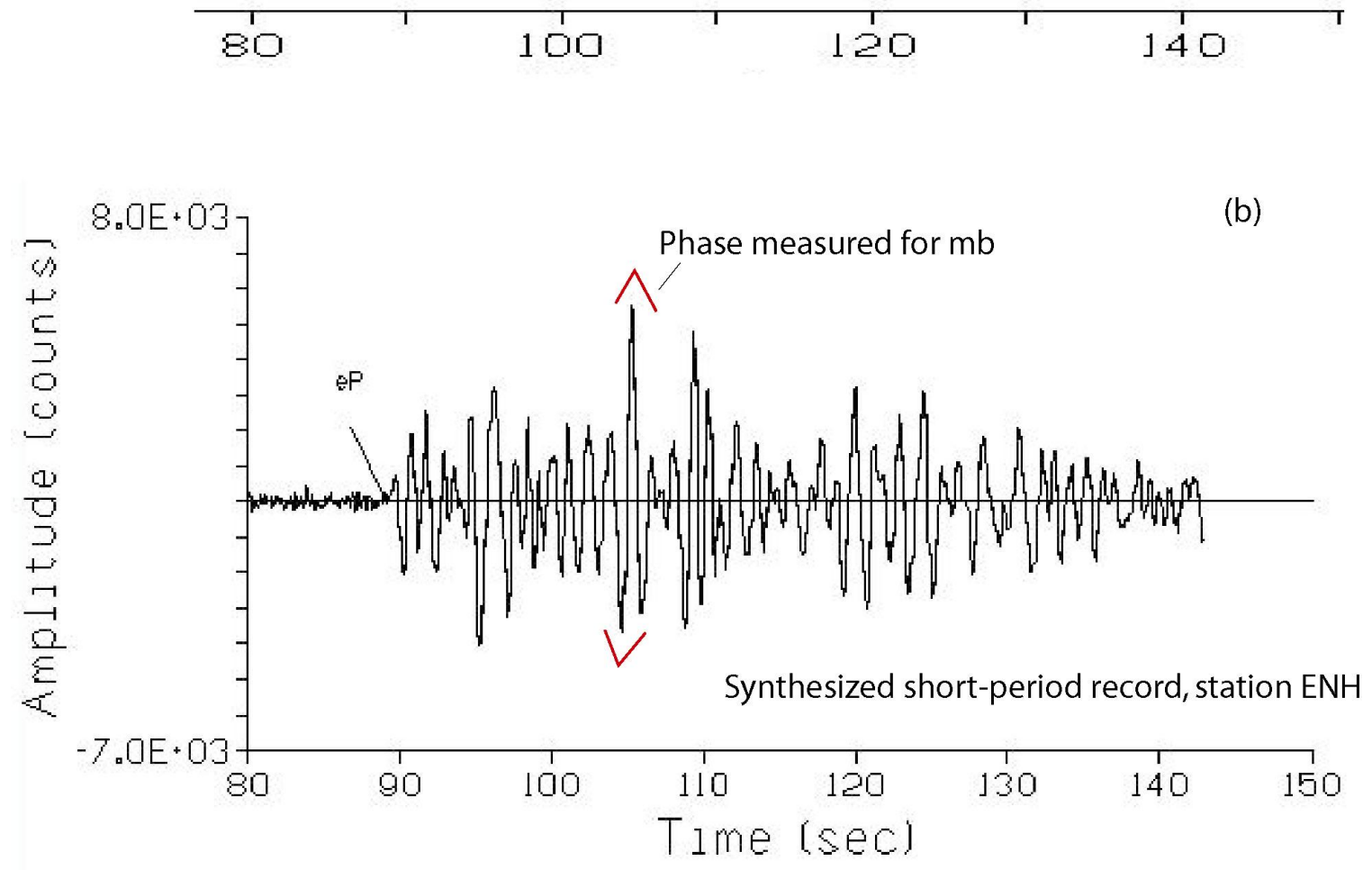

a. Earthquake has $\mathrm{mb}=6.1, \mathrm{Mw}=6.5$

b. Amplitude is measured anywhere in the P-wave train before PP

c Amplitude is measured through a filter that replicates the response of an analog, narrow-band, short-period seismograph.

Figure 1. Example of a measurement of $m b$ for the New Guinea earthquake of 2004.07.28, 03:56 UTC, $m b=6.1, M w=6.5$, made at station ENH. 
mb vs Mw, world-wide, 1977 - 2002

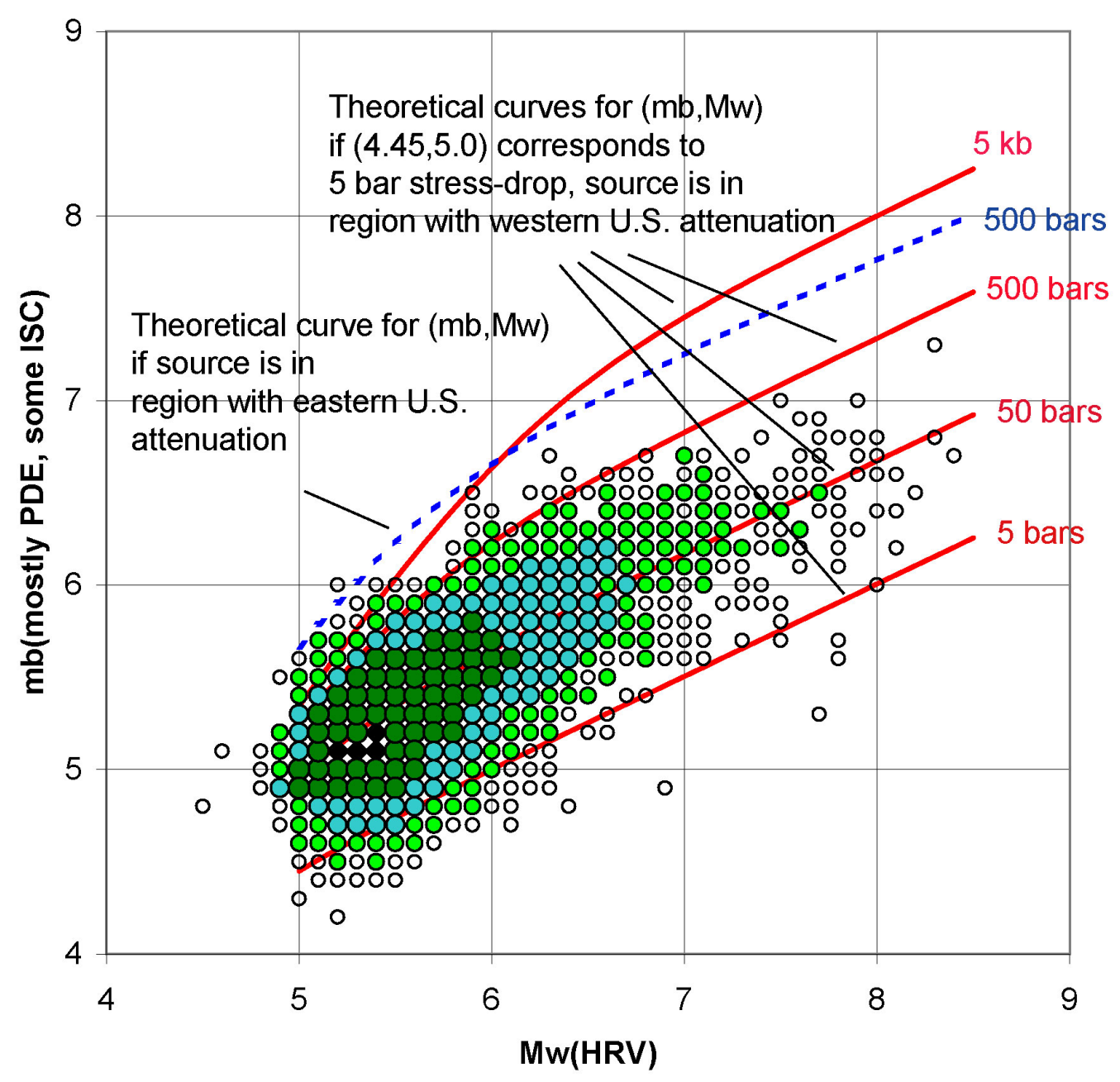

- number of observations ge 256

- number of observations, $64-255$

- number of observations, $16-63$

- number of observations, $4-15$

- number of observations, 1 - 3

Figure 2. Summary of global $\mathrm{mb} / \mathrm{Mw}$ observations for over 13,000 earthquakes, 19772002. Only $M w$ derived from Harvard CMT's are used here. All earthquakes had CMT depths of $50 \mathrm{~km}$ or less. The stress-drop curves are prepared assuming a simple "omegasquared" source-model and assuming that the P-wave amplitude at $1 \mathrm{sec}$ is directly proportional to the displacement spectral amplitude at $1 \mathrm{sec}$. The baseline of the curves is established by assuming that $(m b, M w)=(4.45,5.0)$ corresponds to a 5 bar stress-drop in a region with attenuation characteristics similar to those of the western U.S. 
mb vs Mw, California and Nevada, 1977 - 2002

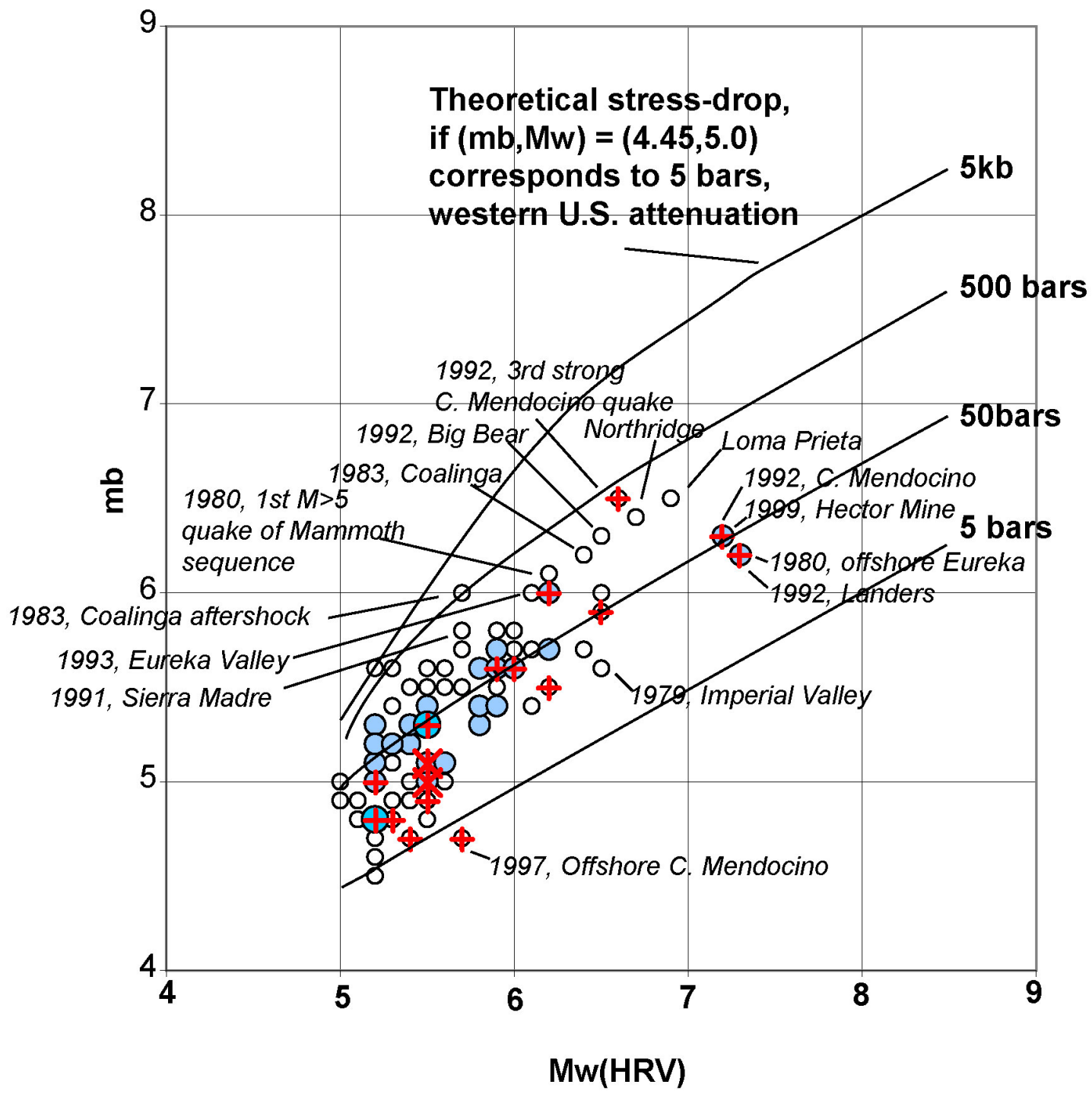

All California and Nevada (1977-2002), including Cape Mendocino
○ 1
O 2-3
$0>3$

\section{Cape Mendocino only}

\section{$+1 \times 2-3$}

Figure 3. Summary of $\mathrm{mb} / \mathrm{Mw}$ observations for 103 earthquakes in California and Nevada, 1977-2002. Considering earthquakes from different regions in California, those from Cape Mendocino (near shore or under land) seemed most anomalous with respect to earthquakes in California and Nevada as a whole. These shocks are therefore represented twice, once pooled with the other shocks and once separately, with different symbols. 
Shocks having anomalously high and low $\mathrm{mb} / \mathrm{Mw}$

in the California/Nevada region, 1977 - 2002

(larger anomalous shocks are labeled)

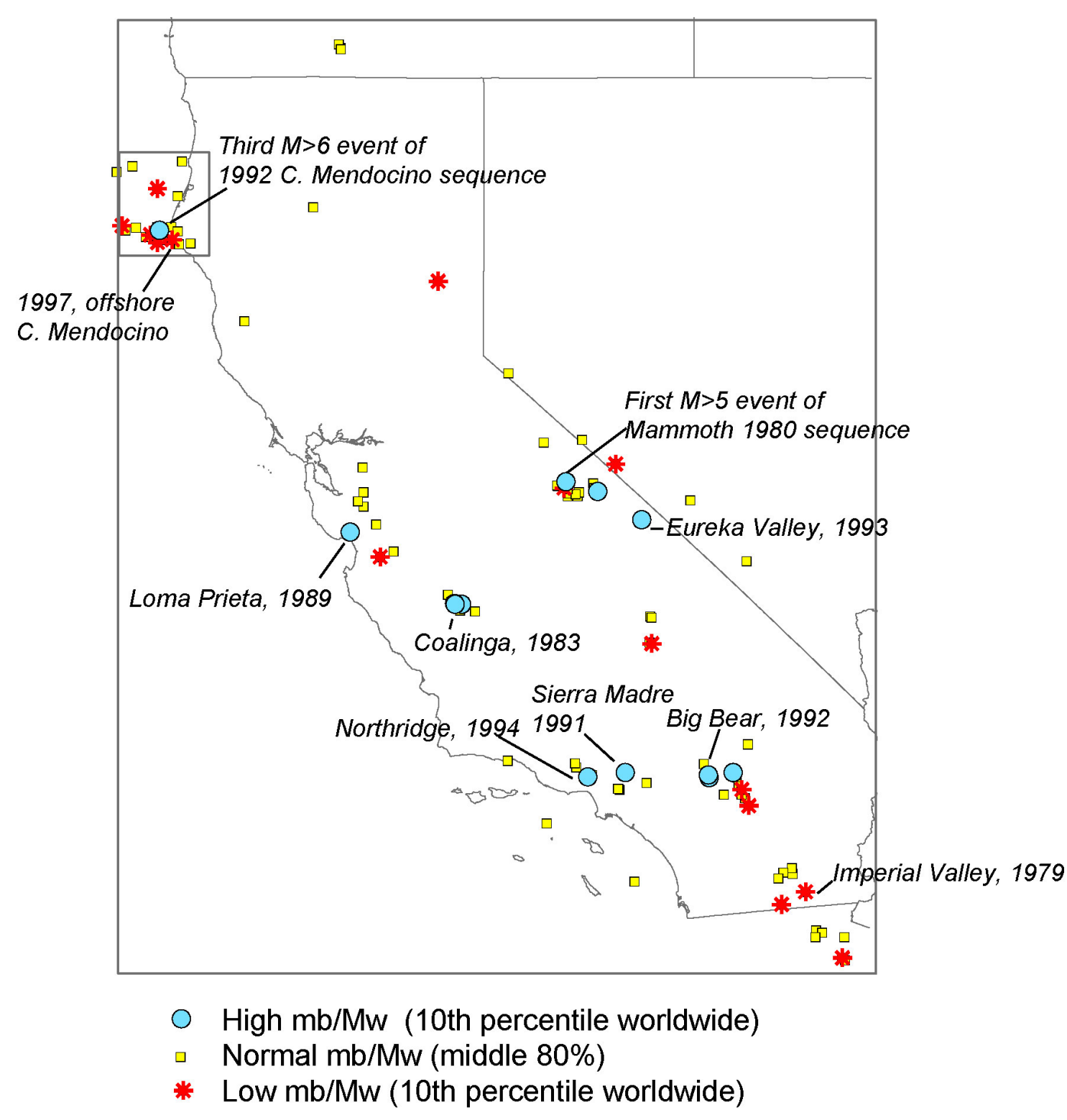

Figure 4. For a given pair of observations $\{m b(I), M w(I)\}$, I calculate $m b(I)-[$ mean $m b$ for all $M w(I)$ worldwide].High $m b / M w$ are in the $10 \%$ upper percentile worldwide. For $M w>6$, and assuming the simple source-model used elsewhere in this study, these events will have stress drops higher by at least a factor of 2 than the global average. Low $\mathrm{mb} / \mathrm{Mw}$ are in the $10 \%$ lower percentile worldwide. These events will have stress drops lower by at least a factor of 2 than the global average. 


\title{
Outliers in Strong-Motion Datasets
}

\author{
Fleur O. Strasser, Julian J. Bommer \\ Dept. of Civil \& Environmental Engineering, Imperial College London, SW7 2BU, UK
}

\section{Introduction}

Ground-motion prediction equations are an essential element of PSHA. The equations generally predict median values of ground-motion parameters as a function of explanatory variables such as magnitude, distance, site classification and style-of-faulting. The aleatory variability associated with the predictions, represented by the distribution of the residuals with respect to the equation, is generally modeled as a Gaussian distribution of the logarithmic residuals, referred to as a lognormal distribution, characterized by a standard deviation $\sigma$. An observation or an estimate of the ground-motion parameter can be defined by the number, $\varepsilon$, of logarithmic standard deviations above the logarithmic mean of the equation. When PSHA is performed for very low exceedance frequencies, the nontruncated lognormal distribution can lead to very high estimates of ground motions as a result of large values of $\varepsilon$ being considered (Bommer et al., 2004). This brief study examines the nature of the distribution of residuals in strong-motion datasets used to derive ground-motion prediction (attenuation) equations and in particular the nature of the highest outliers (i.e. the values with the largest $\varepsilon$ values).

\section{Upper tails of the residual distribution}

A compilation of predictive equations derived worldwide in the years 1971 to 2003 by Douglas (2003) shows that $\sigma$ values have not decreased over time, and are virtually unaffected by the use of larger datasets or the incorporation of additional variables. As a result, the nature of the upper tails of the residual distribution will be a key factor in constraining the aleatory uncertainty on ground motion.

The issue of upper tails was specifically addressed in the PEGASOS project (Abrahamson et al., 2002). Although not quite a consensus, there was a general feeling that the available strong-motion data is insufficient to define the nature of the upper tails of the distributions of residuals. Restrepo-Velez \& Bommer (2003) applied the upper limit lognormal (ULLN) distribution to the residuals of European strong-motion data calculated using the equation of Tromans \& Bommer (2002), from which an upper bound at 6 logarithmic standard deviations above the logarithmic mean was inferred. Since the largest residuals were at about the $3 \sigma$ level, this extrapolation is neither considered robust nor reliable. 


\section{$\underline{\text { Residual datasets for selected predictive equations }}$}

The present study examines the residuals of a number of strong-motion data sets used for the derivation of predictive equations for horizontal spectral ordinates (Ambraseys et al., 1996; Berge-Thierry et al., 2003; Bommer et al., 2003; Chang et al., 2001; Lussou et al., 2001). These equations differ by the extent and provenance of the data, as well as by the number and definitions of the variables used in the regression. However, as illustrated in Figure 1, the largest outliers are consistently at least at the $2.5 \sigma$ to $3 \sigma$ level, all equations using a homoscedastic scatter (i.e. $\sigma$ is independent of the explanatory variables). The overall range of values taken by the residuals varies with the frequency considered, the number of variables included in the regression and the definition of horizontal component used, although no systematic trends could be found.

Examination of the individual residual sets at each frequency shows no correlation with either magnitude or distance, as would be expected for well-conditioned data sets. Neither could a pattern be found with respect to site classification or style-of-faulting, regardless of whether these variables were included in the regression or not. However, all sets displayed a positive correlation between the residuals and the logarithm of the observed ground motion, characterized by a correlation coefficient of about 0.6 , indicating that on average, higher residuals should be expected for higher ground motions.

\section{Characteristics of highest outliers}

In a second step, subsets comprising the 15 highest residuals of the Bommer et al. (2003) and Berge-Thierry et al. (2003) datasets were analyzed to check whether the overall lack of correlation between residuals and explanatory variables is also a feature of these extreme outliers. Despite the strong overall correlation with observed ground motion noted above, the highest outliers span a significant range of ground-motion values, but generally fail to include motions of engineering significance, in particular near-source records. Like the complete sets of residuals, these subsets show a lack of correlation with any of the basic explanatory variables used in regression analysis.

It is customary to associate repeated high residuals at a given station with a site-specific response. Similarly, when all records from a single event exhibit high residuals, this is often interpreted as a source characteristic, such as the often cited explanation of "high stress drop" for the 1985 Saguenay earthquake. However, examination of the individual outliers and the associated data shows that in most instances it is not possible to classify them unambiguously as source- or site-related. Figure 2 illustrates this in the case of the 1984 Lazio Abruzzo (Italy) earthquake, providing the highest PGA residual for the Bommer et al. (2003) equation: although the residuals for this event are well-correlated with observed ground motion, there does not seem to be any consistent pattern with respect to 
distance or site classification, nor any indication that the residuals can be related to a gross source characteristic.

Systematic examination of outlying accelerograms can help to identify the factors contributing to these unexpectedly large motions, such as directivity, site effects, or a particular feature of the path (Strasser et al., 2004a; Strasser, 2005). Published studies on many notable recordings often tend to assign the high ground-motion amplitudes to a single cause, with different authors identifying different factors, which may be interpreted as indicating that the most extreme motions are the result of the favorable combinations of several factors. Therefore, there is great potential benefit in identifying these factors, their ranges of possible values, and most importantly, the ranges of feasible combinations of these values, perhaps expressed in terms of joint probability distributions. This would then help to define the required input into numerical simulations (Strasser et al., 2004b).

\section{Conclusions}

The residual datasets of several recently predictive equations were investigated, with a particular focus on the nature of the highest outliers.

- As a whole, the residual datasets show no correlation with any of the explanatory variables commonly used in predictive equations.

- The highest outliers are mostly related to motions of little engineering significance, despite the fact that overall the residuals are well correlated with observed amplitude.

- Not all of the outliers are of very low amplitude - but few are at short distances.

- Outliers also show no consistent pattern with respect to explanatory variables.

- It is not possible in general to attribute outliers to either source or site effects; the most extreme cases seem to result from combinations of these effects.

- Record processing issues or inadequate definitions of the regression variables may also be the cause of some outliers

\section{Acknowledgements}

The first author would like to express thanks to Tom Hanks and the other members of Extreme Ground Motions at Yucca Mountain committee for the invitation to participate in this workshop. We express our thanks to the individuals who assisted us in obtaining copies of the datasets for the residuals analyzed herein: Catherine Berge-Thierry, T-Y. Chang, Fabrice Cotton, John Douglas, Philippe Lussou and Philippe Roth. 


\section{$\underline{\text { References }}$}

Abrahamson, N.A., Birkhauser P., Koller, M., Mayer-Rosa, D. Smit, P., Sprecher, C., Tinic, S. and Graf, R. (2002). PEGASOS - a comprehensive probabilistic seismic hazard assessment for nuclear power plants in Switzerland. $12^{\text {th }}$ European Conference on Earthquake Engineering, London, Paper No. 633.

Ambraseys, N.N., K.A. Simpson \& J.J. Bommer (1996). Prediction of horizontal response spectra in Europe. Earthquake Engineering \& Structural Dynamics 25, 371-400.

Berge-Thierry, C., F. Cotton, O. Scotti, D.-A. Griot-Pommera \& Y. Fukushima (2003). New empirical response spectral attenuation laws for moderate European earthquakes. Journal of Earthquake Engineering 7(2), 193-222.

Bommer, J.J., J. Douglas \& F.O. Strasser (2003). Style-of-faulting in ground-motion prediction equations. Bulletin of Earthquake Engineering 1, 171-203.

Bommer, J.J., Abrahamson, N.A., Strasser, F.O., Pecker, A., Bard, P-Y., Bungum, H., Cotton, F., Fäh, D., Sabetta, F., Scherbaum, F. and Studer, J. (2004). The challenge of defining upper bounds on earthquake ground motions. Seismological Research Letters 75(1), 82-95.

Chang, T.-Y., F. Cotton \& J. Angelier (2001). Seismic attenuation and peak ground acceleration in Taiwan. Bulletin of the Seismological Society of America 91(5), 1229-1246.

Douglas, J. (2003). Earthquake ground motion estimation using strong-motion records: a review of equations for the estimation of peak ground acceleration and response spectral ordinates. Earth-Science Reviews 61, 41-104.

Lussou, P., P.Y. Bard \& F. Cotton (2001). Seismic design regulation codes: Contribution of K-Net data to site effect evaluation. Journal of Earthquake Engineering 5(1), 13-33.

Restrepo-Vélez, L.F. and Bommer, J.J. (2003). An exploration of the nature of the scatter in ground-motion prediction equations and the implications for seismic hazard assessment. Journal of Earthquake Engineering 7(special issue no.1), 171-199.

Strasser, F.O. (2005). Interpretation and modeling of extreme ground motions. PhD Thesis, Imperial College London.

Strasser, F.O., Bommer, J.J. and Boore, D.M. (2004a). What produces large earthquake motions? (Abstract). Seismological Research Letters 75(2), 289.

Strasser, F.O., Priolo, E., Vuan, A., Bommer, J.J., Klinc, P. and Laurenzano, G. (2004b). Preliminary results of simulations exploring the nature of extreme ground motions using a kinematic deterministic-stochastic finite-fault model: EXWIM (Abstract). Seismological Research Letters 75(2), 283.

Tromans, I.J. and Bommer, J.J. (2002). The attenuation of strong-motion peaks in Europe. Proceedings of the $12^{\text {th }}$ European Conference on Earthquake Engineering, London Paper no. 394. 


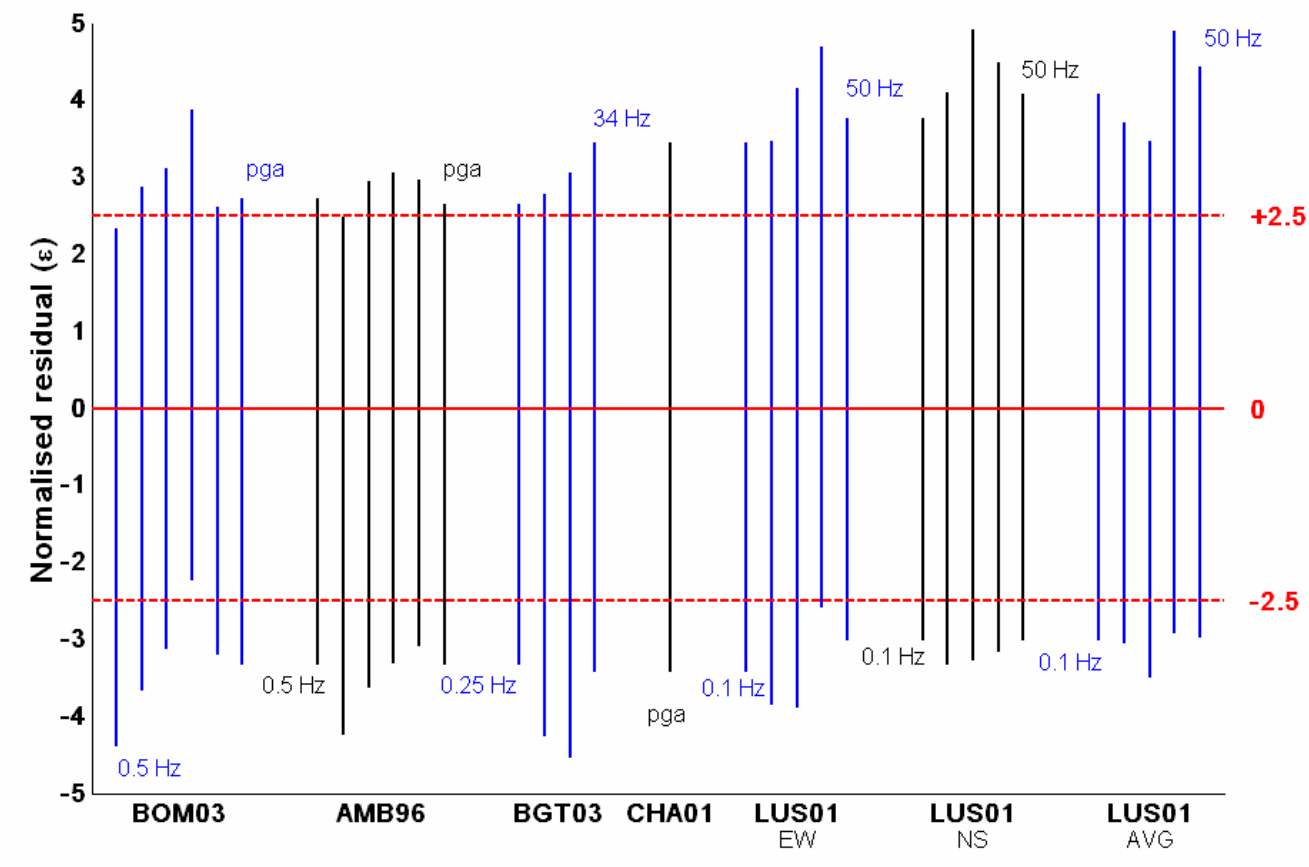

Figure 1. Ranges of values taken by $\varepsilon$ in the data sets used, at different frequencies and for different definitions of the horizontal component.
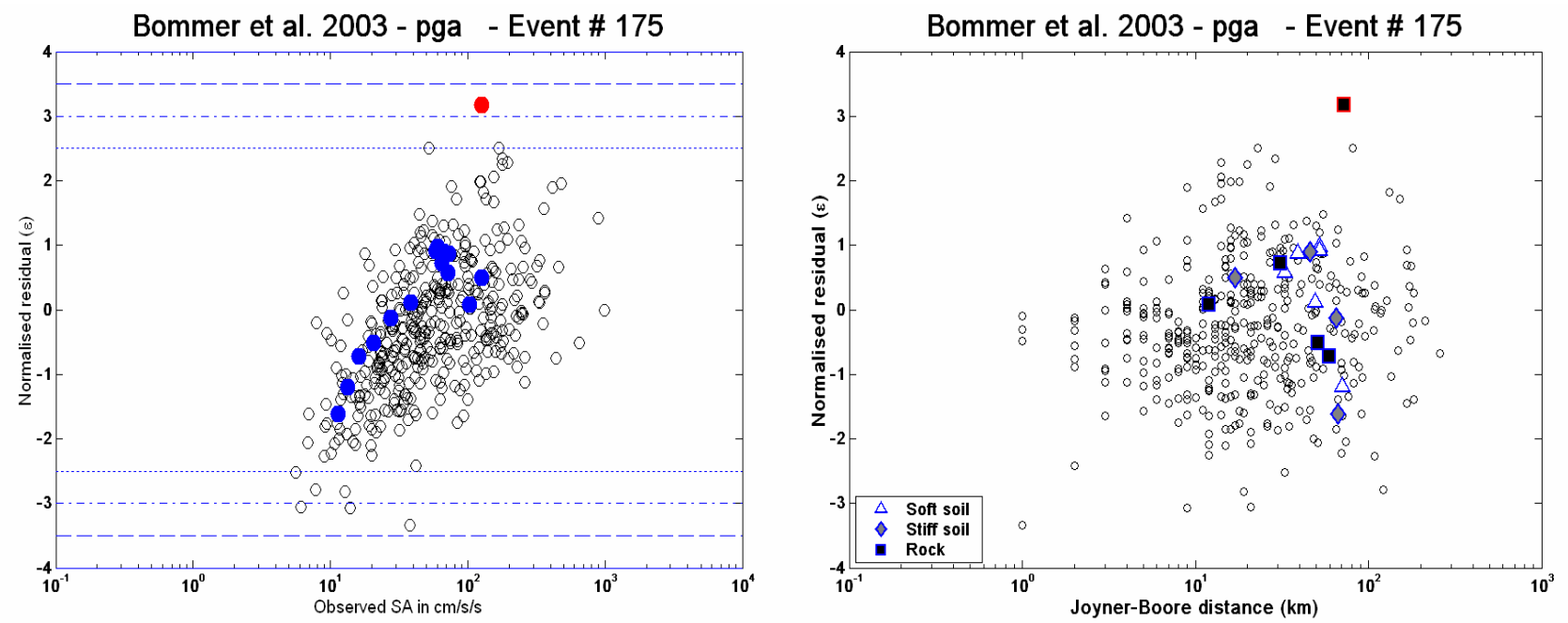

Figure 2. Locations with respect to whole dataset of normalized $\varepsilon$ residuals from all stations available for a single event (Lazio Abruzzo, 07/05/1984, $M_{S}=5.8$ ) plotted against log (SA) (left), and distance, including site classification (right). 
Critically-Stressed Faults in the Yucca Mountain Area and Observations of Complete Stress Drop

\author{
Mark Zoback \\ Department of Geophysics \\ Stanford University \\ Stanford, CA 94305
}

\begin{abstract}
In situ stress data from the Yucca Mountain area indicate that the state of stress at depth is consistent with predictions of Coulomb faulting theory and laboratory-derived coefficients of friction. Similar data from other deep boreholes around the world that similarly imply that the state of stress in the earth's crust is generally in a state of frictional failure equilibrium. Anomalies of stress orientation observed in a number of these boreholes indicate that slip on critically-stressed faults cause stress variations of stress at a variety of scales. Dislocation modeling of these stress rotations (and observations of anomalous stress magnitudes in normal faulting areas) indicate that nearcomplete stress drop (on the order of 10-15 MPa) appears to have occurred on many faults.
\end{abstract}

Introduction

As illustrated in Fig. 1a, the magnitude of in situ stress near Yucca Mountain, as measured in relatively deep boreholes, is consistent with the values predicted from Coulomb faulting theory for critically-stressed normal faults [Stock and Healy, 1988; Stock et al., 1985; Zoback and Healy, 1984]. This means that relatively small stress perturbations are required to activate movement on normal faults in the area that strike perpendicular to the least principal stress. The stress magnitudes shown in Fig. 1a are confirmed by the occurrence of drilling induced hydraulic fractures (and lost circulation) as the holes were being drilled. As shown in Fig. 1b, the direction of least principal stress in this area is approximately E-W, hence the N-S striking Solitario Canyon fault (dashed line in Fig. 1b) should be considered a well-oriented normal fault. 


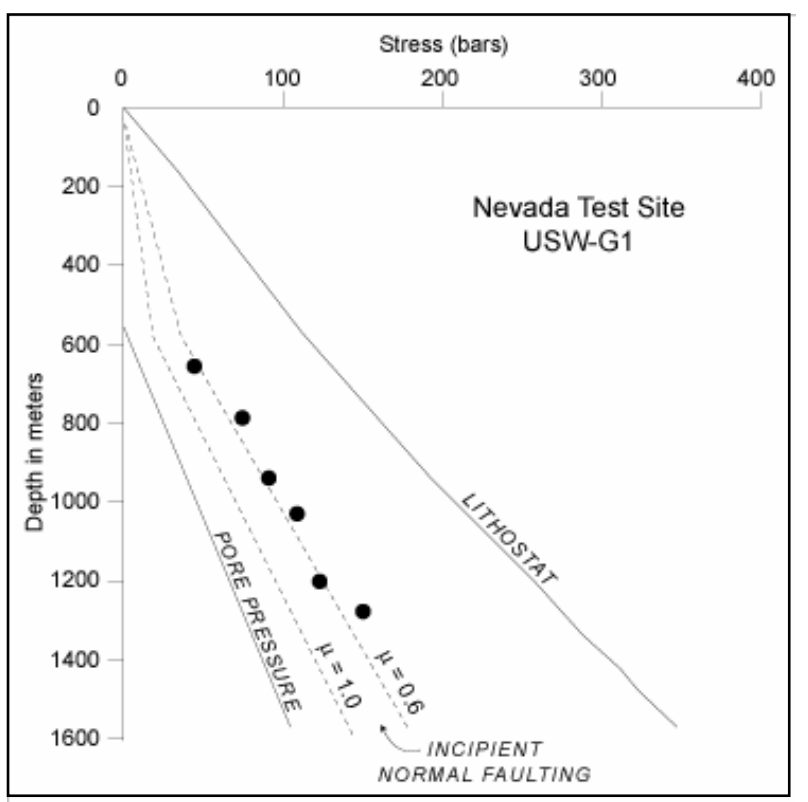

a)

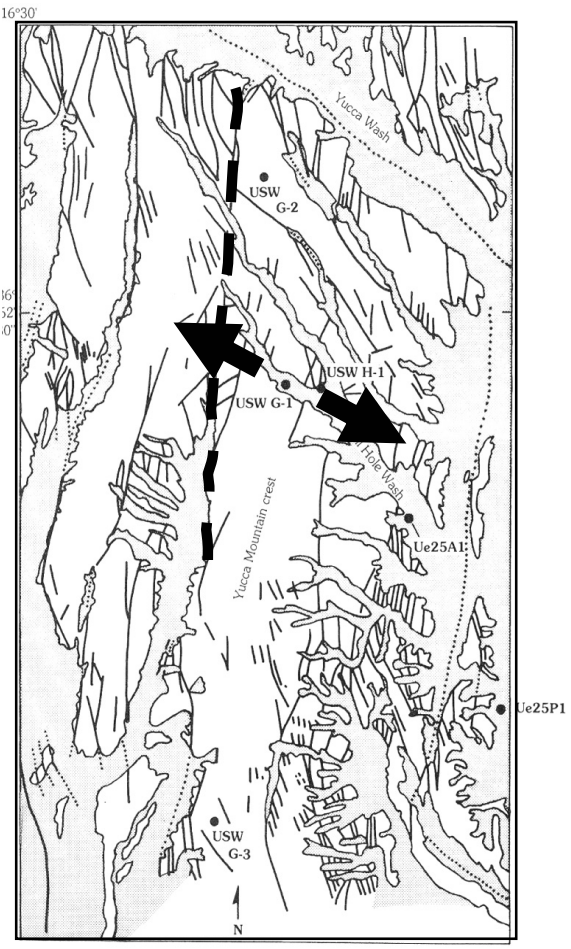

b)

Figure 1 - a) Magnitude of the least principal stress in borehole USW G-1 (after [Stock et al., 1985; Zoback and Healy, 1984]). b) The orientation of the minimum horizontal stress is hole USW G-1 is shown. It is approximately orthogonal to the strike of the Solitario Canyon fault (dashed line).

Stress measurements in deep boreholes around the world indicate stress magnitudes similar to those shown in Fig. 1a in that in the context of Coulomb faulting theory, the stress measurements indicate a crust in failure equilibrium [Townend and Zoback, 2000]. Fig. 2a shows a stress state in failure equilibrium to a depth of $\sim 8 \mathrm{~km}$ at the KTB site in southeastern Germany [Zoback and Harjes, 1997], in this case, it is a strike-slip faulting regime. Confirmation that the stress magnitudes indicate a stress state in frictional 
equilibrium is confirmed by the fact that small perturbations of pore pressure induced by fluid injection at $\sim 9 \mathrm{~km}$ depth were sufficient to trigger microearthquakes.

Fig. 2 b shows stress orientations in the pilot hole at depths between 3000 and $6800 \mathrm{~m}$ as determined from wellbore breakouts [Brudy et al., 1997]. In the figure, each point represents a breakout on one side of the well. In vertical boreholes, breakouts form in pairs, $180^{\circ}$ apart, at the azimuth of the least principal stress. The KTB stress orientation profile indicates that on average, a constant stress orientation is seen with depth that corresponds with the NNE-SSW direction of maximum horizontal compression observed throughout this part of central Europe, but that many minor fluctuations of stress orientation are seen at a variety of wavelengths. Similar fluctuations in stress orientation have been seen in a number of boreholes including the Cajon Pass borehole, near the San Andreas fault. [Shamir and Zoback, 1989] showed that several detailed aspects of the breakout fluctuations could be explained by stress perturbations associated with slip on active faults penetrated by the borehole.

Figures 3 illustrate examples of larger scale stress rotations in the vicinity of active faults. Fig. 3a shows how the ENE-WES regional stress orientations is perturbed near an active fault in S. America. Fig. 3b shows perturbed stress orientations (based on observations of wellbore breakouts in oil wells) in the San Emidio, Los Lobos, Pleito Wheeler Ridge and North Tejon oil fields in the S. San Joaquin basin. [Castillo and Zoback, 1995] showed that the variation from the regional N-S stress orientation (seen in the oil fields immediately to the north), could be explained by the perturbation of the stress field caused by the occurrence of 1952, M 7+ Kern County earthquake.

Following the generalized modeling of breakout rotations by [Shamir and Zoback, 1992], [Barton and Zoback, 1994] showed through dislocation modeling that specific rotations of breakouts observed in the KTB and other boreholes could only be explained if there was near-complete stress drop on the faults causing the breakout rotations. [Castillo and Zoback, 1995] found the same thing in modeling the stress anomaly in the Southern San Joaquin basin. Following the earthquake, principal stresses were oriented nearly parallel and perpendicular to the causative fault (as also seen in Fig. 3a). The same thing was found by [Zoback and Beroza, 1993] when analysing aftershock earthquake focal mechanisms following the 1989 Loma Prieta earthquake. 


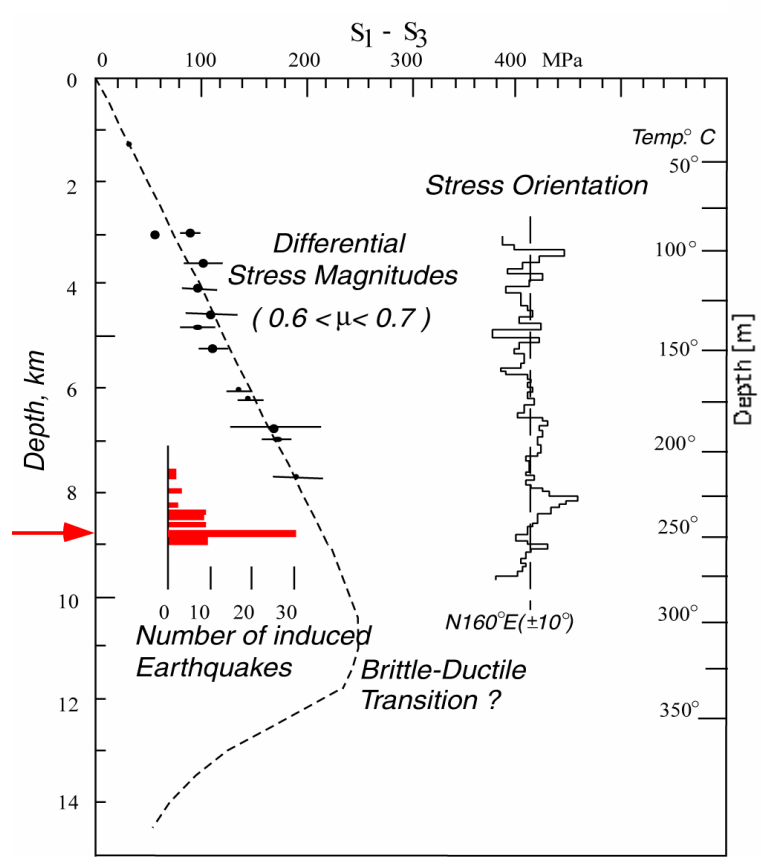

a)
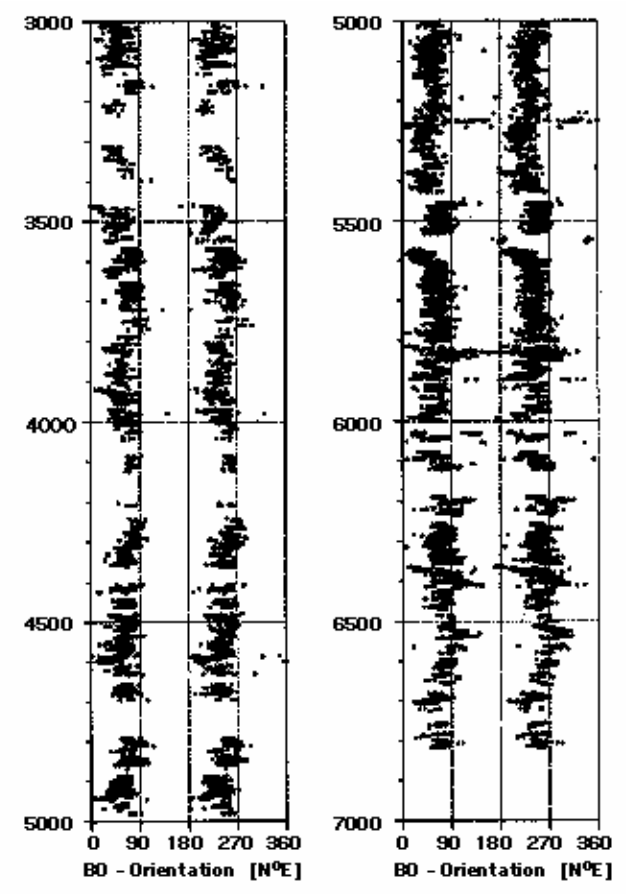

b)

Figure 2 - a) Magnitude of shear stress with depth in the KTB borehole south eastern Germany (modified after [Zoback and Harjes, 1997]). b) Breakout orientation with depth in the KTB borehole from 3000 to $6800 \mathrm{~m}$ depth [Brudy et al., 1997].

Stress magnitude observations in a number of wellbores provide additional evidence of complete (or near complete) stress drop. Fig. 4 shows least principal stress magnitudes from three wells in normal faulting environments (after [Barton and Zoback, 1994]). The normal/strike slip setting of the Cajon Pass borehole in S. California, near the San Andreas fault, the $6^{\text {th }}$ Water Canyon on the Wasatch front in Utah and compilation of hydraulic fracturing stress measurements in several wells near Yucca Mountain. In normal faulting environments, complete stress drop would be associated with a marked increase in the magnitude of the least principal stress (to values approaching the vertical.stress). As the magnitude of the least principal stress can usually be measured with accuracy by hydraulic fracturing, it is noteworthy that while the majority of 


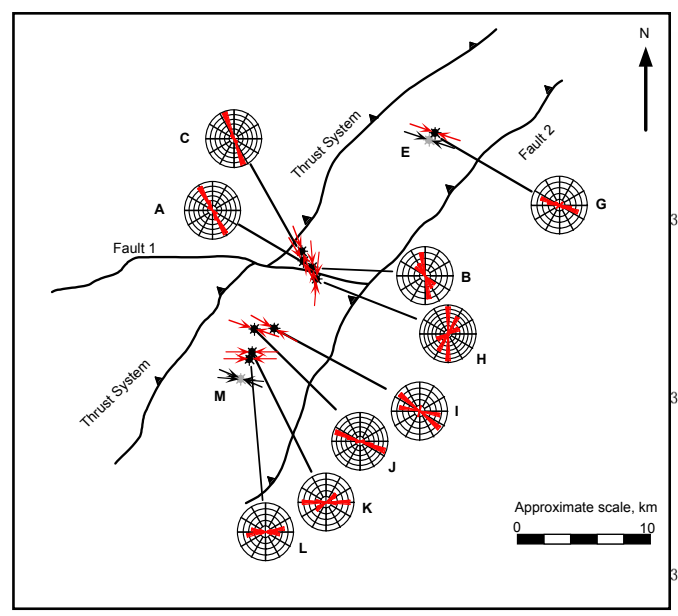

a)

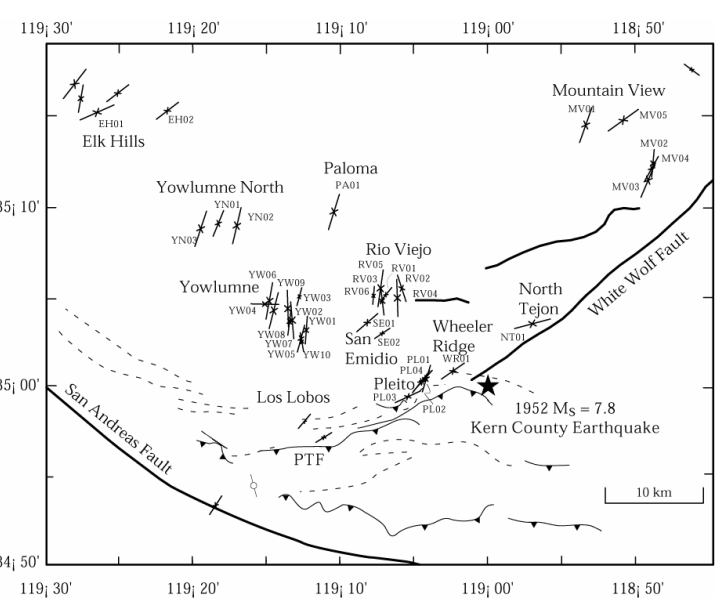

b)

Figure $3-$ a) Marked stress anomaly near an active fault in South America. Wellbore breakout data from four wells near the fault show a markedly different stress orientation than the NNE-SSE orientation of regional stresses observed in surrounding wells. B) Unusual stress orientations in oil fields in the southernmost San Joaquin basin are explainable in terms of the perturbation of the regional stress field caused by the 1952 Kern county earthquake.

measurements of the least principal stress are consistent with Coulomb faulting theory for frictional faulting equilibrium (as illustrated in Figs. 1 and 2), localized increases in the least principal stress are observed in the vicinity of shear zones in each case. These localized increases of the least principal stress indicate changes in shear stress on the faults in question of 10-15 MPa. 

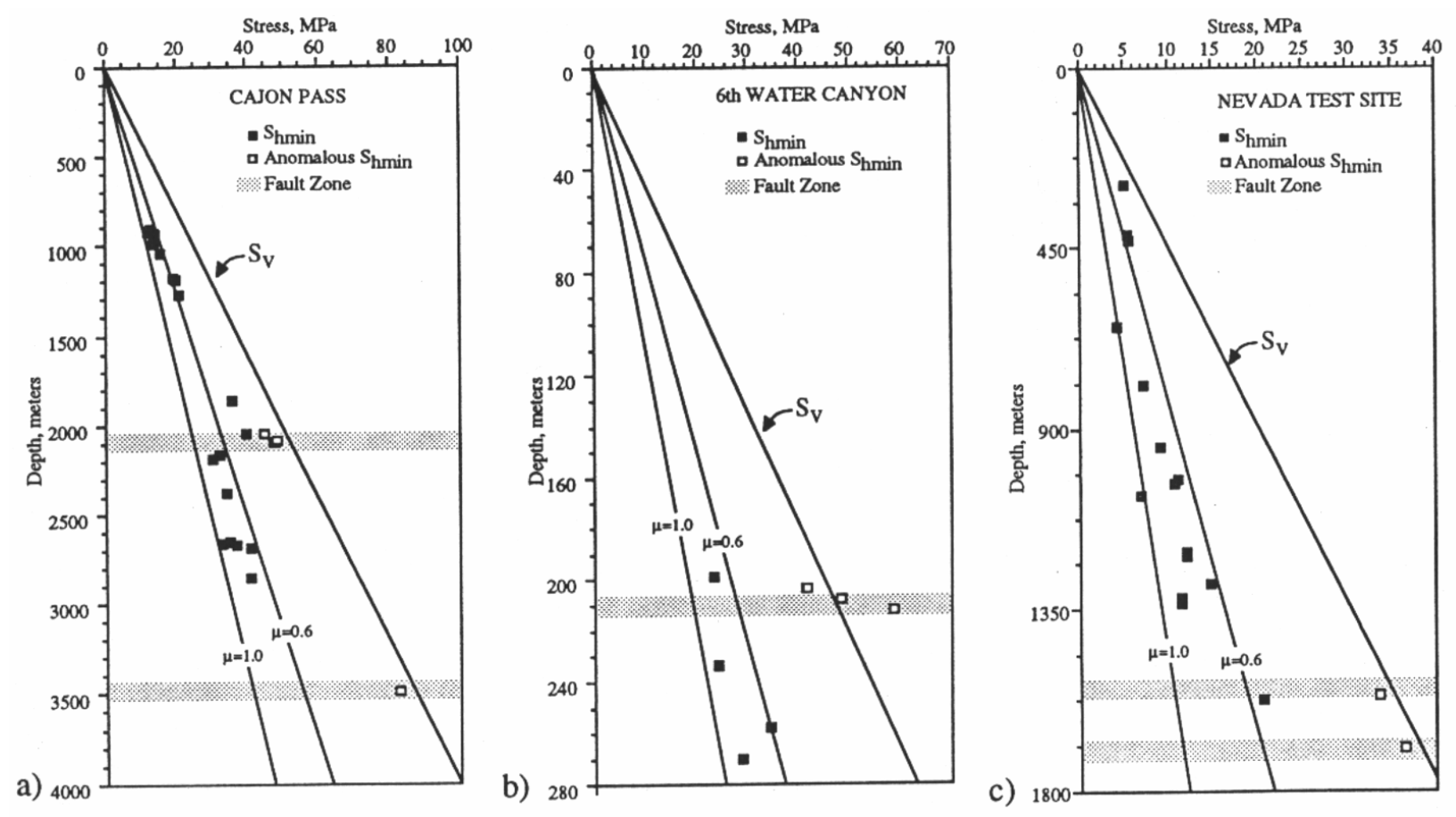

Figure 4 - Measurements of the least principal stress in wellbores in normal (or normal/strike-slip) faulting stress states show $i$ ) overall magnitudes consistent with Coulomb faulting theory and $i$ ) localized increases in stress magnitude in the vicinity of shear zones showing near complete stress drop (after [Barton and Zoback, 1994]).

\section{References}

Barton, C.A., and M.D. Zoback, Stress perturbations associated with active faults penetrated by boreholes: Possible evidence for near-complete stress drop and a new technique for stress magnitude measurements, J. Geophys. Res, 99, 93739390, 1994.

Brudy, M., M.D. Zoback, K. Fuchs, F. Rummel, and J. Baumgärtner, Estimation of the complete stress tensor to $8 \mathrm{~km}$ depth in the KTB scientific drill holes: Implications for crustal strength, J. Geophys. Res, 102, 18,453 -18,475, 1997.

Castillo, D., and M.D. Zoback, Systematic stress variations in the southern San Joaquin valley and along the White Wolf fault: Implications for the rupture mechanics of the 1952 Ms 7.8 Kern County earthquake and contemporary seismicity, Journal of Geophysical Research, 100 (B4), 6249-6264, 1995.

Shamir, G., and M.D. Zoback, The stress orientation profile in the Cajon Pass, California, scientific drillhole, based on detailed analysis of stress induced borehole breakouts, in Rock at Great Depth, Proceedings ISRM-SPE International Symposium, edited by V. Maury, and D. Fourmaintraux, A.A.Balkema, Elf Aquitaine, Pau, 1989. 
Shamir, G., and M.D. Zoback, Stress orientation profile to $3.5 \mathrm{~km}$ depth near the San Andreas Fault at Cajon Pass California, Jour. Geophys Res., 97, 5059-5080, 1992.

Stock, J.M., J.H. Healy, S.H. Hickman, and M.D. Zoback, Hydraulic fracturing stress measurements at Yucca Mountain, Nevada, and relationship to the regional stress field, Journal of Geophysical Research, 90 (B10), 8691-8706, 1985.

Townend, J., and M.D. Zoback, How faulting keeps the crust strong, Geology, 28 (5), 399-402, 2000.

Zoback, M.D., and G.C. Beroza, Evidence for near-frictionless faulting in the 1989 (M 6.9) Loma Prieta, California, earthquake and its aftershocks, Geology, 21, 181$185,1993$.

Zoback, M.D., and H.P. Harjes, Injection induced earthquakes and crustal stress at $9 \mathrm{~km}$ depth at the KTB deep drilling site, Germany, J. Geophys. Res.,, 102, 18477-18491, 1997.

Zoback, M.D., and J.H. Healy, Friction, faulting, and "in situ" stresses, Annales Geophysicae, 2, 689-698, 1984. 


\title{
Source Properties of Mining-Induced Seismicity
}

$\mathrm{Or}$

\section{Control of Strong Ground Motion of Mining-Induced Earthquakes by the Strength of the Seismogenic Rock Mass}

\author{
A. McGarr
}

Summary of presentation at workshop on Extreme Ground Motions at Yucca Mountain on Tuesday, August 24, 2004

The seismogenic setting of the deep gold mines in South Africa is similar in some ways to that at Yucca Mountain and different in others. The similarities include (1) an extensional state of stress for which the maximum principal stress is vertical and the minimum horizontal principal stress is approximately half the vertical, or overburden, stress and (2) a depressed water table. In the case of the deep mines, the water table is depressed from its natural level near the surface due to pumping operations necessary to prevent flooding of the underground workings. The main difference between the two settings is the contrast in geologic age or tectonic activity. Within the Witwatersrand basin where the gold mining takes place, the rocks are of Archean age and there is no tectonic activity in contrast to Yucca Mountain within which the tuffs at the repository horizons are approximately 12 million years old.

The geologic age difference notwithstanding, the well-studied mining-induced seismicity in South Africa can provide insights regarding the nature of the ground motion that might affect Yucca Mountain and, in particular, factors that might limit this ground motion. On Monday, I argued that the highest likely PGV that might affect the repository at Yucca Mountain would be associated with the ground motion adjacent to the Solitario Canyon fault, assuming that it ruptures to the surface. This raises the questions of what factors might limit the near-fault PGV. Here I propose that the strength of the seismogenic rock mass limits the near-fault PGV and review observations that support this assertion.

Figure 1 shows shear strength as a function of depth of the Witwatersrand quartzites estimated using four independent techniques. The circles are estimates based on Byerlee's law of friction with zero pore pressure. The agreement between these and the other three types of estimates (McGarr, 2001) suggests that to a good approximation, the bulk strength of this seismogenic region is that of a pervasively-faulted rock mass and falls somewhere in the range of 30 to $60 \mathrm{MPa}$.

McGarr (2001) showed that based on laboratory evidence and a well-accepted dynamic rupture model (Madariaga, 1976) that near-fault PGV is limited according to

$$
P G V \leq 0.25 \beta \tau / G
$$


where $\beta$ is the shear wave speed of about $3.7 \mathrm{~km} / \mathrm{s}, \tau$ is the shear strength, and $G$ the modulus of rigidity is about $3.76 \times 10^{4} \mathrm{MPa}$. If the shear strength is $60 \mathrm{MPa}$, near the top of the range in Figure 1, then using (1) the near-fault PGV is limited to $1.5 \mathrm{~m} / \mathrm{s}$. This result is consistent with the general observation that the support used in the production stopes can accommodate a rate of stope closure of approximately $3 \mathrm{~m} / \mathrm{s}$ without failing.

The example described in my report presented on Monday is also consistent with the bound on near-fault PGV of $1.5 \mathrm{~m} / \mathrm{s}$. Briefly, the far-field ground velocity indicated a source rise time of $0.16 \mathrm{~s}$, which when divided into the maximum slip of $0.2 \mathrm{~m}$ observed on the extensive fault zone several km below the recording site yielded a near-fault PGV of $1.25 \mathrm{~m} / \mathrm{s}$ or greater.

Stope support occasionally fails, however, over fairly localized production areas suggesting that PGV may sometimes exceed $3 \mathrm{~m} / \mathrm{s}$, or so. These high inferred PGV's may be the result of rupture through previously-intact quartzite. If so, then, as explained by McGarr (2001), the relevant shear strength is at least $164 \mathrm{MPa}$, which, if used in (1) yields a near-fault PGV of $4 \mathrm{~m} / \mathrm{s}$.

There may be seismic evidence for near-fault PGV's that are about this high. Figure 2 shows one component of ground acceleration and velocity recorded at a hypocentral distance of $152 \mathrm{~m}$ from a mining-induced earthquake at a depth of $3 \mathrm{~km}$ (McGarr et al., 1981; McGarr, 1991). The seismic moment of this event, $1.7 \times 10^{12} \mathrm{~N}-\mathrm{m}$, indicates that within the fault zone there was a high-slip patch with about $0.018 \mathrm{~m}$ of offset (McGarr and Fletcher, 2003). Assuming that slip on this patch was responsible for the peak acceleration and peak velocity pulses (Figure 2) each of which have durations of $0.005 \mathrm{~s}$, one can divide the inferred rise time of $0.005 \mathrm{~s}$ into the maximum slip of $0.018 \mathrm{~m} / \mathrm{s}$ to infer an average slip rate of $3.6 \mathrm{~m} / \mathrm{s}$ or a peak slip rate of $7.2 \mathrm{~m} / \mathrm{s}$, which yields a nearfault PGV of $3.6 \mathrm{~m} / \mathrm{s}$. If these inferences are correct and can be generalized, then in a given seismogenic setting, the highest near-fault PGV's are likely to be due to seismic rupture through asperities composed of intact rock within much broader fault zones.

\section{Conclusions:}

1) Rock strength seems to control near-fault PGV according to

$$
P G V \leq 0.25 \frac{\beta}{G} \tau
$$

2) Exceptionally high near-fault PGV's may be due to the failure of asperities composed of intact rock.

3) Mining-induced ground motion results could be applied to the Yucca Mountain PSHA problem if rock strength differences are taken into account.

\section{Recommendations:}

1) Laboratory experiments involving both frictional sliding and fresh rock fracture could be run to investigate the factors that influence PGV and to assess the validity of the inferences presented here. 
2) There are many ground motion data sets for mining-induced earthquakes that can be analyzed to infer near-fault PGV in reasonably well-understood seismogenic circumstances.

\section{Figures}

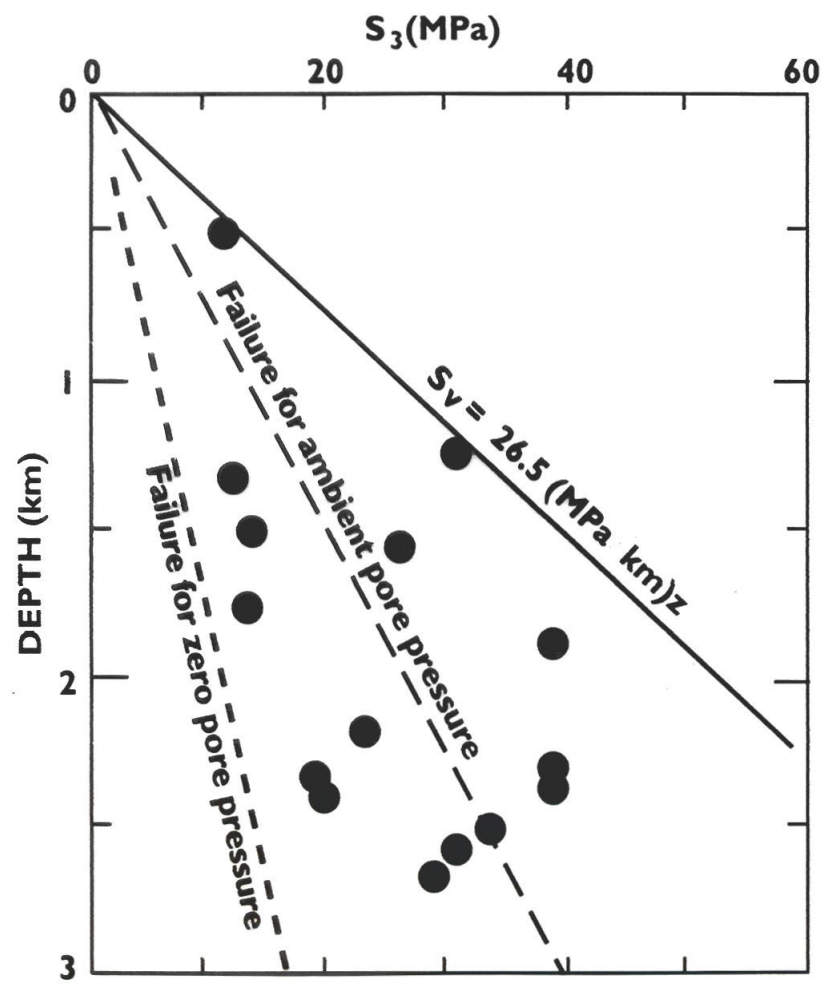

Fig. 1 In situ stresses as function of depth in the Witwatersrand gold fields. 

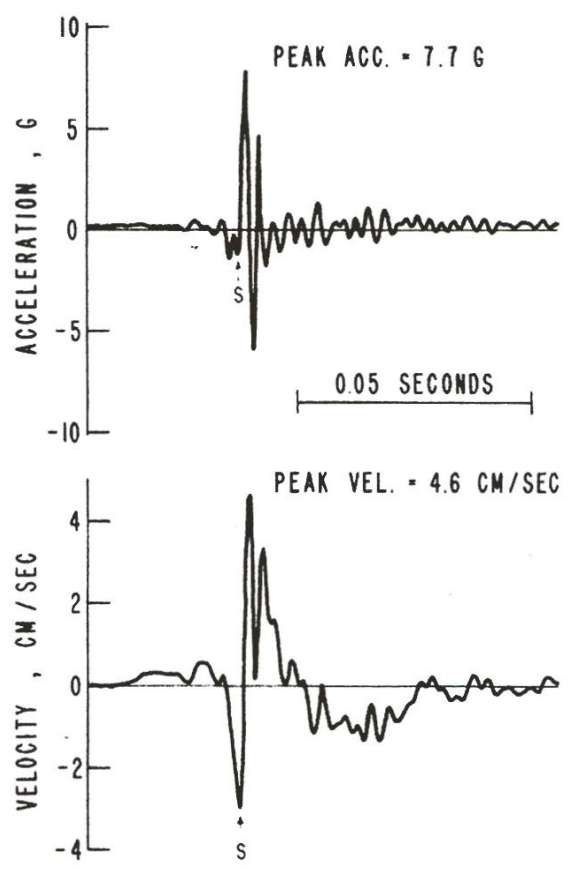

Fig. 2 One component of ground acceleration and velocity measured in a borehole at a hypocentral distance of $152 \mathrm{~m}$ from a mining-induced earthquake at about $3 \mathrm{~km}$ depth.

\section{References}

Madariaga, R. (1976), Dynamics of an expanding circular fault, Bull. Seism. Soc. Am., 66, 639-666.

McGarr, A., Observations constraining near-source ground motion estimated from locally recorded seismograms, J. Geophys. Res., 96, 16,495-16,508, 1991.

McGarr, A., Control of strong ground motion of mining-induced earthquakes by the strength of the seismogenic rock mass, Rockbursts and Seismicity in Mines RaSiM5, South African Institute of Mining and Metallurgy, pp. 69-73, 2001.

McGarr, A., R.W.E. Green, and S.M. Spottiswoode, Strong ground motion of mine tremors: Some implications for near-source ground motion parameters, Bull. Seismol. Soc. Am., v. 71, 295-319, 1981.

McGarr, A. and J. B. Fletcher, Maximum slip in earthquake fault zones, apparent stress, and stick-slip friction, Bull. Seismol. Soc. Am., 93, 2355-2362, 2003. 


\title{
GEOLOGIC EVIDENCE FOR LIMITED GROUND MOTION DAMAGE IN THE TOPOPAH SPRING TUFF, YUCCA MOUNTAIN, NEVADA
}

\author{
David Buesch \\ U.S. Geological Survey, Yucca Mountain Project Branch, Las Vegas, Nevada
}

\begin{abstract}
Introduction
Geologic data from the Topopah Spring Tuff at Yucca Mountain, Nevada, have been compiled and reexamined in the context of how the lithostratigraphic features such as lithophysae (cavities in the tuff, Figure 1) and fractures were formed and whether these features show evidence of seismically induced shear or strain. This evaluation was conducted to better understand the type and amount of potential damage that might have occurred to the rocks at Yucca Mountain during the 12.8 million-year history since the Topopah Spring Tuff was deposited. The Topopah Spring Tuff is the focus of this study for seven main reasons. 1) The lower part of the tuff is the host to the proposed repository for high-level radioactive waste and spent nuclear fuel. 2) The densely welded and crystallized lithostratigraphic units in the Topopah Spring Tuff (Buesch and others, 1996) that include the repository horizon consist of the lower part of the upper lithophysal zone and the middle nonlithophysal and lower lithophysal zones, and the upper part of the lower nonlithophysal zone. 3) A lot of data on fractures and lithophysae have been collected from the tunnels, which are referred to as the Exploratory Studies Facility (ESF) and the Enhanced Characterization of the Repository Block (ECRB) cross drift, and from surface- and tunnel-based boreholes. 4) Studies of the Topopah Spring Tuff and other variously welded and crystallized pyroclastic flow deposits (or ignimbrites) resulted in development of a petrogenetic sequence (spatial and temporal relations) for features in these rocks for the time period between deposition and completion of the cooling phase of the deposit (Buesch and Spengler, 1998; Buesch and others, 1999). 5) Rock properties, including mechanical properties, have been measured in laboratories and rock mechanics models have been developed. 6) Results of rock mechanics modeling indicate various types of lithophysae-fracture relations and damage to the rock mass would occur in rocks that have mechanically "failed" and have experienced static or dynamic strains beyond values of 0.1 to 0.2 percent (Buesch and Damjanac, 2004). 7) These strain limits determined from geologic relations and rock mechanics modeling are used to determine Peak Ground Velocity (PGV) values that range from about 150 to $450 \mathrm{~cm} / \mathrm{sec}$ (King and others, 2004). This correlation and linkage of geologic petrogenetic relations for development of features that formed very early in the history of the Topopah Spring Tuff with the types of damage to these features predicted by rock mechanics modeling, and then the incorporation of these limits into the ground motion, represents an integrated approach to assessing the limits on ground motions at Yucca Mountain for the past 12.8 million years.
\end{abstract}

\footnotetext{
Acknowledgements

The Detailed Line Survey data in the ECRB cross drift were collected by the Bureau of Reclamation (BOR) and summarized in Mongano and others (1999), and the lithophysal data collected in the cross drift was a collaborative effort by BOR personnel and David Buesch. George Eatman, Jeannie Higgins, and Sheldon Johnson (all of the BOR) assisted in re-examination of previous data and collection of new data that are summarized herein. The data and interpretations summarized herein are based on contributions by Buesch to reports developed for the Yucca Mountain Project (YMP) including the Drift Degradation Analysis (ANL-EBS-000027 Rev 03, 2004), Subsurface Geotechnical Parameters Report (800-K0C-WIS0-00400000-00A, 2003), and a soon to be completed report Peak Ground Velocities for Seismic Events at Yucca Mountain, Nevada (ANL-MGR-GS-000004 REV 00A, 2004). For the near term, these YMP reports are internal documents; however, they are anticipated to be available on the Office of Civilian Radioactive Waste Management (OCRWM) website (www.ocrwm.doe.gov) or copies can be requested through the Freedom of Information Act.

\section{Petrogenetic sequence of features related to cooling of the Topopah Spring Tuff}

In the repository area, the Topopah Spring Tuff is as much as $360-\mathrm{m}$ thick, and greater than 90 percent of the thickness is densely welded, and crystallized ignimbrite (Buesch others, 1999). There are minor variations in the amounts and sizes of lithic and pumice clasts throughout the deposit, but no significant changes occur as evidence for a large hiatus in deposition; therefore, the ignimbrite appears to be deposited by rapid aggradation from a single climactic eruption and pyroclastic flow. Welding of the ignimbrite
} 
probably began during or shortly after deposition, and the rapid aggradation and development of densely welded tuff trapped much of the vapor that initially was interstitial to the vitroclastic grain. The redistribution of the vapor phase during welding resulted in some vapor escaping from the deposit; however, much of the vapor accumulated locally to form lithophysal cavities (Figure 1). Numerical models of compaction and welding in ignimbrites indicate that most of these processes occur in the first few years after deposition (Riehle and others, 1995). Adjacent to the lithophysal cavity walls is an area (volume) referred to as a "rim" that consists of 1) slightly coarser grained and more porous intergrowths of feldspar and $\mathrm{SiO} 2$ polymorphs (typically cristobalite or quartz) compared to the surrounding matrix-groundmass, and 2) spherulitic forms of feldspar in the rims. The light gray rims appear to have formed by crystallization of glass in the presence of vapor, but not from the vapor. Likewise, the crystallization of a thin border and surrounding reddish grey matrix-groundmass also appear to have formed from crystallization in the presence of (but lesser interaction with) the outwardly diffusing vapor phase. Crystallization of the glass to form the reddish brown matrix-groundmass is in the absence of the vapor phase. The last feature in lithophysae to develop is the vapor-phase mineral lining (mostly tridymite) that was deposited from the vapor phase during cooling of the rock and vapor. This spatial and temporal development of features (rim, border, reddish grey matrix-groundmass, and vapor-phase mineral lining) also occurs along fractures (Figures 1 and 2).

These relations of spatial and temporal features indicate that the (1) rim, border, and reddish grey matrixgroundmass formed early during cooling of the deposit when the host rock was glass, (2) vapor-phase mineral lining typically formed during late-stage cooling, but actually could develop whenever the vapor became supersaturated in the components that form the vapor-phase minerals, and (3) fractures without rims, borders, or adjacent reddish grey matrix-groundmass and with vapor-phase mineral linings formed during cooling, but after the rock had already crystallized to the matrix-groundmass. It is important to note that some late-stage cooling fractures can form without having vapor-phase mineral coatings simply because once the fracture formed, the geometric relations of the fracture can preclude it from being exposed to the vapor phase. The amount of time needed for a thick, large-volume ignimbrite to cool is poorly constrained; however, it might take several tens of years to perhaps a few hundred years after deposition, but about 100 years after deposition is probably a reasonable period of time. This estimate is based on (1) petrogenetic relations and processes, (2) extrapolations of numerical modeling of welding in ignimbrites (Riehle and others, 1995), and (3) analogy with the Valley of Ten Thousand Smokes in Alaska. The 1912 eruption of the Alaskan Novarupta volcano resulted in pyroclastic flow deposits that might be as great as 200-m thick and formed the Valley of Ten Thousand Smokes (Brantley, 1994); however, the "ten thousand smokes" in the ignimbrite sheet mostly died out by 1930 (Wood and Kienle, 1990).

On the basis of these crystallization and mineralization features, and others such as tubular features and geometric relations, "cooling" fractures are categorized as Type 1 and Type 2 (Buesch and others, 1999), or $1 \mathrm{~s}$ and $2 \mathrm{~s}$, respectively, where fractures are shorter than 1 meter. Fractures that have no cooling related features are categorized as "indeterminate" and could have formed at any time after the rock cooled to ambient paleogeomorphic surface temperatures (these are categorized as Type 3); however, some "indeterminate" fractures can be late-stage cooling fractures that simply do not have the vapor-phase mineralization to identify them as such. To resolve "intermediate" fractures into Type 2 and Type 3 categories, other geometric relations need to be evaluated such as orientation (i.e., strike and dip), trace length, surface morphologic relations (i.e., roughness and planarity on various length scales), and possibly termination characteristics.

\section{Fractures in slabs of core and in the ECRB cross drift}

Fractures in 115, spatially distributed core samples from the crystallized Topopah Spring Tuff collected from surface- and tunnel-based boreholes of various sizes were mapped and categorized using 10 characteristics that, in the end, can be simplified into "Cooling" or "Indeterminate" fractures. Core samples are from 10 different lithostratigraphic zones and subzones; however, most are from the upper lithophysal and lower lithophysal zones. Samples from the small-diameter "Thermal Conductivity" (ThermK) boreholes in the upper and lower lithophysal zones are identified as Tptpul*TK and Tptpll*TK, respectively. Map categories were based on how well developed are the crystallization and mineralization features, or the absence of these features, and 2022 fractures were mapped. A ratio of cooling to indeterminate fractures for each sample (i.e., the $\mathrm{C} / \mathrm{I}$ Ratio) indicates which process dominated the 
formation of fractures in the sample. For all lithostratigraphic units (especially those with 5 or more samples), cooling fractures typically are more abundant than indeterminate fractures (Figure 3 ). The fractures in slabs are categorized into Type $1 \mathrm{~s}$, Type $2 \mathrm{~s}$, and Indeterminate, but because many fractures have poorly developed rims or borders, a category of "Type 1s+" was (Figure 4). Because of the poor development of features identified with the Type $1 \mathrm{~s}+$ fractures, these fractures are transitional from Type 1 to 2 , and with the detailed scale of examination in this slab study, many of the Type $1 \mathrm{~s}+$ fractures might not have been identified in previous studies. Conclusions from the fractures in slab data include (1) about 70 percent of the fractures are cooling and 30 percent are indeterminate, (2) there are more shorter (less than 1 $\mathrm{cm}$ long) fractures per $\mathrm{cm}^{2}$ of sample in most lithostratigraphic units (especially the lower lithophysal and lower nonlithophysal zones) than fractures that are longer than $1 \mathrm{~cm},(3)$ the largest amount of fractures (and especially cooling fractures) occur in the lower lithophysal zone, and (4) evidence of shear or mechanical fragmentation of a fracture is extremely rare.

A total of 1810 discontinuities (fractures, shears, and faults) were documented in the ECRB cross drift using Detailed Line Survey methods and 21 types of data were collected on all fractures with trace lengths greater than $1 \mathrm{~m}$. Re-examination of the types of material that fills (or partially fills) the fractures (i.e., vapor-phase mineral linings), and characteristic cooling features such as tubular structures, rims, and geometric relations that categorize discontinuities as vapor-phase partings or cooling joints indicates about 71 percent of the fractures are "Cooling" fractures (Types 1, 1+, and 2) and 29 percent are "Indeterminate" fractures (Figure 4). As with the slab study, Type 1+ are transitional from Type 1 to 2 . In the cross drift, there are 34 faults or fault zones and 111 shears (i.e., discontinuities with less than $10 \mathrm{~cm}$ of slip separation across the feature). Other than the fault and damage zone associated with the $260 \mathrm{~m}$ of dip-slip separation on the Solitario Canyon fault (Figure 5), only three faults (the Sundance fault near 11+36, and two "not named" faults at $22+36$ and 26+57) have dip-slip separations of greater than $5 \mathrm{~m}$ (the diameter of the tunnel), and all other faults have separations of between 0.1 to $2 \mathrm{~m}$ (Mongano and others, 1999). Additionally, there are 25 faults and fault zones filled with "fault rubble" or "fault gouge", and 293 discontinuities filled (or partially filled) with "broken or crushed rock or sand" and "breccia" (Figure 5). All shears are filled (or partially filled) with "broken or crushed rock or sand" (Br) or "breccia" (Bx, which is the same as $\mathrm{Br}$, but slightly more lithified), and faults are filled with $\mathrm{Br}, \mathrm{Bx}$, fault rubble (Fr), or fault gouge (Fg). This relation of "broken or crushed rock or sand" or "breccia" to shears (and faults) and fractures indicates that approximately 50 percent of discontinuities are filled with broken rock or sand, but they do not have any documented separation across the feature (Figure 5). Additionally, many of the discontinuities with broken rock or sand are also associated with vapor-phase mineral linings (about in the same proportion as fractures without the broken rock or sand). The minimum separation documented on a shear is $1 \mathrm{~cm}$; however, the inference is that some of the fractures simply dilated during cooling (i.e., thermal contraction) or minor extension of the block as a result of tilting along the block bounding faults. Furthermore, the broken rock or sand was apparently deposited into these crevasses because shearing or mechanical degradation of the wall rock does not appear to have been the mechanism to form the broken material. These structural and lithostratigraphic relations from the cross drift indicate that the majority of fractures formed during cooling, some fractures were dilated during cooling (Type 1 or 2) or afterward during minor extension of the structural block associated with faulting and tilting (Type 3), a few "dilated and filled" fractures were sheared, and a very few shears were activated enough to form faults.

\section{Shapes of lithophysae}

Lithophysal cavities form as part of the welding process in rocks that are able to viscously deform (i.e., are glass) and have become densely welded. Unlike features such as pumice and shards that collapse during welded, lithophysae inflate to form a variety of shapes. Four main shapes of lithophysal cavities have been documented in the Topopah Spring Tuff (and other tuffs) including (1) simple, (2) cuspate, (3) merged, and (4) expansion-crack lithophysae (Figure 6). All these shapes can vary in aspect ratio (in a 2-dimensional cross section it is the longest axis divided by the shortest axis), and the ratios can range from about 20 to 1 (or sometimes reported as 20:1 to 1:1) where 1 represents a circle. "Simple" shapes are ovoid (possibly even lens- or disk-shaped) (Figure 6A). Typically, there are small (a few millimeters wide and deep) expansion cracks that formed as the rim crystallized, but as the gas pressure continued to increase, the rim fractured during inflation and the "plates" of the cavity walls moved apart (Figure 6B). Where walls between two or more lithophysae were breached during the inflation of the cavities, merged lithophysae were formed (Figure 6C). Formation of some lithophysae were controlled by propagation of early-formed 
expansion cracks to form irregular or "star burst" shapes; hence the name "expansion-crack" lithophysae (Figure 6D). "Cuspate" lithophysae are typically fairly simple in shape, although one or more parts of the cavity wall merge into fractures such that the cavity appears to have partially collapsed (possibly during release of the vapor along the fractures). Some cuspate lithophysae might be part of larger expansion-crack lithophysae; however, the exposure is such that the complete shape of the lithophysae can not be identified. These shapes of cavities are all consistent with processes that could have been (were) active during the early formation of the lithophysae.

During mapping between 2001 and 2004, the four main shapes of lithophysal cavities (simple, cuspate, merged, and expansion-crack lithophysae) have been documented for 1434 lithophysae in the Topopah Spring Tuff along the cross drift (Figure 7). Mapping and documentation of lithophysae included use of Panel Maps and Panel Photographs (maps drawn on photographs of cleaned tunnel walls), two types of linear traverses, and lithophysae-specific inventories (i.e., point data). Panel Maps are 1x3-m-sized areas in which all lithostratigraphic features are mapped, including lithophysal cavities, and Panel Photographs are $2 \times 7-\mathrm{m}$-sized areas in which only lithophysae larger than $20 \mathrm{~cm}$ in diameter were photographically identified as to shape of the lithophysal cavities. In the Panel Photographs, 34 lithophysae are "backfilled" with "muck" from the tunnel boring machine (i.e., they were not completely cleaned out during washing of the wall), so specific shapes could not be clearly identified; however, none appeared to be collapsed. Although the lithophysae data were largely collected for other mapping efforts, the compilation of available data indicates that none of the lithophysal cavities exhibited any evidence for damage or collapse structures. Additionally, only 18 lithophysae are intercepted (partially or transected) by fractures, and only 5 are transected by shears. Modeling of lithophysal and nonlithophysal tuff using the rock mechanics "Universal Distinct Element Code" (UDEC) with various seismic waveform and particle velocity data sets indicates that some sets result in extensive damage to the rock mass. The lack (or rarity) of damage to lithophysae in the cross drift indicates that the rock mass probably has not been subjected to the larger values of ground motions (Buesch and Damjanic, 2004).

\section{Relations of fractures and lithophysae}

The relations of fractures and lithophysal cavities were not explicitly mapped during the lithophysal studies between 2001 and 2004; however, rock mechanics modeling using the "Particle Flow Code" (PFC) indicates that when rocks are strained to the point of failure, a characteristic inter-lithophysae fracture pattern develops (Figure 8, Buesch and Damjanic, 2004). The PFC model is a 1x1-m area where lithophysae are represented as voids in the "rock material", and some model runs used "stenciled" shapes of lithophysal cavities from Panel Maps (Figure 8). "Stenciled", unconfined compression test, PFC model runs such as those in Panel Map "1624" indicate (1) peak strain at failure of 0.17 to 0.30 percent with (2) micro-fractures in blue formed at pre-peak-strength failure, (3) micro-fractures in red formed at post peakstrength failure, and (4) development of inter-lithophysal fracture patterns. Using photographic interpretation methods, a total of 300 fractures were mapped on the photograph used for the Panel Map at 1624 on the right wall of the cross drift, and although there are a few fractures that intersect lithophysal cavities, the inter-lithophysal fracture pattern did not develop in this rock (Figure 8). A total of 38 Panel Map and Panel Photographs were photographically reviewed for the inter-lithophysal fracture pattern, and again, although there are a few fractures that intersect lithophysal cavities, the inter-lithophysal fracture pattern did not develop in these rocks.

\section{Summary of geologic and rock mechanics limits on ground motion}

The petrogenetic sequence of lithostratigraphic feature development in the densely welded and crystallized Topopah Spring Tuff provides textural and mineralogical evidence that the lithostratigraphic features and most of the fractures formed in a relatively short period of time (possibly 100 years) after deposition of the tuff. Rock mechanics models such as UDEC and PFC provide quantitative values of rock strengths for the failure of the rocks, and "predictions" of features such as damaged (collapsed) or inter-lithophysal fracture patterns that would develop where rocks are statically or dynamically strained beyond their failure strength. The overall lack of damage to "cooling" related features such as lithophysae and most fractures is consistent with the rock mass of the Topopah Spring Tuff having never been strained beyond the static or dynamic failure strength since deposition 12.8 million years ago. However, fracture-fill materials and geometric relations of discontinuities in the cross drift indicate that strain has been localized along a relatively few faults and distributed along 141 minor faults and shears. 


\section{References}

Brantley, S.R. 1994. Volcanoes of the United States. VOLCUS1994: U.S. Geological Survey, Information Services, $12 \mathrm{p}$.

Buesch, D.C., and Damjanac, Branko, 2004, Geologic and rock mechanics limits on maximum potential strain in the 12.8-M.Y. history of the Topopah Spring Tuff at Yucca Mountain, Nevada: Geological Society of America, Boulder, Colorado, Annual Meeting Abstracts with Programs, v. 36, no. 5 , p. 33.

Buesch, D.C., Beason, S.C., and Spengler, R.W., 1999, Relations among welding, vapor-phase activity, crystallization, and fractures in the Tiva Canyon and Topopah Spring Tuffs at Yucca Mountain, Nevada: Geological Society of America Abstracts with Programs, v. 31, p. A476-A477.

Buesch, D.C., and Spengler, R.W., 1998, Character of the middle nonlithophysal zone of the Topopah Spring Tuff at Yucca Mountain: in International High-Level Radioactive Waste Management Conference, American Nuclear Society, Le Grange Park, Illinois, p. 16-23.

Buesch, D.C., Spengler, R.W., Moyer, T.C., and Geslin, J.K., 1996, Proposed stratigraphic nomenclature and macroscopic identification of lithostratigraphic units of the Paintbrush Group exposed at Yucca Mountain, Nevada: U. S. Geological Survey Open-File Report 94-469, 47 p.

Flint, L.E., 1998, Characterization of Hydrogeologic Units Using Matrix Properties, Yucca Mountain, Nevada: U.S. Geological Survey Water-Resources Investigations Report 97-4243, 64 p.

King, J.L, Coppersmith, K.J, and Quittmeyer, R.C., 2004, Bounding peak ground velocities for seismic events at Yucca Mountain, Nevada: Geological Society of America, Boulder, Colorado, Annual Meeting Abstracts with Programs, v. 36, no. 5, p. 33.

Mongano, G.S.; Singleton, W.L.; Moyer, T.C.; Beason, S.C.; Eatman, G.L.W.; Albin, A.L.; and Lung, R.C. 1999, Geology of the ECRB Cross Drift - Exploratory Studies Facility, Yucca Mountain Project, Yucca Mountain, Nevada: Bureau of Reclamation and U.S. Geological Survey accessed April 16, 2004 at http://www.ocrwm.doe.gov/technical/doclist.

Munsell Color Company, 2000, "Munsell Soil Color Charts, 2000 Revised Edition” GretagMacbeth, New Windsor, New York., 11 p., 20 plates.

Otto, S.J., and Buesch, D.C. 2003, Porosity, bulk density, and rock-particle density of lithostratigraphic components in lithophysal rocks of the Topopah Spring Tuff at Yucca Mountain, Nevada: Geological Society of America Abstracts with Programs, v. 35, no. 6, p. 434-435.

Riehle, J.R.; Miller, T.F.; and Bailey, R.A. 1995, Cooling, Degassing and Compaction of Rhyolitic Ash Flow Tuffs: A Computational Model: Bulletin of Volcanology, v. 57, no. 5, p. 319-336.

Wood, C.A. and Kienle, J., eds. 1990. "Volcanoes of North America, United States and Canada", Cambridge University Press, Cambridge, England, p. 70. 


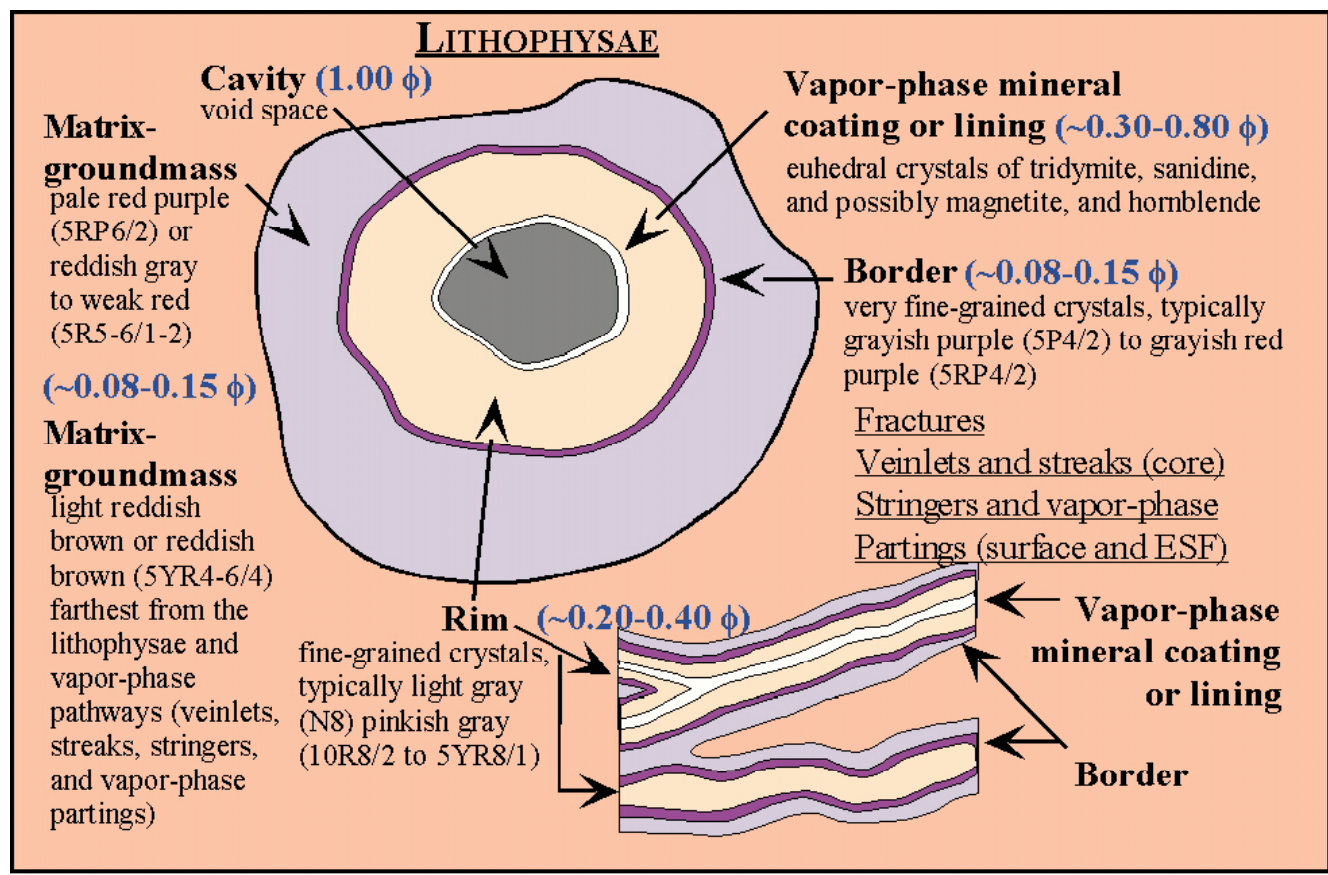

Figure 1. Welding, crystallization, and mineralization features related to lithophysae and fractures in densely welded and crystallized Topopah Spring Tuff. Porosity values for the matrix-groundmass are from Otto and Buesch (2003), approximated from Flint (1998), and Buesch (2003, not published). Values for rims are from Otto and Buesch (2003), and the values for borders and vapor phase mineral coatings are estimates by Buesch (2003, not published). Nomenclature and symbols of colors (e.g., pale red purple is 5RP6/2) are based on comparisons with the Munsell Soil Color Chart (Munsell Color Company 1994).

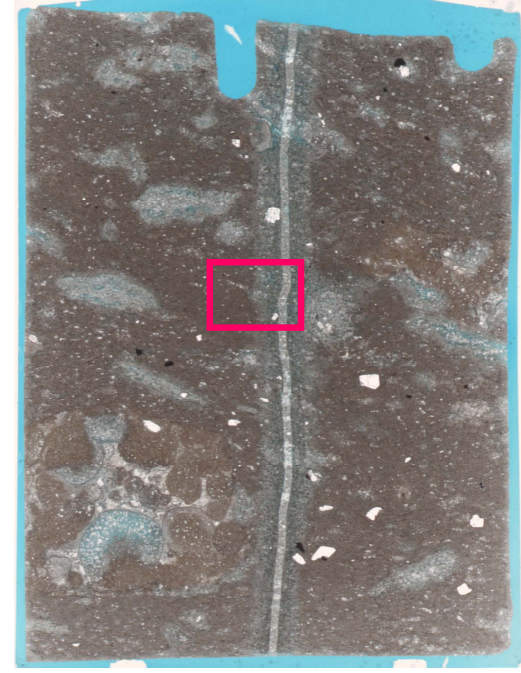

Sample number 0028274.

Area is approximately $21 \times 27 \mathrm{~mm}$.

Thin section is vertical with top of the section toward top of formation.

Some small white areas are crystal fragments,

but most are tridymite deposited in corroded shards or small circular vapor pockets.

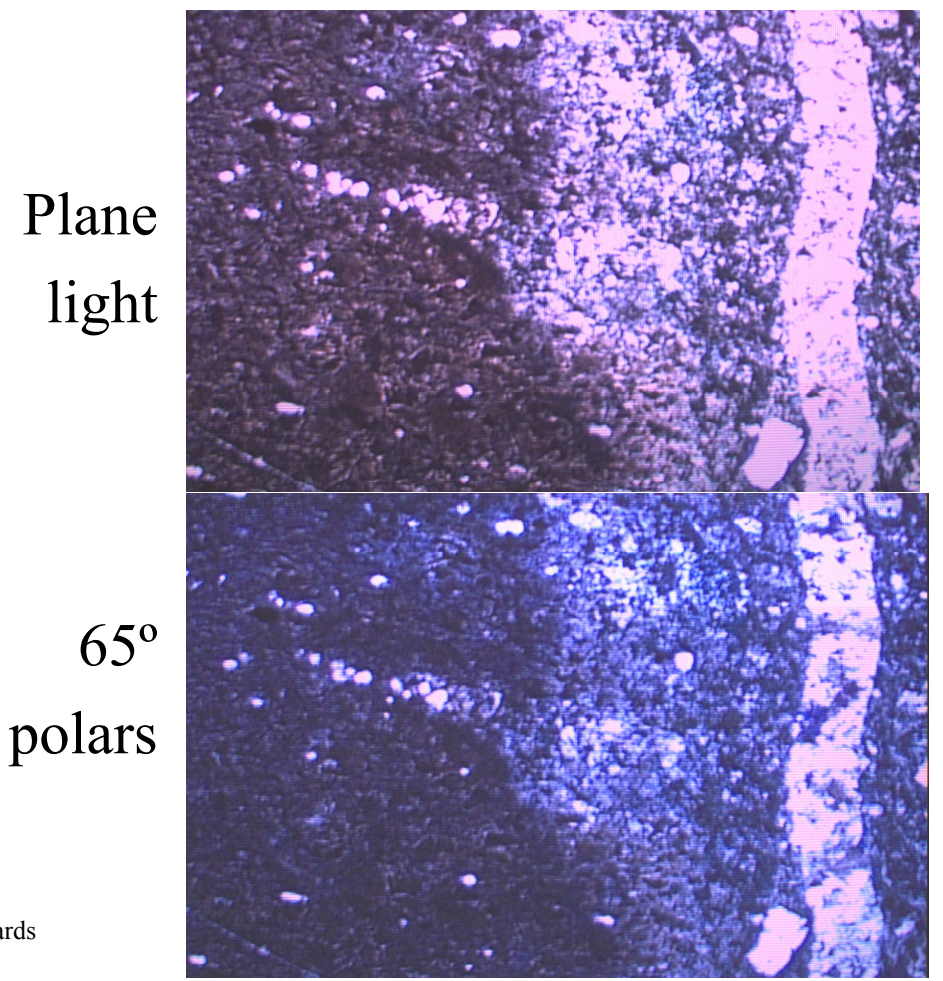

Figure 2. Thin section and photomicrographs of densely welded and crystallized Topopah Spring Tuff from the middle nonlithophysal zone (Tptpmn) in borehole USW NRG-6 at a depth of $730 \mathrm{ft}$. The rim and vapor-phase mineral lining are identifiable in the full thin section and in the close up views. 


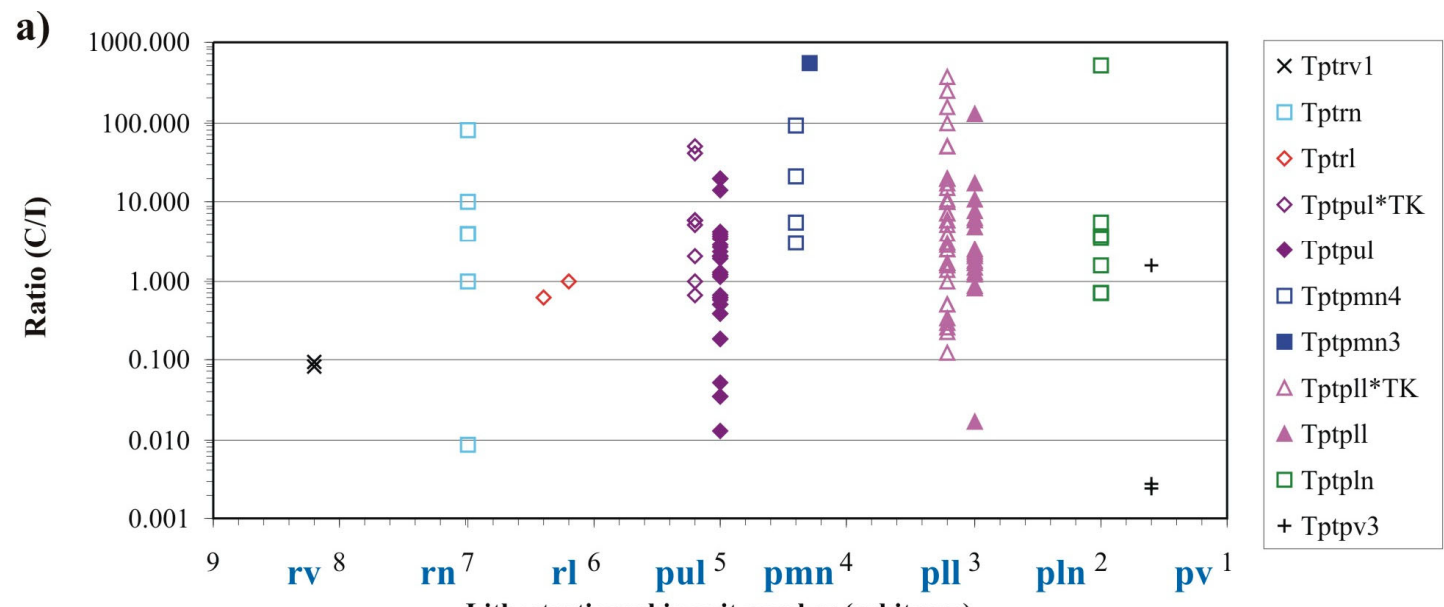

b)

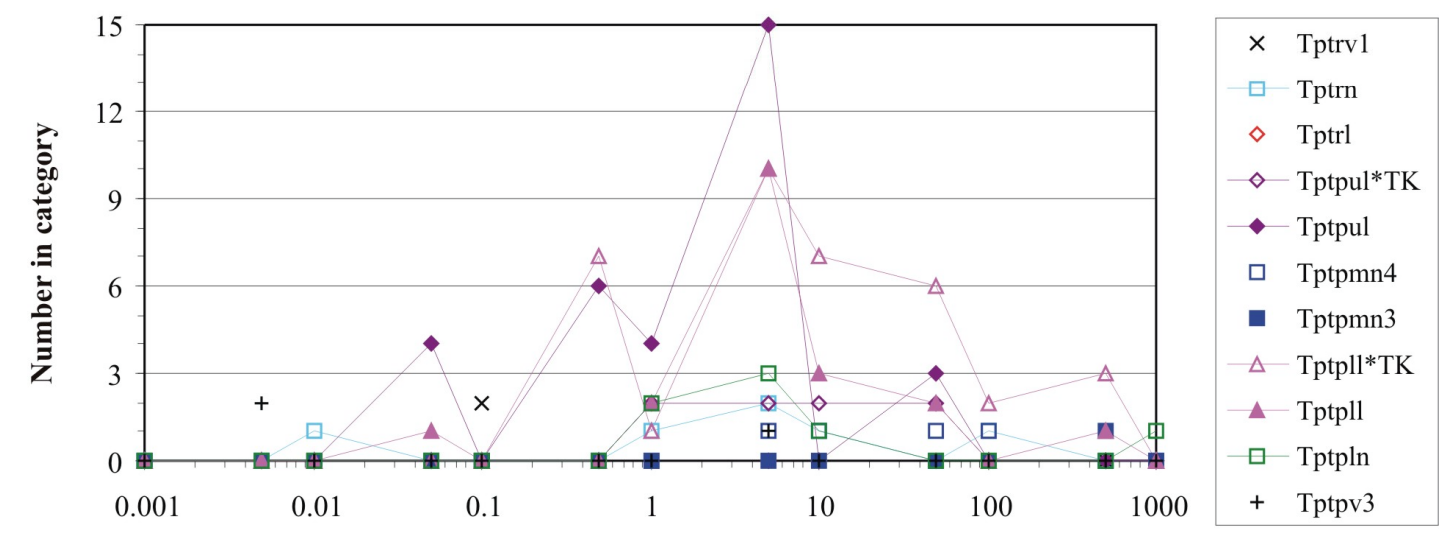

Ratio of $\mathrm{C} / \mathrm{I}\left(5 \times 10^{\mathrm{x}}\right.$ increments)

Figure 3. "Cooling to Indeterminate Ratio" (C/I Ratio) of fractures by lithostratigraphic zone or subzone in the densely welded and crystallized Topopah Spring Tuff. A) C/I Ratios of individual samples plotted by lithostratigraphic zone or subzone. B) The number of C/I Ratio values in $5 \times 10^{\mathrm{x}}$ increments plotted by lithostratigraphic zone or subzone. Lines are only plotted for units with 5 or more samples
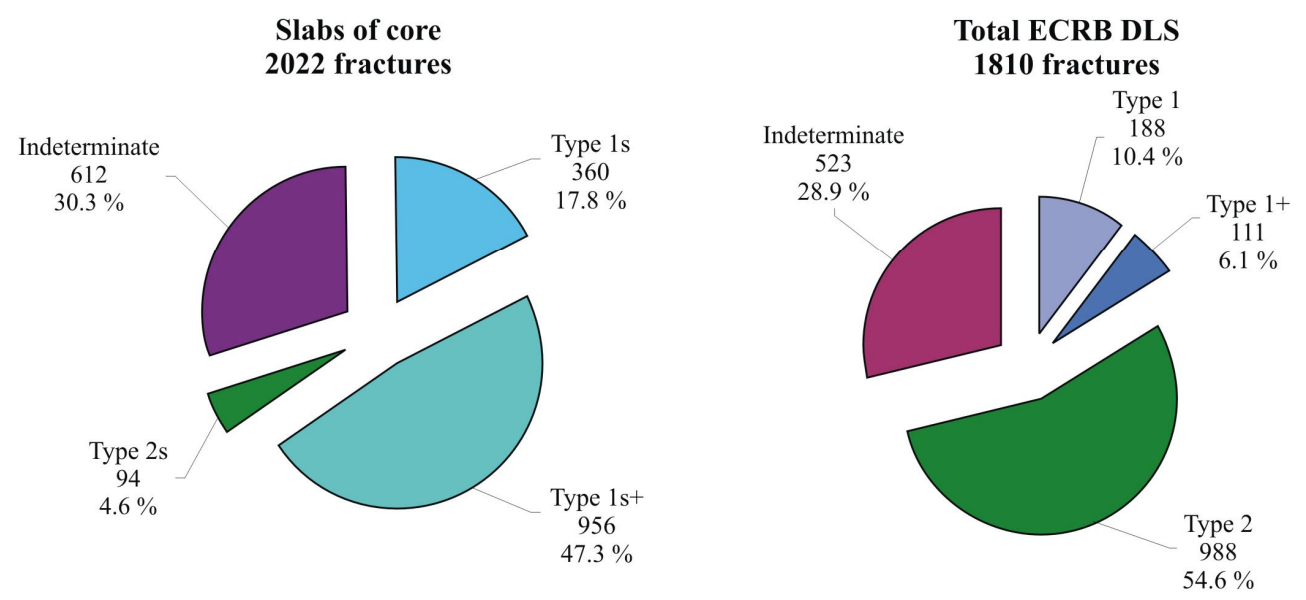

Figure 4. "Cooling" fractures (Type 1,1+, and 2) and "Indeterminate" fractures in slabs of core and ECRB DLS data. In the DLS data, plots of trace length and orientation (stereo plots) indicate vary similar geometric relations of cooling and indeterminate fractures. 


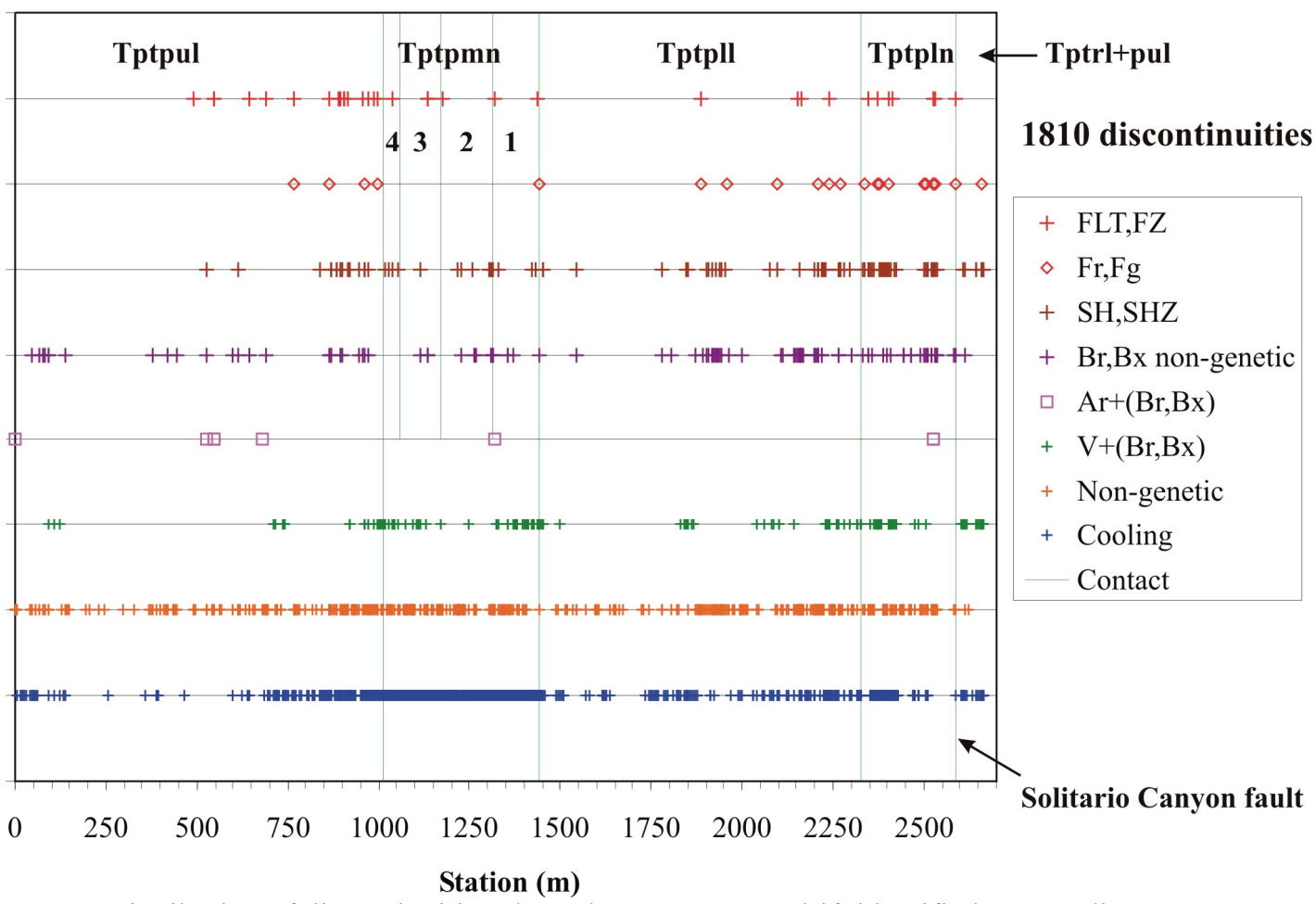

Figure 5. Distribution of discontinuities along the ECRB cross drift identified as "Cooling", "Non-genetic" (or indeterminate), those filled with "broken or brecciated rock, or sand" ( $\mathrm{Br}$ or $\mathrm{Bx}$ ), shears and shear zones (SH and SHZ), faults and fault zones (FLT and FZ), and fault breccia or fault gouge (Fr or Fg). Fracturefill conditions with "broken or brecciated rock, or sand" that include clay $[\mathrm{Ar}+(\mathrm{Br}, \mathrm{Bx})]$, and vapor-phase minerals $[\mathrm{V}+(\mathrm{Br}, \mathrm{Bx})]$.
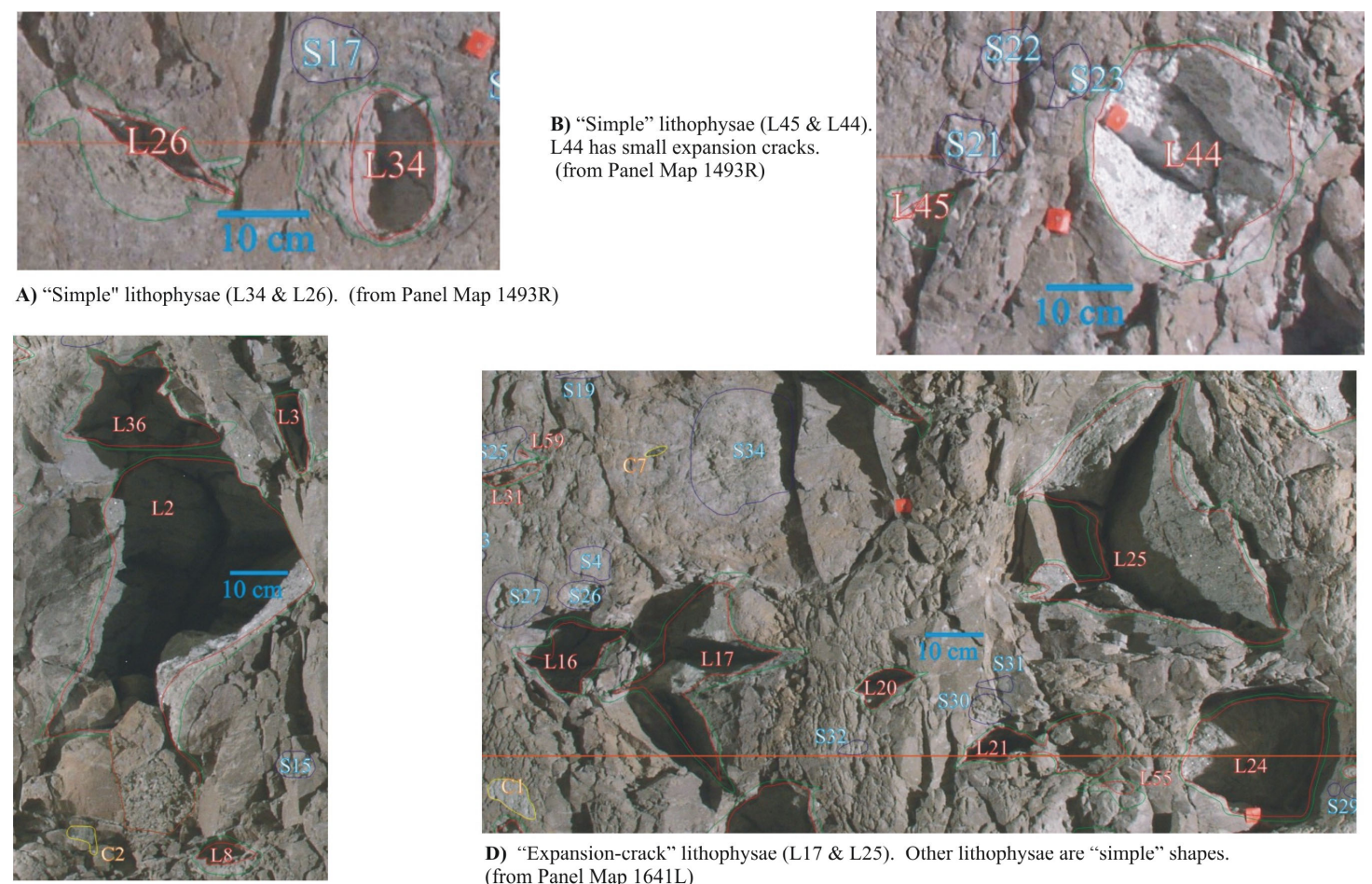

D) "Expansion-crack" lithophysae (L17 \& L25). Other lithophysae are "simple" shapes.

C) Merged lithophysae(L2 \& L36). (from Panel Map 1641L) (from Panel Map 1641L)

Figure 6. Shapes of lithophysae in the densely welded and crystallized Topopah Spring Tuff. 
Workshop on "Extreme Ground Motion at Yucca Mountain" -- August 23 to 25, 2004
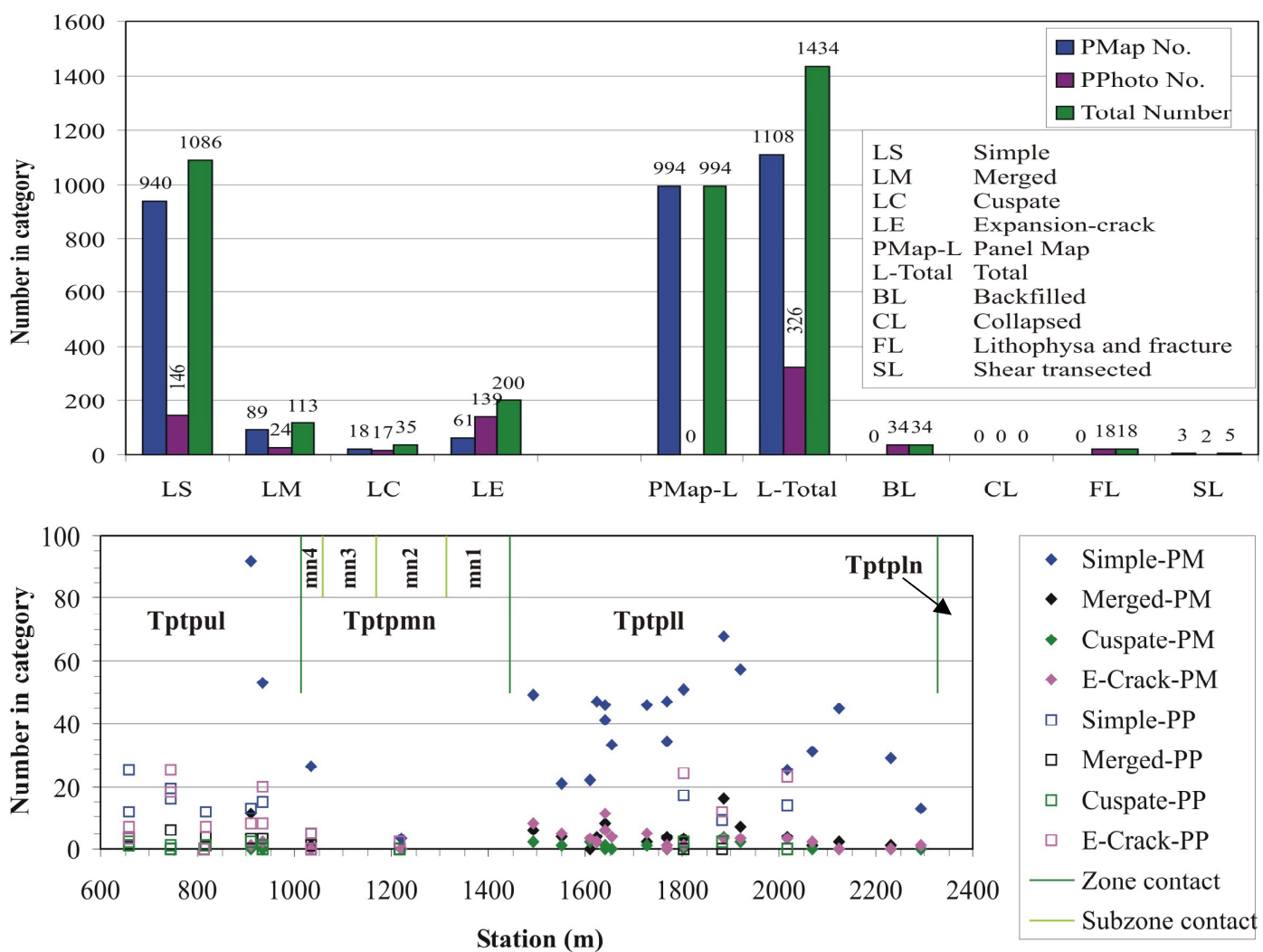

Figure 7. Summary of shapes of lithophysae in the Topopah Spring Tuff exposed in the ECRB cross drift and cataloged in Panel Maps (PM) and Panel Photographs (PP).

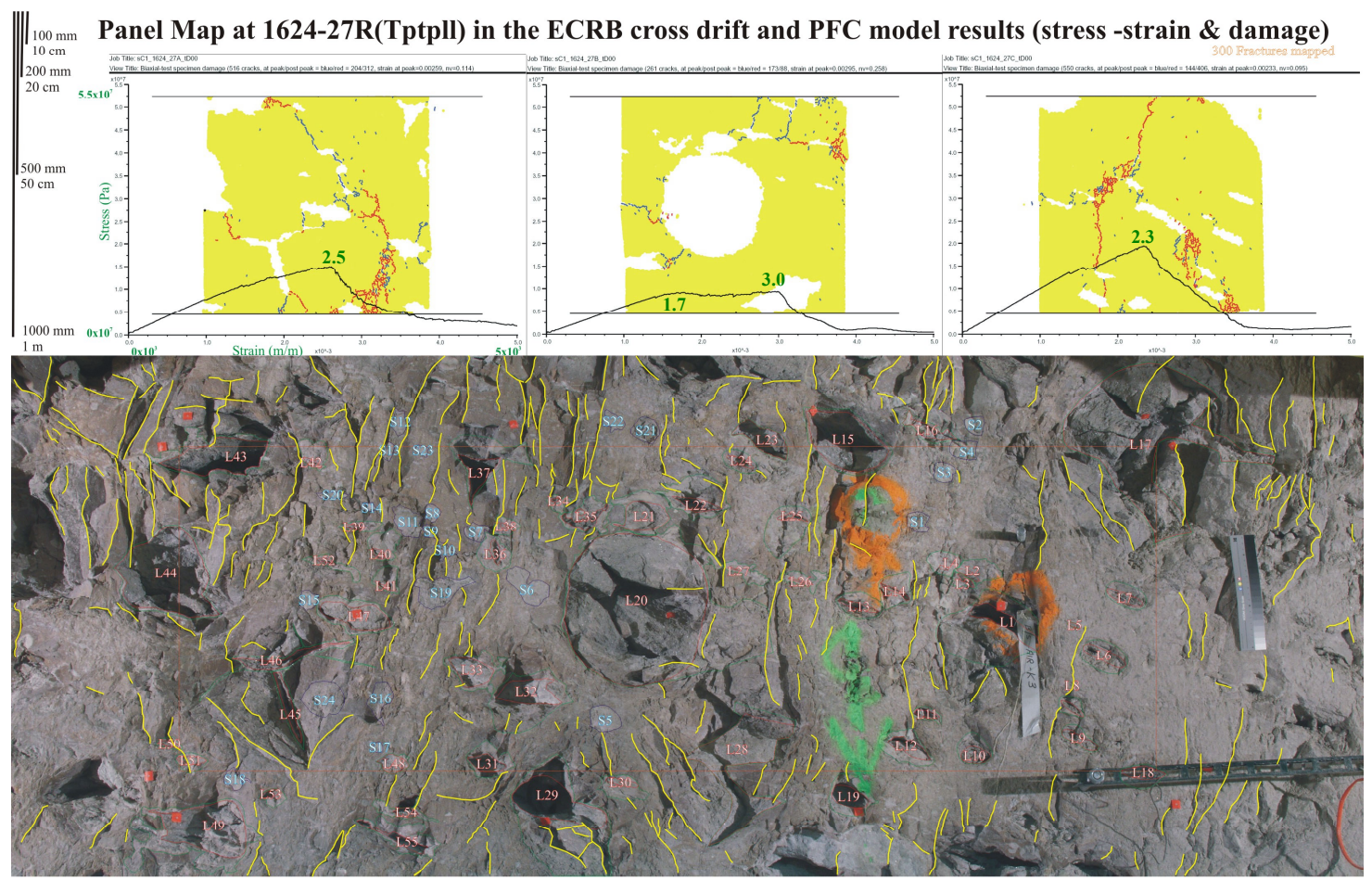

Figure 8. Panel Map location 1624 to 1627 on the right wall of the ECRB cross drift with overlays of 300 photographically interpreted fracture traces. The inset diagrams are of the PFC results from the 1x1-m stenciled models and the associated stress-strain relations. 


\title{
Petrographic evidence of past seismicity from secondary mineral deposits in the unsaturated zone at Yucca Mountain, Nevada
}

\author{
J.F. Whelan
}

\section{INTRODUCTION}

Performance objectives for the proposed high-level radioactive waste repository at Yucca Mountain, Nevada, require waste containment for a minimum of 10,000 years. However, modeling studies of long-term drift stability, based on Probabilistic Seismic Hazard Analysis, predict that some drifts, especially in the lower lithophysal unit of the Topopah Spring Tuff, are likely to collapse. In apparent contradiction, however, deposits of secondary calcite and silica on fracture footwalls and lithophysal cavity floors in the tuffs, although commonly fragile, are well preserved and undamaged. On fractures the coatings may be loosely attached and easily dislodged and in lithophysal cavities they often contain delicate calcite blades several centimeters tall with bulky overgrowths of calcite and opal. Modeling or physical testing of the ground motions required to disrupt these textures might provide an upper bound on past ground motions in the repository units.

During the course of USGS studies of these deposits since 1995, approximately 450 samples have been collected, most with one or more thin sections made for petrographic examination. Evidence of damage to fracture coatings has been observed in several samples, but is rare; lithophysal cavity deposits are typically undamaged. These observations are, however, preliminary and anecdotal; neither the samples nor the thin sections were systematically examined for evidence of seismic damage.

\section{SECONDARY MINERAL DEPOSITS}

Calcite and silica (quartz, chalcedony, and opal) with minor amounts of fluorite, zeolites, and manganese oxides are found in some open fractures and lithophysal cavities in the Topopah Spring and Tiva Canyon Tuffs in the UZ (Whelan and others, 1994; Paces and others, 2001; Whelan and others, 2002). Published studies of these deposits have concluded that the secondary minerals formed in the UZ during the past $10+$ million years from meteoric waters percolating along fractures to the water table (Szabo and Kyser, 1990; Whelan and others, 1994; Paces and others, 2001). Underground exposures in the ESF and ECRB Cross Drift tunnels show the deposits to be sparsely and heterogeneously distributed in less than 10 percent of potential fracture and cavity depositional sites and generally restricted to the floors of lithophysal cavities and the footwalls of fractures in the welded tuffs (Paces and others, 2001; Whelan and others, 2002), evidence that is consistent with UZ depositional conditions.

The secondary mineral deposits range in thickness from a fraction of a millimeter $(\mathrm{mm})$ to as much as 5 centimeters $(\mathrm{cm})$. Typical coatings are 5 to $10 \mathrm{~mm}$ thick in cavities and 1 
to $5 \mathrm{~mm}$ thick on fractures. Secondary mineral deposits on fracture footwalls tend to form coatings of relatively uniform thickness or masses of calcite-cemented fracture (or fault) breccia. On the floors of lithophysal cavities, the deposits are coarser grained and commonly contain tall, thin blades of calcite. A generalized paragenetic sequence of secondary mineral deposition in the UZ divides them into early, intermediate, and late stages (Whelan and others, 2002).

The early stage consists of calcite, followed by calcite that is locally admixed with fluorite and commonly capped by deposition of botryoidal chalcedony and (or) drusy quartz. The intermediate and late stages are mineralogically similar, both consisting largely of calcite and opal, but texturally different. Intermediate-stage calcite typically displays an elongate, thin-bladed habit, whereas late-stage calcite typically forms overgrowths on older calcite, often as distinctive knobby or corniced masses on the tips of intermediate-stage blades. Intermediate- and late-stage opal forms botryoidal masses and laminar sheets on or interlayered with calcite (Whelan and others, 2002).

\section{TEXTURAL EVIDENCE OF PAST SEISMICITY}

Field and thin section relations suggest three possible records of past seismicity: (1) incorporation of tuff fragments into the coatings; (2) preservation of delicate bladed crystals; and (3) preservation weakly attached or detached coatings on fracture walls.

Incorporation of tuff fragments. Many deposits, in lithophysal settings in particular, contain fragments of tuff that have been incorporated into the deposit during deposition (Fig. 1). This relationship is relatively common in the early stage but rare to absent in the intermediate and late stages.

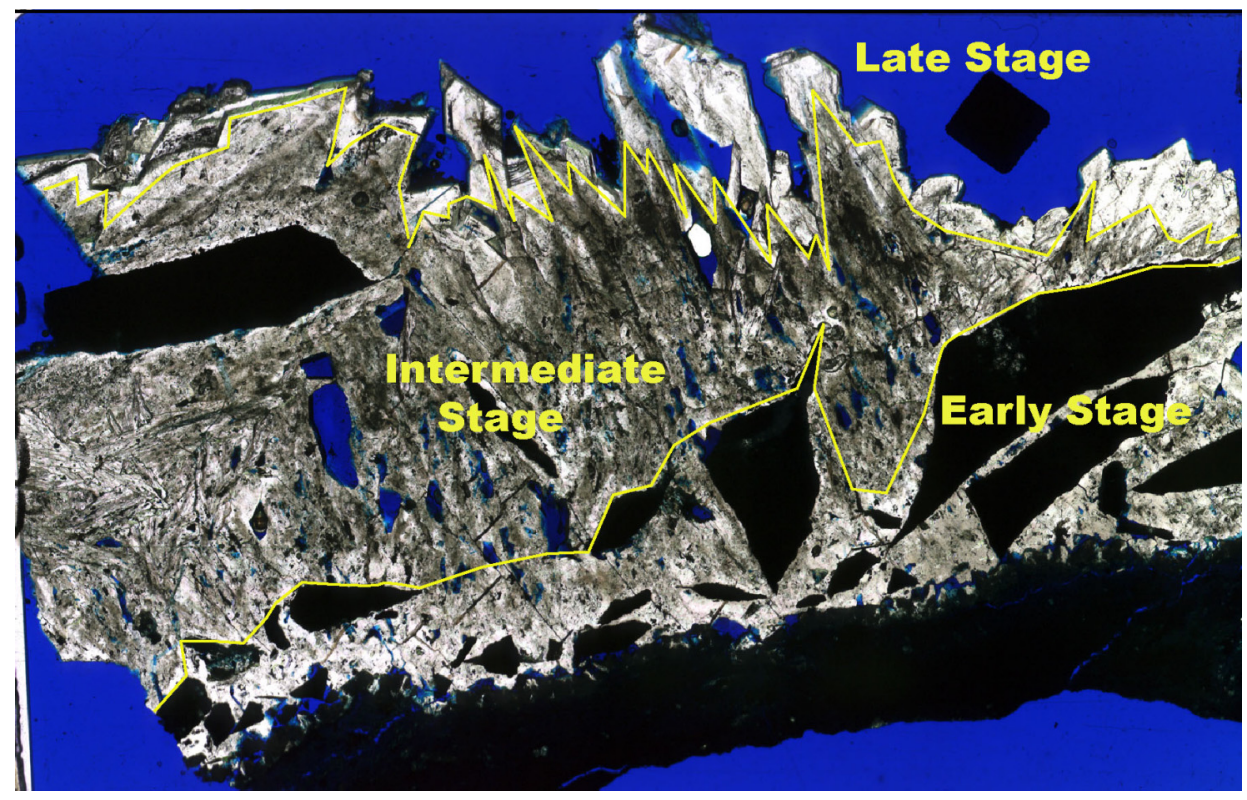

Figure 1. Photomicrograph of calcite-cementing tuff fragments from a lithophysal cavity deposit at ECRB 10+10. The paragenetic stages are labeled and the small square has $\sim 2.3$ mm sides. 
Preservation of bladed crystals. The characteristic calcite habits of the intermediate stage bladed crystals and the late stage overgrowths consisting of calcite and opal have resulted in blade-form crystals with large bulbous tops. These "sceptered" crystals are common in lithophysal cavity settings and in at least one instance, a cavity at ESF $30+18$, resulted in extremely delicate free-standing crystals. These fragile crystals may rest on thin blades less than $0.6 \times 0.2$ millimeters in cross section (Fig. 2) and their preservation indicates that ground motions during the late stage have not been strong enough to break them. In spite of their fragile appearance, however, modeling studies by McCallen (this report) indicate that the seismic intensities necessary to break them are extremely unlikely.
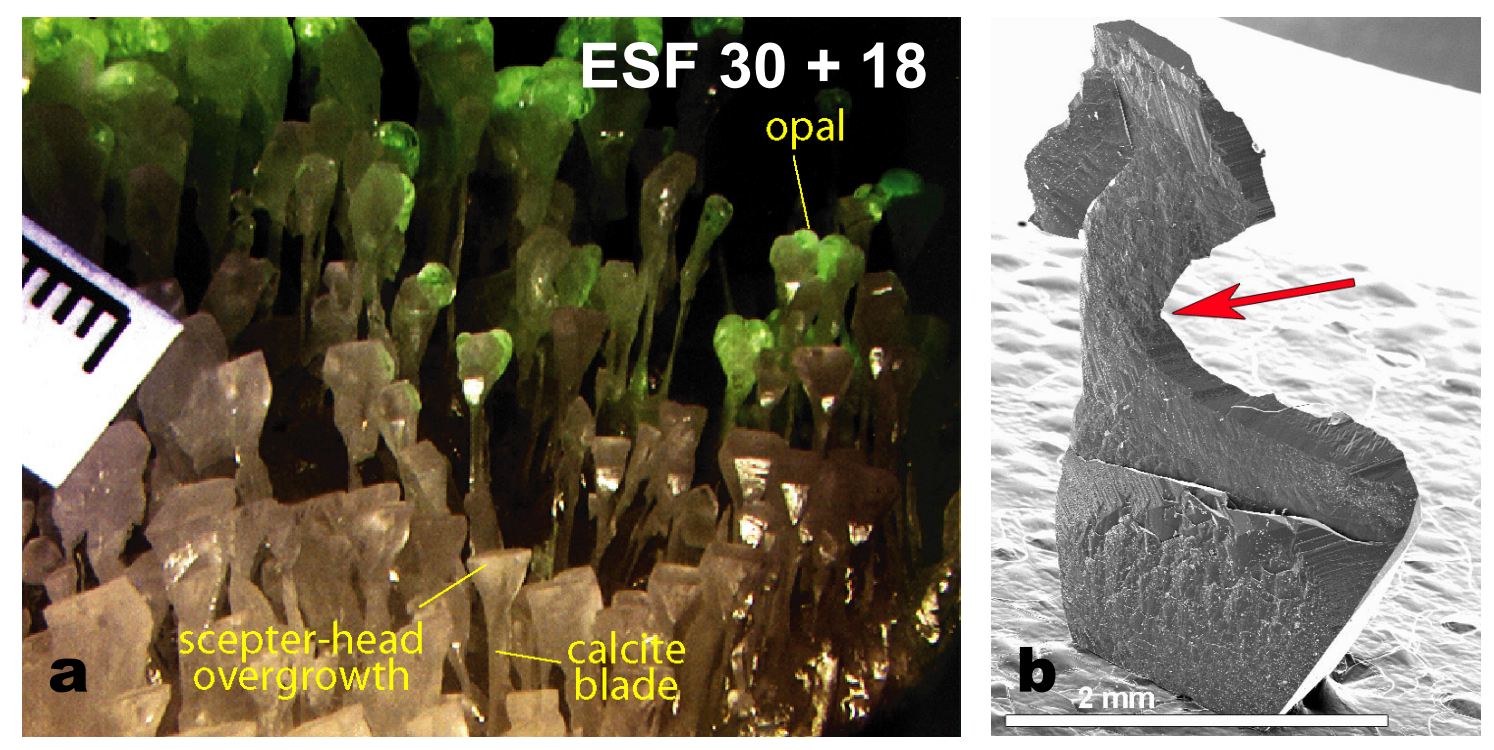

Figure 2. Scepter head crystals from ESF $30+18$ consisting of late-stage overgrowths of calcite and opal on intermediate-stage blades. (a) is a photograph in mixed white and short-wave ultraviolet illumination; the green color is from the ultraviolet fluorescence of the opal. The scale is marked in millimeters and shows that the crystal cross sections are often $<<1$ millimeter. (b) is an SEM image of a broken blade allowing a more precise estimate of the minimum blade dimensions indicated by the red arrow. The scale bar is 2 millimeters.

Preservation of weakly attached coatings. During sample collection it was noted that the coatings on some fracture surfaces were not securely attached. Indeed, some could be, and were, removed by hand. Furthermore, in several other deposits, thin section examination showed that, locally, similar coatings had become detached in the past, accumulated within the fracture, and subsequently cemented together by later calcite (Fig. 3). Although the preservation of weakly attached coatings places some constraints on the intensity of past ground motions, converting that observation to an estimate of those ground motions is probably not feasible. Nonetheless, such fragment accumulations do suggest that past ground motions were sufficient to dislodge those coatings. 


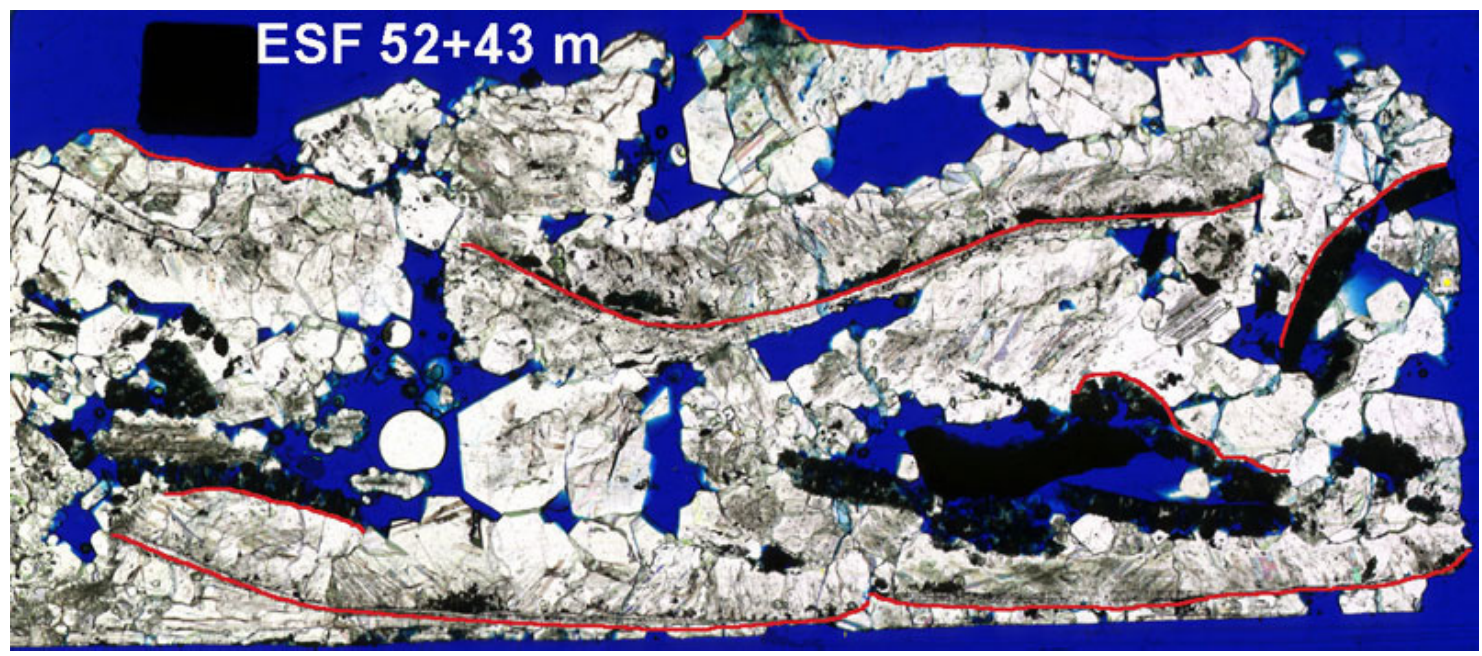

Figure 6. Photomicrograph of a petrographic section of a secondary mineral deposit at Exploratory Studies Facility (ESF) station 52+43, a steeply dipping fracture in the Topopah Spring Tuff. The sample consists of accumulated coating fragments that have been cemented together by later, probably late-stage, calcite deposition. The initial tuff attachment surfaces of several coating fragments are traced in red (dashed where uncertain). The sample was impregnated with blue-dyed epoxy to label primary porosity. The black square $\sim 2.3$ millimeters on a side.

\section{SUMMARY}

Secondary minerals, largely calcite and silica, deposited on fractures and in cavities in the 12.7 to $12.8 \mathrm{Ma}$ Topopah Spring and Tiva Canyon Tuffs of Yucca Mountain record evidence, both positive and negative, of past seismic shaking. In the early paragenetic stage, the deposits commonly incorporated tuff fragments that fell into them; however, tuff fragments are rare to non-existent in the intermediate and late stages. The preservation of delicate textures and presence of weakly attached fracture coatings indicate that ground motions during the late stage were inadequate to disturb those coating features.

These observations are anecdotal and not systematic. Systematic examination of archived samples and thin sections could provide insights into the timing and distribution of tuff fragmentation and document the distribution of damaged textures in the deposits. Laboratory experiments to directly measure the motions required to damage the delicate blades or to dislodge the weakly attached coatings may be possible but would require further underground study of the deposits to identify and collect suitable samples of the secondary mineral deposits.

\section{REFERENCES}


Paces, J.B., Neymark, L.A., Marshall, B.D., Whelan, J.F., and Peterman, Z.E., 2001, Ages and origins of calcite and opal in the Exploratory Studies Facility tunnel, Yucca Mountain, Nevada: U.S. Geological Survey Water-Resources Investigations Report 01-4049, $95 \mathrm{p}$.

Szabo, B.J., and Kyser, T.K., 1990, Ages and stable isotope compositions of secondary calcite and opal in drill cores from Tertiary volcanic rocks of the Yucca Mountain area, Nevada: Geological Society of America Bulletin, v. 102, no. 12, p. 1714-1719.

Whelan, J.F., Vaniman, D.T., Stuckless, J.S., and Moscati, R.J., 1994, Paleoclimatic and paleohydrologic records from secondary calcite - Yucca Mountain, Nevada, in HighLevel Radioactive Waste Management, Proceedings of the Fifth Annual International Conference, Las Vegas, Nevada, May 22-26, 1994: La Grange Park, Illinois, American Nuclear Society, p. 2738-2745.

Whelan, J.F., Paces, J.B., and Peterman, Z.E., 2002, Physical and stable-isotope evidence for formation of secondary calcite and silica in the unsaturated zone, Yucca Mountain, Nevada: Applied Geochemistry, v. 17, no. 6, p. 735-750. 


\section{Evaluating Fragile Blades and Filaments in the Lithophysae for}

Constraints on Long Return Period Earthquake Ground Motions at Yucca Mountain Nevada

August 2004 Workshop on Extreme Ground Motions at Yucca Mountain USGS, Menlo Park Ca

D. McCallen

Yucca Mountain and Repository Science Program

Lawrence Livermore National Laboratory

Livermore, California
J. Whelan

Environmental Science Team Yucca Mountain Project Branch United States Geological Survey Denver, Colorado 


\section{The lithophysal voids contain delicate geologic structures of potential interest for constraining historical motions}

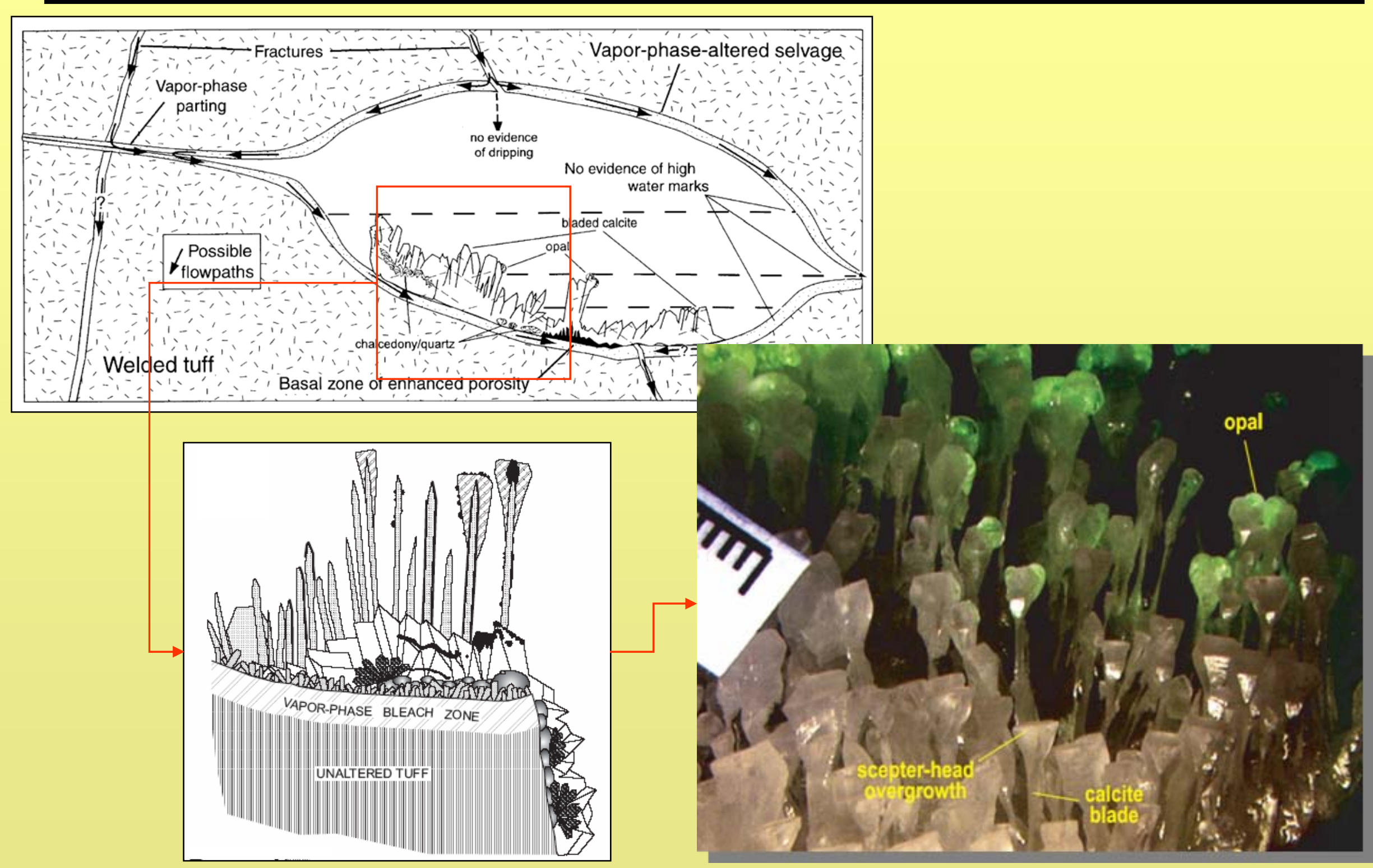




\section{Would such delicate mineral structures be subject to damage under large earthquake motions?}

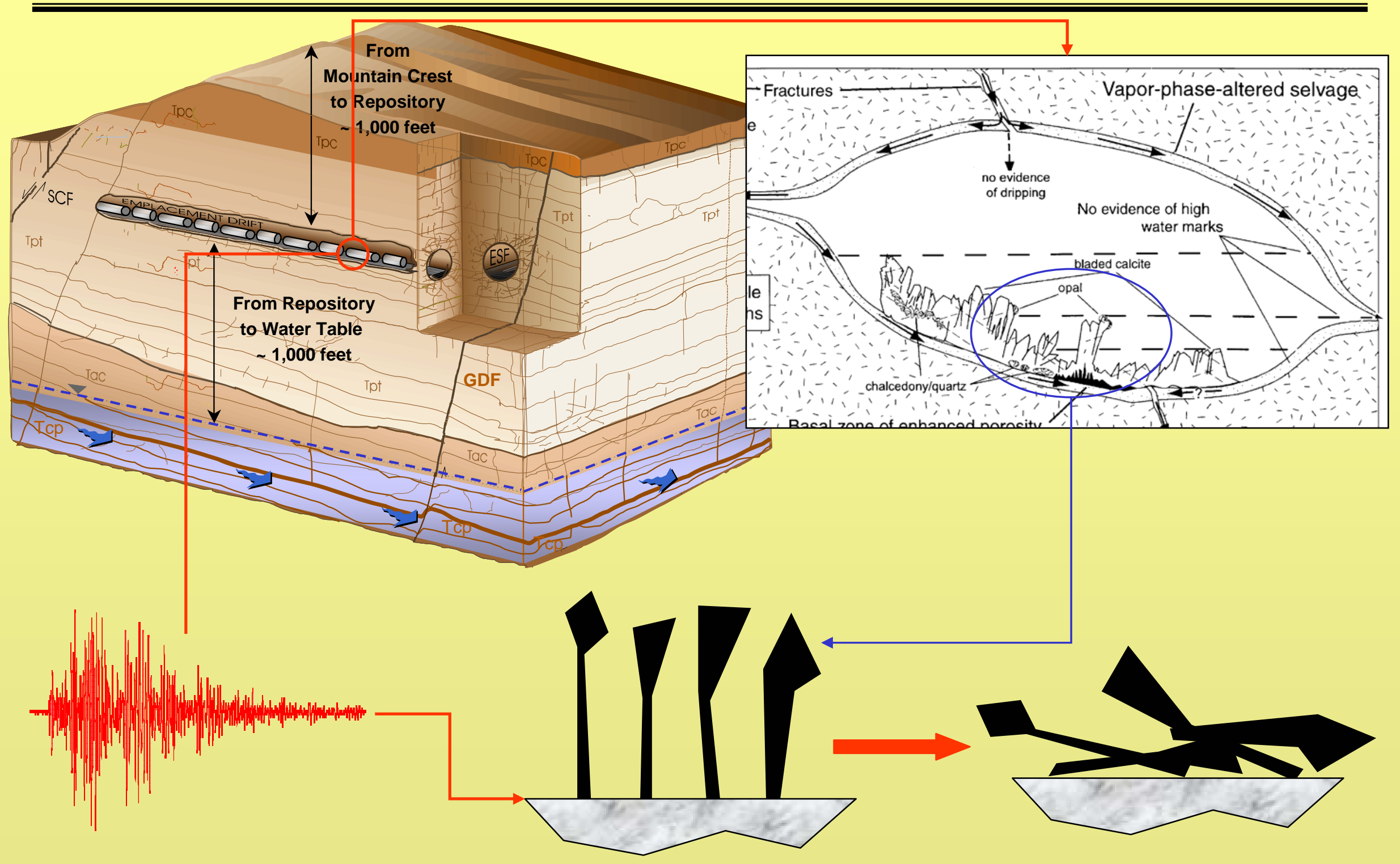


If so, does the existence of fine geologic structure allow us to constrain historical ground motion levels?

What dynamic regime are we operating in?

Ground motions at depth

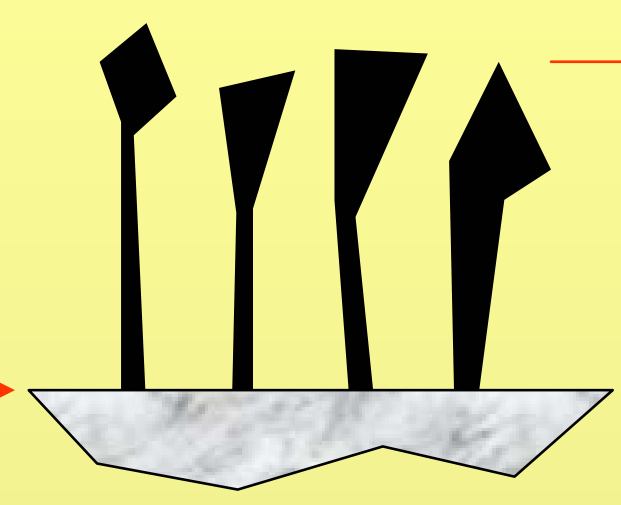

$2 g$ ?
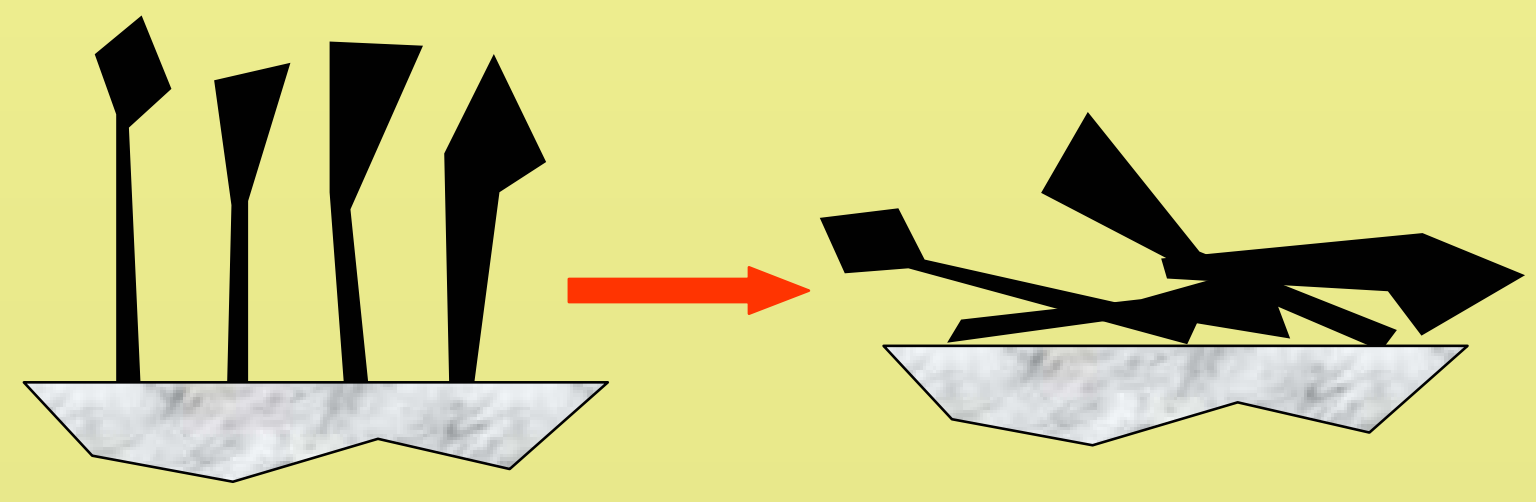

$5 g$ ?

$50 g ?$

$100 g ?$ 
A simple beam model can be invoked to shed light on the dynamics of the blade structures
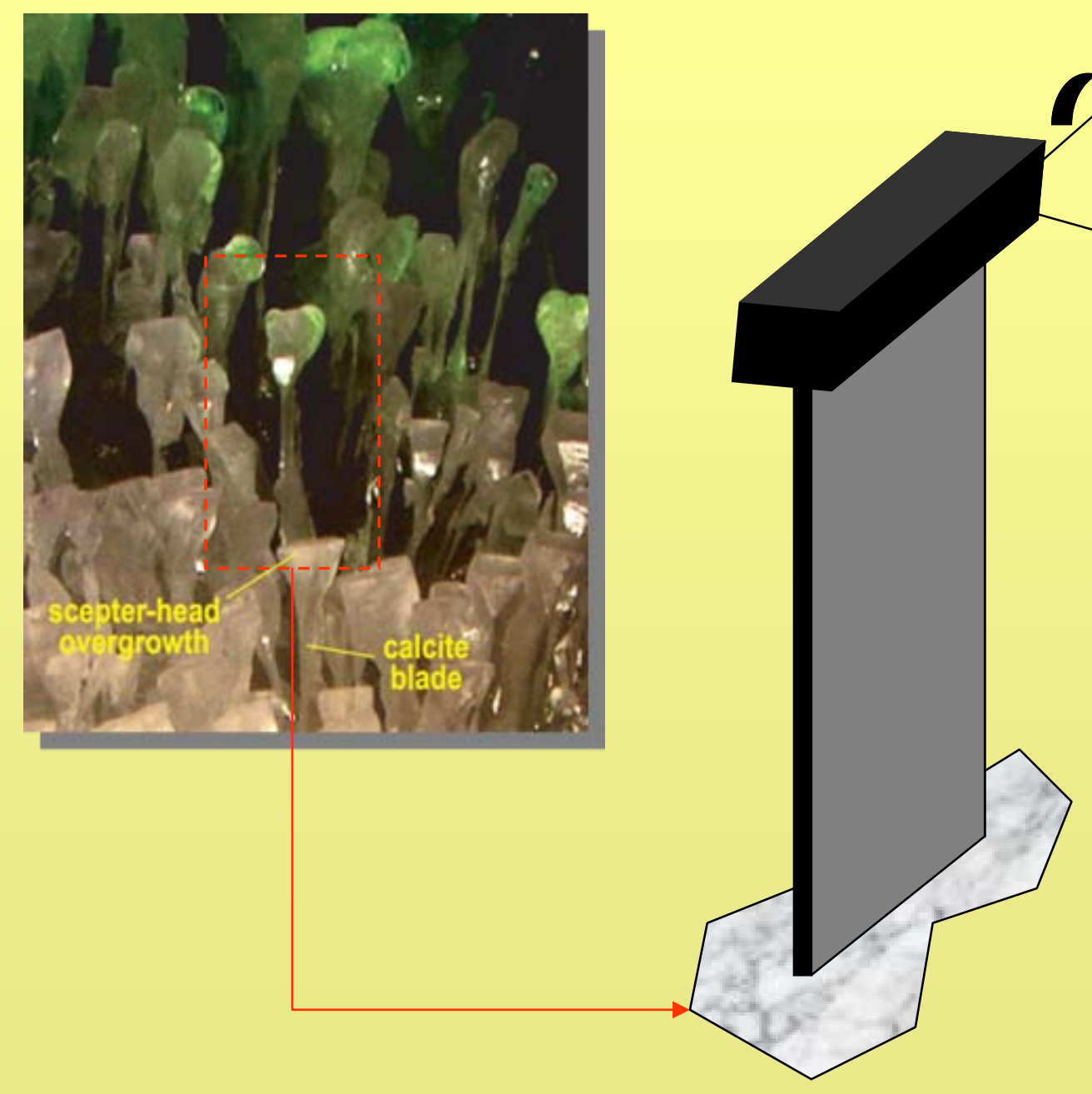

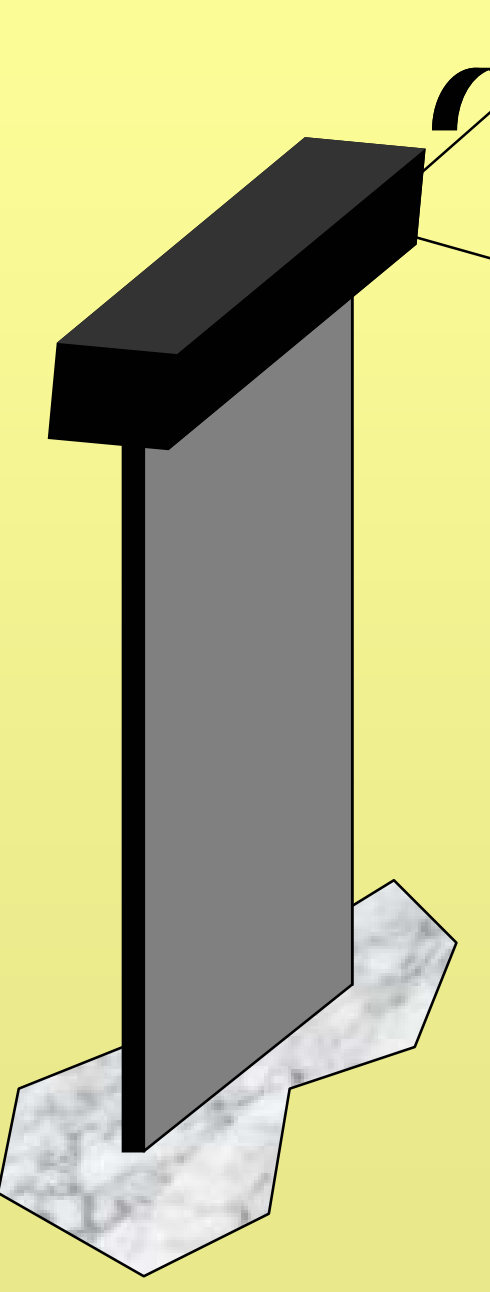

Strong axis
$U(t)$

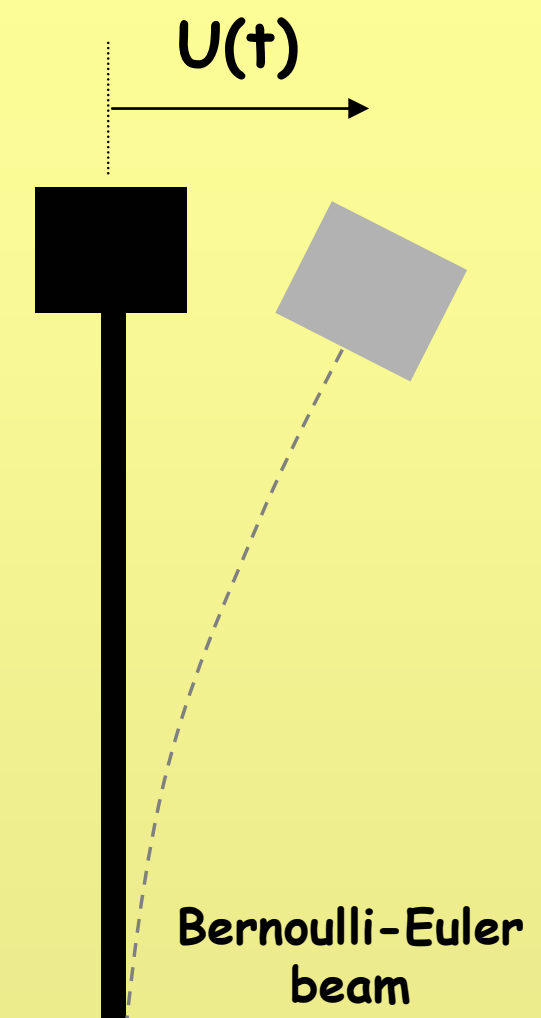

beam 
This idealization can essentially reduce the blade to a single degree of freedom oscillator

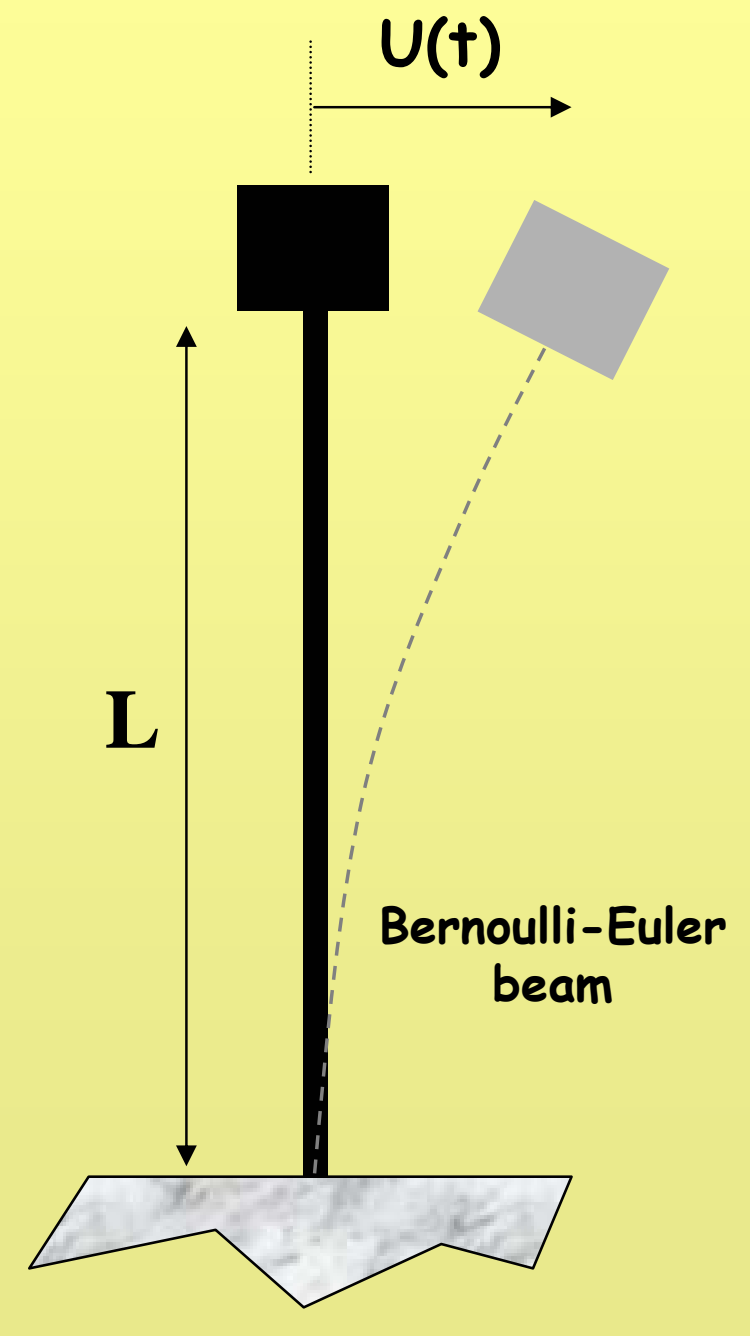

System stiffness

$$
K=\frac{3 E I}{L^{3}}
$$

$E=$ modulus of elasticity

$I$ = moment of inertia

$\mathrm{L}$ = length of blade

\section{System natural frequency}

$$
f=\frac{1}{2 \pi} \sqrt{\frac{K}{M}}
$$

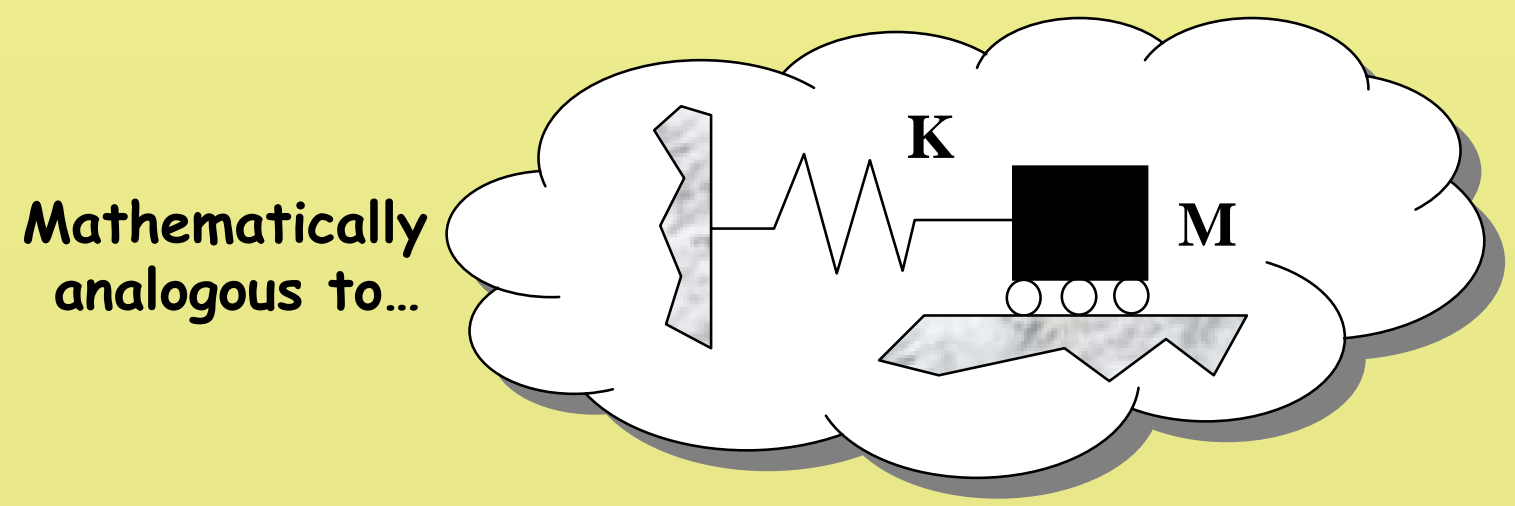


The blade structures are small and delicate, but the mass is also small
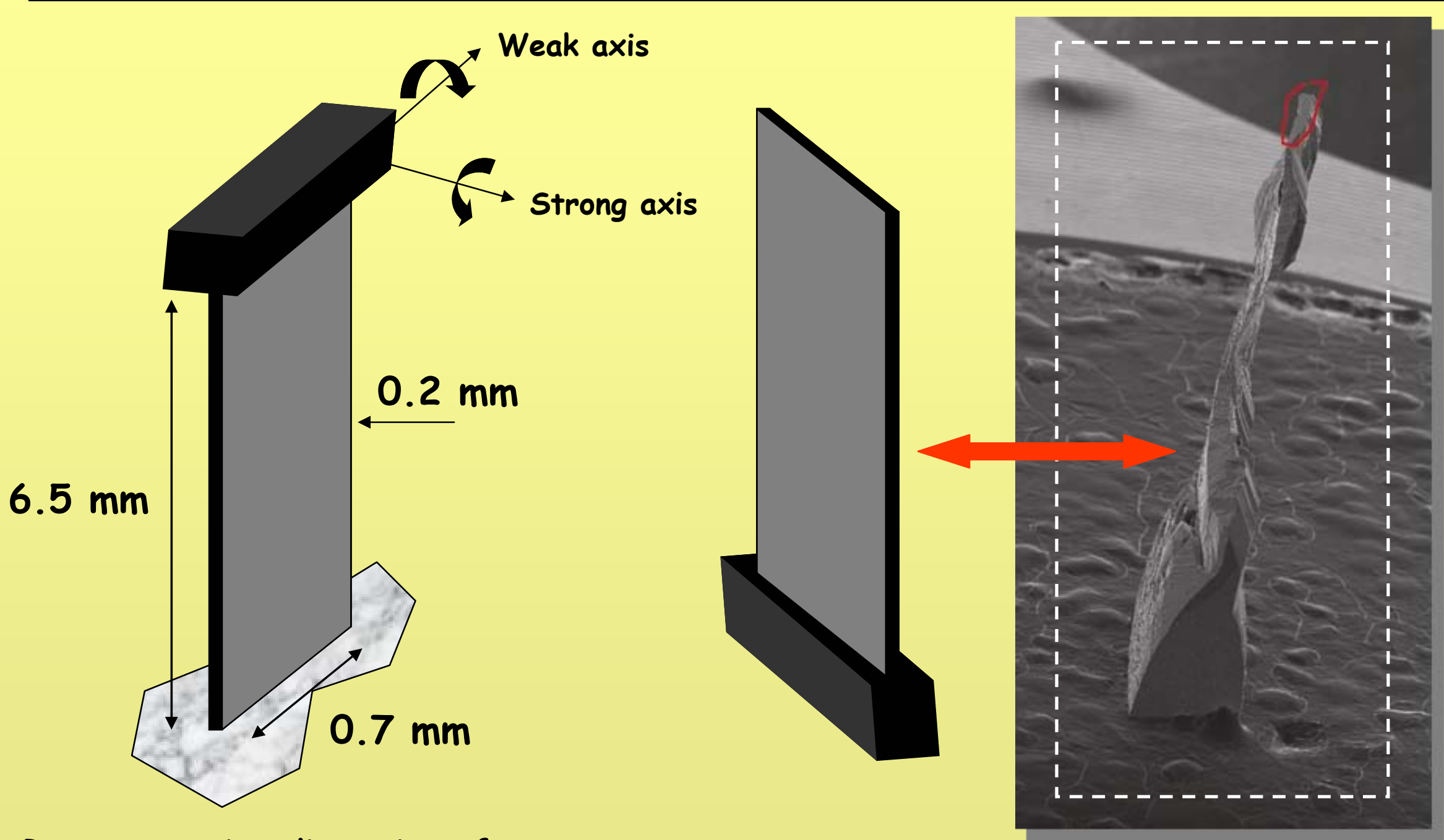

Representative dimensions for one blade (per Whalen)

Scanning electron microscope image of a broken blade 
The frequency of the current blade identified in the USGS inventory is quite high

\begin{tabular}{|l|c|c|}
\hline $\begin{array}{c}\text { Stiffness } \\
\text { Value (K) }\end{array}$ & $428(\mathrm{~N} / \mathrm{m})$ & $\begin{array}{c}\mathrm{E}=8.4 \times 10^{10} \mathrm{~N} / \mathrm{m}^{2} \\
\mathrm{I}=4.667 \times 10^{-16} \mathrm{~m}^{4} \\
\mathrm{~L}=6.5 \times 10^{-3} \mathrm{~m}\end{array}$ \\
\hline Mass & \multirow{2}{*}{$1.042 \times 10^{-5}(\mathrm{Kg})$} & $\begin{array}{c}1 / 2 \text { Beam mass }= \\
1.229 \times 10^{-6} \mathrm{Kg} \\
\text { Opal head mass }= \\
9.196 \times 10^{-6} \mathrm{Kg}\end{array}$ \\
Value (M) & & Mother Nature is \\
Frequency & $\sim 1000(\mathrm{~Hz})$ & not cooperating! \\
$(\mathrm{Hz})$ & & \\
\hline
\end{tabular}


The frequency of the blade is quite high compared to the dominant frequencies of the YMP motions

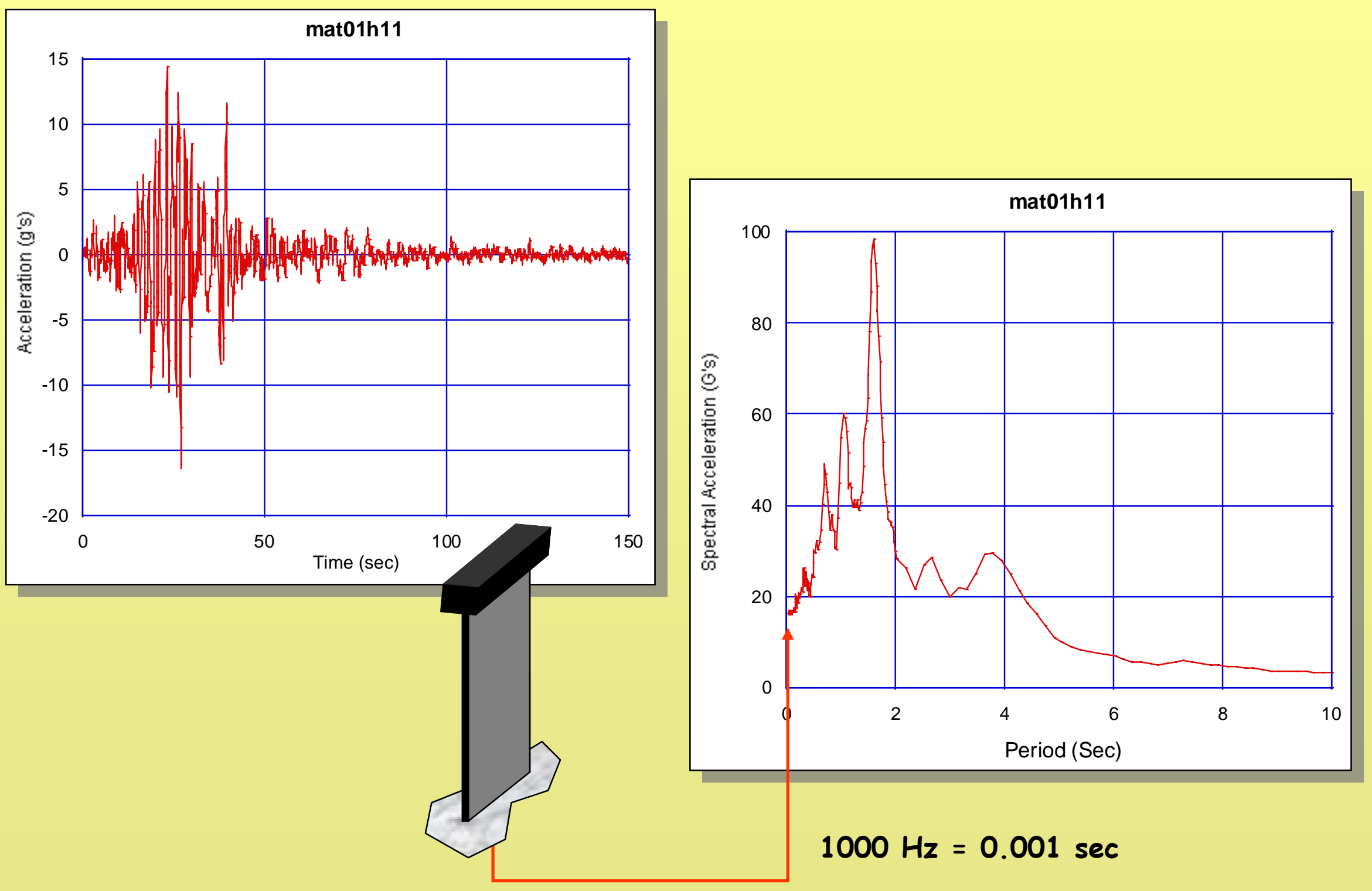


Due to the high frequency of the blade, it will respond essentially as a rigid body to the earthquake motions

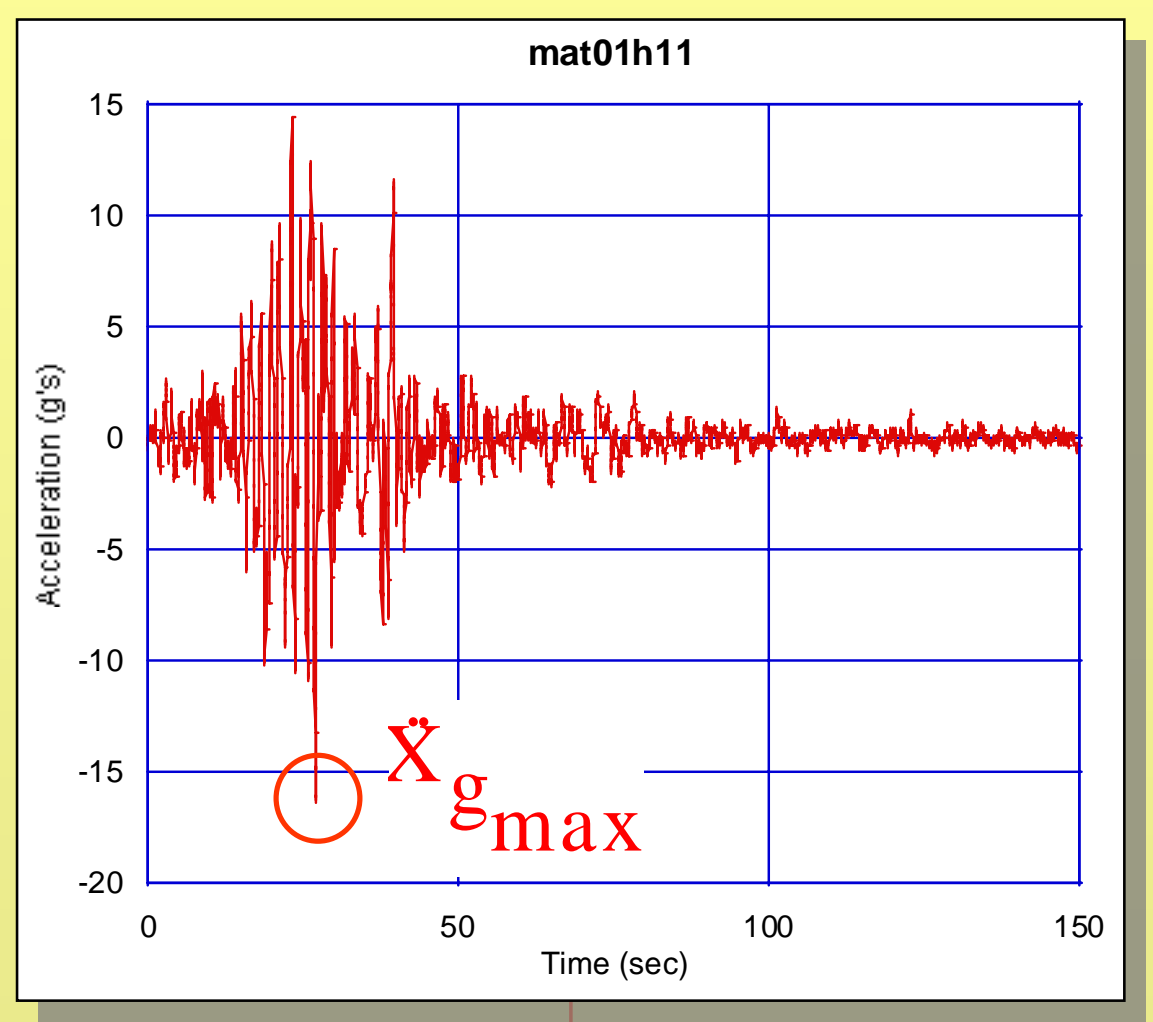

$\mathrm{F}=\mathrm{M} \ddot{X}_{\mathrm{g}_{\text {max }}}$

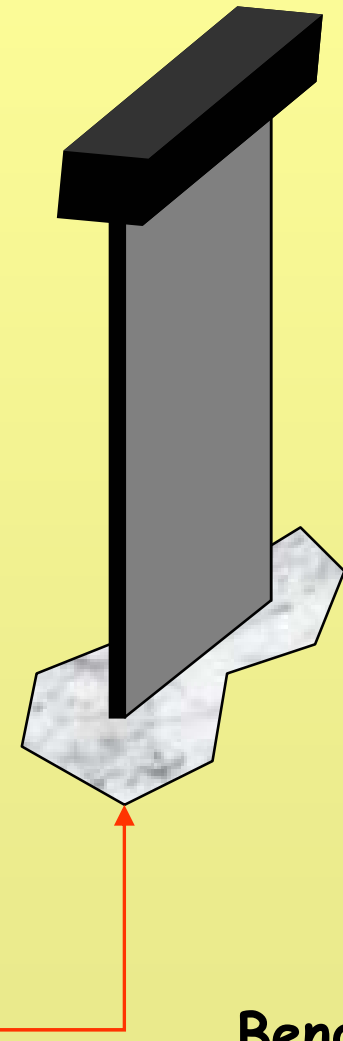

Bending stresses
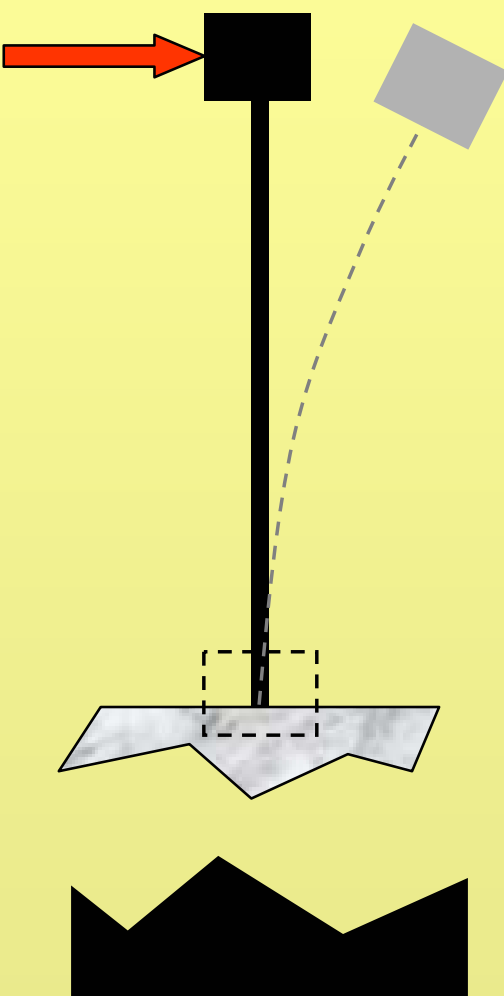
西 
The stress level in the blade can be computed with a static equation of equilibrium using peak ground acceleration

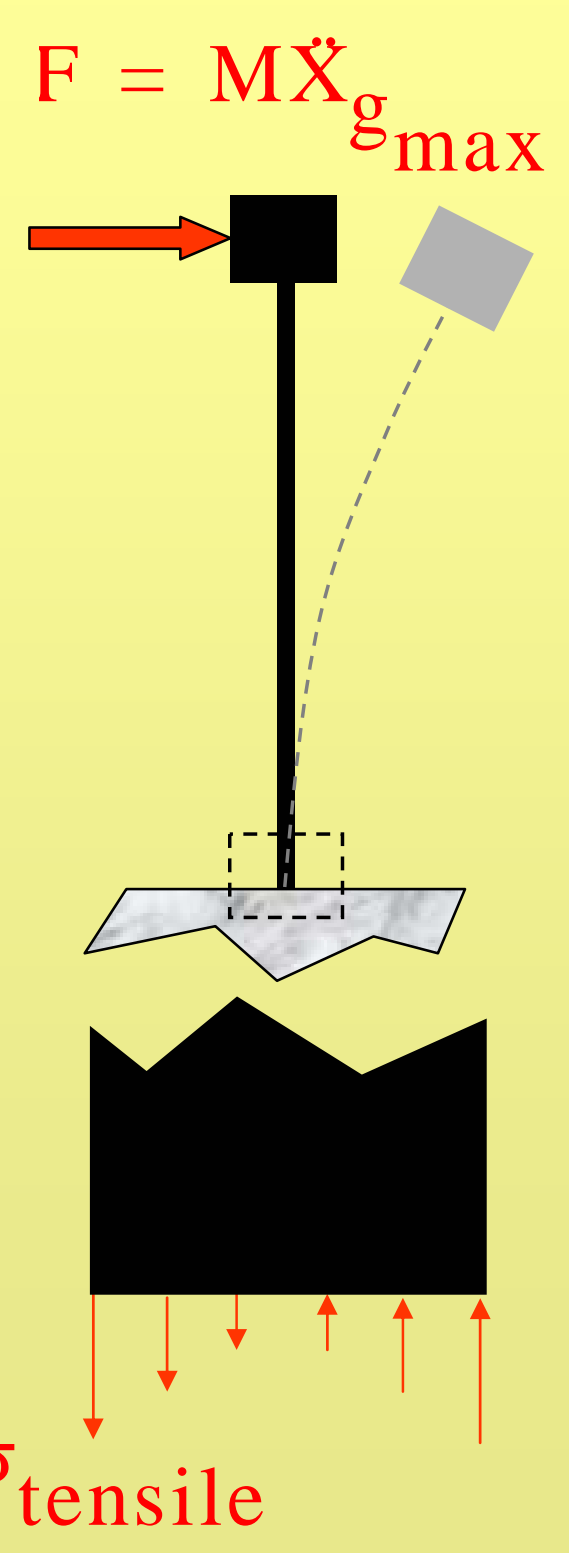

$$
\sigma_{\text {tensile }}=\frac{\mathrm{TY}}{\mathrm{I}}
$$$$
\mathrm{T}=\text { Moment applied at } \operatorname{root}(\mathrm{F} \times \mathrm{L})
$$$$
\mathbf{Y}=\text { Extreme fiber distance from }
$$$$
\text { centroidal axis (thickness/2) }
$$$$
\mathrm{I}=\text { Moment of inertia of beam }
$$
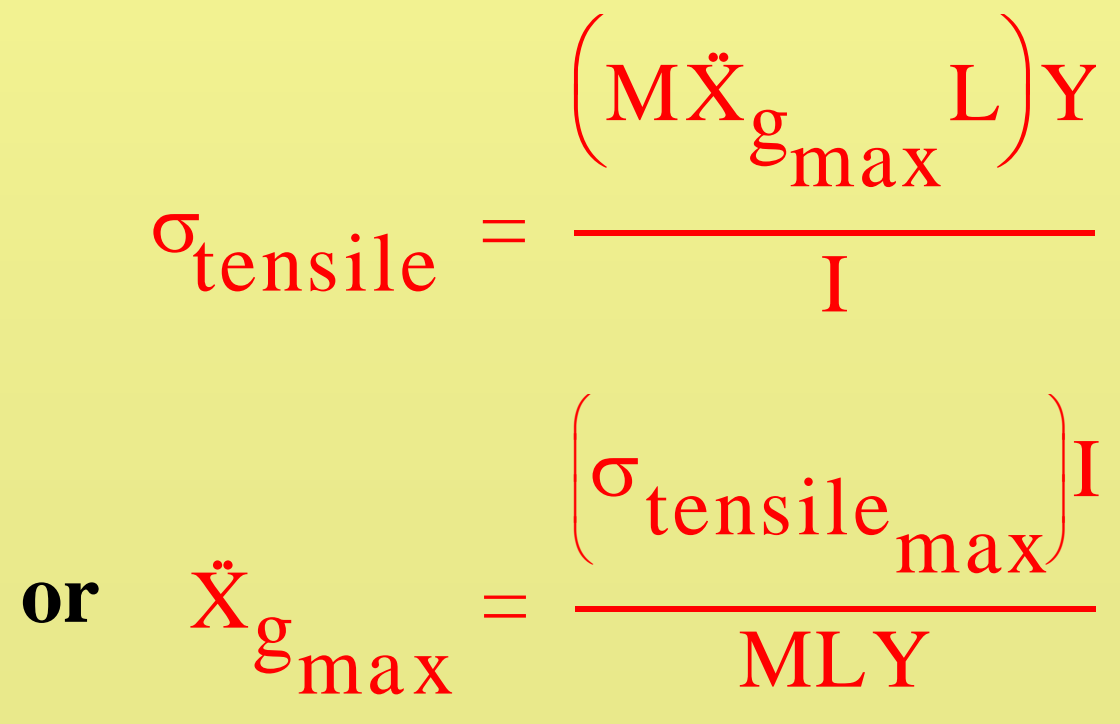
Given the tensile strength of calcite, we can estimate the peak ground acceleration causing fracture of the blade
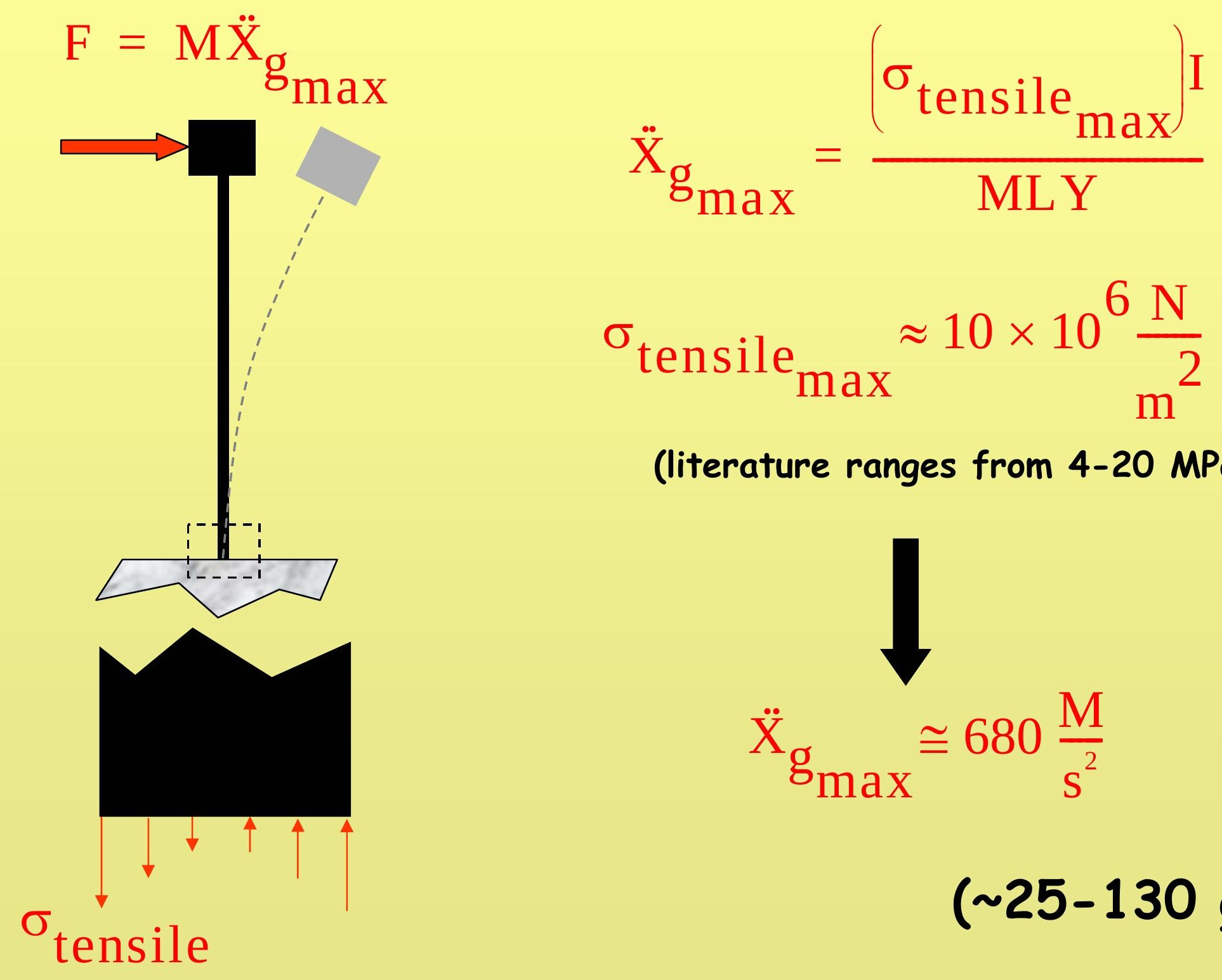

(Calcite)

(literature ranges from 4-20 $\mathrm{MPa}$ )

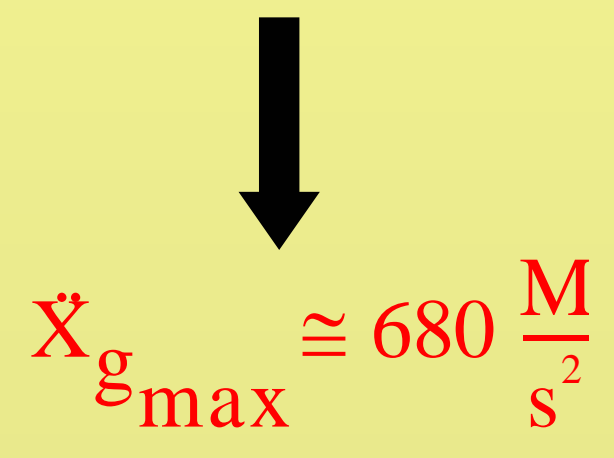

$$
\text { ( 25-130 g's!) }
$$


Question - what size of a blade would we have to find to actually constrain the motions?

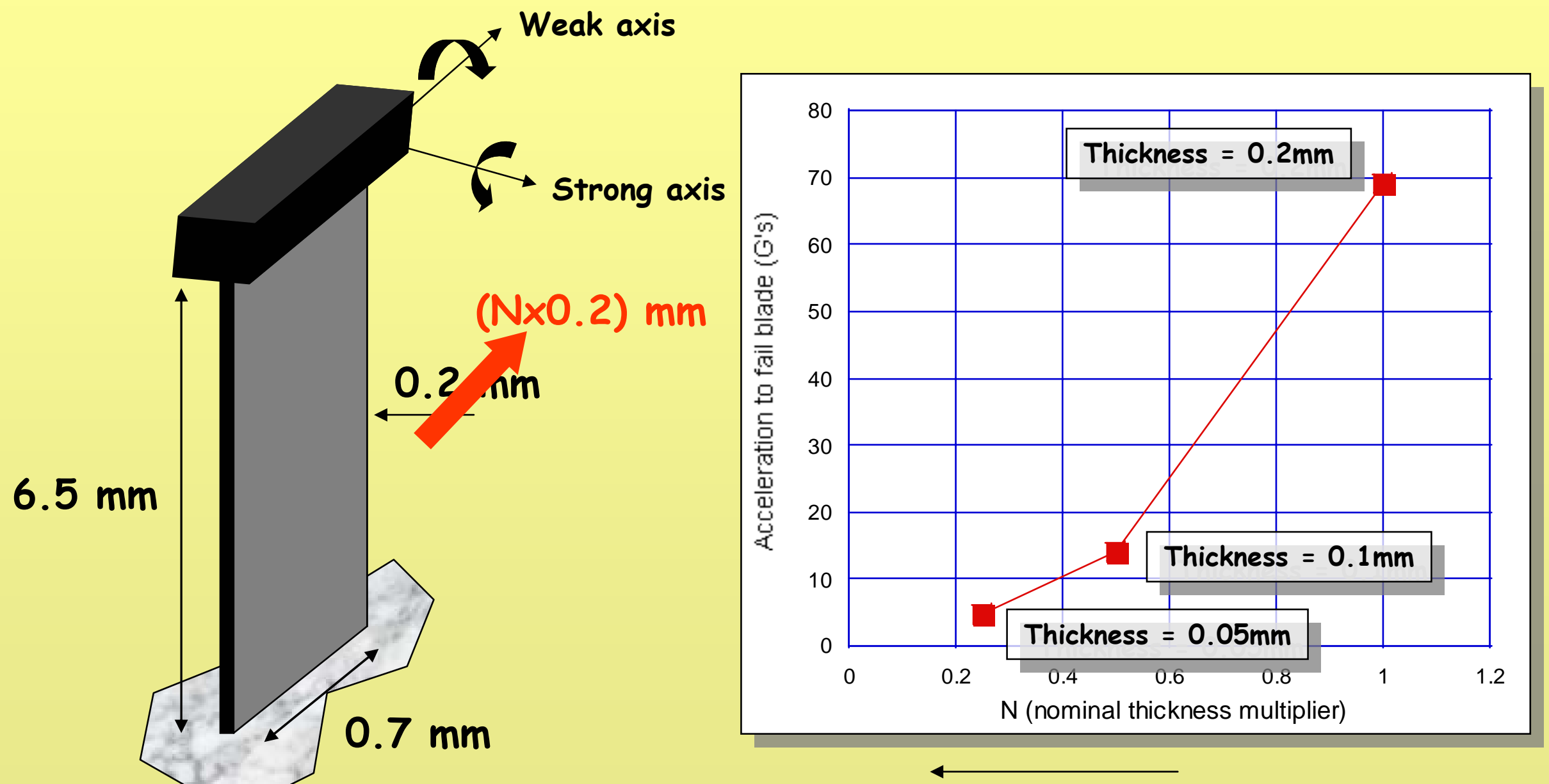

Tends towards tickness ${ }^{2}$ dependence as Thickness diminishes 
There are a very large number of lithophysal voids evident in the exploratory drifts - many potential blades
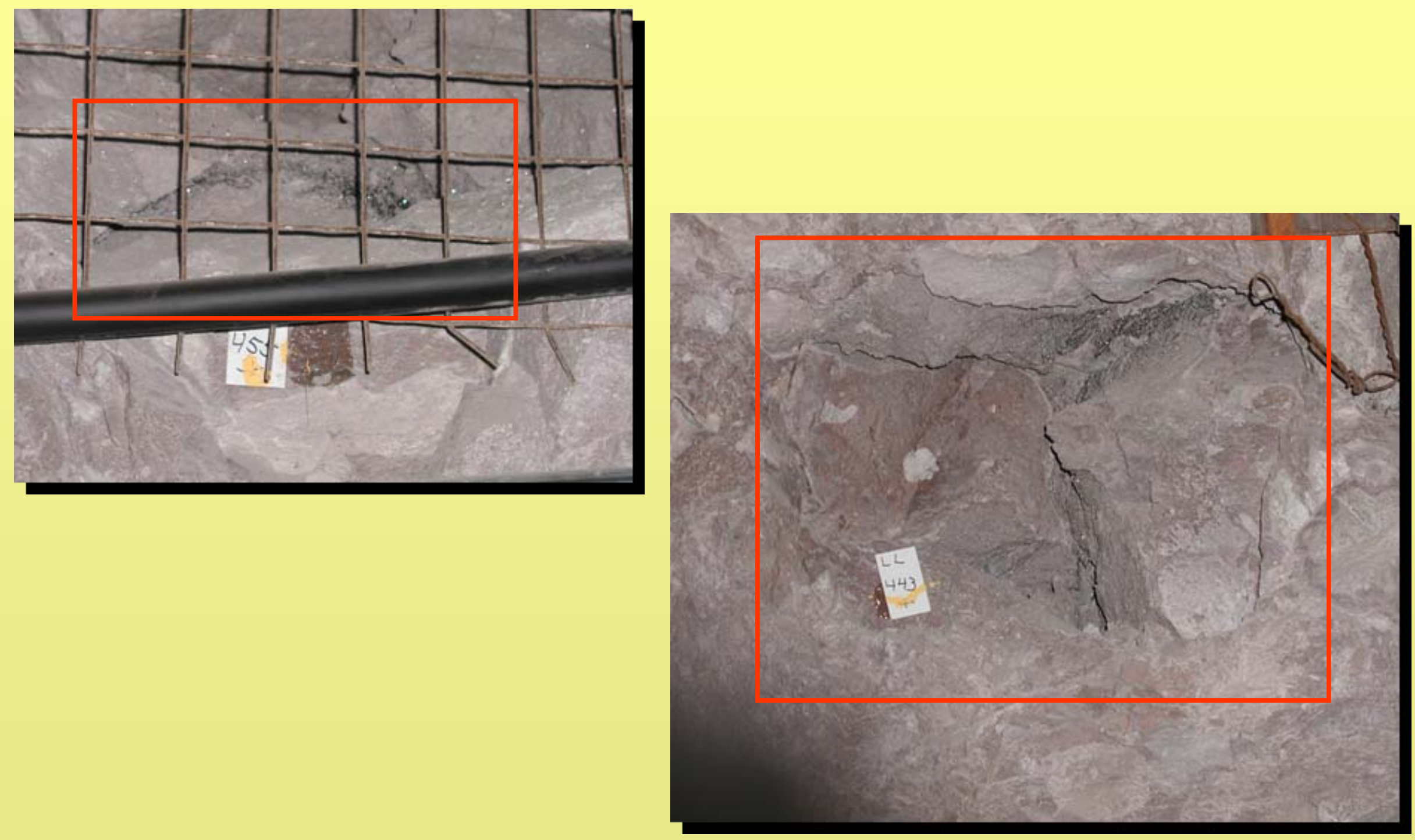


\section{What could be done?}

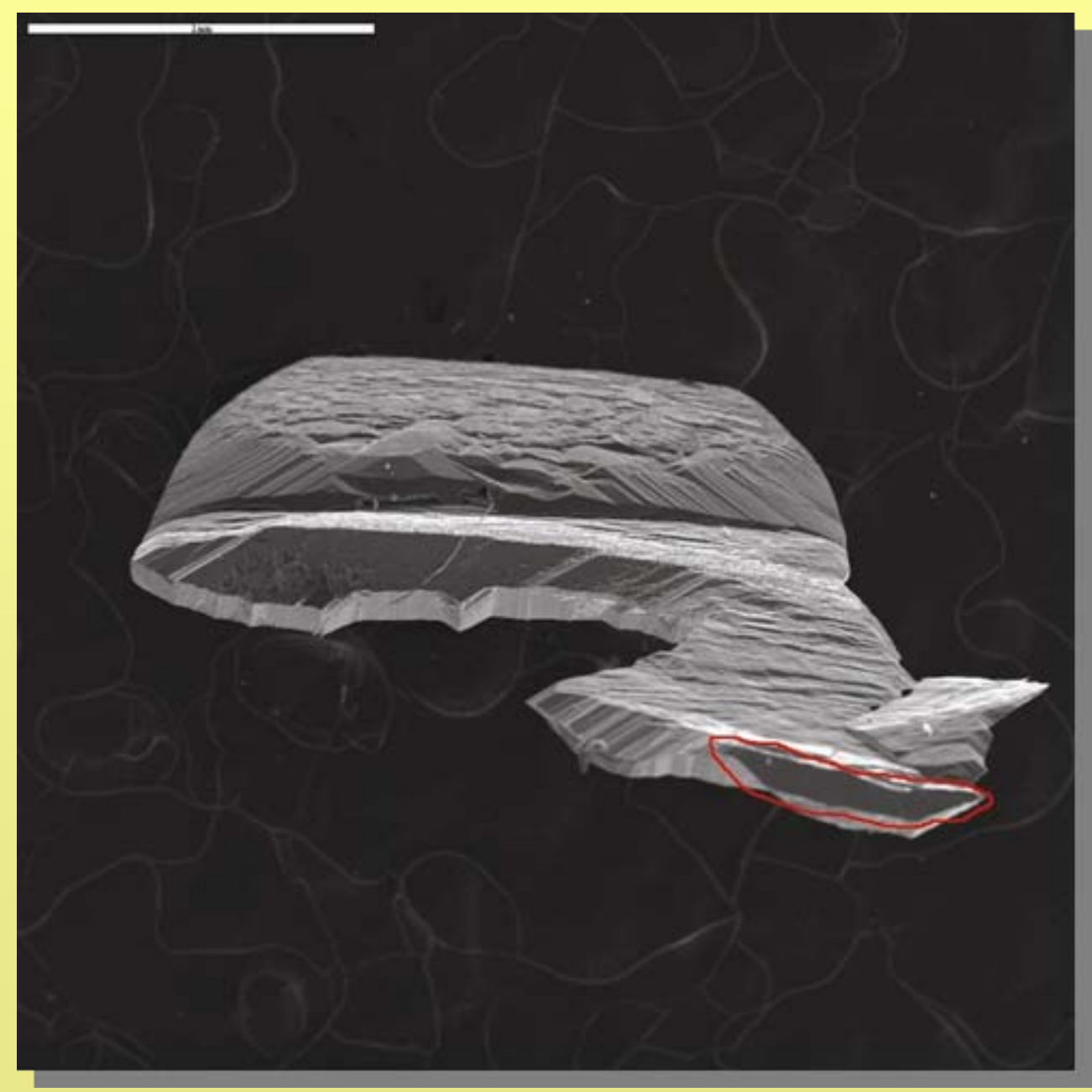

- Thorough search for more delicate blades

- Determine if blades of interest could actually survive tunnel boring and excavation

- Construct a better model (numerical finite element model) of critical blades

- Establish material tensile strengths and validate model with destructive testing of a few selected blades

- Compute fragility of constraining blades and validate with destructive test 


\title{
EXTREME GROUND MOTION RECORDED IN THE NEAR- SOURCE REGION OF UNDERGROUND NUCLEAR EXPLOSIONS
}

\author{
Bill Foxall \\ Lawrence Livermore National Laboratory
}

\begin{abstract}
Introduction
Free-field recordings of underground nuclear explosions constitute a unique data set within the near-source region of seismic events ranging in magnitude from M3 to M6.5. The term "free-field" in this context refers to recordings from instruments emplaced in boreholes or tunnel walls such that the initial portions of the records ( $\sim 0.1$ to 1 second) do not contain effects resulting from reflections at the free surface. In addition to the free-field instruments deployed to record ground motions from selected underground nuclear explosions at the Nevada Test Site (NTS) and elsewhere, surface arrays were routinely deployed to record surface accelerations and velocities from underground nuclear tests conducted at NTS.
\end{abstract}

Underground explosions are quite different from earthquakes in that they are compressional rather than shear seismic sources, have a much higher energy density, and are detonated much closer to the surface - generally on the order of $1 \mathrm{~km}$ or less - than typical earthquake focal depths. The loading and failure mechanisms in the surrounding materials are therefore fundamentally different. However, there appears to be sufficient similarity in the damage and subsequent attenuation mechanisms produced by the two types of sources that it is likely that free-field recordings can provide important information to characterize highly non-linear energy dissipation mechanisms in the immediate source vicinity that limit extreme ground motions, and the transition through weak non-linearity to elastic wave propagation. The data also hold the potential of constraining the mechanical properties of materials analogous to those at Yucca Mountain under high strain loading. Furthermore, both free-field and surface recordings are a rich source of information on near-surface spall produced by explosions, which can be used to calibrate field observations that J. Brune has proposed as a potential means of placing limits on ground motions from earthquakes.

In this paper we provide an overview of the types of data recorded during the U.S. underground nuclear testing program and their availability, and briefly discuss potential uses of the data in investigating the limits on ground motions generated by earthquakes.

\section{Instrument Arrays}

The vast majority of the U.S. underground nuclear tests carried out between the mid1950s and the end of testing in 1992 took place within three main areas at NTS, Yucca Flat, Pahute Mesa and Rainier Mesa. Detonation points of tests under Yucca Flat were in various tuff units or in the thick overlying alluvium section. Tests under Pahute Mesa and Rainier Mesa were detonated in tuffs, and were recorded on tuff and/or in thin 


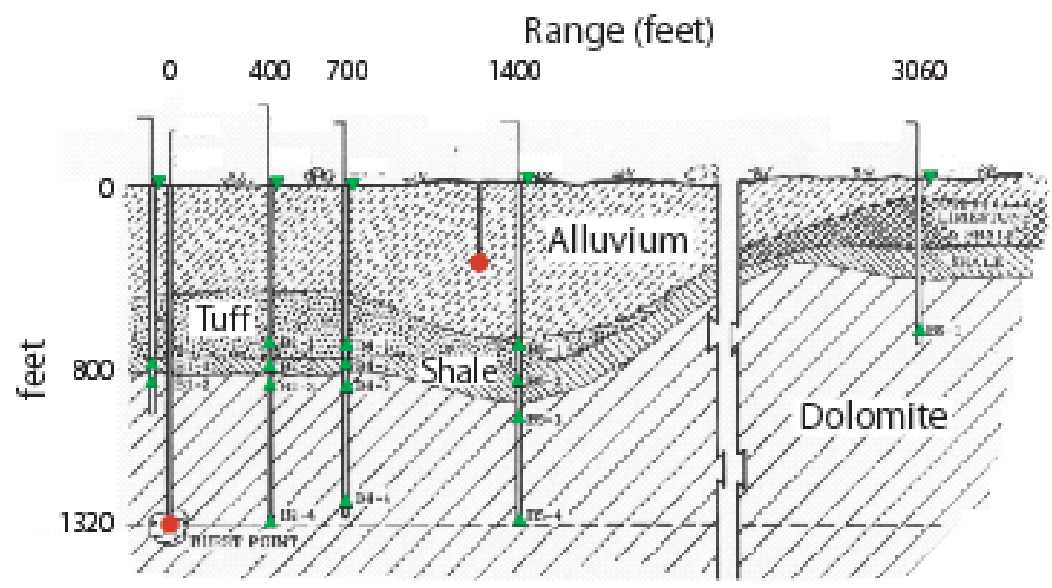

Figure 1: Surface and subsurface arrays (green) deployed for the HANDCAR_MUDPACK shots (red) superficial alluvium

layers. The mechanical

properties of shot point

tuffs vary over a wide

range, but include

densely welded materials

such as the Rainier Mesa

member analogous to

materials at repository

depth at Yucca

Mountain. Elaborate

free-field and surface

arrays of accelerometers

and velocity sensors

were deployed for

several of the earlier (pre 1974) events conducted as weapons tests or as part of the Plowshare program (peaceful uses), or for non-proliferation experiments. For example, Figure 1 shows the array deployed for the 1964 HANDCAR-MUDPACK events. A more typical layout consisted of a string of accelerometers and/or velocity sensors deployed in a single borehole offset 10-30 m from the device emplacement hole, as shown in Figure 2. Lawrence Livermore National Laboratory (LLNL), for example, deployed such arrays on average once per year from 1978 onwards with the specific objective of calibrating dynamic models of wave propagation and material response conducted for containment purposes. The surface arrays routinely deployed by LLNL, LANL and Sandia (SNL) generally recorded strong ground motions within surface ranges $\sim 1 \mathrm{~km}$ or less from surface ground zero, but extended to regional distances for certain special studies.

\section{Data Availability}

We have compiled a spread sheet of events for which we know free-field and/or surface ground motion exist. These include tests carried out by all agencies involved in the test program, including LLNL, LANL, and the Department of Defense (DOD). Most of the ground motion data are held by LLNL, LANL and SNL. Of the 381 events presently in the spread sheet, 169 have free-field data, 164 surface data, and 44 ground motion data from containment plugs in the emplacement hole. The LLNL containment program archive includes CDs of digital ground motion data for 189 NTS events between 1977 and 1992. LANL maintain a computerized data base that contains ground motion data for about 150 NTS events, including digitized analog data (App, 1994). The waveform data in both of these archives are unclassified and are available as ASCII or LLNL Seismic Analysis Code (SAC) files. (The yields of most of the tests remain classified.) In addition to the waveforms themselves, instrument calibrations are included in the archives, at least for the mid-1970s onwards. In situ geologic and material property data routinely compiled from the logs for every test emplacement hole are available either as printed reports or computer files. Material properties routinely compiled include P-wave velocity, bulk density and porosity, and water saturations for each lithologic unit. Other material property data were determined for specific units from laboratory tests. SNL are 


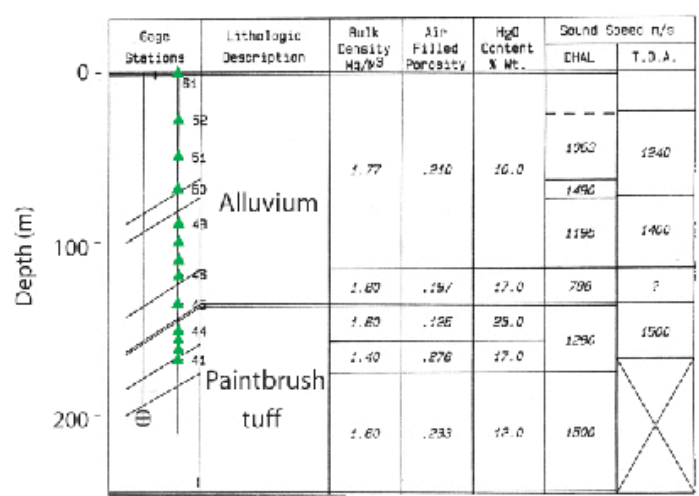

Figure 2: PERA vertical arrav (green) in the process of compiling a data base for 17 Rainier Mesa tunnel shots, which includes raw ground motion waveforms in ASCII format and associated calibration and other metadata. We have also located an archive of paper analog records at the DOE Nevada Operations Office in Las Vegas. These are presumably from early tests, but we have not yet examined the record catalogs in detail.

\section{Overview of the Explosion Source}

In order to describe the characteristics of free-field motion recorded in the near-source region, we first provide a brief overview of the explosion source. Figure 3 shows a generalized cartoon of the near-source region within an homogeneous half-space following a nuclear explosion. The rapidly expanding high temperature, high pressure bubble of gas (vaporized rock) created by the detonation creates a shock wave that first melts and then pulverizes the rock immediately surrounding the detonation point to create a cavity, radius $\mathrm{R}_{\mathrm{c}}$. At a short distance (less than the final cavity radius) from the detonation, the shock wave separates into an elastic precursor traveling at the P-wave speed of the undisturbed medium and the peak pressure pulse that propagates at a subsonic plastic wave speed. The peak stress of the shock wave as it propagates beyond the final cavity radius exceeds the yield shear stress of the rock and creates a zone of macroscopic damage out to a distance of about three cavity radii.

The principal stresses (one radial, two tangential) within this zone are all compressive, and the predominant damage modes are pore compaction and collapse, and shear failure accompanied by dilatation. Damage and plastic yielding within the compaction zone rapidly attenuate the plastic wave such that the peak pressure falls below the yield stress and the tangential principal stresses become tensile on reaching the boundary of the zone, resulting in relatively minor tensile failure out to about five cavity radii. Within this zone the peak stress (main wave)

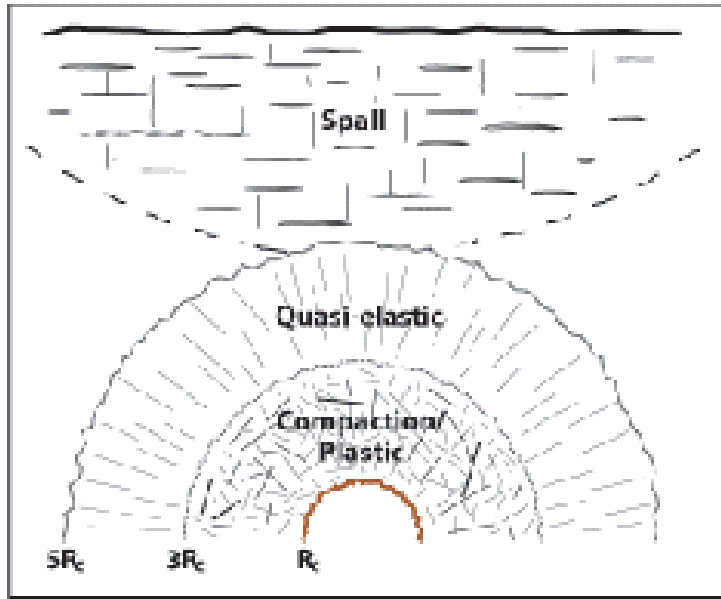

Figure 3: Explosion source propagates at the elastic $\mathrm{P}$-wave speed but it attenuates quasi-elastically. Beyond this wave propagation is essentially elastic, but with minor non-linear behavior at $\sim 10^{-6}$ strain. At about the time the shock wave has traversed the compaction zone the cavity wall 
rebounds, followed by re-expansion and re-compaction and, finally, damped oscillations. These pulses propagate outwards to become later arriving peaks of an elastically propagating wave train beyond the quasi-elastic zone. When the main compressional peak reaches the free surface it is reflected as a tensional wave front that exceeds the tensional strength of the material, resulting in tensional failure, or spall, down to some depth such that near-surface layers actually detach and go ballistic. Table 1 summarizes empirical scaling of magnitude $\left(\mathrm{m}_{\mathrm{b}}\right)$ and $\mathrm{R}_{\mathrm{c}}$ and normal depth of burial with explosive yield, $\mathrm{W}$, in kilotons.

\section{Ground Motion Characteristics}

To illustrate some of the general characteristics of near-source waveforms recorded by free-field arrays we summarize the analysis by Terhune and Heusinkveld (1983) of data recorded on the PERA array shown in Figure 2 and on similar vertical arrays for events NORBO, KARAB and TILCI. All of these tests were conducted under Yucca Flat. The first three were detonated in tuff, and TILCI, in alluvium. Figure 4a shows travel time curves for the main (peak velocity) wave for PERA (P), NORBO (N) and TILCI (T), and for the elastic precursor for KARAB (X); the detonation depths are indicated on the figure. Close to the source, the main waves propagate at subsonic (plastic) speeds before abruptly accelerating to elastic P-wave speeds similar to the speed of the elastic precursor from $X$. This transition defines the sharp boundary between the compaction and quasistatic zones (Figure 3), which Terhune and Heusinkveld show is also well defined by the limits of residual volumetric strain derived from the velocity data. Figure $4 \mathrm{~b}$ shows peak velocity as a function of slant range (normalized to PERA) for events $\mathrm{P}, \mathrm{N}$ and $\mathrm{T}$. Out to a normalized range of about $80 \mathrm{~m}$, again corresponding to the perimeter of the compaction zone, the peak velocity attenuates rapidly at $\sim \mathrm{R}^{-3}$, indicative of strong energy dissipation by pore compaction and plastic yielding. At the perimeter of the zone, the attenuation rate abruptly changes to $\sim \mathrm{R}^{-1}$, indicating quasi-elastic behavior. Note that the
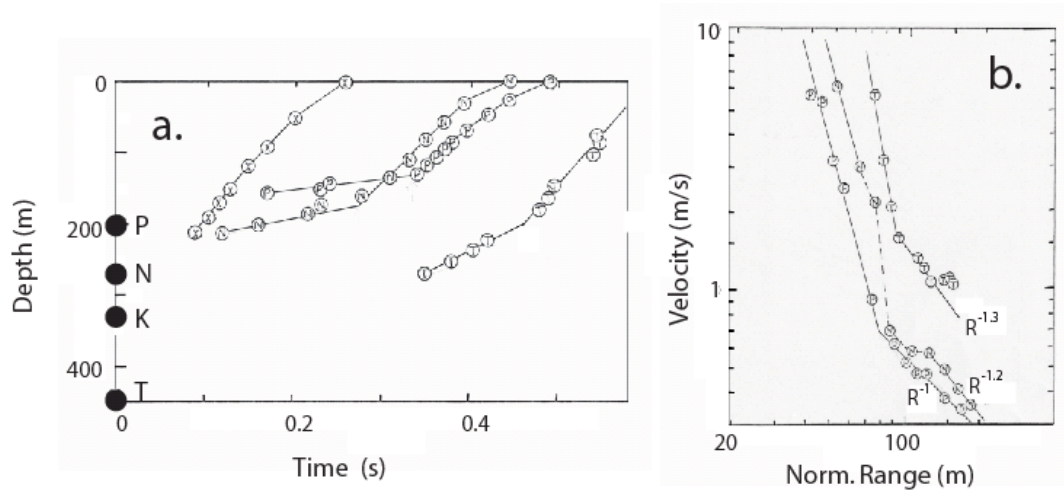

Figure 4: Travel time (a) and attenuation (b) curves transitions in both velocity and attenuation rate are clearly defined by the data.

Figure 5 shows the velocity waveforms recorded on the four sensors closest to shot NORBO [yield $<20 \mathrm{kt}$ (DOE, 2000)], within the compaction zone (Figure 3). The waveforms are time-shifted to the first (elastic precursor) arrival time at one sensor, and amplitudes $V_{i}$ are normalized such that $V_{i}^{\prime}=V_{i}\left(R_{i} / R_{0}\right)^{\alpha}$, where $R_{i}$ and $R_{0}$ are the slant ranges to sensor $i$ and the reference sensor, respectively, and $\alpha$ is the average of the attenuation rates of the elastic precursor and the main wave across the four sensors. The first, compaction, pulse comprises the elastic precursor (PC) and the peak (main) velocity wave (PW), followed by the rebound (negative) and recompaction 
(positive) pulses and the damped oscillations. The entire wave train propagates in-phase across the zone, each of the pulses having a constant duration. The compaction pulse attenuates very rapidly across the zone, but the later pulses attenuate at the same rate as the elastic precursor, suggesting quasi-elastic behavior within the compaction zone after the main compaction

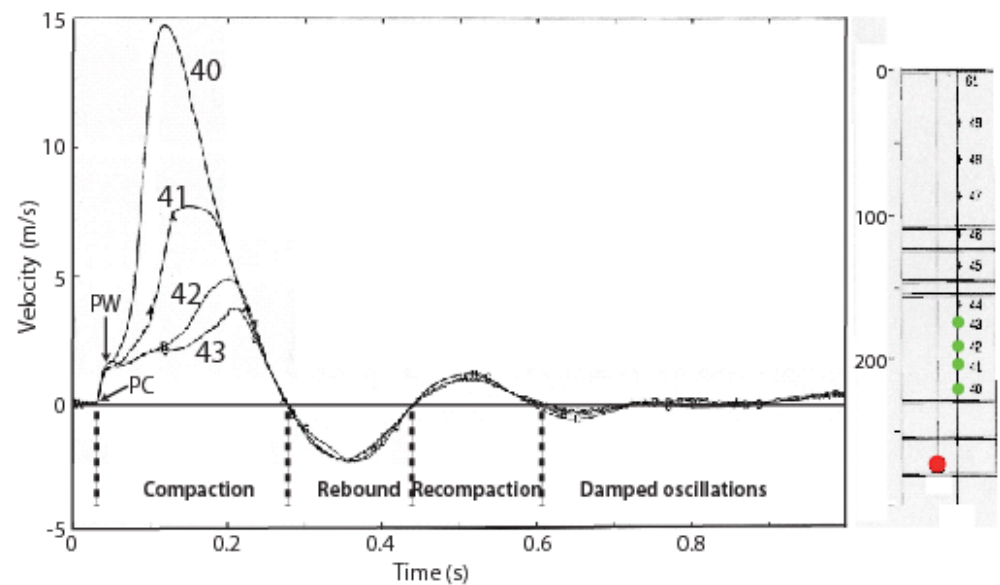

Figure 5: Velocity time histories for four sensors (green) within the compaction zone of event NORBO (red). pulse has passed. Figure 6 shows the PERA [yield $<20 \mathrm{kt}$ (DOE, 2000)] waveforms recorded just outside the compaction zone, where the pulses that developed in the compaction zone are still clearly defined and propagate in-phase at the P-wave speed. The entire wave train attenuates at the same rate as the precursor, so that the overall

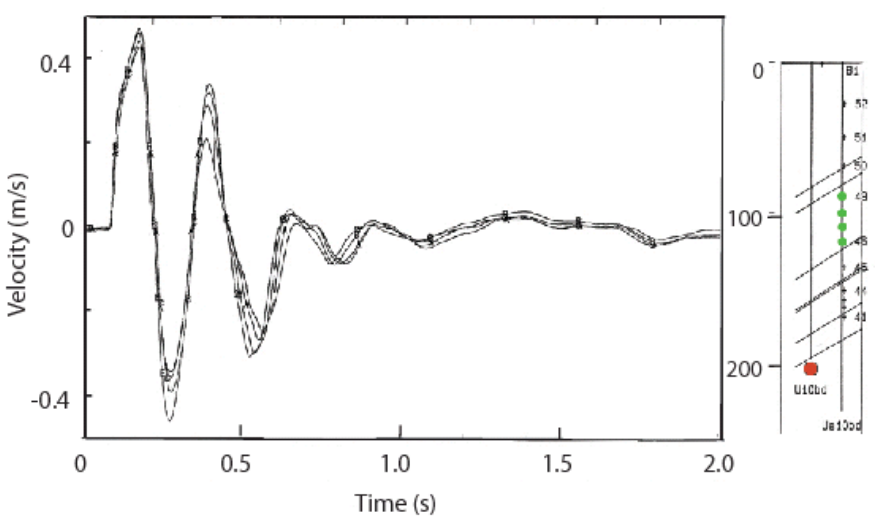

Figure 6: Velocity time histories for four sensors (green) within the quasi-elastic zone of event PERA (red). behavior is quasi-elastic. Figures 5 and 6 illustrate the general quality of the data recorded on the free-field arrays. We chose these examples because they clearly show the near-source phenomenology. More generally, however, the waveforms are complicated by refractions, reflections and wave conversions from lithological boundaries, which often have strong impedance contrasts in the highly stratified lithologies at NTS.

Figure 6 shows a typical surface accelerogram recorded at a slant

range of $1.1 \mathrm{~km}$. The main wave peak acceleration at about $0.5 \mathrm{sec}$ is almost $5 \mathrm{~g}$. This is followed by spall onset at about $0.6 \mathrm{sec}$, and ballistic free-fall $(-1 \mathrm{~g})$ followed by the large slap-down peak at $0.9 \mathrm{sec}$.

\section{Discussion and Conclusions}

The vast amount of ground motion data recorded during the U.S. underground nuclear testing program provides unique insights into material response and wave propagation and attenuation within the near-source regions of seismic events as large as $\sim$ M6. These regions extend from the zone of intense macroscopic damage and highly non-linear behavior under high strain and strain rate loading close to the detonation point through 
the transition to elastic wave propagation to the response of the free-surface, where material response can again becomes non-linear owing to spalling under tensional failure. Much of this data set, together with instrument calibrations and material properties, is available to researchers through the archiving efforts at LLNL, LANL and SNL.

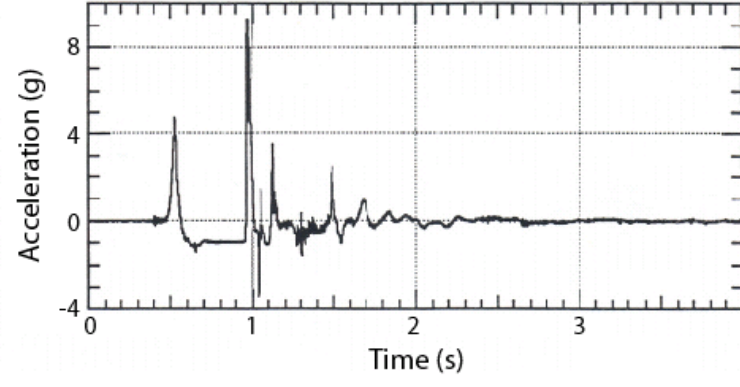

Figure 7: Ground surface vertical acceleration time history at a slant range of $1.1 \mathrm{~km}$ from event $M O L B O$.

The data show that ground motions generated by nuclear explosions are severely attenuated by highly non-linear damage mechanisms and yielding within a few hundred meters of the detonation point, but that the transition to quasielastic and elastic material response is sharp and well defined. Although explosions and earthquakes are quite different seismic sources, this behavior is likely analogous to damage and nonlinear attenuation mechanisms within a fault zone resulting from dynamic shear rupture that inherently limit the energy that can be propagated elastically. Although shear failure is one of the primary damage mechanisms close to an explosion source, pore compaction under a purely compressive stress regime also predominates in many of the materials at NTS. Therefore, the extent to which explosion data can be applied to the earthquake source should be one of the first topics of research in this field. Irrespective of the loading and damage mechanisms themselves, the ground motion and other data available for NTS have the potential to provide significant insights into the properties of materials analogous to the tuffs at the repository level at Yucca Mountain at high strains and strain rates. One way to achieve this is to use the recorded data to constrain the parameters in dynamic models of wave propagation and damage from selected explosions. This was done extensively as part of the containment programs at the national laboratories, and the data continue to be used to constrain more sophisticated models of explosion effects (e.g. Antoun et al., 1999).

\section{Acknowledgments}

I would like to thank Jeff Wagoner and John Rambo for detective work and assembling the spread sheets, and the LLNL D\&NT Containment program for support. This work was performed under the auspices of the U.S. Department of Energy by University of California, Lawrence Livermore National Laboratory under Contract W-7405-Eng-48.

\section{References}

Antoun, T.H., O.Y. Vorobiev, I.N. Lomov, and L.A. Glenn, Simulations of an underground explosion in granite, American Physical Society Proc. $11^{\text {th }}$ Topical Conference on Shock Compression of Condensed Matter, Snowbird, Utah, Jun 27-Jul 2, 1999.

App, F.N., The NTS ground motion data base, LAUR-94-1557, Los Alamos National Laboratory, 5 p., 1994.

Terhune, R.W., and M. Heusinkveld, Analysis of near field ground motion from nuclear detonations in high porosity media, Proc. Second Symposium on Containment of Underground Nuclear Explosions, Albuquerque, NM, Aug 2-3, 1983, v. 2, 123-164, 1983. 
U.S. Department of Energy, United States nuclear tests, July 1945 through September 1 1992, DOE/NV-209-REV 15, 162 p., 2000. 


\title{
CONSTRAINTS ON EXTREME GROUND MOTIONS AT LOW PROBABILITIES
}

Brune, James N., Seismological Laboratory, University of Nevada, Reno, NV 89557, USA, brune@seismo.unr.edu

\begin{abstract}
Probabilistic seismic hazard analysis (PSHA) makes statistical assumptions which are very questionable when extended to very low probability maximum ground motions (the order of $10 \mathrm{~g}$ acceleration and $10 \mathrm{~m} / \mathrm{s}$ velocity, with 10-6 to 10-8 annual probabilities. The short historical database for instrumental recordings is not sufficient to resolve the uncertainties in the statistical assumptions. This suggests that we look for geomorphic and geologic evidence constraining ground motions over long periods in the past. Since the extrapolated ground motions are so large we might expect to find evidence for them if they have occurred in recent geologic time. Such evidence might include lack of precariously balance rocks (10 ka to $100 \mathrm{ka}$ ), rock avalanches from formerly unstable cliff's (a few hundred ka), strain-shattered rock (up to tens of millions of years), and motion along ancient cracks (up to ten million years). A critical question for lowprobability PSHA is: can the lack of any or all of these indicators be used as reliable evidence that such high ground motions have not occurred over periods from tens of thousands to tens of millions of years? Related critical questions are: can statistical evidence from the San Andreas Fault, where some rocks have been subjected to tens of thousands of $\mathrm{M} \sim 8$ earthquakes, be applied to other tectonic regimes such as Yucca Mountain, or to thrust regimes? Can indirect evidence from shattering of rocks on the hanging walls of thrusts in Southern California, and lack of such shattering in other areas, be used to constrain ground motions?
\end{abstract}

\section{PRECARIOUS ROCK CONSTRAINTS ON EXTREME GROUND MOTIONS}

As a result of the discovery of numerous precariously balanced rocks in the vicinity of Yucca Mountain, a methodology was developed to use these rocks as constraints on the probable ground motion to be expected at the potential repository. The precarious rock methodology gives a direct indication of the upper bound on the amplitude of past ground shaking at a site (in contrast to the indirect inference provided by trenching studies, which cannot directly constrain characteristics of ground motions associated with observed fault slip evidence).

In many types of terrain in California and Nevada, groups of precariously balanced rocks have evolved naturally by erosion. The common presence of rock varnish on such rocks indicates that they have been in their current unstable positions for thousands of years. Therefore, groups of precariously balanced rocks can be used as low-resolution strong-motion seismoscopes that have been operating on solid rock outcrops for thousands of years. As such, they provide important information about seismic hazard at low annual probabilities. We have established the mechanical basis for estimates of the horizontal accelerations necessary to topple precarious rocks, using field observations and numerical and physical modeling (Anooshepoor et al., 2004). The distribution of precarious rocks relative to known active faults and intensity zones produced by historical earthquakes confirms their usefulness in outlining areas that have or have not undergone recent strong ground shaking (Brune, 1996; 1999; 2002 a,b; 2004; 2005).

We evaluated estimates of peak acceleration made from observations of precarious or toppled rocks at the Nevada Test Site (NTS). We improved our estimates by field-testing of rocks and 
by using observed waveforms of nuclear explosions in our shake table tests. Theoretically predicted values of ground motion were calculated from existing attenuation relations for nuclear explosions. In general the results confirm our estimates of ground motion based on precarious rocks (Brune et al. 2003).

The relatively large horizontal ground accelerations predicted by the recently completed Yucca Mountain Probabilistic Seismic Hazard Analyses (PSHA, Stepp et al., 2001)) are not consistent with the preliminary results from the precarious rock survey conducted by Brune and Whitney (2000), nor the results described in the DOE Task 6 final report (Anooshehpoor et al., 2002). Therefore, further development of the precarious rock methodology may provide important constraints on the statistical assumptions which lead to extremely high ground motion predictions at very low probabilities.

\section{Cosmogenic Age Dating of Precarious Rock Pedestals}

We have carried out preliminary determinations of cosmogenic age dates of precarious rock pedestals in Solitario Canyon (Brune, Whitney and Zreda, unpublished results, presented at DOE sponsored conferences). The cosmogenic age dates for precarious rock pedestals all exceed previous estimates (Bell et al.. 1998) based on rock varnish. This is not unexpected, since the rock varnish dates are minimum dates (because the rock varnish formation process can be "reset' by periods of intense weathering, as might be expected during ice ages). Cosmogenic pedestal age dates range from about $36 \mathrm{ka}$ to $250 \mathrm{ka}$, with most values about 50-100 ka. These are considerably higher than the minimum dates from rock varnish (generally $10.5 \mathrm{ka}$ ). Although we have not fully analyzed the implications for seismic hazard, these dates are consistent with the idea that no large ground motions (greater than about $0.3 \mathrm{~g}$ ) have occurred since before the most recent large event proposed from trenching studies (about $70 \mathrm{ka}$ ago on the Solitario Canyon fault and about $90 \mathrm{ka}$ on the Paintbrush Canyon fault).

We need to further quantify precarious rock constraints on ground motion, especially for ground motion parameters other than PGA, for example, PGV (peak ground velocity), and response spectrum at various periods.

\section{Lack of Data from the Hanging Wall of Normal Faults}

The seismic hazard at the repository site, at very low probabilities, is determined primarily by the Solitario Canyon fault, which is immediately adjacent to the site. However, some of the hazard also comes from the Paintbrush Canyon fault (Most Recent Earthquake, MRE, $90 \mathrm{ka}$ ). The repository is on the footwall of the Solitario Canyon fault but on the hanging wall of the Paintbrush Canyon fault. There is abundant precarious rock evidence that the ground motion on the foot wall of normal faults is considerably lower than predicted by standard attenuation curves (Brune, 2000, 2003; Shi et al., ), consistent with the precarious rock evidence from Yucca Mountain. Numerical and physical modeling confirms that low ground motion is expected on the foot wall of normal faults (Brune and Anooshepoor, 1999; Shi et al., 2003)

However, there is very little precarious rock evidence constraining the ground motion on the hanging wall of normal faults. This is primarily because for most normal faults the hanging wall is covered by sedimentary fill (alluvium) to a distance of several $\mathrm{km}$ or more from the fault trace, so there is no exposed bedrock to form precarious rocks. Yucca Mountain is an exception 
because the fault slip rate on the Paintbrush Canyon fault is so slow that a deep sedimentary basin has not formed on the hanging wall. There are a few cases where river erosion has been fast enough to expose rocks on the hanging wall of active faults with Recent (Holocene) earthquakes (e.g., normal faults near the Carson and Walker Rivers). However these areas have not been studied in detail. Preliminary reconnaissance surveys have indicated that there are some exposures of rocks (of the types which form precarious rocks) at these sites. It is important to obtain any available precarious rock evidence constraining the ground motion at these sites. This might help confirm the direct evidence at Yucca Mountain that the last event on the Paintbrush Canyon fault (MRE $90 \mathrm{ka}$ ) has not caused intense ground shaking at the repository site.

\section{UNSTABLE CLIFFS IN THE VICINITY OF YUCCA MOUNTAIN}

In addition to numerous precarious and semi-precarious rocks in the vicinity of Yucca Mountain, there are numerous unstable cliff faces with numerous loose rocks stacked on top of each other. Such cliffs are common throughout the area, a result of differential erosion of welded and unwelded tuffs (Brune and Whitney, 2000). These cliffs appear to be obviously unstable with regard to horizontal ground shaking. That this is so in fact is demonstrated further north in NTS where the cliff faces have been shaken down by ground motion from nuclear explosions (Brune et al, 2003). Very near large NTS explosions, there are no precarious rocks. Cliff faces are shattered and numerous recent rockfalls and rock avalanches are evidenced by fresh white surfaces covered by caliche (calcium carbonate), clear indication that the rockfalls have been caused by the explosions. The caliche will dissolve off the rocks in a few hundred years. As the distance from the explosions increases, rock avalanches disappear and less and less rockfalls are observed. Keefer (1984) associates rock avalanches with intensities of roughly VIII (accelerations of roughly 0.30 to 0.5 , or greater), rockfalls with intensities of roughly VI to VII (accelerations of roughly $0.05 \mathrm{~g}$ to 0.2 . Thus lack of evidence of rock avalanches is a constraint on extreme ground motions over the time period necessary to remove the evidence of such avalanches (typically a pile of rubble at the base of the cliffs and shallower cliff slopes).

The 1992 Richter local magnitude $\left(\mathrm{M}_{\mathrm{L}}\right)$ 5.6 Little Skull Mountain (LSM) earthquake, located about $20 \mathrm{~km}$ southeast of Yucca Mountain confirms the rough relationship of horizontal ground acceleration with rockfalls and rock avalanches. The earthquake caused a number of rockfalls on steep cliff faces in the near-source region, but no rock avalanches, while some precarious rocks remained in place (Brune and Smith, 1996, Brune et al., in press, 2005)). The,. rockfalls were easily recognized by the presence of white carbonate and silicate left exposed on the faces of blocks broken away from the cliff face just as in the case of the NTS rockfalls, --otherwise, the rocks are universally covered with a very dark rock varnish. This contrast allows easy recognition of rockfalls along the crest of LSM. The fact that ground motion was sufficient to cause some rockfalls and yet leave semi-precarious rocks in place yields both upper- and lowerbound estimates on the ground motion at LSM, both during and prior to the earthquake, and these estimates are consistent with the ground motion estimates from NTS explosions. Thus a useful constraint on strong ground motion at Yucca Mountain may be obtained by estimating the time it would take for shaken down cliffs, with consequent piles of rubble at their base, to be re-eroded to their current unstable conditions (no rubble at the base of the cliffs, many 
unstable stacks of rocks). Preliminary estimates based on cosmogenic age dating described above, suggest times of the order of $100 \mathrm{ka}$

\section{CONSTRAINTS FROM UNFRACTURED SANDSTONES ALONG THE SAN ANDREAS FAULT}

Constraints on rare ground motions may be provided by sandstones located along the San Andreas fault at several locations between Tejon Pass and Cajon Pass (Brune et al., 2004) These sandstones are as old as or older than the San Andreas fault and thus have been exposed to San Andreas earthquakes for about 5 million years. At the current inferred rate of occurrence of large earthquakes this might translate into about 20,000 M+ 8 events,-- enough to provide statistical constraints at very low probabilities. Assuming that the ground motions for $\mathrm{M} \sim 7$ events at Yucca Mountain are less than or comparable to ground motions for $\mathrm{M} \sim 8$ events on the San Andreas fault (a very secure assumption), this corresponds to a constraint for an annual probability of 10-8 at Yucca Mountain.

Preliminary measurements of tensile strength of the San Andreas sandstones indicate values of less than 10 bars. If these values correspond to the true tensile strength of rocks in bulk at depth, over the history of the rocks, they provide constraints on very rare ground motions. At some sites about $1 \mathrm{~km}$ of the sandstone sections has been exposed by tilting and folding. At most sites at least $30 \mathrm{~m}$ of exposure has been created by erosion in canyons. Detailed studies of the sandstones have indicated that at some time in the past they may have been buried at least $1 \mathrm{~km}$.

Very large vertical accelerations, over $3 \mathrm{~g}$, would be expected to spall the rocks at a depth of about $20 \mathrm{~m}$. No evidence of such spalling is observed. Internally, if the particle velocities exceed about $1 \mathrm{~m} / \mathrm{s}$ at about $1 / 4$ wavelength depth, the internal strains would fracture the rocks in tension. Again, there is no evidence of such fracturing. The inferred upper limits on ground motion are consistent with the current ( $\sim 50$ year sample) instrumental strong motion data set, but in addition suggest that very much larger ground motions have not occurred over the 5 ma history of the San Andreas fault.

Confirmation of these constraints on ground motion will require: (1) further testing of the tensile strength of these rocks from samples further from the weathered surface, (2) accurate measurement of shear velocities, (3) accurate calculation of stresses from various ground motion waveforms, (4) further demonstration that no fractures exist, and (5) accurate detailed local geologic mapping to verify the depths of the sandstones as a function of time. 


\title{
Caves, Speleothems and Excavations in Seismically Active Areas
}

\author{
John S. Stuckless, USGS
}

Natural analogues provide one possible way of assessing ground motion because they can add a dimension of time that is not available with instrumental or even historical records. Archaeological examples such as tombs and tunnels and natural features, such as caves and balanced rocks can provide insight into long-term seismic records. For example, pillars at the Byzantine church of Sussita in the Golan Heights of Syria were knocked down by an earthquake January 18, 749 A.D. They apparently all tipped in the same direction in response to the first motion, and their orientation on the ground still retains that record of that direction.

Brune and Whitney (2000) have shown that precariously balanced rocks, such as those at Yucca Mountain, Nevada, can act as natural strong-motion detectors. Strongly varnished rocks piled atop one another or perched at the edge of ledges attest to long periods of seismic stability. Additionally, sparse occurrences of large boulders at the base of Yucca Mountain suggest a lack of events that might have dislodged precariously balanced rocks for extended periods of time. Yucca Mountain provides a second type of natural analogue for seismicity. On the west side of Busted Butte erosion has exposed the Paintbrush fault where it cuts a series of nearly continuously deposited sediments. This exposure records the timing and amount of vertical displacement for each rupture during the last 760,000.

Anecdotal information suggests that effects of earthquakes are much greater for surface structures than for subsurface ones. In general, amplitudes of surface motions are about double those at depth, and effects die out with increasing depth, and thus openings at the surface are more affected than areas at depth. Mines and tunnels intersected by faults are usually damaged. Close proximity to an epicenter yields more damage, and larger earthquakes cause more damage. Damage is least in competent rock. Anecdotal information is likely bias in that null effects may be under-reported.

Raney (1988) summarized the effects on western US mines from 28 historic earthquakes of intensity 8 or greater. Most mines (24) reported no damage at depth; a few reported minor (3) to major (3) damage. Damage to surface structures was ubiquitous. Dowing and Rozen (1978) and Powers et al. (1998) compiled damage reports for tunnels as a function of peak ground acceleration at the surface. Both compilations showed no underground damage at less than $0.2 \mathrm{~g}$ and little to moderate damage between 0.2 and $0.5 \mathrm{~g}$. Commonly, when damage was reported, it was near the portal or in areas of shallow cover. Powers et al. (1998) also noted that damage was most likely in unlined tunnels and that reinforced concrete never suffered heavy damage.

Natural analogues can be used to extend the seismic record even further back in time. Five examples of tunnels in seismically active areas and apparently undamaged by multiple earthquakes include:

1) Naples tunnel (Italy) $400 \mathrm{~m}$ in length, excavated in the $4^{\text {th }}$ century B.C.

2) Nemi tunnel (near Rome, Italy) $1653 \mathrm{~m}$ in length, excavated in the mid $4^{\text {th }}$ century B.C. 
3) Albano tunnel (near Rome, Italy) $1450 \mathrm{~m}$ in length, excavated in the $5^{\text {th }}$ century B.C.

4) Eupalinus tunnel (Samos, Greece) $1045 \mathrm{~m}$ in length, excavated in the mid $6^{\text {th }}$ century B.C.

5) Hezakiah tunnel (Jerusalem) $553 \mathrm{~m}$ in length, excavated in the $8^{\text {th }}$ century B.C.

Other examples of man-made underground structures surviving for extended periods of time include the dozens of Egyptian tombs across the Nile River from Luxor which are excavated in limestone, dozens of pre-Roman mines, and hundreds of Roman mines. Buddhist temples in north western India, excavated in basalt, have withstood seismic activity for 1400 to 2200 years. As a finally, there is a large $(70 \times 40 \mathrm{~m})$ cistern under Istanbul that was built in 602 A.D. The roof is a series of masonry arches supported by 336 columns all, of which have withstood several large earthquakes including the 1999 Izmet earthquake $(M=7.4)$.

The inclusion of caves in natural analogue studies extends the time record by orders of magnitude and greatly increases the geographic area covered. Caves do record seismic activity, as shown by Mitchell Caverns in southern California which had to be closed for a few weeks after the Hector Mine Earthquake $(\mathrm{M}=7.1)$ in 1999 for which surface rupture was located about 60 miles to the west. Damage, however, was restricted to one entrance; delicate structures deeper in the cave were undamaged. Southerland Peak Cave in southern Arizona was within intensity zone IX of the Southerland Peak earthquake in 1887. One stalagmite fell (probably due to failure of its clay base), and several soda straws broke and stuck in the clay floor. A larger, but otherwise similar stalagmite in nearby Kartchner Cavern apparently was unaffected. The base of the Kartchner stalagmite is known to be $60 \mathrm{~m}$ below land surface. Depth below land surface is likely an important variable for speleothem damage, but that datum is rarely reported.

Several caves in Europe have been studied extensively as recorders of paleoseismology. For example, broken soda straws on the floor at the $60-\mathrm{m}$ level of Observatoire Cave in Monaco can be correlated with an 1887 earthquake of intensity VIII. Gilli et al. (1999) concluded that such breakage required an acceleration of 7 $\mathrm{m} / \mathrm{sec}^{2}$ or greater. Drilling of the flow stone on the cave floor revealed other episodes of soda-straw breakage including one more than 35,000 years old. Male and Cervo caves in central Italy record at least five major seismic events that caused collapse or speleothem damage in the first $400 \mathrm{~m}$ of the caves:
1) $130 \pm 20 \mathrm{ka}$
2) $100 \pm 10 \mathrm{ka}$
3) $35 \pm 5 \mathrm{ka}$
4) Pre $350 \mathrm{ka}$
5) 1456 A.D. earthquake

In northern Italy, seismicity has been accompanied by movement of the cave floor. In some cases this is indicated by breakage and regrowth of stalagmites. In Frassini Cave, one opening is offset nearly a meter along a joint plane. In Spipola and Buco dei Buoi Caves, stalagmites record multiple episodes of changes in growth axis, and these can be correlated with known seismic events from 1929 back to 770 A.D. 
Caves cited to this point have all been developed in limestone. All appear to have remained open through even strong seismic events. The same must be true for caves of southwestern Europe that contain Paleolithic cave paintings that date from 15,000 to 30,000 years ago. The oldest continuously open cave found in the current survey is Lechuguilla in southern New Mexico where alunite formed on the cave floor yielded an age of 11.3 Ma.

Lava tubes are perhaps a better analogue for the welded tuffs of Yucca Mountain. These occur typically in of basaltic to intermediate composition, and they have cooling joints like those found in welded tuffs. Most lava tubes have stood open for thousands to hundreds of thousands of years, but ones as old as 4 million years are known. Some of the most spectacular are located in the Canary Islands, where Corona Volcano produced one tube $7.5 \mathrm{~km}$ long with diameters up to $35 \mathrm{~m}$. The lava forming that tube has been dated at $21+/-6 \mathrm{ka}$.

The geologic and archaeological records lack clear evidence of extreme ground motion, or at least of motion sufficient to cause catastrophic collapse. Thus, such events are either extremely rare, or are poorly preserved or perhaps non-existent. Null evidence is never conclusive, but a large body of evidence could be assembled that might strengthen this conclusion. 


\title{
Charcteristics of Quaternary Faulting at Yucca Mountain, Nevada
}

\author{
John Whitney
}

Yucca Mountain is an erosional remnant of a volcanic apron located on the southern flank of a complex of Miocene calderas in southern Nevada. The mountain is composed of north-trending and east-dipping fault blocks that are bounded by high-angle normal faults. These typical Basin-and-Range faults were formed by east-west extension during the waning phases of active volcanism 14.0 to 11.4 Ma. Yucca Mountain lies within the Walker Lane tectonic zone, which is characterized by long strike-slip faults that are interpreted to accommodate much of the Miocene extension along the western edge of the Basin and Range province. Quaternary faulting at Yucca Mountain continues the Middle Miocene pattern of normal-faulting deformation, but with substantially lower stain rates (Fridrich and others, 1999).

Detailed geological and structural mapping at Yucca Mountain identified eight north-striking, block-bounding faults that show evidence of multiple surface-rupture earthquakes during the Quaternary (Simonds and others, 1995; Keefer and others, 2004). Several inter-blocks faults were also identified; however, no evidence for Quaternary displacement was found on these bedrock faults. The anastomosing pattern, relatively short lengths $(6-25 \mathrm{~km})$, and close spacing between the faults indicate probable structural interconnection between some faults, either along strike or at depth.

Paleoseismic studies (Keefer and others, 2004) on the eight active faults indicate preferred slip rates of 0.001 to $0.05 \mathrm{~mm} /$ year and preferred average recurrence intervals of 10,000 to more than 100,000 years. Estimated ages of displacements from the paleoseismic trench studies indicate similar ages for ruptures on several faults within the resolution of the dating techniques used (see figure below). Distributive surface ruptures may have occurred on multiple faults that are close to one another and, possibly, linked at depth. Fissures along three different faults on the west side of Yucca Mountain contain basaltic ash that correlates with the eruption of the nearby Lathrop Wells volcanic center at $77 \pm 6 \mathrm{ka}$; thus, coeval surface ruptures on these faults were probably contemporaneous with that eruption. Though less certain, age data also indicate two or more faults may have been active simultaneously near $3 \mathrm{ka}$ and three other faulting events at about 50, 3020, and $13 \mathrm{ka}$ (Keefer and Menges, 2004).

The three longest faults at Yucca Mountain -- the Paintbrush Canyon, Solitario Canyon and Windy Wash Faults -- are also the most active. The Paintbrush Canyon Fault is a major block-bounding fault on the east side of Midway Valley. The fault is exposed for a distance of $5 \mathrm{~km}$ in bedrock forming the highlands north of Yucca Wash, where it dips $56^{\circ}-76^{\circ}$ westward. Along that section of the fault, the trace is marked by a discontinuous, west-dipping fault scarp, 0.3 to $4.0 \mathrm{~m}$ high. To the south, the fault extends beneath alluvial cover for $5 \mathrm{~km}$ before strands are exposed for about $1 \mathrm{~km}$ in bedrock along the west side of Fran Ridge; it may then continue southward for another $8 \mathrm{~km}$ to a possible intersection with the southwest-striking Stagecoach Road Fault. Estimates of the amount of bedrock displacement on the Paintbrush Canyon Fault range from $210 \mathrm{~m}$ in the northern segment to as much as $500 \mathrm{~m}$ along other segments (Day and others, 1998a). 
Total observed displacement of Quaternary deposits range from 5.5 to $8.0 \mathrm{~m}$. The two largest surface ruptures recorded in the walls of the Busted Butte sand ramp have preferred net displacements of $142 \mathrm{~cm}$ and $167 \mathrm{~cm}$ (Menges and others, 1994).

Bedrock displacements on the Solitario Canyon Fault range from about $50 \mathrm{~m}$ down to the east at the north end to as much as $500 \mathrm{~m}$ down to the west near the mouth of Solitario Canyon to the south (Day and others, 1998a). Thus, the fault zone displays a scissors geometry that contains a null point with essentially no displacement where movement is reversed. Dips on the Solitario Canyon Fault range from $60^{\circ}$ to $80^{\circ} \mathrm{W}$. south of the null point; slickenside measurements indicate that the net slip is left oblique. The mapping of four trenches on the Solitario Canyon Fault indicates that Middle- to late Quaternary deposits are displaced 1.7 to $2.5 \mathrm{~m}$ down to the west. The largest surface displacement recorded along the Solitario Canyon Fault was 110-150 cm during the past 200,000 years (Ramelli and others, 2004).

The Windy Wash Fault in Crater Flat shows clear evidence of late Holocene faulting; however, only about $3.7 \mathrm{~m}$ of net displacement have occurred during the past 400,000 years. The largest displacement appears to be slightly less than $1 \mathrm{~m}$ (Whitney and others, 1994).

The potential for large-magnitude earthquakes near the potential HLNW repository is limited by both fault length and the history fault displacements. Average co-seismic displacement range from 20-127 cm and maximum displacements on the Yucca Mountain faults range from 32-205 cm. Preferred surface rupture lengths, as assessed by PSHA panels, range from 6-8 km on the shorter faults and 19-27 km on the Paintbrush Canyon, Solitario Canyon and Windy Wash faults (Stepp and others, 2001). Based largely on these characteristics, the largest earthquake magnitude assessed by the six seismic source teams in the PSHA analyses ranged from 6.6 to 7.0 at $10^{-5}$ cumulative annual frequency (Stepp and others, 2001).

Elements of the landscape at Yucca Mountain support the paleoseismic evidence of low slip rates and long recurrence intervals. Erosion on the slopes and hilltops composed of volcanic tuffs has been relatively slow for a semiarid climate. The preservation and distribution of early and middle Quaternary deposits on and around Yucca Mountain indicate that, except for a modest amount of hillslope erosion and climatically controlled vegetation changes, the landscape looks very much today as it did 100,000 years ago. Approximate long-term, average erosion rates can be calculated from the dated hillslope deposits. These average, long-term erosion rates range from $<0.1 \mathrm{~cm}$ to $.6 \mathrm{~cm} / \mathrm{ka}$. An unusually long Quaternary record is preserved in the Yucca Mountain landscape. Early and middle Quaternary hillslope and basin alluvial deposits are common, while late Quaternary deposits are generally confined to the present washes. The preservation of these older deposits, which range to over 1 million years in age, indicates an unusual geomorphic stability exists on these hillslopes, caused by both low rates of tectonic activity and small fluctuations in climate.

Another aspect of slope stability at Yucca Mountain is the preservation of precarious rocks on the footwall of the Solitario Canyon fault. Precariously balanced rocks 75,000-80,000 years old are preserved near the op of Yucca Mountain, which 
indicates that it is very unlikely that these slopes have not exceeded ground motions of greater than 0.3 gravitational acceleration during this time period (Brune and Whitney, 2001). The preservation of hillslope deposits and precarious rock that are tens of thousands, and in some cases hundreds of thousands of years old strong suggests that tectonic slip rates are not only very low, but that earthquakes, when they do occur, are not of large magnitudes. 


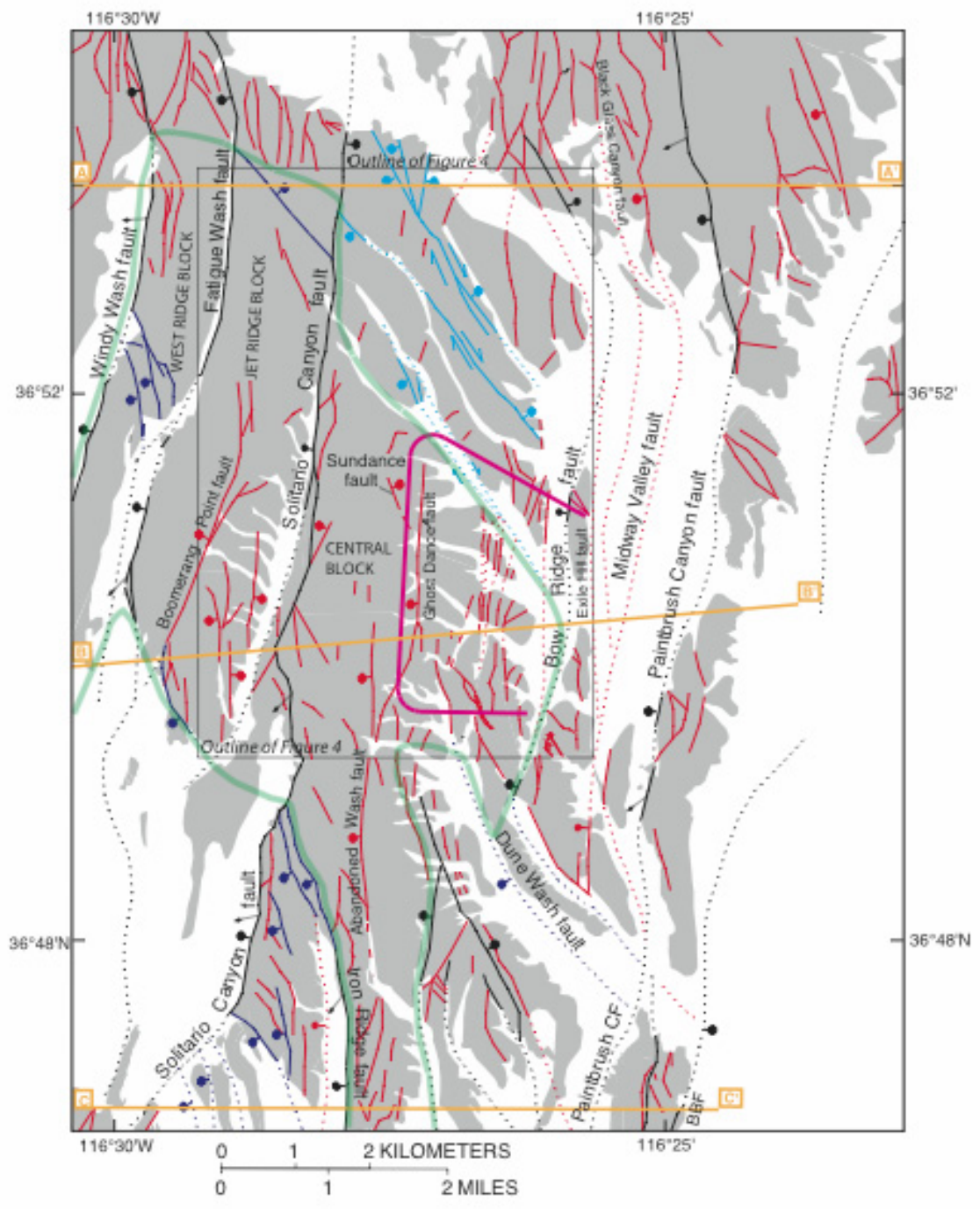




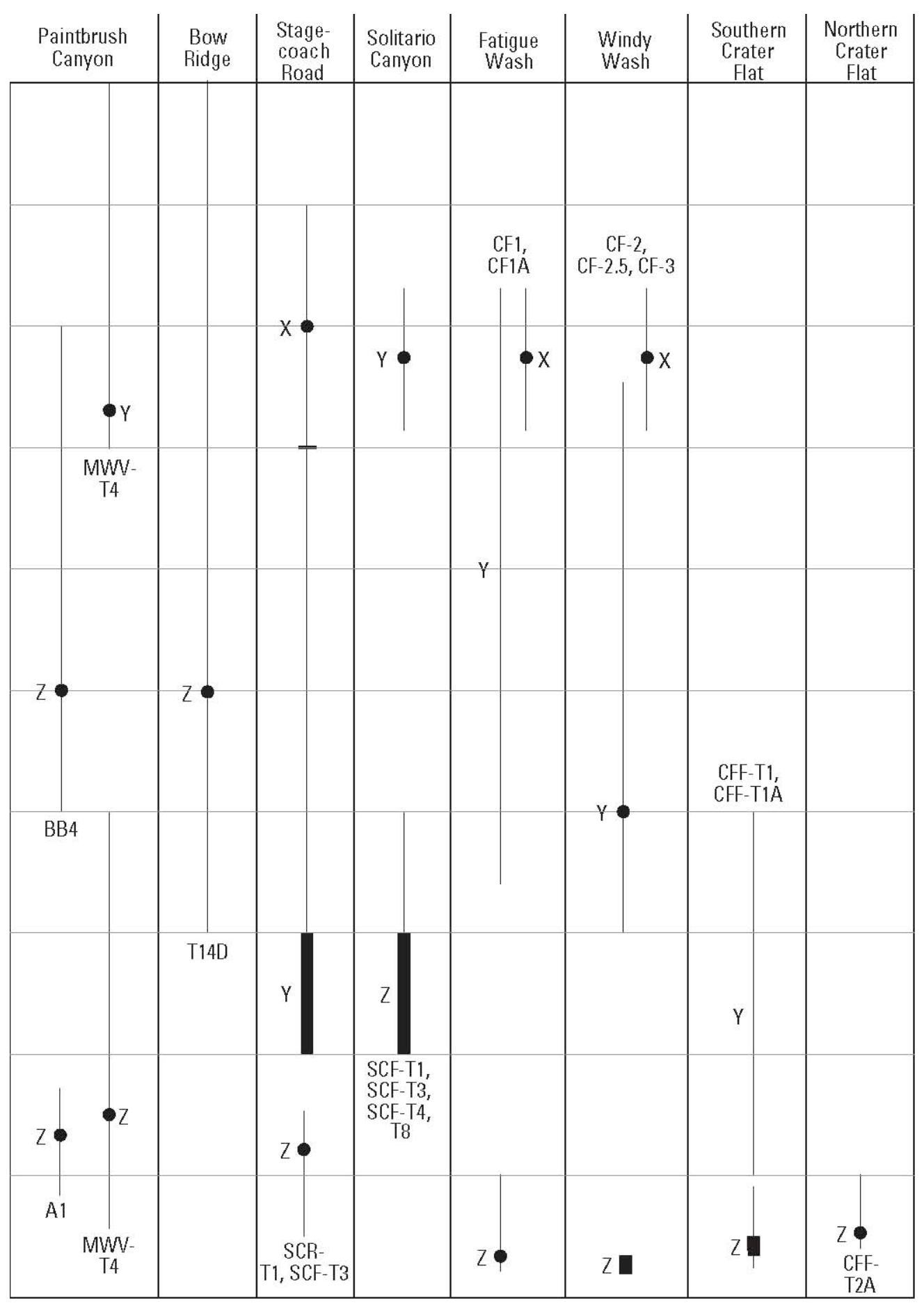




\section{References}

Brune, J.N. and Whitney, J.W., 2000, Precarious Rocks and Seismic Shaking at Yucca Mountain, Nevada: in Whitney, J.W. and Keefer, W.R., eds., Geologic and geophysical studies of Yucca mountain, Nevada, A potential high-level radioactive-waste repository, USGS Digital Data Series 058, Chapter M, 19 p.

Fridrich, C.J., Whitney, J.W., Hudson, M.R., and Crowe, B., 1999, Space-time patterns of Late Cenozoic extension, vertical axis rotation, and volcanism in the Crater Flat basin, southwest Nevada: in Wright, L.A. and Troxel, B.W., eds, Cenozoic Basins of the Death Valley Region, Geological Society of America Special Paper 333, p. 197-212.

Harrington, C.D., Whitney, J.W., Jull, A.J.T., and Phelps, W., 2000, Cosmogenic Dating and Analysis of Scarps Along the Solitario Canyon and Windy Wash Faults, Yucca Mountain, Nevada: in Whitney, J.W. and Keefer, W.R., eds., Geologic and geophysical studies of Yucca mountain, Nevada, A potential high-level radioactive-waste repository, USGS Digital Data Series 058, Chapter G, 9p.

Keefer, W.R., Whitney, J.W. and Taylor E.M, editors, 2004, Quaternary paleoseismology and stratigraphy of the Yucca Mountain Site Area: U.S. Geological Survey Professional Paper 1689, 212 p. and trench logs.

Keefer, W.R. and Menges, C., 2004, Summary of the Temporal and Spatial Relations of Quaternary Faulting During the Past 100 k.y. at Yucca Mountain: Evidence for Distributive Surface Ruptures on Multiple Faults: in Keefer, W.R., Whitney, J.W. and Taylor E.M, Quaternary paleoseismology and stratigraphy of the Yucca Mountain Site Area: U.S. Geological Survey Professional Paper 1689, p. 197200.

Menges, C.M., Taylor, EM., Wesling, J.W., Swan, F.H., Coe, J.A., Ponti, D. J., Whitney, J.W., 2004, Summary of Quateranry faulting on the Paintbrush Canyon, Bow Ridge, and Stagecoach Road fault: in Keefer, W.R., Whitney, J.W. and Taylor E.M, editors, 2004, Quaternary paleoseismology and stratigraphy of the Yucca Mountain Site Area: U.S. Geological Survey Professional Paper 1689, p 41-70.

Ramelli and others, 2004, Quaternary faulting on the Solitario Canyon fault: in

Keefer, W.R., Whitney, J.W. and Taylor E.M, editors, 2004, Quaternary paleoseismology and stratigraphy of the Yucca Mountain Site Area: U.S. Geological Survey Professional Paper 1689, p. 89-110.

Simonds, F.W., Whitney, J.W., Fox, K.F., Ramelli, A.R., Yount, J.C., Carr, $\quad$ M.D., Menges,C.M., Dikerson, R.P., and Scott, 1995, Fault map of the Yucca Mountain area, Nye County, Nevada: U.S. Geological Survey Miscellaneous Investigations Series Map I-2520, scale 1:24,000

Stepp, J.C., Wong, I., Whitney, J.W., Quittmeyer, R, Abrahamson, N, Toro, G., Youngs, R., Coppersmith, K., Savy, J., Sullivan, T., 2001, Probabilistic Seismic Hazard 
Analyses for ground motion and fault displacement at Yucca Mountain, Nevada: Earthquake Spectra, v. 17, p. 113-151.

Whitney, John W. and Berger, David L., 2000, A 3.7-Million-Year Offset Rate on the Windy Wash Fault at the South End of Yucca Mountain, Nevada: in Whitney, J.W. and Keefer, W.R., eds., Geologic and geophysical studies of Yucca mountain, Nevada, A potential high-level radioactive-waste repository, USGS Digital Data Series 058, Chapter F, 9 p.

Whitney, J.W., Simonds, F.W., Shroba, R.R., Murray, M. 2004, Quateranry faulting on the Windy Wash Fault: in Keefer, W.R., Whitney, J.W. and Taylor E.M, editors, 2004, Quaternary paleoseismology and stratigraphy of the Yucca Mountain Site Area: U.S. Geological Survey Professional Paper 1689, p. 125-134. 


\title{
Maximum Earthquake Magnitudes in the Basin and Range: A Geologic Perspective
}

\author{
David P. Schwartz \\ US Geological Survey \\ Menlo Park, CA \\ dschwartz@usgs.gov
}

One of the issues surrounding the potential for extreme ground motions at Yucca Mountain is the magnitude of the largest earthquake that can possibly occur on a fault in the Basin and Range at a probability of $10^{-8} / \mathrm{yr}$. With a short historical record and the occurrence of only seven surface-faulting events with magnitudes higher than 6.5 (range $\mathrm{Mw} 6.6$ to $\mathrm{Mw} 7.3)$ the argument can certainly be made that larger events are possible. But how large? And is there a physical basis for placing an upper bound on this magnitude? A potential answer comes not from the historical occurrence of earthquakes but from the past earthquake history of the region, namely the paleoseismic record.

One of the first concepts a geology student is exposed to is "the present is the key to the past". Understanding the nature and variability of present-day processes, whether sediment deposition in deltas, the morphology of active landslide deposits, or the geomorphic expression of surface rupture from a historical event provides a basis for more accurate interpretation of similar features preserved in the geologic record. Seismic hazard analysis requires that we estimate what is likely to occur-whether it is the magnitude of a future earthquake, the amount of future displacement at a point on a fault, or ground motions. For those of us working with seismic hazards arena there is also a second basic concept, which is "the past is the key to the future". Knowledge of what has or has not happened over a range of time intervals is critical for forecasting what can occur in the future. To develop a better understanding of the magnitude of future earthquakes in the Basin and Range we can turn to past behavior of the region's active faults.

\section{Locations of Past and Future Slip-The Fault Inventory}

Figure 1 shows the locations of faults that have ruptured in the Basin and Range during intervals extending from historical time through the entire Quaternary. The historical record is short and contains few earthquakes. During the past $15 \mathrm{ka}$ faulting has been more widespread, with multiple rupture of some sources, but is unrepresentative of the region as a whole. Faulting during the past $130 \mathrm{ka}$ is broadly distributed and this distribution is not significantly different from the $750 \mathrm{ka}$ interval. The lower map in Figure 1 shows the locations of faults that have slipped during Quaternary time. This series of maps provides an inventory of earthquake sources during the past approximately 2 million years. Future events will almost invariably occur along these existing faults. As such this fault inventory contains the information, in the form of displacement per event and timing, on the size of past earthquakes. 

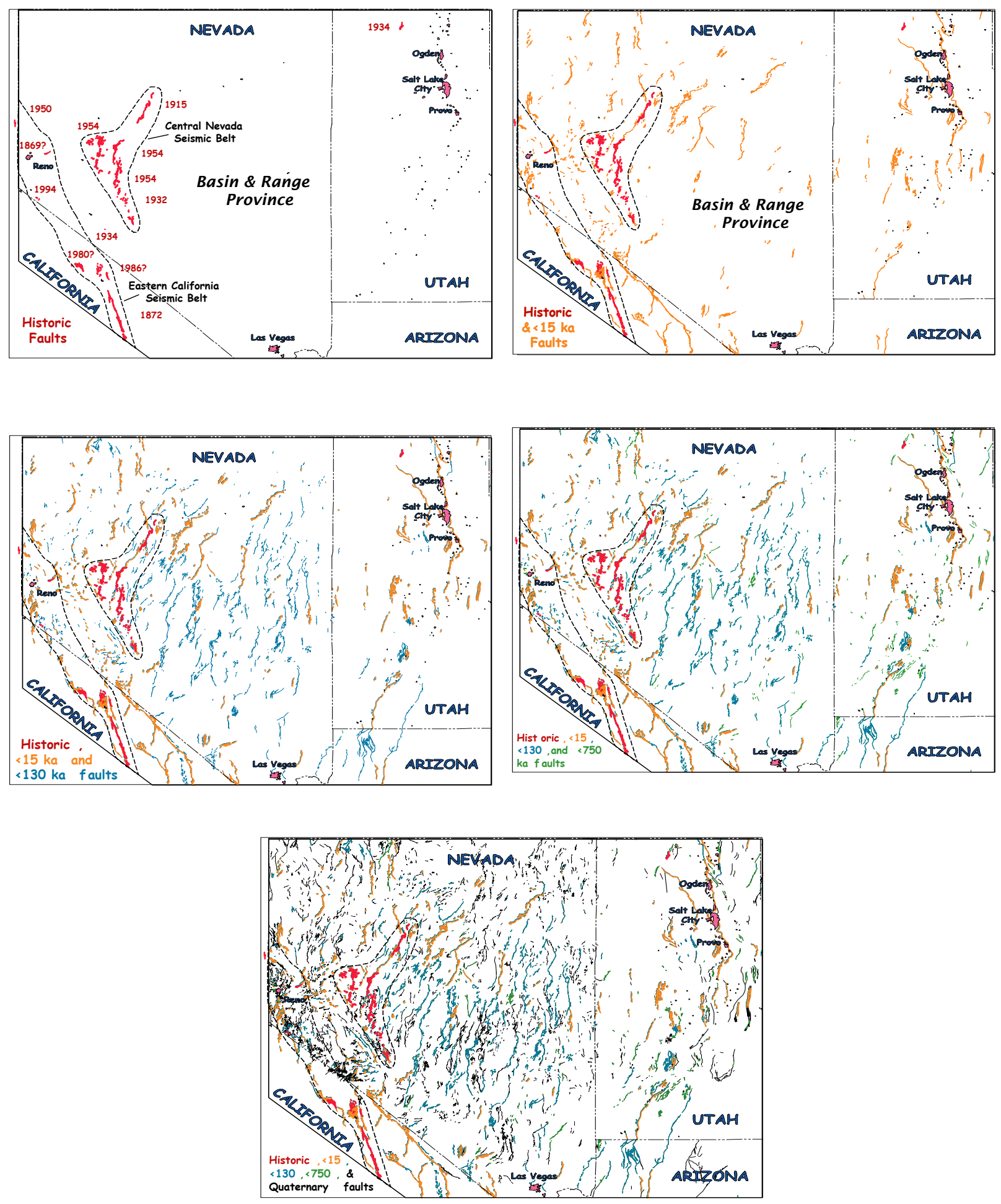

Figure 1. The distribution of faulting during different intervals in the Quaternary (developed by M. Machette from the US Quaternary Faults and Fold Database) 


\section{Earthquake Magnitudes}

The seismic moment of an earthquake is the product of the fault rupture area (rupture length and rupture width), the average slip, and the shear modulus. This can be converted to moment magnitude by the relation $\mathrm{Mw}=2 / 3 \log M o-10.7$ (Hanks and Kanamori, 1979). Investigations of historical earthquakes show that surface rupture length and the average measured surface offset, along with a fault width derived from the average depth distribution of aftershocks or regional seismcity (thickness of seismogenic crust) provide estimates of magnitude comparable to the seismologic magnitude. In a recent example the magnitude of the 2002 Denali fault Alaska earthquake is calculated as Mw7.8 using surface fault observations, essentially the same as the seismologic magnitude of M7.9 (Haeussler et al, 2004).

Fault Slip Distributions and Segments of Scarp-Forming Basin and Range Earthquakes
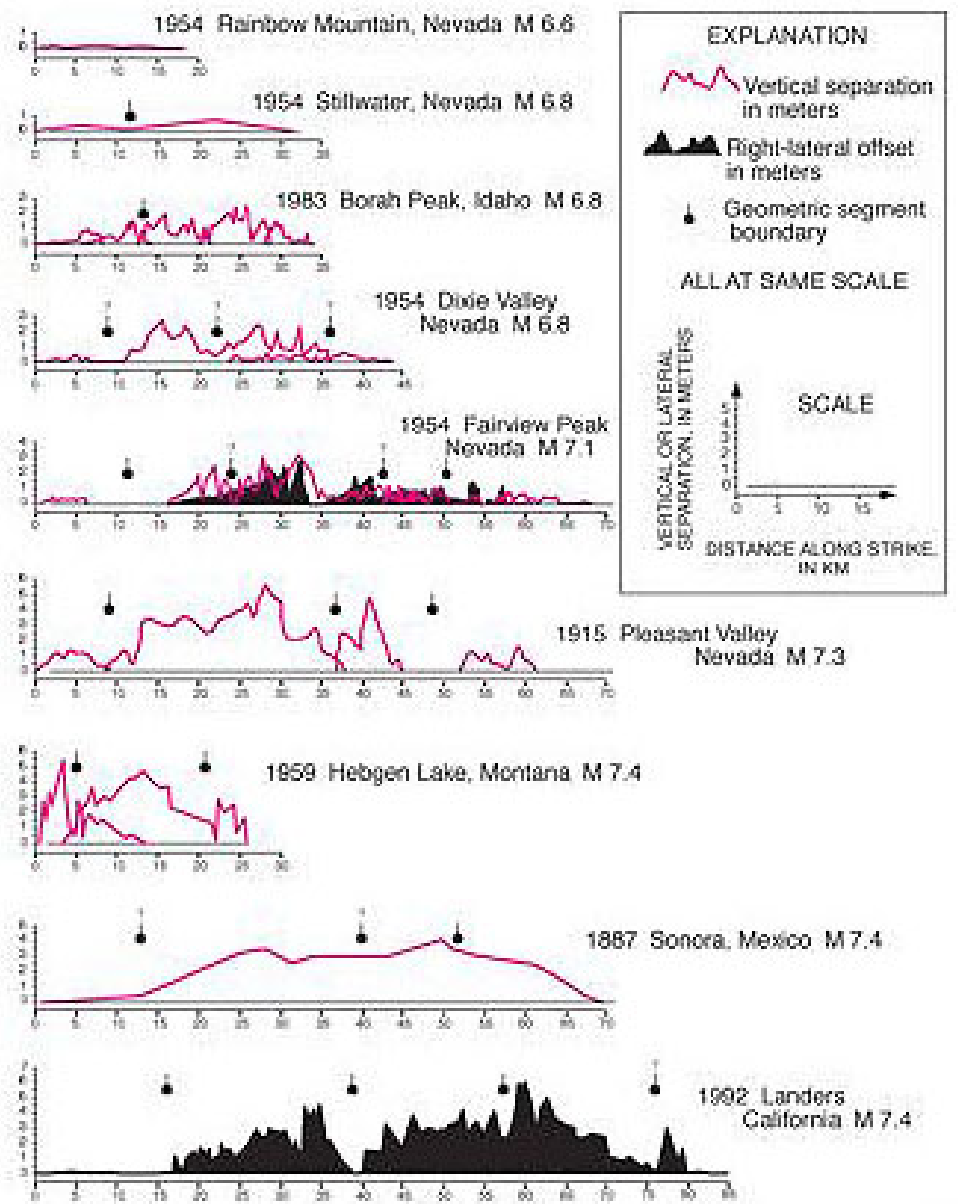

Figure 2. Historica

USGS-YMP Rrawswe, Oxt, on

Trenching and scarp morphologic studies provide data on the amount of surface slip during individual paleoearthquakes. Rupture length can be developed from information on the timing (similarities/differences) of events along the length of a fault, which allows individual rupture segments to be identified. An important uncertainty in calculating paleo rupture lengths is the potential for multi-segment ruptures (see, for example, Chang 
and Smith, 2002). Just how far can a normal fault rupture propagate? Figure 2 shows the surface rupture lengths and slip distributions from historical Basin and Range earthquakes. Rupture lengths have ranged from $18 \mathrm{~km}$ to $70 \mathrm{~km}$. The maximum observed historical surface slip approaches $6 \mathrm{~m}$. In general the average and maximum surface displacement increase as rupture length increases along range bounding faults. However, the largest average historical slip occurred during the 1959 Hebgen Lake earthquake where the Hebgen and Red Canyon faults ruptured for a combined length of only $27 \mathrm{~km}$. These faults lie within a range, and perhaps there is a difference between range front and within-range faults with regard to average slip per event and stress drop.

Fault width is defined by the dip of the fault and its down-dip extent. Figure 3 shows current thinking and a working model for normal-faulting earthquakes. In the Basin and Range the average thickness of the seismogenic crust is about $15 \mathrm{~km}$. This may vary locally (thinner or thicker) but appears to be quite representative of normal fault nucleation depths both here and worldwide. There is also uncertainty in estimating the dip of faults that have not had historical ruptures; there may be those with shallower dips that could result in somewhat larger magnitude earthquakes.

\section{A Working Model For Normal-Faulting Earthquakes}
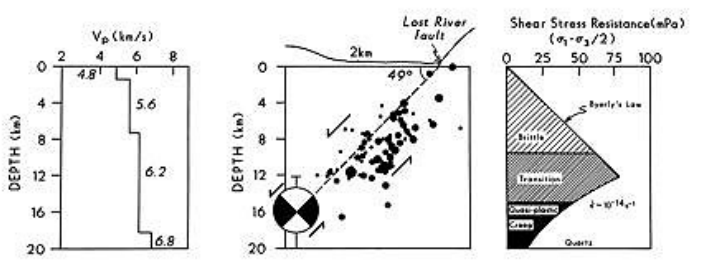

Smith and Arabasz, 1991

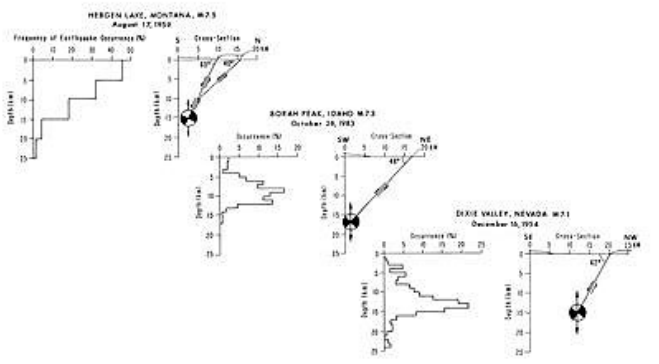

3) Multisegment rupture.

1) Nucleation at brittleductile transition,

2) $45^{\circ}$ to $60^{\circ}$ dipping planar dip-slip,

Figure 3. A model of nucleation depths and dips for normal-faulting earthquakes (from Smith and Arabasz, 1991).

\section{Bounding the Magnitude of the Largest Basin and Range Earthquakes-Looking Back to Look Ahead}

It is not unreasonable to assert that the historical record is too short to have shown us the largest earthquake that can occur in the Basin and Range. But how large can this earthquake be? The geologic record of faulting in the Quaternary y provides an inventory of earthquake sources containing information on past magnitudes (slip and length) across the entire region. At present much of this is has not been sampled paleoseismically. But 
where studies have been done, primarily on faults that have ruptured during the past 130 $\mathrm{ka}$, there is no indication of a "planet buster"- that is, an event with slip that is many factors larger than anything already observed. To date the maximum net coseismic surface slip observed both historically and paleoseismically is 5-6m, and even these slip values have occurred only along limited sections of a rupture. In general, repeated net surface displacement observed at individual points along Basin and Range faults is 1$3 \mathrm{~m}$. The maximum rupture length that has occurred historically is $70 \mathrm{~km}$. Large earthquakes require sources with dimensions that can produce them. The Wasatch fault is currently the longest continuous active normal fault in the Basin and Range with a total length of $350 \mathrm{~km}$. It is divided into six rupture segments (Machette et al, 1992), each considered a source of future earthquakes. If a scenario is used in which all six segments rupture with an average slip of $4 \mathrm{~m}$ (slip of about $2 \mathrm{~m} /$ event is what is actually observed in trenches along each segment) and an average dip of 40 degrees through a $15 \mathrm{~km}$ thick seismogenic crust, the resulting Mw would be 7.85 . Increasing the average slip to $8 \mathrm{~m}$ would increase the magnitude to 8.15

In extending probabilities to $10^{-8} / \mathrm{yr}$ one is placed in a position where is it essentially impossible to never say never. However, our present understanding of fault behavior and crustal rheology combined with expanded observations of faulting (especially paleoseismic slip per event) can provide the basis for a rational and physically realistic upper bound on the magnitude of the maximum earthquake that can be expected to occur on a fault in the Basin and Range.

\section{References}

Chang, W. L. and R. B. Smith, Integrated seismic-hazard analysis of the Wasatch Front, Utah, Bull. Seismol. Soc. Am., 92, 1904-1922, 2002.

Haeussler, P.J., Schwartz, D.P., Dawson, T.E., Stenner, H.D., Lienkaemper, J.L., Sherrod, B., Cinti, F.R., Montone, P., Craw, P.A., Crone, A.J., and Personius, S.F., 2004, Surface rupture and slip distribution of the Denali and Totschunda faults in the 3 November 2002 M 7.9 earthquake, Alaska, Bulletin of the Seismological Society of America, v. 94, n. 6b, pp S23-S52.

Hanks, T. C., and H. Kanamori, 1979, A moment magnitude scale, J. Geophys. Res. 84, 2348-2350.

Machette, M.N., Personius, S.F., Nelson, A.R., Schwartz, D.P., and Lund, W.R., 1991, The Wasatch fault zone, Utah-Segmentation and history of Holocene earthquakes: Journal of Structural Geology, v. 13, no. 2, p. 137-139.

Smith, R.B., and Arabasz, W.J., 1991, Seismicity of the Intermountain seismic belt. In D.B., Slemmons, E.R. Engdahl, M.D. Zoback, and D.D. Blackwell (eds.), Neotectonics of North America, Geol. Soc. Am. Decade Map 1:185-228

Quaternary Faults and Fold Database of the United States http://Qfaults.cr.usgs.gov/ 